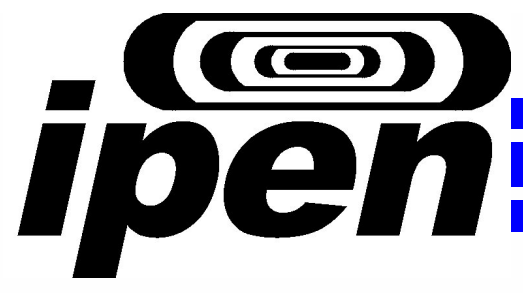

AUTARQUIA ASSOCIADA À UNIVERSIDADE DE SÃO PAUL

\title{
DESENVOLVIMENTO DE UM SISTEMA DE REFERÊNCIA PARA DETERMINAÇÃO DO EQUIVALENTE DE DOSE PESSOAL E DA CONSTÂNCIA DE FEIXES DE RADIAÇÃO X
}

Tese apresentada como parte dos requisitos para obtenção do Grau de Doutor em Ciências na Área de Tecnologia Nuclear - Aplicações.

Orientadora:

Dra. Linda V. E. Caldas 
INSTITUTO DE PESQUISAS ENERGÉTICAS E NUCLEARES

AUTARQUIA ASSOCIADA À UNIVERSIDADE

DE SÃO PAULO

\section{DESENVOLVIMENTO DE UM SISTEMA DE REFERÊNCIA PARA DETERMINAÇÃO DO EQUIVALENTE DE DOSE PESSOAL E DA CONSTÂNCIA DE FEIXES DE RADIAÇÃO X}

VITOR VIVOLO

Tese apresentada como parte dos requisitos para obtenção do Grau de Doutor em Ciências na Área de Tecnologia Nuclear Aplicações

Orientadora:

Dra. Linda V.E. Caldas

SÃO PAULO

2006 
À minha família, aos meus pais e ao meu irmão, por seu amor, compreensão e carinho. 


\section{AGRADECIMENTOS}

Gostaria de expressar os meus sinceros agradecimentos a minha orientadora, $\mathrm{Dr}^{\mathrm{a}}$ Linda V. E. Caldas, que partilhou seu escasso tempo disponível, entre suas ocupações acadêmicas e profissionais, coordenando, sugerindo, comentando e analisando os diversos aspectos do desenvolvimento deste trabalho, com muito empenho e dedicação.

Meus sinceros agradecimentos:

À $\operatorname{Dr}^{\mathrm{a}}$ Maria da Penha A. Potiens, pelos comentários e sugestões, e pela ajuda na solução dos problemas de informática durante a realização deste trabalho.

À Dr ${ }^{\mathrm{a}}$ Ulrike Ankerhold, do PTB, Alemanha, pelos comentários e sugestões, na confecção da câmara de ionização com eletrodo coletor de grafite, e referente à grandeza $\mathrm{Hp} \mathrm{(10).}$

Ao Sr. Luiz Carlos A. Caetano, do Departamento de Suporte Técnico da Acheson do Brasil Ind. Com. Ltda., Cotia, SP, Brasil, pelas informações e pela visita técnica, e ainda pela doação de amostra de tinta para a confecção das janelas de grafite das câmaras de ionização.

À Sra. Regina de Souza, Técnica do Departamento de Suporte Técnico da Central de Metais Ind. Com. Ltda., São Paulo, SP, Brasil, pelas informações técnicas e o fornecimento de placas de alumínio para a confecção das placas frontais utilizadas nas câmaras de ionização.

Ao Sr. Vittorio Vivolo, Assessor Técnico em Tampografia, Lay-out e Serigrafia, São Paulo, SP, Brasil, pelas informações técnicas e testes realizados com o processo denominado "Método do Tornete", aplicado na confecção das janelas das câmaras de ionização.

Ao Sr. Paulo Ribeiro, Técnico do Departamento de Suporte Técnico da Savion Ind. Com. de Acrílicos Ltda., São Paulo, SP, Brasil, pelas informações técnicas relativas ao processo de secagem dos materiais acrílicos.

A todos funcionários da Oficina Mecânica do IPEN, em especial aos Srs. José Carlos Sabino e Idacir Mantovani, responsáveis pelo setor de usinagem e montagem e calderaria, por sua presteza na confecção das peças em acrílico e eletrodos coletores de alumínio das câmaras de ionização.

A todos colegas do Laboratório de Calibração do IPEN que sempre apoiaram e incentivaram a elaboração deste trabalho. 
Aos colegas Mércia L. Oliveira, Ana F. Maia, Ana Carolina Bessa, Luciana Afonso e Oscar Alvarez, pelo apoio nos trabalhos em grupo durante o decurso das disciplinas cursadas, e nas discussões e informações sempre úteis.

Às Sras. Adriana C. de A. Lima e Filomena de F. Beraldo, pelo apoio nos assuntos administrativos.

À Dr ${ }^{\mathrm{a}}$ Letícia L. C. Rodrigues, pela permissão de utilização dos laboratórios do Centro de Metrologia das Radiações do IPEN, para a realização dos ensaios.

A todos da Divisão de Ensino e da Comissão de Pós-Graduação do IPEN, por todo o auxílio prestado.

Ao IPEN, Instituto de Pesquisas Energéticas e Nucleares, pela infra-estrutura oferecida para realização deste trabalho.

À Fundação de Amparo à Pesquisa do Estado de São Paulo (FAPESP), pelo apoio financeiro parcial. trabalho.

A todos aqueles que de um modo ou de outro colaboraram com este 


\title{
DESENVOLVIMENTO DE UM SISTEMA DE REFERÊNCIA PARA \\ DETERMINAÇÃO DO EQUIVALENTE DE DOSE PESSOAL E DA \\ CONSTÂNCIA DE FEIXES DE RADIAÇÃO X
}

\author{
Vitor Vivolo
}

RESUMO

Um sistema de referência para determinação do equivalente de dose pessoal, $H_{P}(10)$, e um programa de controle da qualidade de sistemas geradores de raios $X$ utilizados em radioproteção inclui a verificação periódica da constância dos feixes de raios $\mathrm{X}$ empregados na calibração de instrumentos medidores de radiação em laboratórios de calibração de instrumentos. Neste trabalho foram desenvolvidas duas câmaras de ionização de placas paralelas inseridas em objetos simuladores de tronco humano. Uma das câmaras de ionização possui eletrodo coletor de grafite, para a medida do equivalente de dose pessoal; a segunda câmara de ionização foi confeccionada com eletrodo coletor de alumínio para, juntamente com a primeira câmara de ionização, formarem um sistema Tandem. A dependência energética diferente da resposta das duas câmaras de ionização é que permite a formação do sistema Tandem, que apresenta grande utilidade na verificação da constância de feixes de radiação $X$. Foram ainda implantados feixes padronizados de radiação $X$ de energias médias (48 keV a $118 \mathrm{keV}$ ), nível radioproteção, por meio do desenvolvimento de uma metodologia dosimétrica e da análise dos parâmetros físicos destes feixes. As câmaras desenvolvidas foram testadas em relação às suas características operacionais e foram calibradas em feixes de radiação $\mathrm{X}$, níveis radioproteção, radiodiagnóstico, mamografia e radioterapia, e ainda em campos de radiação gama, seguindo as recomendações internacionais. Apresentaram bom desempenho. Foi estabelecido o procedimento da determinação do equivalente de dose pessoal, $\mathrm{Hp} \mathrm{(10).}$ 


\title{
DEVELOPMENT OF A REFERENCE SYSTEM FOR THE DETERMINATION OF THE PERSONAL DOSE EQUIVALENT AND THE CONSTANCY OF X- RAY BEAMS
}

\author{
Vitor Vivolo
}

\begin{abstract}
A reference system for the determination of the personal dose equivalent, $H_{p}(10)$, and a quality control program of X-ray equipments used in radioprotection require the periodic verification of the X-ray beams constancy. In this work, two parallel-plate ionization chambers were developed with inner electrodes of different materials, and inserted into PMMA slab phantoms. One ionization chamber was developed with inner carbon electrodes and the other with inner aluminium electrodes. The two ionization chambers can be used as a Tandem system. The different energy response of the two ionization chambers allowed the development of the Tandem system that is very useful for the checking of the constancy of beam qualities. Standard intermediary energy X-ray beams (from $48 \mathrm{keV}$ to $118 \mathrm{keV}$ ), radioprotection level, were established through the development of a dosimetric methodology and the analysis of their physical parameters. The ionization chambers were studied in relation to their operational characteristics, and they were calibrated in X-ray beams (radioprotection, diagnostic radiology, mammography and radiotherapy levels) in accordance to international recommendations. They presented good performance. The determination procedure of personal dose equivalent, $H_{P}(10)$, was established.
\end{abstract}




\section{SUMÁRIO}

\section{INTRODUÇÃO}

Página

2 FUNDAMENTOS TEÓRICOS 8

2.1 Sistemas de Raios X 8

2.2 Interação da radiação com a matéria 9

2.2.1 Interação de fótons com a matéria 10

2.2.2 Efeito fotoelétrico 11

2.2.3 Espalhamento Compton 12

2.2.4 Produção de pares 13

2.2.5 Atenuação de fótons 14

2.2.6 Teoria cavitária 15

2.2.7 Equilíbrio eletrônico 16

2.3 Câmaras de ionização 17

2.3.1 Câmara de ar livre $\quad 20$

2.3.2 Câmara cavitária 21

2.3.3 Câmara cilíndrica (tipo dedal) 21

2.3.4 Câmara de placas paralelas (tipo superficial) 22

2.3.5 Câmara de extrapolação 23

2.3.6 Calibração das câmaras de ionização 24

2.3.7 Qualidade dos feixes de radiação $X$

2.3.8 Energia equivalente (efetiva) 26

2.4 Grandezas dosimétricas 27

2.5 Sistema Tandem 36

2.6 Espectrometria de feixes de radiação 38

$\begin{array}{lll}2.7 & \text { Avaliação das incertezas } & 40\end{array}$ 
3 MATERIAIS E MÉTODOS

3.1 Sistemas de medida $\quad 43$

3.2 Sistemas de radiação 46

3.3 Sistemas auxiliares $\quad 53$

4 ESTABELECIMENTO DE CAMPOS PADRÕES DE RADIAÇÃO $X$, DE ENERGIAS INTERMEDIÁRIAS, NÍVEL RADIOPROTEÇÃO

5 PROJETO E CONSTRUÇÃO DAS CÂMARAS DE IONIZAÇÃO

5.1 Considerações preliminares

5.2 Detalhes construtivos do projeto e de contrução das câmaras de ionização e sua montagem dentro do simulador de tronco humano

5.3 Estimativa de custo na confecção das câmaras de ionização dentro dos simuladores de tronco humano

6 CARACTERIZAÇÃO DAS CÂMARAS DE IONIZAÇÃO EM FEIXES DE RADIAÇÃO, NÍVEL RADIOPROTEÇÃO

6.1 Saturação, eficiência de coleção de íons e efeitos de polaridade

6.2 Variação da resposta com o tamanho do campo

6.3 Tempo de estabilização

6.4 Estabilidade a curto prazo ou teste de repetitividade

6.5 Estabilidade a longo prazo

6.6 Corrente de fuga sem irradiação

6.7 Corrente de fuga após irradiação

6.8 Linearidade da resposta

6.9 Dependência angular 
6.11 Dependência energética

7 DETERMINAÇÃO DE H (10) EM CAMPOS PADRÕES DE RADIAÇÃO X, NÍVEL RADIOPROTEÇÃO

8 APLICAÇÃO DAS CÂMARAS DE IONIZAÇÃO EM OUTROS CAMPOS PADRÕES DE RADIAÇÃO $X$, NÍVEIS RADIODIAGNÓSTICO E RADIOTERAPIA

8.1 Saturação, eficiência de coleção de íons e efeitos de polaridade 124

8.2 Variação da resposta com o tamanho do campo

8.3 Tempo de estabilização

8.4 Estabilidade a curto prazo ou teste de repetitividade

8.5 Corrente de fuga após irradiação

8.6 Linearidade da resposta

8.7 Dependência angular

8.8 Calibração das câmaras de ionização

8.9 Dependência energética

8.10 Formação dos sistemas Tandem 


\section{LISTA DE FIGURAS}

3.1 Sistema dosimétrico composto por um eletrômetro PTW UNIDOS e uma câmara de ionização esférica de 1,0 litro (PTW 32002-A) e outra câmara de ionização de placas paralelas de $1,0 \mathrm{~cm}^{3}$ (PTW 77334)

3.2 Sistema de radiação gama, marca STS, modelo OB85, no detalhe ao fundo, e câmara de ionização posicionada para irradiação

3.3 Sistema de radiação X, marca Rigaku-Denki, modelo Geigerflex, no detalhe ao fundo, e câmara de ionização posicionada para calibração

3.4 Sistema e radiação X, marca Pantak/Seifert, modelo ISOVOLT 160 HS, com caixa moldada em chumbo (10 $\mathrm{mm}$ de espessura) para blindagem do tubo de raios $X$

4.1 Câmara de ionização de referência (1 litro) posicionada para medida das taxas de kerma no ar das qualidades de radiação $X$, nível radioproteção, de energias intermediárias, no sistema Pantak/Seifert

4.2 Câmara de ionização PTW $31002\left(0,125 \mathrm{~cm}^{3}\right)$ posicionada para medida da linearidade de sua resposta com a corrente do tubo de raios $\mathrm{X} e$ para o mapeamento do campo das qualidades de radiação $X$, nível radioproteção, de energias intermediárias, no sistema Pantak/Seifert

4.3 Dependência da resposta da câmara de ionização PTW 31002 $\left(0,125 \mathrm{~cm}^{3}\right)$ em relação à corrente no tubo de raios $X$, para a distância foco-detector de 2,5 m, no sistema Pantak/Seifert

4.4 Mapeamento do campo de radiação $X$, na direção horizontal, utilizando a câmara de ionização PTW 31002, no sistema de radiação $X$ Pantak/Seifert (tensão de 60 kV, corrente de $30 \mathrm{~mA}$ e sem filtração adicional, a 2,5 $\mathrm{m}$ de distância do foco do tubo de raios $\mathrm{X}$ ao detector) 
4.5 Mapeamento do campo de radiação X, na direção vertical, utilizando a câmara de ionização PTW 31002, no sistema de radiação $X$ Pantak/Seifert (tensão de 60 kV, corrente de $30 \mathrm{~mA}$ e sem filtração adicional, a 2,5 $\mathrm{m}$ de distância do foco do tubo de raios $\mathrm{X}$ ao detector)

5.1 Anel de guarda da câmara de ionização fixado no centro do sistema de homogenização de pintura ("método do tornete"), momentos antes de receber a camada de tinta spray com grafite (a), e após receber uma camada de pintura (b). O controle de velocidade é realizado por meio de um reostato, adequado para uso em tensão alternada (Variac), acoplado a uma furadeira elétrica comercial

5.2 Câmara de ionização de placas paralelas, volume sensível de $10 \mathrm{~cm}^{3}$, eletrodo coletor e anel de guarda com espessura de $5 \mathrm{~mm}$ e janela com 0,04 mm de espessura, no meio de placas de PMMA. As áreas achuradas representam as placas de PMMA; a letra $G$ representa o anel de guarda

5.3 Conjunto simulador de tronco humano confeccionado com 12 placas de PMMA justapostas, com $10 \mathrm{~mm}$ de espessura cada uma e pinos de PMMA que dão sustentação ao conjunto, além de servirem como guia para a colocação das placas. A parte achurada representa as placas de PMMA e a parte branca os pinos de PMMA

5.4 Conjunto objeto simulador de tronco humano multicamadas, em perspectiva, confeccionado com placas de PMMA

5.5 Câmara de ionização de placas paralelas, inserido no objeto simulador de tronco humano (confeccionado com PMMA, com dimensões de $300 \mathrm{~mm} \times 300 \mathrm{~mm} \times 120 \mathrm{~mm}$ ) para a medida do equivalente de dose pessoal $H_{p}(10)$, com eletrodo coletor de grafite; em destaque estão os 04 pinos de referência (salientes no painel frontal), que permitem manter o alinhamento das placas do simulador com as placas da câmara de ionização 
5.6 Câmara de ionização de placas paralelas, com eletrodo coletor de alumínio, inserida em um simulador de tronco humano (confeccionado com PMMA, com dimensões de $300 \mathrm{~mm} \times 300 \mathrm{~mm} \times 120 \mathrm{~mm}$ )

6.1 Curva de saturação da câmara de ionização com eletrodo coletor de alumínio. Qualidade de radiação X, ISO N-60, tensão 60 kV e corrente de 45 mA, distância foco-detector de 2,5 m

6.2 Curva de saturação da câmara de ionização com eletrodo coletor de grafite. Qualidade de radiação X, ISO N-60, tensão 60 kV e corrente de 45 mA, distância foco-detector de 2,5 m

6.3 Variação da resposta da câmara de ionização com eletrodo coletor de grafite, comparada com a média ao longo de 25 medidas, do ensaio de estabilidade a longo prazo

6.4 Variação da resposta da câmara de ionização com eletrodo coletor de alumínio, comparada com a média ao longo de 25 medidas, do ensaio de estabilidade a longo prazo

6.5 Linearidade de resposta da câmara de ionização (com eletrodo coletor de alumínio) com a corrente, para raios $\mathrm{X}$, nível radioproteção, ISO N-60, $60 \mathrm{kV}(0,247 \mathrm{mmCu})$

6.6 Linearidade de resposta da câmara de ionização (com eletrodo coletor de grafite) com a corrente, para raios $X$, nível radioproteção, ISO N-60, $60 \mathrm{kV}(0,247 \mathrm{mmCu})$

6.7 Resposta relativa em função da inclinação da câmara de ionização com eletrodo coletor de alumínio para raios $\mathrm{X}$, nível radioproteção, ISO N-60

6.8 Resposta relativa em função da inclinação da câmara de ionização com eletrodo coletor de grafite para raios $\mathrm{X}$, nível radioproteção, ISO N-60

6.9 Resposta relativa em função da inclinação da câmara de ionização com eletrodo coletor de alumínio, para a fonte de ${ }^{137} \mathrm{Cs}$

6.10 Resposta relativa em função da inclinação da câmara de ionização com eletrodo coletor de alumínio, para a fonte de ${ }^{60} \mathrm{Co}$ 
6.11 Resposta relativa em função da inclinação da câmara de ionização com eletrodo coletor de grafite, para a fonte de ${ }^{137} \mathrm{Cs}$

6.12 Resposta relativa em função da inclinação da câmara de ionização com eletrodo coletor de grafite, para a fonte de ${ }^{60} \mathrm{Co}$

6.13 Fatores de correção da resposta da câmara de ionização com eletrodo coletor de alumínio, para as qualidades de raios $\mathrm{X}$, nível radioproteção, normalizados para a camada semi-redutora de $1,10 \mathrm{mmCu}$

6.14 Fatores de correção da resposta da câmara de ionização com eletrodo coletor de grafite, para as qualidades de raio $\mathrm{X}$, nível radioproteção, normalizados para a camada semi-redutora de $1,10 \mathrm{mmCu}$

6.15 Curva Tandem para qualidades de raios $X$, nível radioproteção, das câmaras de ionização com eletrodos coletores de alumínio e de grafite

7.1 Dependência angular da câmara de ionização com eletrodo coletor de grafite para a qualidade de radiação $X$, ISO N-60

7.2 Dependência angular da câmara de ionização com eletrodo coletor de grafite para a qualidade de radiação $X$, ISO N-80

7.3 Dependência angular da câmara de ionização com eletrodo coletor de grafite para a qualidade de radiação $X$, ISO N-100

7.4 Dependência angular da câmara de ionização com eletrodo coletor de grafite para a qualidade de radiação $X$, ISO N-150

7.5 Dependência angular da câmara de ionização com eletrodo coletor de grafite para radiação gama de ${ }^{137} \mathrm{Cs}$

7.6 Dependência angular da câmara de ionização com eletrodo coletor de grafite para radiação gama de ${ }^{60} \mathrm{Co}$

7.7 Dependência energética do coeficiente de calibração $N_{H}$, obtido com a câmara de ionização com eletrodo coletor de grafite nas qualidades de radiação X, da norma ISO 4037-1 ${ }^{(16)}$, da série $N$, nível radioproteção, e radiação gama das fontes de ${ }^{137} \mathrm{Cs}$ e ${ }^{60} \mathrm{Co}$, em função da energia da radiação 
8.1 Curva de saturação da câmara de ionização com eletrodo coletor de alumínio. Qualidade de radiação X, RQR 3, tensão 50 kV e corrente de 10 mA, distância foco-câmara de $1 \mathrm{~m}$

8.2 Curva de saturação da câmara de ionização com eletrodo coletor de grafite. Qualidade de radiação X, RQR 3, tensão 50 kV e corrente de 10 mA, distância foco-câmara de $1 \mathrm{~m}$

8.3 Linearidade de resposta da câmara de ionização com eletrodo coletor de alumínio, para raios $X$, nível radiodiagnóstico, RQR 3, de $50 \mathrm{kV}$ $(1,5 \mathrm{mmAl})$

8.4 Linearidade de resposta da câmara de ionização com eletrodo coletor de grafite, para raios $X$, nível radiodiagnóstico, RQR 3, de $50 \mathrm{kV}$ $(1,5 \mathrm{mmAl})$

8.5 Resposta relativa em função da inclinação da câmara com eletrodo coletor de alumínio, para raios $\mathrm{X}$, nível radiodiagnóstico, RQR 3

8.6 Resposta relativa em função da inclinação da câmara com eletrodo coletor de grafite, para raios $X$, nível radiodiagnóstico, RQR 3

8.7 Fatores de correção da resposta da câmara de ionização com eletrodo coletor de alumínio, para as qualidades de raios $\mathrm{X}$, nível diagnóstico, feixes diretos, normalizados para a camada semi-redutora de $2,35 \mathrm{mmAl}$

8.8 Fatores de correção da resposta da câmara de ionização com eletrodo coletor de alumínio, para as qualidades de raios $\mathrm{X}$, nível diagnóstico, feixes atenuados, normalizados para a camada semi-redutora de $6,86 \mathrm{mmAl}$

8.9 Fatores de correção da resposta da câmara de ionização com eletrodo coletor de grafite, para as qualidades de raios $\mathrm{X}$, nível diagnóstico, feixes diretos, normalizados para a camada semi-redutora de $2,35 \mathrm{mmAl}$ 
8.10 Fatores de correção da resposta da câmara de ionização com eletrodo coletor de grafite, para as qualidades de raios $\mathrm{X}$, nível diagnóstico, feixes atenuados, normalizados para a camada semi-redutora de $6,86 \mathrm{mmAl}$

8.11 Fatores de correção da resposta da câmara de ionização com eletrodo coletor de alumínio, para as qualidades de raios $\mathrm{X}$, nível mamografia, feixes de entrada, normalizados para a camada semi-redutora de $0,34 \mathrm{mmAl}$

8.12 Fatores de correção da resposta da câmara de ionização com eletrodo coletor de alumínio, para as qualidades de raios $\mathrm{X}$, nível mamografia, feixes de saída, normalizados para a camada semi-redutora de $0,61 \mathrm{mmAl}$

8.13 Fatores de correção da resposta da câmara de ionização com eletrodo coletor de grafite, para as qualidades de raios $X$, nível mamografia, feixes de entrada, normalizados para a camada semi-redutora de $0,34 \mathrm{mmAl}$

8.14 Fatores de correção da resposta da câmara de ionização com eletrodo coletor de grafite, para as qualidades de raios $X$, nível mamografia, feixes de saída, normalizados para a camada semi-redutora de $0,61 \mathrm{mmAl}$

8.15 Curva Tandem para qualidades de raios $X$, nível diagnóstico, feixes diretos, das câmaras de ionização com eletrodos coletores de alumínio e de grafite

8.16 Curva Tandem para qualidades de raios $\mathrm{X}$, nível diagnóstico, feixes atenuados, das câmaras de ionização com eletrodos coletores de alumínio e de grafite

8.17 Curva Tandem para qualidades de raios $X$, nível mamografia, feixes de entrada, das câmaras de ionização com eletrodos coletores de alumínio e de grafite 
8.18 Curva Tandem para qualidades de raios $X$, nível mamografia, feixes de saída, das câmaras de ionização com eletrodos coletores de alumínio e de grafite 


\section{LISTA DE TABELAS}

2.1 Resumo das grandezas operacionais para monitoração de área e individual

3.1 Características dos eletrômetros utilizados neste trabalho

3.2 Características dos sistemas padrões utilizados nos ensaios

3.3 Características do sistema Rigaku-Denki para as qualidades de radioterapia de energias baixas; filtração inerente: $1 \mathrm{mmBe}$

3.4 Características do sistema Rigaku-Denki para as qualidades de mamografia; feixes de entrada (ou diretos), filtração inerente: $1 \mathrm{mmBe}$

3.5 Características do sistema Rigaku-Denki para as qualidades de mamografia; feixes de saída (ou atenuados), filtração inerente: $1 \mathrm{mmBe}$

3.6 Características do sistema Rigaku-Denki para as qualidades de radioproteção, de energias baixas; filtração inerente: $1 \mathrm{mmBe}$

3.7 Características do sistema Pantak/Seifert para as qualidades de radiodiagnóstico; feixes diretos (ou de entrada), filtração inerente: $1 \mathrm{mmBe}$

3.8 Características do sistema Pantak/Seifert para as qualidades de radiodiagnóstico; feixes atenuados (ou de saída), filtração inerente: $1 \mathrm{mmBe}$

4.1 Características dos feixes de radiação $X$, nível radioproteção, segundo a norma ISO 4037-1, para feixes estreitos. Em todos os casos foram adicionados ainda 4,0 mmAl à filtração de $\mathrm{Cu}$ e $\mathrm{Sn}$, perfazendo a filtração total para cada qualidade de radiação

4.2 Características dos feixes de radiação $X$, nível radioproteção, implantados no LCI / IPEN. Em todos os casos foram adicionados ainda 4,0 mmAl à filtração de $\mathrm{Cu}$, perfazendo a filtração total para cada qualidade de radiação 
4.3 Parâmetros dos feixes de radiação $X$, nível radioproteção, implantados no LCI / IPEN, para distâncias foco-detector de 1,0 m e 2,5 m

4.4 Coeficientes de calibração das câmaras de ionização utilizadas na caracterização dos feixes de radiação $X$, nível radioproteção, segundo a norma ISO 4037-1, para feixes estreitos, implantados no LCI, para distância foco-detector de 2,5 m

5.1 Detalhamento da estimativa de custo de confecção das câmaras de ionização com eletrodos coletores de grafite e alumínio, e do simulador de tronco humano, confeccionado em PMMA

6.1 Efeito de polaridade da câmara de ionização com eletrodo coletor de alumínio

6.2 Efeito de polaridade da câmara de ionização com eletrodo coletor de grafite

6.3 Eficiência de coleta de íons das duas câmaras de ionização para a qualidade de radiação ISO N-60 (raios X, nível radioproteção)

6.4 Tamanho de campo útil para o ensaio de resposta relativa em função do tamanho do campo para posicionamento das câmaras de ionização desenvolvidas

6.5 Resposta relativa das câmaras de ionização desenvolvidas, em função do tamanho do campo para radiação X, nível radioproteção (ISO N-60). Distância foco-detector $=2,5 \mathrm{~m}$

6.6 Tempo de estabilização: resposta relativa da câmara de ionização com eletrodo coletor de alumínio em função do tempo

6.7 Tempo de estabilização: resposta relativa da câmara de ionização com eletrodo coletor de grafite em função do tempo

6.8 Corrente de fuga ( $\mathrm{fA}$ ) sem irradiação, medida nos intervalos de tempo especificados após a aplicação de tensão de polarização de $+400 \mathrm{~V}$ às câmaras de ionização desenvolvidas 
6.9 Resposta relativa da câmara de ionização com eletrodo coletor de alumínio em função da inclinação e da qualidade da radiação (nível radioproteção) com sistema Pantak/Seifert

6.10 Resposta relativa da câmara de ionização com eletrodo coletor de alumínio em função da inclinação e da qualidade da radiação (nível radioproteção) com sistema irradiador STS $\left({ }^{137} \mathrm{Cs}\right)$ e sistema irradiador IPEN $\left({ }^{60} \mathrm{Co}\right)$

6.11 Resposta relativa da câmara de ionização com eletrodo coletor de grafite em função da inclinação e da qualidade da radiação (nível radioproteção), com o sistema Pantak/Seifert

6.12 Resposta relativa da câmara de ionização com eletrodo coletor de grafite em função da inclinação e da qualidade da radiação, com sistema irradiador STS $\left({ }^{137} \mathrm{Cs}\right)$ e sistema irradiador IPEN $\left({ }^{60} \mathrm{Co}\right)$

6.13 Coeficientes de calibração das câmaras de ionização (com eletrodos coletores de alumínio e grafite) para radiação X (nível radioproteção) e radiação gama de ${ }^{137} \mathrm{Cs}$ e ${ }^{60} \mathrm{Co}$

7.1 Valores da taxa de kerma no ar obtidos com a câmara de ionização padrão, nas qualidades de radiação $X$, nível radioproteção, espectro estreito, da norma ISO 4037-1, e para radiação gama das fontes de ${ }^{137} \mathrm{Cs} \mathrm{e}{ }^{60} \mathrm{Co}$

7.2 Valores obtidos da câmara de ionização com eletrodo coletor de grafite, nas qualidades de radiação $X$, nível radioproteção, da norma ISO 40371 , espectro estreito, e para radiação gama das fontes de ${ }^{137} \mathrm{Cs}$ e ${ }^{60} \mathrm{Co}$

7.3 Valores de taxa de equivalente de dose pessoal, $H_{P}(10)$, para as qualidades de radiação $X$ (nível radioproteção) ISO N-60, ISO N-80, ISO N-100, ISO N-150, com a câmara de ionização com eletrodo coletor de grafite, no sistema Pantak/Seifert 
7.4 Valores de taxa de equivalente de dose pessoal, $H_{P}(10)$, para radiação gama, com a câmara de ionização com eletrodo coletor de grafite, no sistema irradiador STS $\left({ }^{137} \mathrm{Cs}\right)$ e sistema irradiador IPEN $\left({ }^{60} \mathrm{Co}\right)$

7.5 Coeficientes de calibração $\left(\mathrm{N}_{\mathrm{H}}\right)$, obtidos com a câmara de ionização com eletrodo coletor de grafite desenvolvida neste trabalho, em relação aos valores obtidos por Ankerhold, nas qualidades de radiação $X$, da norma ISO 4037-1, nível radioproteção, e radiação gama de fontes de Cs e Co

7.6 Planilha das incertezas na determinação do equivalente de dose pessoal, $H_{P}(10)$, para radiação gama, com a câmara de ionização com eletrodo coletor de grafite, no sistema irradiador STS $\left({ }^{137} \mathrm{Cs}\right)$ e sistema irradiador IPEN $\left({ }^{60} \mathrm{Co}\right)$ e para o sistema de radiação $\mathrm{X}$, Pantak/Seifert

8.1 Efeito de polaridade da câmara de ionização com eletrodo coletor de alumínio

8.2 Efeito de polaridade da câmara de ionização com eletrodo coletor de grafite

8.3 Eficiência de coleta de íons das duas câmaras de ionização para a qualidade de radiação $\mathrm{RQR} 3$ (raios $\mathrm{X}$, nível radiodiagnóstico)

8.4 Tamanho de campo útil para o ensaio de resposta relativa em função do tamanho do campo para posicionamento das câmaras de ionização desenvolvidas

8.5 Resposta relativa das câmaras de ionização desenvolvidas, em função do tamanho do campo para radiação $\mathrm{X}$, nível radiodiagnóstico, feixes atenuados (RQR 3)

8.6 Resposta relativa das câmaras de ionização desenvolvidas, em função do tamanho do campo para radiação $X$, nível radiodiagnóstico, feixes diretos (RQA 3)

8.7 Tempo de estabilização: resposta relativa da câmara de ionização com eletrodo coletor de alumínio em função do tempo 
8.8 Tempo de estabilização: resposta relativa da câmara de ionização com eletrodo coletor de alumínio em função do tempo

8.9 Resposta relativa da câmara de ionização com eletrodo coletor de alumínio em função da inclinação, para a qualidade da radiação $X$ RQR 3, nível radiodiagnóstico, com o sistema Pantak/Seifert

8.10 Resposta relativa da câmara de ionização com eletrodo coletor de grafite em função da inclinação para a qualidade da radiação X RQR 3, nível radiodiagnóstico, com o sistema Pantak/Seifert

8.11 Coeficientes de calibração das câmaras de ionização (com eletrodos coletores de alumínio e grafite) para radiação $X$, nível radiodiagnóstico (feixes diretos e atenuados)

8.12 Coeficientes de calibração das câmaras de ionização (com eletrodos coletores de alumínio e grafite) para radiação X (níveis radioterapia e mamografia) 


\section{LISTA DE ABREVIATURAS}

CDRH - Center for Devices and Radiological Health

CNEN - Comissão Nacional de Energia Nuclear

CRPq - Centro de Reatores de Pesquisa do IPEN

CSR - Camada Semi-Redutora

DKD - Deutscher Kalibrierdienst

FDA - Food and Drug Administration

$H_{P}(10)$ - Grandeza operacional de proteção radiológica, equivalente de dose pessoal

HPGe - Detector semicondutor de germânio hiper-puro

IAEA - International Atomic Energy Agency

ICRP - International Commission on Radiological Protection

ICRU - International Commission on Radiation Units and Measurements

IEC - International Electrotechnical Commission

IPEN - Instituto de Pesquisas Energéticas e Nucleares

IRD - Instituto de Radioproteção e Dosimetria

ISO - International Organization for Standardization

kerma - Kinetic energy released in material

kVp - Tensão de pico em milhares de volts

LCI - Laboratório de Calibração de Instrumentos

LNMRI - Laboratório Nacional de Metrologia das Radiações Ionizantes

NIST - National Institute of Standards and Technology

NPL - National Physical Laboratory

PMMA - Polimetil metacrilato

PTB - Physikalisch-Technische Bundesanstalt

PTW - Physikalisch-Technische Werkstätten

RQA - Nomenclatura adotada para os feixes atenuados na norma IEC 61267, 1994.

RQR - Nomenclatura adotada para os feixes diretos na norma IEC 61267, 1994.

SRS 16 - Safety Report Series 16 da IAEA 
STS - Steuerungstechnik \& Strahlenschutz GmbH

TL - Termoluminescência, Termoluminescente

TRS 133 - Technical Report Series 133 da IAEA

VARIAC - Alternating Current Variator

$\mathrm{V}_{\mathrm{V}}$ - Valor verdadeiro de uma grandeza

$\mathrm{V}_{\mathrm{VC}}$ - Valor verdadeiro convencional de uma grandeza

Z - Número atômico de um dado material 


\section{INTRODUÇÃO}

O desenvolvimento de diferentes pesquisas tecnológicas ao longo dos últimos anos, e o conseqüente surgimento de novos processos e tratamentos (materiais, alimentos, saúde, entre outros) que utilizam radiação têm colaborado para o crescente aumento das aplicações das radiações ionizantes na Indústria, Medicina e Agricultura, sob forma principalmente de irradiadores, equipamentos de raios $\mathrm{X}$ e fontes seladas. Vem aumentando, consequentemente, a utilização de dispositivos que permitem medir os efeitos diretos e indiretos provocados pela radiação, com o objetivo de controlá-los. Desse modo, a maior parte das câmaras de ionização utilizadas nos processos anteriormente citados são de projeto e fabricação comercial, sendo raro encontrar-se trabalhos recentes com câmaras de ionização que incluam detalhes técnicos sobre seu projeto e construção. O conhecimento de detalhes construtivos das câmaras de ionização auxiliam na sua confecção, principalmente quando são necessárias correções nos valores das grandezas medidas por elas.

Em todo mundo há uma preocupação no sentido de compreender, quantificar e evitar danos à saúde, associados ao uso das radiações, mantendo-as dentro de limites aceitáveis e/ou controláveis ${ }^{(1-9)}$, tanto para trabalhadores, como para pacientes e ainda o público, submetidos a procedimentos diagnósticos com radiação ou a tratamentos com radioterapia (teleterapia e braquiterapia).

Desse modo, necessita-se conhecer muito bem as características dos feixes de radiação antes de sua utilização tanto em clínicas de radioterapia e radiodiagnóstico como em laboratórios de calibração de detectores de radiação. 
$\mathrm{Na}$ atualidade, a utilização de ferramentas diagnósticas para a determinação do volume do alvo e os aceleradores avançados de irradiação devem ser empregados de forma adequada com precisão e exatidão altas para a determinação de doses. Existe, desse modo, uma tendência em se enfatizar a necessidade de uma exatidão alta nos resultados obtidos, ou seja, deseja-se uma maior acurácia na obtenção das doses, e nas medidas de dose ${ }^{(10-11)}$.

Todas as etapas de um processo que utilize radiação ionizante incluem algumas incertezas, sendo necessária atenção especial em cada um dos procedimentos de modo a assegurar uma qualidade aceitável. Desse modo, um programa de controle de qualidade em radiodiagnóstico e radioterapia pode levar à aplicação de doses mínimas aos pacientes sob tratamento e de uma maior acurácia na determinação das doses a eles aplicadas.

A Agência Internacional de Energia Atômica (IAEA) vem se preocupando com este assunto já há algum tempo, publicando diversas recomendações e procedimentos que envolvem tanto a calibração de feixes de radiação e de instrumentos detectores de radiação como a determinação de doses absorvidas, utilizando-se tipos diferentes de instrumentos e radiações ${ }^{(12-15)}$. Foram também publicadas recomendações sobre a calibração de instrumentos com radiação eletromagnética ${ }^{(16)}$, pela International Organization for Standardization (ISO), entre outras, mostrando a preocupação atual com os efeitos da radiação e seus danos ao ser humano, às populações e ao meio ambiente.

Diversos trabalhos foram realizados enfocando a construção de câmaras de ionização cada vez mais adequadas às necessidades atuais, levando em conta as recomendações internacionais quanto ao seu desempenho e de modo a facilitar os procedimentos rotineiros de coleta de $\operatorname{dados}^{(17-21)}$. Vem havendo no Brasil um interesse crescente em se desenvolver câmaras de ionização para dosimetria da radiação $\mathrm{X}$, gama, beta e de elétrons, para utilização principalmente nas áreas de Metrologia das Radiações e de Física Médica. 
Inicialmente foram desenvolvidas as câmaras de ionização para radiação $X^{(22)}$ e radiação beta ${ }^{(23)}$, respectivamente pelo Instituto de Radioproteção e Dosimetria (IRD), CNEN, Rio de Janeiro, e pela Escola de Engenharia da Universidade Federal de Minas Gerais, mostrando a viabilidade de construção de detectores de radiação, empregando-se materiais disponíveis no mercado nacional.

No grupo do Laboratório de Calibração de Instrumentos do Instituto de Pesquisas Energéticas e Nucleares (IPEN) foram projetadas e construídas diversas câmaras de ionização de placas paralelas para radiação $X$ de energias baixas $\mathrm{e}$ médias, e beta ${ }^{(24-28)}$, para elétrons de energias altas ${ }^{(29-30)}$, de extrapolação para raios$X$ de energias baixas ${ }^{(31)}$, para dosimetria de elétrons ${ }^{(32)}$, para dosimetria beta e aplicadores dermatológicos ${ }^{(33-35)}$, e câmaras de ionização Tandem para programas de controle de qualidade em radioterapia e radiodiagnóstico ${ }^{(36-38)}$, uma micro-câmara de extrapolação para radiação beta ${ }^{(39)}$, e uma câmara para dosimetria de feixes de tomografia computadorizada ${ }^{(40)}$.

Ankerhold e col. construíram na Alemanha, PTB (Physikalisch-Technische Bundesanstalt) um primeiro protótipo de uma câmara de ionização como um sistema padrão secundário, otimizada para obter uma resposta aproximadamente constante do equivalente de dose pessoal, $\mathrm{H}_{\mathrm{p}}(10)$, em um simulador ${ }^{(41-43)}$.

No campo da dosimetria pessoal, muitos protocolos têm sido desenvolvidos ao longo dos anos. As grandezas operacionais para monitoração individual são o equivalente de dose pessoal $H_{p}(10)^{(6,16,44-46)}$, para feixes de radiação muito penetrantes, e $H_{p}(0,07)$ e $H_{p}(3)$, para feixes pouco penetrantes, na pele e no cristalino do olho, respectivamente. No Conselho Diretivo 96/29/Euraton ${ }^{(47)}$, os limites de dose para exposição dos trabalhadores foram definidos como: "O limite efetivo de dose para exposição dos trabalhadores deve ser $100 \mathrm{mSv}$ em um período de cinco anos consecutivos" e "o limite de dose equivalente para a pele deve ser $500 \mathrm{mSv}$ por ano"(47). 
De acordo com a norma internacional ISO/FDIS 4037-3(48), o valor verdadeiro convencional do equivalente de dose pessoal, $H_{p}(10)$, está baseado na grandeza kerma no ar livre, $\mathrm{K}_{\mathrm{ar}}$. A International Commission on Radiological Protection (ICRP) ${ }^{(49)}$, na sua Publicação $74^{(50)}$, e a International Commission on Radiation Units and Measurements (ICRU), na sua Publicação $57^{(51)}$, fornecem os valores dos coeficientes de conversão de $K_{a r}$ para $H_{p}(10)$ para feixes de fótons monoenergéticos, em um simulador, para diferentes ângulos de incidência, entre o campo de fótons unidirecional e o ângulo normal $\left(0^{\circ}\right)$ formado com a superfície do simulador. Estes coeficientes de conversão apresentam dependência energética e angular, principalmente para energias baixas ${ }^{(50,51)}$.

A norma ISO/FDIS $4037-3^{(48)}$ fornece os coeficientes de conversão para feixes padrões de radiação de fótons como especificado na norma ISO/FDIS 4037 $1^{(16)}$; estes valores correspondem aos espectros reais produzidos sob condições experimentais padrões. Entretanto, a distribuição espectral de qualidades de raios $X$, nominalmente iguais, mas geradas por aparatos diferentes (máquinas ou sistemas geradores), irão sempre apresentar pequenas diferenças nos espectros produzidos. Isto é de importância particular para qualidades de radiação que incluem um número apreciável de fótons de energias baixas, que podem levar à indicação de diferentes coeficientes de conversão para as mesmas qualidades de raios $X$; os seus valores podem diferir até em dezenas de vezes (em termos percentuais).

No Brasil, a Comissão Nacional de Energia Nuclear (CNEN) exige dos Serviços de Monitoração Individual que os sistemas dosimétricos sejam capazes de determinar tanto a dose absorvida (no ar ou no tecido), como a energia da radiação incidente, para possíveis estudos dos efeitos biológicos das radiações ${ }^{(1)}$.

A garantia da qualidade em sistemas de raios $X$ pode ser definida como um conjunto de etapas (ou um programa), onde se assegure confiabilidade no desempenho dos equipamentos e sistemas de radiação X. Os programas de garantia de qualidade devem basicamente incluir revisões periódicas dos padrões de 
referência (câmaras de ionização, fontes radioativas padrões, entre outras), treinamento rotineiro dos trabalhadores, inspeções nas instalações, avaliação do desempenho dos equipamentos entre outras etapas ${ }^{(7,52-53)}$, que podem ser definidas conforme as necessidades dos laboratórios de calibração de equipamentos, clínicas, indústrias que utilizam materiais e/ou equipamento emissores de radiação $X$, gama, beta, entre outros.

Um programa de garantia de qualidade pode objetivar a obtenção de imagens diagnósticas, de boa qualidade, ou que contenham todas as informações diagnósticas indispensáveis, porém com economia de material, redução do tempo gasto nestes processos, reduzindo ainda a exposição à radiação ionizante tanto dos pacientes como dos trabalhadores expostos a estas radiações.

A verificação dos sistemas ou equipamentos de raios $X$ é uma das etapas de um programa de controle de qualidade. Desse modo, um programa de garantia da qualidade consiste em um conjunto de atividades e testes técnicos dos equipamentos, que garantam o cumprimento de requisitos pré-estabelecidos de qualidade e que assegurem o funcionamento correto dos equipamentos de modo a se obter uma otimização dos serviços como um todo.

Alguns testes que podem ser realizados nos equipamentos e sistemas de raios $X$, empregados em calibração de instrumentos, são propostos em regulamentos técnicos e normas em âmbito nacional ${ }^{(7,8)}$ e ainda internacional ${ }^{(52-54)}$, entre outros.

Desse modo, sempre houve uma preocupação no desenvolvimento de procedimentos de controle de qualidade de feixes de radiação. Um método muito utilizado para a verificação da constância de feixes de radiação é o método denominado "Tandem", que basicamente consiste na utilização de dois dosímetros com dependências energéticas diferentes de suas respostas, permitindo por meio da razão das suas leituras a determinação da energia efetiva de um dado feixe de radiação. A metodologia ou sistema "Tandem" pode ser aplicado utilizando-se 
dosímetros termoluminescentes ${ }^{(55-57)}$ (TL), ou mesmo, câmaras de ionização construídas para esta finalidade.

Assim, o desenvolvimento de protótipos de câmaras de ionização, constituindo um Sistema Tandem ${ }^{(26,36-38)}$, para a medida do equivalente de dose pessoal, $H_{p}(10)$, num simulador, e para a determinação da energia dos feixes incidentes, para utilização como um sistema de referência para laboratórios de calibração de instrumentos, torna-se justificável.

Será possível, com este tipo de sistema dosimétrico, a avaliação da dose absorvida, e ainda a verificação da constância de feixes ou campos padrões de radiação (como boa estabilidade e uniformidade) ${ }^{(54)}$, o conhecimento dos espectros ${ }^{(58)}$ dos feixes que serão utilizados, e ainda as características das câmaras de ionização descritas por Knoll ${ }^{(59)}$ e Attix ${ }^{(60)}$, para calibração de instrumentos ${ }^{(61,62)}$.

As câmaras de ionização a serem desenvolvidas deverão ser adequadas ao intervalo de energias ${ }^{(63)}$ que se deseja medir e ao tipo de radiação ${ }^{(64-66)}$. Estas câmaras de ionização podem formar um sistema "Tandem" de medida, versátil e prático.

\section{Objetivos e aspectos relevantes do trabalho}

O objetivo principal deste trabalho foi o desenvolvimento de câmaras de ionização para a medida do equivalente de dose pessoal, Hp (10). Para os testes deste tipo de câmara de ionização foi necessária a implantação de feixes padronizados de radiação $X$ de energias médias, nível radioproteção, por meio do desenvolvimento de uma metodologia dosimétrica e da análise dos parâmetros físicos destes feixes, complementando os arranjos experimentais do Laboratório de Calibração de Instrumentos do IPEN. 
Uma das principais inovações do trabalho está no fato de que as câmaras de ionização formam um sistema Tandem, que permitem a verificação da constância de feixes de radiação $X$, nível radioproteção.

As câmaras de ionização desenvolvidas permitirão a obtenção de uma resposta do equivalente de dose pessoal $\mathrm{Hp}(10)$ para fótons com energias variando de cerca de $48 \mathrm{keV}$ a $1250 \mathrm{keV}$, para ângulos de incidência entre $0^{\circ}$ e $30^{\circ}$. 


\section{FUNDAMENTOS TEÓRICOS}

\section{1 - Sistemas de Raios X}

Os equipamentos de raios $\mathrm{X}$ chamados de "equipamentos de quilovoltagem" são amplamente utilizados nas áreas de radioproteção, radiodiagnóstico e radioterapia. Estes equipamentos de raios $X$ são ainda bastante utilizados no Brasil, embora estejam sendo substituídos pelos equipamentos de megavoltagem e de elétrons nas clínicas. Os equipamentos de raios $X$ representam um custo mais baixo que os aceleradores; além disso, o custo da terapia com elétrons pode ser proibitivo para alguns serviços de radioterapia ${ }^{(67)}$. No entanto, com a fabricação nos últimos cinco anos de diversos modelos de aceleradores de elétrons e com sua grande divulgação nos meios médicos, estes sistemas, hoje, são muito utilizados nos hospitais, tanto públicos como particulares. Estes tipos de aceleradores são empregados nos procedimentos dos tratamentos com radioterapia.

O método de produção de raios $X$ de quilovoltagem para radioproteção, diagnóstico e terapia, consiste no uso de um tubo de raios $X$ convencional. Os tubos de raios $X$ são constituídos de um terminal denominado catodo e de um outro denominado anodo, inseridos no interior de uma ampola de vidro, onde é formado vácuo. O catodo consiste de um filamento (normalmente de tunstênio) com formato de uma bobina colocada num sistema focalizador. Quando o filamento é aquecido, elétrons são liberados de sua superfície, sendo este fenômeno conhecido como emissão termoiônica. Quando uma alta tensão (ou quilovoltagem) é aplicada entre o ando e o catodo, os elétrons liberados são dirigidos em direção ao anodo e, desse 
modo, estabelece-se uma corrente elétrica no circuito. A corrente obtida é da ordem de alguns miliamperes e normalmente medida por um amperímetro (galvanômetro, ou em um painel digital nos equipamentos mais modernos).

Considerando-se que o meio entre o anodo e catodo está sob alto vácuo, os elétrons, ao atravessarem a distância que separa o anodo e catodo, adquirem velocidades muito altas. No processo de desaceleração dos elétrons, ao colidirem com o anodo, raios $X$ são emitidos em diversas direções. A produção de raios $X$ que acompanha a desaceleração de elétrons é o Bremsstrahlung (radiação de freamento). Cerca da metade destes raios $\mathrm{X}$ são absorvidos no próprio anodo; da porção restante, somente aqueles raios $X$ que emergem no cone do feixe primário são úteis.

Cerca de $99 \%$ da energia depositada no anodo é perdida na forma de calor e somente cerca de $1 \%$ dessa energia é transformada em raios $X$. O sistema focalizador tem a função de concentrar os elétrons sobre uma pequena parte do anodo, denominada ponto focal. Esta parte, para onde os elétrons são focalizados, normalmente é feita de tungstênio ou de uma liga equivalente ao tungstênio. Este material foi escolhido devido ao seu ponto de fusão e número atômico altos (qualidades necessárias para um material ser utilizado como alvo de tubo de raios $\mathrm{X}$ ). Vários critérios de projeto e operação de sistemas de raios $X$ são abordados por Johns e Cunningham ${ }^{(68)}$.

\section{2 - Interação da radiação com a matéria}

Qualquer forma de radiação que tenha energia suficiente para causar a liberação de um ou mais elétrons de um átomo é denominada radiação ionizante. As formas comuns de uso na Medicina são as radiações $X$, gama e de elétrons, que também são utilizados na área industrial (gamagrafia, irradiação de materiais, entre outros) e nos laboratórios de calibração de equipamentos monitores de radiação. 
As radiações possuem energia, como no caso das partículas em movimento, ou por sua própria natureza, como é o caso das radiações eletromagnéticas. Ao atravessar um meio (interagindo com a matéria), a radiação transfere sua energia (total ou parcialmente) para os átomos e moléculas deste meio. A transferência da energia de uma partícula ou de um fóton para os átomos do material absorvente (meio) ocorre por mecanismos de ionização e excitação.

Um processo de interação da radiação com o meio no qual resulte a remoção de um elétron, de um átomo ou molécula, deixando-o com uma carga resultante positiva, é denominado ionização. No entanto, a adição de energia a um sistema atômico ou molecular irá elevá-lo do estado normal de energia ao estado de excitação.

De um modo geral, quando a radiação de partículas carregadas ou radiação eletromagnética atravessa a matéria, o mecanismo predominante da perda de energia é a sua interação com os elétrons do meio (material). No caso das partículas carregadas, isto é facilmente evidenciado a partir da dispersão que elas apresentam ao interagirem com a matéria: no caso das partículas pesadas (prótons, partículas alfa, entre outros), elas são pouco desviadas de sua direção original quando interagem com o meio, perdendo energia. Os elétrons, por sua vez, são desviados em ângulos muito maiores. Estas perdas de energia resultantes de colisões com núcleos são de várias ordens de grandeza menores que a perda de energia que ocorre na interação com os elétrons.

\subsection{1 - Interação de fótons com a matéria}

Vários fenômenos físicos podem ocorrer durante a interação da radiação $X$ com a matéria; os mecanismos de interação dependem da energia dos fótons, bem como da composição do material alvo (anodo). Os fótons incidentes podem ser desviados de sua trajetória inicial ou podem ser totalmente absorvidos. Quando um desses dois fenômenos ocorrer por meio de uma única interação, tem-se ionização 
primária, por meio da qual um elétron é arrancado de um átomo por processos diferentes. Este elétron liberado é chamado elétron secundário e sua energia poderá até ser igual à do fóton incidente, e poderá provocar novas ionizações até que toda sua energia seja liberada. A conseqüência direta desse fato é que as ionizações ocorridas na matéria, devido às interações com fótons, são pequenas, e a maior parte das ionizações são causadas pelos elétrons secundários.

Entre os mecanismos principais de interação de fótons (radiação gama ou X) com a matéria pode-se citar três: o efeito fotoelétrico, o efeito Compton e a produção de pares. A probabilidade de ocorrência de um desses processos é determinada pela energia do fóton incidente e pelo número atômico do meio (material). Na interação entre um fóton e a matéria são emitidos ou criados elétrons ou pósitrons que ionizam os átomos do meio.

\subsection{2 - Efeito fotoelétrico}

O efeito fotoelétrico ou absorção fotoelétrica ${ }^{(69)}$ é uma interação entre um fóton e um elétron orbital das camadas mais internas do átomo. $O$ fóton é absorvido pelo átomo e um elétron é ejetado. A energia cinética do elétron ejetado é igual à energia do fóton menos a energia de ligação do elétron. A energia de ligação de um elétron é a energia que deve ser fornecida a ele para removê-lo do átomo.

Para que ocorra este efeito, o fóton incidente no material deve ter uma energia $\left(E_{f}\right)$ pelo menos maior do que a energia de ligação do elétron $(W)$. $O$ excesso de energia do fóton é transferido ao elétron sob forma de energia cinética $\left(E_{c}\right)$. Portanto, a velocidade com que o elétron será ejetado do átomo depende da energia incidente e da energia de ligação do elétron ao átomo. A energia cinética obtida pelo elétron é dada por:

$$
E_{c}=E_{f}-W
$$


Quando o elétron é ejetado do átomo, este fica num estado excitado, retornando ao estado fundamental quando um outro elétron de uma camada mais externa ocupar o espaço deixado pelo elétron ejetado. Esta ocupação fará com que seja emitido um fóton de raios $\mathrm{X}$ característico.

A probabilidade de absorção fotoelétrica depende da energia do fóton incidente e do número atômico $(Z)$ do absorvedor. O intervalo de probabilidade de ocorrência deste efeito é na faixa de 0 a $100 \mathrm{keV}^{(59)}$, para um material absorvedor com número atômico (Z) variando entre 1 e 70 . Quanto maior o Z, maior será a probabilidade de ocorrer o efeito fotoelétrico, já que este efeito envolve os elétrons ligados ao átomo; quanto maior o número de elétrons, maior será a probabilidade de interação ${ }^{(68)}$.

\subsection{3 - Espalhamento Compton}

O efeito Compton ou espalhamento Compton consiste na colisão entre um fóton e um elétron (que pode ser considerado livre) das camadas mais externas do átomo.

Um elétron deste tipo pode ser considerado livre quando a energia do fóton incidente é muito maior que a energia de ligação do elétron. A energia cinética do elétron espalhado depende do ângulo de espalhamento. Nesse processo, o fóton não é absorvido e, portanto, continua interagindo com os outros elétrons.

Neste caso, o elétron também é ejetado apenas com uma parte da energia do fóton incidente, que é, então, espalhado com uma energia $\left(E^{\prime}=h s^{\prime}\right)$ menor do que tinha antes da colisão $\left(E=h_{0}\right)$, sendo defletido num ângulo $\varphi$, em relação à direção original; o elétron é ejetado com um ângulo $\Theta$ em relação à direção do fóton incidente. 
O elétron ejetado é chamado de elétron de recuo, e a energia cinética $\left(E_{c}\right)$ adquirida por este elétron é dada por:

$$
E_{c}=E[\Theta(1-\cos \varphi) /[1+\Theta(1-\cos \varphi)]
$$

onde $\Theta=E / m_{0} c^{2}$, sendo $E=h_{ง_{0}}$ a energia do fóton incidente $e m_{0} c^{2}$ a energia de repouso do elétron $(0,511 \mathrm{MeV})$.

O efeito Compton, no ar, é predominante para energias de fótons acima de $40 \mathrm{keV}$, envolve uma interação entre um fóton e um elétron quase livre e decresce com o aumento da energia. A probabilidade de ocorrência do efeito Compton por átomo do absorvedor depende do número de elétrons disponíveis como alvos.

\subsection{4 - Produção de pares}

O processo de produção de pares elétron-pósitron ocorre quando a energia do fóton incidente é maior que pelo menos duas vezes a massa de repouso do elétron, isto é, $1,022 \mathrm{MeV}$. Neste processo, um fóton perde toda a sua energia em uma colisão com o núcleo, criando um par elétron-pósitron, com uma certa energia cinética. Este efeito aumenta rapidamente com o aumento da energia mínima para formação de pares. A equação 2.3 mostra a distribuição da energia do fóton incidente:

$$
E=1,022 \mathrm{MeV}+E_{e-}+E_{e+}
$$

A energia excedente a 1,022 MeV é transferida às duas partículas, sob forma de energia cinética, sendo dividida igualmente entre elas.

Tanto o elétron como o pósitron perdem energia no meio, e quando o pósitron praticamente não apresentar mais energia cinética, este irá se aniquilar com qualquer elétron livre do meio, e serão originados dois fótons, em sentidos opostos, com energia de 0,511 MeV cada um. 


\subsection{5 - Atenuação de fótons}

Quando se imagina um experimento onde fótons monoenergéticos são colimados em um feixe estreito e incidem em um detector após passarem através de um absorvedor de espessura variável $x$, o resultado deve ser uma atenuação exponencial da intensidade dos fótons. Cada um dos processos de interação remove o fóton do feixe por absorção ou por espalhamento para fora da direção do detector, podendo ser caracterizado por uma probabilidade fixa de ocorrência por unidade de comprimento de caminho no absorvedor. A soma destas probabilidades é simplesmente a probabilidade por unidade de comprimento de caminho de que o fóton seja removido do feixe e é chamada de coeficiente de atenuação linear $\mu$. 0 número de fótons transmitidos I é então dado em termos do número de fótons $\mathrm{I}_{0}$ sem um absorvedor por:

$$
\mathrm{I} / \mathrm{I}_{0}=\mathrm{e}^{-\mu \mathrm{x}}
$$

Um outro conceito útil para a caracterização de fótons é o de camada semiredutora. A camada semi-redutora é definida como sendo a espessura de material necessária para atenuar metade dos fótons, sendo dada pela relação:

$$
\mathrm{CSR}=\ln 2 / \mu=0,693 / \mu
$$

Este conceito é utilizado para descrever a qualidade de um feixe de raios $\mathrm{X}$, como será discutido na seção 2.3.7.

O uso do coeficiente de atenuação linear, no entanto, é limitado, pelo fato de que ele varia com a densidade do material absorvedor. Desse modo, o coeficiente de atenuação de massa é muito mais prático e mais utilizado, sendo definido como: 


$$
\text { coeficiente de atenuação de massa }=\mu / \rho
$$

onde $\rho$ representa a densidade do meio.

\subsection{6 - Teoria cavitária}

Para se determinar a dose absorvida num meio é necessário introduzir um instrumento sensível à radiação nesse meio. De modo geral, esse instrumento (detector de radiação) difere em número atômico e densidade do meio onde é inserido, representando uma descontinuidade, ou melhor, constitui uma cavidade nesse meio. O tamanho da cavidade, quando comparado com o alcance dos elétrons presentes no meio, determina o tipo de teoria cavitária a ser aplicada.

A teoria cavitária relaciona a dose absorvida numa cavidade, ou em um detector de tamanho e composição arbitrários, com a dose absorvida num meio de número atômico ou composição diferentes.

Existem vários modelos de teoria cavitária, sendo que o que mais se destaca é a teoria de Bragg-Gray, descrita por Attix ${ }^{(60)}$, tendo sido o primeiro modelo e o mais simples, apesar de muitas considerações terem sido feitas posteriormente para se chegar a uma teoria mais elaborada.

Para se determinar a dose absorvida em um meio exposto à radiação ionizante, um objeto sensível à radiação deve ser introduzido neste meio, como já dito, sendo que estes meios irão diferir em densidade e número atômico. De acordo com a teoria de Bragg-Gray, esta descontinuidade pode ser um gás, um líquido ou ainda um sólido, e é referida, de uma maneira geral, como uma cavidade.

Em 1929, Gray foi o primeiro a enunciar o princípio cavitário, embora Bragg em 1912 já tivesse discutindo este tema qualitativamente. 
Considerando o meio uniformemente irradiado e a ocorrência de equilíbrio eletrônico (definido no item 2.2.7), a energia depositada por elétrons secundários num elemento de volume é igual à energia perdida por fótons por meio de suas interações no elemento de volume, supondo desprezíveis as radiações de freamento. Desse modo, o princípio da equivalência, enunciado por Gray, diz que "a energia perdida pelos elétrons na cavidade, por unidade de volume é $1 / \rho$ vezes a energia perdida pela radiação gama, por unidade de volume do sólido", sendo $1 / \rho$ a razão entre os poderes de freamento dos elétrons na cavidade e no meio.

A relação de Bragg-Gray pode ser dada por:

$$
D_{\text {meio }}=D_{\text {cavidade }} \cdot\left(\mathrm{m}^{\mathrm{meio}} / \mathrm{m} \mathrm{S}^{\text {cavidade }}\right)
$$

onde $D_{\text {meio }}$ e $D_{\text {cavidade }}$ representam a dose absorvida no meio e na cavidade, respectivamente, e $(\mathrm{m} S$ meio $/ \mathrm{mS}$ cavidade $)$ é a razão entre os poderes de freamento de massa médio do meio e da cavidade.

A relação de Bragg-Gray é um modelo de perda contínua de radiação, pois não leva em conta a produção dos raios delta que depositam energia fora do volume de interesse, mas considera que toda energia perdida pelos elétrons é dissipada localmente e, portanto, incluída no poder de freamento, e que este é independente da energia dos elétrons.

\subsection{7 - Equilíbrio eletrônico}

A condição de equilíbrio eletrônico está diretamente ligada à definição da grandeza exposição. De acordo com a definição, os elétrons produzidos pela interação da radiação com a matéria devem perder toda sua energia por meio de ionizações num volume específico de ar, e as cargas de mesmo sinal devem ser somadas. Entretanto, alguns elétrons produzidos neste volume específico depositam sua energia fora deste mesmo volume, produzindo cargas que não serão consideradas na soma total. Por outro lado, os elétrons produzidos fora do volume 
específico podem entrar neste volume e serem considerados na soma total das cargas produzidas. Se as cargas produzidas foram compensadas pelas cargas a mais consideradas, existe a condição de equilíbrio eletrônico, necessária para a definição de exposição.

Desse modo, "as capas de equilíbrio eletrônico" empregadas nas câmaras de ionização são utilizadas somente para campos de radiação de energias altas, para atenuar os fótons e proporcionar a condição desejada (equilíbrio eletrônico).

\section{3 - Câmaras de ionização}

Durante muitos anos, a dosimetria das radiações esteve diretamente relacionada com a prática da radiologia. Com o objetivo de se controlar a intensidade de radiação, liberada pelas máquinas de raios $X$ então existentes, foram desenvolvidos diversos tipos de sistemas detectores.

Em meados dos anos 30, devido à alta sensibilidade, à boa estabilidade e à boa reprodutibilidade, que fazem parte de suas características operacionais, a câmara de ionização tornou-se o instrumento principal para a deteç̧ão de radiação X.

Atualmente, apesar do surgimento de outros sistemas de medida, a câmara de ionização ainda é considerada o instrumento mais prático e preciso para medidas de taxas de exposição e de dose absorvida.

No Brasil, nos últimos anos, diversas câmaras de ionização foram projetadas e construídas para diferentes aplicações, apresentando bons resultados. As câmaras de ionização possuem basicamente um eletrodo coletor central e uma parede de material apropriado que delimita uma cavidade preenchida por um gás.

Os detectores que se baseiam na ionização de um gás são construídos levando-se em conta a coleta de íons produzidos pela radiação ionizante no volume sensível do detector. 
A câmara de ionização é o mais simples dos detectores a gás, sendo que sua operação está baseada na coleta de todas as cargas elétricas criadas por ionização direta, por meio da aplicação de um campo elétrico.

Muitos autores de livros clássicos relativos a câmaras de ionização, como Knoll ${ }^{(59)}$, abordam o tema, mas com omissão de detalhes. Outros autores fornecem em seus textos informações úteis sobre câmaras de ionização, como Attix ${ }^{(60)}$, Johns e Cunningham ${ }^{(68)}$, $\operatorname{Khan}^{(69)}$, e Rajan ${ }^{(70)}$.

As câmaras de ionização mais simples são constituídas por um eletrodo coletor central (anodo) e pela parede da câmara que é revestida de material condutor e que funciona como catodo. O volume sensível do detector é delimitado pela parede da câmara e constitui uma cavidade preenchida por um gás ou mistura de gases, a uma pressão relativamente baixa. A forma geométrica da cavidade não é definida pela teoria cavitária de Bragg-Gray, mas se deve levar em conta alguns fatores, tais como a distância entre os eletrodos, para o caso da recombinação dos íons, e a espessura da parede para se obter a condição de equilíbrio eletrônico.

Entre o anodo e o catodo é aplicada uma diferença de potencial, para separar os pares de íons produzidos, fazendo com que os íons negativos migrem para o anodo e os íons positivos para o catodo. Este fluxo de íons produz uma corrente elétrica extremamente baixa (da ordem de $10^{-12} \mathrm{~A}$ ) e um instrumento eletrônico sensível (eletrômetro) é utilizado para a sua medida.

Na prática, o equilíbrio eletrônico não pode ser completamente alcançado em uma câmara de ionização com dimensões finitas. Isto é devido à diferença no fluxo de elétrons na entrada e na saída da câmara, que leva à produção de quantidades diferentes de elétrons secundários em posições diferentes da câmara. $O$ termo mais 
adequado para condições reais de medição é, portanto, equilíbrio eletrônico transiente.

Desse modo, o detector utilizado para realizar medições sob condições de equilíbrio eletrônico tem que satisfazer às seguintes exigências:

- a espessura da parede do detector deve ser pelo menos igual ao alcance dos elétrons secundários. Isto assegura que os elétrons secundários gerados fora do meio sensível não alcancem o detector;

- a parede do detector deve ser feita de um material equivalente ao meio sensível do próprio detector de modo a assegurar que o espectro e a distribuição angular dos elétrons gerados na parede sejam iguais ao espectro e à distribuição angular dos elétrons gerados no detector.

As câmaras de ionização normalmente não são seladas, ou seja, o ar no seu interior é o mesmo do ambiente, por isso é necessário fazer a correção das leituras para uma densidade do ar de referência, ou seja, para temperatura $20{ }^{\circ} \mathrm{C}$ e a pressão atmosférica de 101,3 kPa. A umidade também pode afetar as leituras obtidas com esses instrumentos, produzindo uma corrente denominada "corrente de fuga", o que torna necessário o controle da umidade no ambiente do laboratório por meio de desumidificadores de ar e aparelhos de ar condicionado. Costuma-se manter as câmaras de ionização, quando não estão sendo utilizadas, em sistemas desumidificadores com sílica. A correção da leitura de uma câmara de ionização para variação de temperatura e pressão deve ser feita utilizando-se o fator de correção ${ }^{(62)}$ por:

$$
F_{T, p}=[(273,2+T) /(273,2+20)] \times[101,3 / p]
$$

onde: $\mathrm{p}$ é a pressão em $\mathrm{kPa}$ e T é a temperatura em ${ }^{0} \mathrm{C}$. 
O efeito da umidade sobre a resposta de uma câmara de ionização pode ser importante, e é praticamente constante para a faixa de umidade relativa do ar de 20 a $80 \%$, onde a resposta da câmara é aproximadamente $0,3 \%$ maior que no ar $\operatorname{seco}^{(62)}$.

Existem vários tipos de câmaras de ionização com dimensões e formas de cavidades diferentes. $\mathrm{O}$ uso de cada uma depende da finalidade à qual a câmara será destinada (medir exposição ou dose absorvida), bem como do tipo de radiação a ser medida, de sua intensidade e de sua variação no espaço e no tempo.

\subsection{1 - Câmara de ar livre}

Para a medida de exposição segundo a sua definição foi projetada uma câmara de ionização, denominada câmara de ar livre. Este tipo de câmara de ionização é utilizada para a calibração de outros instrumentos que detectam radiação por ionização.

A medida de exposição com uma câmara de ar livre está diretamente relacionada ao princípio de equilíbrio eletrônico. À medida que a energia dos fótons aumenta, é necessário que as dimensões da câmara aumentem consideravelmente, de modo que os critérios adequados para a medida operacional da grandeza exposição sejam obedecidos. Desta forma, surgem diversos problemas técnicos diretamente relacionados com as dimensões físicas, nas medidas de fótons com energia acima de $300 \mathrm{keV}$. Com o aumento da energia, as câmaras de ar livre tornam-se maiores e os coeficientes de correção e tornam elevados, determinando um limite de energia da radiação para a utilização da câmara de ar livre como um padrão primário à pressão atmosférica. As câmaras de ionização de ar livre são largamente utilizadas para medidas de exposição com grande acurácia, para radiação gama e X com energias abaixo de $100 \mathrm{keV}$. 


\subsection{2 - Câmara cavitária}

Como a câmara de ar livre, à pressão atmosférica, está limitada a valores de energia de fótons abaixo de $300 \mathrm{keV}$, foi desenvolvido um outro tipo de câmara de ionização para servir como padrão primário nas medidas de exposição em feixes de fótons. Esta câmara cavitária utiliza como princípio de medida a teoria de Bragg-Gray, baseando-se na determinação da dose absorvida num material, e que permite medidas de exposição de radiação $X$ e gama até $3 \mathrm{MeV}$, cobrindo-se a câmara com uma capa de equilíbrio eletrônico. Esta é uma das razões pelas quais a câmara de ionização padrão não pode ser usada para energias maiores que $3 \mathrm{MeV}$ e, como conseqüência a unidade antiga Roentgen não é definida para radiações de energia maiores que $3 \mathrm{MeV}^{(68)}$.

\subsection{3 - Câmara cilíndrica (tipo dedal)}

As câmaras do tipo padrão primário não são adequadas para as medidas de rotina, sendo geralmente utilizadas em laboratórios de padronização primária. Para as medidas rotineiras foi desenvolvido um outro tipo de câmara de ionização, cuja utilização apresenta facilidade de manuseio e grande versatilidade: é denominada câmara de ionização cilíndrica ou do tipo dedal. O seu funcionamento está baseado não apenas no princípio de equilíbrio eletrônico, mas também na teoria cavitária de Bragg-Gray. A combinação destes dois princípios torna possível a determinação da exposição no intervalo entre $40 \mathrm{keV}$ e $3 \mathrm{MeV}$, usando-se apenas um instrumento de medida.

Este tipo de câmara não mede diretamente a exposição e, por isso, precisa ser calibrada em relação a um sistema do tipo padrão primário, sendo portanto denominada de padrão secundário.

A câmara de ionização dedal consiste de um instrumento de pequenas dimensões, com uma parede sólida condutora que delimita um certo volume de ar. 
Neste volume está inserido, no centro, um eletrodo para coleta dos íons formados no ar. A fim de não causar perturbação no campo de radiação, tanto o material da parede da câmara quanto o do eletrodo central devem ser equivalentes ao ar, em relação à interação dos fótons e dos elétrons secundários. Esta equivalência significa que a parede se comporta como uma camada de ar condensado, fazendo com que a fluência e o espectro de energia dos fótons e dos elétrons secundários (gerados pela interação da radiação primária com o material da parede, e no volume ativo do ar) não sejam perturbados pela parede. Esta parede possui uma espessura sempre maior que o alcance dos elétrons secundários gerados fora da câmara; isto significa que toda ionização detectada pelo eletrodo central pode ser associada aos elétrons secundários gerados e freados dentro do volume de ar, já que ocorre o equilíbrio eletrônico. Portanto, a transferência de energia dos elétrons secundários (gerados na parede) para o volume ativo do ar é igual à dos elétrons (gerados no volume de ar) para a parede da câmara.

Para feixes de fótons com o valor de energia acima de $300 \mathrm{keV}$, surgem dificuldades experimetais para se obter o equilíbrio eletrônico. Para medidas, por exemplo, em feixes de ${ }^{60} \mathrm{Co}(1,25 \mathrm{MeV})$, é necessária a utilização de espessura adicional na parede da câmara de ionização, ou seja, utilização de uma capa de equilíbrio eletrônico (build-up), geralmente feita de polimetil metacrilato (Lucite), a fim de impedir que os elétrons criados fora da câmara penetrem no seu volume ativo.

\subsection{4 - Câmara de placas paralelas (tipo superficial)}

A dosimetria da radiação $\mathrm{X}$ gerada a baixos valores de potencial (12 a $70 \mathrm{kV}$ ) apresenta dificuldades especiais devido à absorção considerável desta radiação mesmo quando se utiliza paredes com pequena espessura de material equivalente ao ar no detector de radiação.

Geralmente, nestes casos, são utilizadas câmaras de ionização de placas paralelas, também chamadas de câmaras superficiais por serem aplicadas em 
procedimentos de dosimetria de feixes de radiação $X$ de energias baixas (feixes de radioterapia superficial), onde se pretende determinar a dose a ser dada ao paciente.

As próprias paredes das câmaras de placas paralelas constituem os eletrodos, distanciados um do outro de aproximadamente $5 \mathrm{~mm}$. Deste modo, a probabilidade dos íons positivos e negativos, formados ao longo das trajetórias dos elétrons secundários, liberados na cavidade de ar existente entre os eletrodos da câmara, sofrerem recombinações antes de atingirem o eletrodo coletor, será muito pequena. Isto garante que todos os íons produzidos dentro do volume sensível da câmara serão coletados, isto é, tem-se a saturação da corrente de ionização, mesmo em taxas de exposição altas.

Estas câmaras são muito utilizadas tanto como padrões secundários, como para medidas rotineiras da exposição produzida por campos de radiação $\mathrm{X}$ de energias baixas e intermediárias.

As câmaras de ionização de placas paralelas também são recomendadas para a detecção de elétrons com energias menores que $10 \mathrm{MeV}$, devendo ser necessariamente utilizadas nas medidas em feixes de elétrons com energias mais baixas que $5 \mathrm{MeV}^{(14,15)}$. Dependendo da distância entre a câmara de ionização e a fonte, as medidas desta câmara plana se aproximam de uma câmara de extrapolação.

\subsection{5 - Câmara de extrapolação}

Um tipo especial de câmara de ionização de placas paralelas é a câmara de extrapolação, que é também baseada na teoria cavitária de Bragg-Gray, sendo muito utilizada para as medidas de taxas de dose absorvida em campos de radiação $\mathrm{X}$ de energias baixas e de radiação beta, sendo ambas pouco penetrantes na matéria. 
Este tipo de câmara de ionização possui um parafuso micrométrico, que permite variar com precisão a distância entre os seus eletrodos, obtendo-se assim a corrente de ionização produzida em função da espessura da camada de ar contida dentro do volume sensível da câmara.

As câmaras de extrapolação possibilitam a determinação da dose superficial na pele e a determinadas profundidades do tecido. Estas câmaras são utilizadas para a caracterização de campos padrões de radiação beta, empregados na calibração de detectores de radiação beta.

\subsection{6 - Calibração das câmaras de ionização}

De modo a garantir que o valor indicado por uma câmara de ionização esteja o mais próximo do valor verdadeiro convencional ("valor real") da grandeza medida, torna-se necessária a calibração da câmara. Obtém-se um fator multiplicativo pelo qual a leitura com a câmara de ionização é corrigida em relação aos valores obtidos com uma câmara padrão (calibrada e com boa qualidade metrológica).

A calibração de uma câmara de ionização pode ser realizada por dois

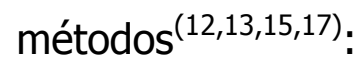

- Método ponta-a-ponta, onde a câmara de ionização a ser calibrada e a câmara padrão são irradiadas ao mesmo tempo, posicionadas lado a lado com os eixos longitudinais coincidentes. É essencial que as câmaras tenham construção similar para que a radiação espalhada que irá atingí-las seja aproximadamente a mesma;

- Método da substituição, onde a câmara padrão é exposta ao feixe de radiação e suas leituras são anotadas; em seguida coloca-se a câmara a ser calibrada na mesma condição geométrica da câmara padrão, 
registrando-se as leituras dela. Ao final do processo costuma-se recolocar a câmara padrão novamente no feixe de radiação para verificar se houve alguma mudança significativa no feixe.

O segundo método de calibração é usado para a calibração de instrumentos com raios $\mathrm{X}$, em qualidades de radiação, níveis radioproteção, diagnóstico e terapia ${ }^{(12,13,16)}$. Os dosímetros clínicos são sempre calibrados utilizando-se a técnica da substituição, seja com radiação $X$ ou gama.

Existem, ainda, outros procedimentos de calibração de instrumentos; cada método possui vantagens e desvantagens, e o laboratório de calibração pode escolher um dos métodos em algumas ocasiões e outros métodos em outras ocasiões.

\subsection{7 - Qualidade dos feixes de radiação $X$}

Antes de um equipamento de raios $X$ ser utilizado para fins terapêuticos ou para a calibração de instrumentos de campo, é necessário fazer-se um estudo das características dos seus feixes de radiação ${ }^{(13,16)}$. Este estudo compreende a determinação não só da taxa de exposição ou da taxa de dose absorvida a uma determinada distância, mas também de parâmetros que especifiquem a natureza desta radiação, ou seja, a qualidade da radiação. Tal informação permite um melhor conhecimento do poder de penetração do feixe em um determinado meio de interesse.

A qualidade da radiação é caracterizada pela diferença de potencial aplicada entre os eletrodos do tubo de radiação $X$, pela filtração total (inerente + adicional) e pela camada semi-redutora. Alguns laboratórios especificam ainda outras grandezas, tais como: o coeficiente de homogeneidade, a energia equivalente do feixe de radiação e, quando necessário, a distribuição espectral dos fótons de feixes de radiação $X$. 
Informações mais completas sobre a qualidade de um feixe de radiação $\mathrm{X}$ e sobre o número e a energia dos fótons presentes neste feixe são dados pelo seu espectro de energia. A determinação destes espectros é possível com a utilização de sistemas espectrométricos adequados para esta finalidade. Entretanto, na prática, estas medidas envolvem processos complexos, dificultando a sua realização rotineiramente. Desse modo, um método alternativo e indireto de determinação do poder de penetração de um feixe de radiação $X$ em alguns materiais foi desenvolvido, levando-se em conta a atenuação do feixe de radiação X. Este método foi baseado na determinação das camadas semi-redutoras, para as diversas energias do feixe.

A camada semi-redutora é definida como sendo a espessura de material absorvedor que atenua um feixe de radiação $X$, de forma que sua intensidade seja reduzida à metade do seu valor inicial ( $1^{\underline{a}}$ CSR), ou a um quarto do seu valor inicial, no caso da obtenção da $2^{\underline{a}}$ CSR. $O$ quociente entre 0 valor da $1^{\underline{a}}$ e da $2^{\underline{a}}$ camadas semi-redutoras fornecerá o coeficiente de homogeneidade do campo de radiação, que permite verificar o grau de homogeneidade do feixe de radiação. Quanto mais próximo do valor 1 for o coeficiente de homogeneidade, mais homogêneo será o feixe de radiação $X$, isto é, mais próximo de um feixe monoenergético.

A descrição da qualidade de um feixe de radiação apenas em termos da camada semi-redutora não é suficiente. Muitas vezes pode ocorrer que se obtenha um mesmo valor de camada semi-redutora para diferentes combinações de filtração adicional e diferença de potencial aplicado entre os eletrodos de um tubo de raios $\mathrm{X}$, apesar dos espectros de energia dos feixes de radiação, em cada caso, não serem semelhantes. Esta diferença pode ser caracterizada por meio do coeficiente de homogeneidade desses feixes.

\subsection{8 - Energia equivalente (efetiva)}

O conhecimento da $1^{\underline{a}}$ CSR permite fazer-se uma comparação entre os espectros gerados por feixes heterogêneos e homogêneos (monoenergéticos). Para 
isto é necessária a determinação da energia equivalente, que é definida como sendo a energia de um feixe monoenergético que possui a mesma camada semi-redutora de um feixe heterogêneo ${ }^{(12,13)}$.

Por meio do valor da $1^{\text {a }}$ CSR do feixe de raios $X$ (para alguns materiais de referência, como $\mathrm{Al}, \mathrm{Cu}, \mathrm{Sn}, \mathrm{Pb}$, entre outros), pode-se determinar o coeficiente de atenuação e, utilizando-se tabelas de padrões de coeficientes de atenuação ${ }^{(71)}$, verificar qual a energia correspondente. Este coeficiente ${ }^{(60)}$ pode ser obtido por:

$$
[\mu / \rho]=[\ln 2 / \rho . C S R]
$$

onde $\rho$ é a densidade do material $\left(\mathrm{g} / \mathrm{cm}^{3}\right)$ considerado e $\mu / \rho$ o seu coeficiente de atenuação de massa $\left(\mathrm{cm}^{2} / \mathrm{g}\right)$ para uma energia tal que resulte num valor de CSR (cm) idêntico àquele de um feixe monoenergético. Os valores de $\mu / \rho$ são tabelados para vários materiais em função da energia.

\section{4 - Grandezas dosimétricas}

Entre as modificações ocorridas na matéria exposta à radiação ionizante, na prática, pode-se medir com boa precisão a energia depositada em um material irradiado (simulador, tecido, material dosimétrico, entre outros). Os efeitos da radiação na matéria ainda dependem da extensão do campo de radiação e do grau de interação entre a radiação e a matéria. As grandezas dosimétricas têm como finalidade fornecer uma medida física, num ponto ou numa região de interesse, que esteja relacionada com o efeito biológico real (ou danos) da radiação ionizante. Para fins deste trabalho serão somente apresentadas as grandezas dosimétricas relevante ao bom entendimento dele.

Grandezas dosimétricas como exposição, kerma, dose absorvida e dose equivalente são de grande importância em dosimetria das radiações, assim como nos procedimentos de calibração, sendo suas definições apresentadas na Publicação ICRU $60^{(72)}$. 
A grandeza exposição, $\mathrm{X}$, é o quociente de dQ por dm, onde dQ é a carga total de um mesmo sinal produzida no ar quando todos os elétrons liberados pelos fótons em uma determinada massa de ar $d m$ são completamente freados:

$$
X=d Q / d m
$$

A grandeza exposição foi a primeira grandeza definida, para fins de radioproteção, sendo definida como a habilidade ou a capacidade dos raios $\mathrm{X}$ e gama em produzir ionizações no ar. Ela não é definida para nêutrons, partículas alfa ou beta.

A grandeza exposição é expressa no Sistema Internacional em C. $\mathrm{kg}^{-1}$ como mostrado pela definição, sendo a sua unidade antiga o roentgen $\left(1 \mathrm{R}=2,58 \times 10^{-}\right.$ $\left.{ }^{4} \mathrm{C} . \mathrm{kg}^{-1}\right)$, cujo uso não é mais recomendado. A exposição possui duas limitações fundamentais: uma é que ela está somente definida para fótons que interagem no ar; a outra é que envolve um limite superior de energia dos fótons em cerca de $3 \mathrm{MeV}$.

Estas limitações foram superadas com a introdução da grandeza kerma, K, que é o quociente de $d E_{t r}$ por $d m$, onde $d E_{t r}$ é a soma da energias cinéticas iniciais de todas as partículas carregadas liberadas pelas partículas não-carregadas (fótons e nêutrons) em uma massa dm de material, assim:

$$
\mathrm{K}=\mathrm{dE}_{\mathrm{tr}} / \mathrm{dm}
$$

A unidade de kerma é o J. $\mathrm{kg}^{-1}$ ou gray (Gy). Esta grandeza é definida com respeito ao material específico em que as interações estão ocorrendo (kerma no ar, kerma na água, entre outras).

A dose absorvida em um material, $D$, é o quociente de $d \bar{E} / d m$, onde $d \bar{E}$ é a energia média transferida à matéria de massa dm: 


$$
D=d \bar{E} / d m
$$

A unidade de dose absorvida é $J \cdot \mathrm{kg}^{-1}$ ou gray (Gy). A dose absorvida é utilizada como um bom indicador físico de resposta biológica.

A dose equivalente é uma grandeza conhecida e discutida principalmente porque seu nome, sua representação e sua unidade causam alguma confusão em relação ao equivalente de dose. Representada por $\mathrm{H}_{T}$, a dose equivalente diferenciase do equivalente de dose (que pode ser medido diretamente) por utilizar fatores de peso da radiação, fato este que é importante considerar quando o campo de radiação é composto por tipos diferentes de radiações. Desse modo, a dose equivalente ${ }^{(62)}$ é dada por:

$$
\underset{\mathrm{R}}{\mathrm{H}_{\mathrm{T}}}=\Sigma \mathrm{W}_{\mathrm{R}} \cdot \mathrm{D}_{\mathrm{T}, \mathrm{R}}
$$

onde $W_{R}$ é o fator de peso da raaıaçao $R$ e $D_{T, R}$ é a dose absorvida média num tecido $\mathrm{T}$ devido à radiação $R$. Sua unidade no S.I. é o $\mathrm{J}^{\mathrm{kg}^{-1}}$ e também recebe o nome especial de sievert (Sv).

Nos últimos anos, a IAEA tem incorporado as recomendações da ICRP, quanto à limitação de dose para fins de radioproteção. O sistema de limitação de dose adotado pela IAEA está baseado nas doses equivalentes em vários órgãos ou tecidos, $\mathrm{H}_{\mathrm{t}}$, de uma dose individual e ainda atribuindo pesos à soma da dose equivalente em alguns tecidos e órgãos, ou melhor, à dose efetiva, E. Estas grandezas de radioproteção não são mensuráveis. Elas devem ser estimadas, por meio do uso das grandezas que podem ser mensuráveis sob condições operacionais. Estas grandezas são definidas de acordo com o meio que irá recebê-las, ou melhor, se for o corpo humano o meio receptor, denominam-se grandezas para monitoração individual $^{(62)}$.

As radiações ionizantes podem ser denominadas como sendo pouco ou muito penetrantes, sendo determinado um valor limitador de equivalente de dose, por 
exemplo, para limitação de dose para radiações pouco penetrantes, o equivalente de dose no cristalino ou na pele. Para radiações muito penetrantes, estabeleceu-se a dose efetiva como limitador de dose mais adequado para a proteção dos indivíduos, que trabalham com radiação ionizante ${ }^{(62)}$.

Desse modo, foram introduzidas as grandezas operacionais especialmente definidas para uso em radioproteção nas práticas de monitoração de área e individual. Objetivando definir grandezas operacionais que: pudessem ser aplicadas a todos os tipos de radiações, que fossem relacionadas às grandezas primárias, que fossem mensuráveis e definidas em um ponto em um simulador adequado e, que estimassem de forma aceitável as grandezas limitantes, a ICRU introduziu para monitoração de área o equivalente de dose ambiental, $\mathrm{H}^{*}$ (d), e o equivalente de dose direcional, $\mathrm{H}^{\prime}(\mathrm{d})$, e, para monitoração individual, o equivalente de dose pessoal, $\mathrm{H}_{\mathrm{p}}$ (d). A Tabela 2.1 mostra um resumo das grandezas operacionais.

Tabela 2.1 - Resumo das grandezas operacionais para monitoração de área e individual $^{(62)}$

\begin{tabular}{cccc}
\hline & & \multicolumn{2}{c}{ Grandeza operacional para } \\
\cline { 3 - 4 } $\begin{array}{c}\text { Radiação } \\
\text { externa }\end{array}$ & $\begin{array}{c}\text { Grandeza } \\
\text { limitante }\end{array}$ & $\begin{array}{c}\text { Monitoração } \\
\text { de área }\end{array}$ & $\begin{array}{c}\text { Monitoração } \\
\text { individual }\end{array}$ \\
\hline $\begin{array}{c}\text { Radiação } \\
\text { fortemente } \\
\text { penetrante }\end{array}$ & Dose efetiva & $\mathrm{H}^{*}(10)$ & $\mathrm{H}_{\mathrm{P}}(10)$ \\
$\begin{array}{c}\text { Radiação } \\
\text { fracamente } \\
\text { penetrante }\end{array}$ & Dose na pele & $\mathrm{H}^{\prime}(0,07)$ & \\
\hline
\end{tabular}

O equivalente de dose ambiental e o equivalente de dose direcional são grandezas operacionais para monitoração de área. São grandezas definidas em um 
objeto simulador, a esfera da ICRU, que é uma esfera de material equivalente ao tecido (tissue equivalent), com $30 \mathrm{~cm}$ de diâmetro e densidade de $1 \mathrm{~g} . \mathrm{cm}^{-3}$, sendo que esta esfera é considerada similar ao tronco humano no que se refere ao espalhamento e à atenuação dos campos de radiação.

O equivalente de dose ambiental, $\mathrm{H}^{*}$ (d), em um ponto de um campo de radiação, é o equivalente de dose que poderia ser produzido por um correspondente campo expandido e alinhado, na esfera da ICRU, em uma profundidade $d$, no raio oposto à direção do campo alinhado. A sua unidade é o $\mathrm{J}^{\mathrm{kg}}{ }^{-1}$. O nome da sua unidade especial é sievert (Sv).

O equivalente de dose direcional, $\mathrm{H}^{\prime}(\mathrm{d}, \Omega)$, para um ponto no campo de radiação, é o equivalente de dose que poderia ser produzido por um campo expandido, na esfera da ICRU em uma profundidade d, no raio em uma direção específica $\Omega$. A sua unidade é o J. $\mathrm{kg}^{-1}$. O nome da sua unidade especial é sievert (Sv).

No caso de radioproteção, é desejável caracterizar-se a irradiação potencial dos indivíduos em termos de uma única grandeza equivalente de dose, que pode ser verificada por meio da utilização de um objeto simulador de corpo humano, ou de partes do corpo humano; ele deve possuir dimensões adequadas ao tamanho e ao formato do órgão que se deseja simular, e ainda com densidade do material próxima ao do tecido humano.

Para monitoração individual, foram introduzidas as grandezas operacionais denominadas equivalente de dose pessoal $H_{p}(10)$ para radiações muito penetrantes, e $H_{p}(3)$ e $H_{p}(0,07)$ para radiações pouco penetrantes. $O$ equivalente de dose pessoal, $H_{p}(d)$, é o equivalente de dose em um tecido equivalente da ICRU ${ }^{(62)}$, a uma certa profundidade apropriada $d$, em um ponto especificado no corpo humano. Para fins de simplificação, a indicação deve ser expressa em milímetros. 
O equivalente de dose pessoal é dado em J. $\mathrm{kg}^{-1}$, sendo sua unidade especial o sievert (Sv).

A calibração de um dosímetro é definida como a determinação quantitativa, sob um conjunto de condições padrões e controladas, da indicação dada por um instrumento medidor de radiação, como uma função do valor da grandeza que o instrumento pretende medir ${ }^{(12,13,16,62)}$.

Com as calibrações rotineiras pretende-se determinar um coeficiente de calibração apropriado para as aplicações de rotina do monitor de radiação. A calibração rotineira pode ser de natureza confirmatória; desse modo, ela é realizada para verificar se a calibração inicialmente realizada pelo fabricante no instrumento está ainda válida, ou melhor, se o valor do coeficiente de calibração obtido na calibração inicial permanece ainda adequado mesmo após um longo tempo de uso do equipamento.

Calibrações especiais podem ser realizadas nos instrumentos medidores de radiação, quando os instrumentos forem operar em condições anormais ou especiais de uso, ou melhor, em condições diferentes daquelas rotineiras. É importante verificar se o equipamento escolhido para a aplicação especial possui características que permitem que ele opere nestas condições. Caso contrário, os equipamentos só devem operar nas condições para os quais foram projetados e desenvolvidos, ou seja, conforme as especificações que constam dos manuais técnicos, fornecidos por seus fabricantes.

O valor verdadeiro convencional $\left(V_{v c}\right)$ de uma determinada grandeza é a melhor estimativa de seu valor, que deverá ser determinado por meio de um sistema padrão primário ou secundário de medida, ou por um instrumento de referência que tenha sido calibrado contra um padrão primário ou secundário ${ }^{(62)}$. O $\mathrm{V}_{\mathrm{vc}}$, em geral, é tido como um valor suficientemente próximo do valor verdadeiro $\left(V_{V}\right)$ de uma grandeza. A diferença entre estes valores é considerada insignificante para um 
determinado uso (ou seja, os valores de $V_{v c}$ e $V_{V}$ são muito próximos, sendo que o primeiro valor pode representar o segundo com grande aproximação).

$\mathrm{Na}$ calibração de um sistema detector de radiação, surge um elemento importante que é o coeficiente de calibração. Ele é definido como o $V_{v c}$ da grandeza que o instrumento pretende medir (o mensurando), dividido pela indicação obtida pelo dosímetro (que pode ser corrigida, se necessário).

Para a calibração de dosímetros, quando se deseja transformar uma grandeza dosimétrica em outra, são empregados os coeficientes de conversão. Um coeficiente de calibração muito empregado nas rotinas de calibração de dosímetros é o coeficiente de conversão de kerma no ar para equivalente de dose no caso de qualidades de radiação de fótons.

Desse modo, pode-se determinar as etapas adequadas para a obtenção do equivalente de dose pessoal, $\mathrm{H}_{\mathrm{p}}(10)$, a partir das medidas de carga realizada pela câmara de ionização com eletrodo coletor de grafite, cujo desenvolvimento será apresentado neste trabalho, para utilização em campos padrões de radiação X, nível radioproteção, definidos na norma ISO 4037-1 ${ }^{(16)}$.

Para a determinação do $V_{v c}$ do equivalente de dose pessoal, $H_{p}(10)$, utilizando-se a câmara de ionização com eletrodo coletor de grafite, deve-se estabelecer um procedimento inicial de medição.

Considerando que, durante a calibração de um dosímetro, podem ocorrer variações moderadas nas grandezas físicas que caracterizam as propriedades dosimétricas do campo de radiação (por exemplo, taxa de kerma no ar), a utilização de um instrumento monitor (câmara monitora) permite realizar a correção do valor medido, caso haja uma variação nos feixes de radiação. Esta técnica é frequentemente empregada durante as calibrações de dosímetros em feixes de raios$X$, para corrigir as variações na taxa de kerma no ar, quando é utilizada a técnica de calibração por substituição (ou melhor, quando alternadamente o dosímetro de 
referência é substituído pelo dosímetro sob calibração, que deve ser posicionado no mesmo lugar onde o de referência havia sido posicionado, na mesma geometria de irradiação, em relação ao mesmo ponto focal do tubo de raios-X).

A grandeza equivalente de dose $\mathrm{H}$ no ponto de teste, está relacionada ao coeficiente de calibração da câmara monitora, $\mathrm{N}_{\mathrm{m}}$, e o seu valor medido (ou indicado), m , é dado por:

$$
H=N_{m} \times m
$$

De modo análogo, as relações 2.15 e 2.16 estão relacionadas aos coeficientes de calibração do dosímetro de referência $\left(N_{R}\right)$ e do dosímetro sob calibração respectivamente $\left(\mathrm{N}_{\mathrm{I}}\right)$.

$$
\begin{aligned}
& \mathrm{N}_{\mathrm{R}}=\mathrm{H} / \mathrm{hM}_{\mathrm{R}} \\
& \mathrm{N}_{\mathrm{I}}=\mathrm{H} / \mathrm{M}_{\mathrm{I}}
\end{aligned}
$$

onde $\mathrm{h}=$ coeficiente de conversão, da grandeza medida pelo instrumento de referência para a grandeza de equivalente de dose associada com o instrumento sob calibração;

$M_{R}=$ valor medido pelo instrumento de referência, corrigido para as condições de referência de temperatura e pressão;

$\mathrm{M}_{\mathrm{I}}=$ valor medido pelo instrumento sob calibração, corrigido para as condições de referência de temperatura e pressão;

$N_{R}$ = coeficiente de calibração do instrumento de referência;

$\mathrm{N}_{\mathrm{I}}$ = coeficiente de calibração do instrumento sob calibração.

Nas relações anteriores, 2.15 e 2.16 , pode-se eliminar a grandeza $H$, por meio da introdução dos valores das leituras da câmara monitora, quais sejam, $m_{R}$ e $\mathrm{m}_{\mathrm{I}}$, que correspondem às medidas realizadas pela câmara monitora durante as 
irradiações do instrumento de referência e sob calibração, corrigidas para variações da densidade do ar, respectivamente.

Desse modo, com a introdução dos valores das medidas da câmara monitora nas relações 2.15 e 2.16 , obtém-se:

$$
\begin{aligned}
& \mathrm{N}_{\mathrm{R}}=\mathrm{N}_{\mathrm{m} \cdot} \cdot \mathrm{m}_{\mathrm{R}} / \mathrm{hM_{ \textrm {R } }} \\
& \mathrm{N}_{\mathrm{I}}=\mathrm{N}_{\mathrm{m} \cdot} \cdot \mathrm{m}_{\mathrm{I}} / \mathrm{M}_{\mathrm{I}}
\end{aligned}
$$

onde $\mathrm{m}_{\mathrm{R}}=$ valor medido pelo câmara monitora durante a irradiação do instrumento de referência, corrigido para as condições de referência de pressão e temperatura;

$\mathrm{m}_{\mathrm{I}}=$ valor medido pelo câmara monitora durante a irradiação do instrumento sob calibração, corrigido para as condições de referência de pressão e temperatura.

Dividindo-se a relação 2.18 pela relação 2.17 , obtém-se uma relação onde o coeficiente de calibração da câmara monitora, $\mathrm{N}_{\mathrm{m}}$, desaparece, e desse modo, temse o coeficiente de calibração do instrumento sob calibração, $\mathrm{N}_{\mathrm{I}}$.

A relação 2.19 mostra como se determina o coeficiente de calibração do dosímetro a ser calibrado.

$$
N_{I}=N_{R}\left(h M_{R} / m_{R}\right) \cdot\left(m_{I} / M_{I}\right)
$$

Quando a calibração de um dosímetro é realizada pelo método da substituição, ou seja, a câmara de ionização sob calibração é posicionada no feixe de radiação imediatamente após a medida com a câmara padrão que será retirada, e estando ambas sob as mesmas condições de irradiação e geometria, pode-se eliminar os termos $m_{R}$ e $m_{I}$ da relação (2.19), uma vez que, se houver uma variação nas leituras, esta será pequena ${ }^{(61-62)}$; então não será necessária a correção das leituras pelo valor obtido pela câmara monitora. 


\section{5 - Sistema Tandem}

Existem casos em que a determinação da energia efetiva não pode ser feita pela definição, isto é, pela medida da camada semi-redutora, como por exemplo para feixes não unidirecionais ou quando se deseja determinar a energia efetiva de um feixe de radiação num material sólido ${ }^{(56)}$. Para estes casos, existe um método alternativo, baseado na determinação da exposição com a aplicação de dois dosímetros possuindo diferentes dependências energéticas. Este método, denominado "Tandem", consiste em se utilizar a dependência energética da razão entre os valores das curvas de calibração em energia das respostas dos dosímetros para a determinação da energia efetiva de um dado feixe de radiação(73).

A exatidão do método dependerá não só das incertezas inerentes dos dosímetros utilizados no sistema Tandem mas também do grau de dependência energética das suas respostas. Quanto mais elas diferirem entre si, tanto maior será a variação da razão entre elas em função da energia e maior a exatidão na determinação desta ultima grandeza.

Kenney e Cameron ${ }^{(54)}$ em 1963 e Gorbics e Attix ${ }^{(55)}$ em 1968 foram os primeiros a sugerirem o uso de materiais termoluminescentes na determinação da energia de radiações gama e $\mathrm{X}$ por meio do método Tandem.

Uma avaliação experimental da energia de um campo de radiação $X$ ou gama por dosímetros termoluminescentes pode ser realizada por meio do método Tandem. Este método consiste em se determinar a razão entre as respostas de dois materiais termoluminescentes de diferentes números atômicos efetivos, ambos expostos em condições idênticas a vários feixes de radiação X com energias diferentes. Obtém-se a curva Tandem. Uma grande diferença nos números atômicos efetivos dos dois materiais termoluminescentes causa uma acentuada diferença nas suas respostas, 
quando irradiados com fótons de energias baixas e intermediárias. O sistema Tandem melhor será formado quando:

a) um dos dosímetros possuir uma acentuada dependência energética em relação ao segundo e,

b) o outro dosímetro apresentar uma resposta pouco dependente da energia.

É conveniente salientar que quanto maior for a inclinação da curva Tandem, maior será a precisão na determinação da energia. O conhecimento da energia permite a avaliação da dose absorvida em um ponto de interesse dentro de um meio, por meio de uma curva de calibração numa energia de referência.

O método Tandem de câmaras de ionização, proposto por Albuquerque e Caldas ${ }^{(24,25,26)}$, exige o conhecimento detalhado da dependência energética das respostas das câmaras utilizadas (neste caso foram utilizadas câmaras de ionização idênticas, mas que possuíam eletrodos coletores de materiais diferentes). Esta dependência energética é determinada em termos de energia efetiva obtida por meio do uso do conceito de camada semi-redutora.

O método, extremamente simples, pode portanto ser utilizado para a determinação tanto da energia efetiva como da taxa de exposição no ar de um feixe de radiação $X$, apenas pela medida das respostas das duas câmaras do sistema Tandem. A energia efetiva é determinada pela razão entre as medidas do par de câmaras de ionização utilizadas para formar o sistema Tandem, e a taxa de exposição ou a taxa de dose pode ser obtida pela medida da câmara com dependência energética praticamente desprezível (que é recomendada pelas normas internacionais para a faixa de energia em questão).

Inicialmente é necessário determinar-se as camadas semi-redutoras pelo método convencional (com absorvedores especiais) para posteriormente poder-se utilizar o sistema Tandem para as verificações rotineiras das condições do feixe de 
raios $\mathrm{X}$ utilizado, num período de tempo muito menor do que aquele necessário para as medidas de camadas semi-redutoras.

O procedimento do sistema Tandem é rápido, prático e dispensa o uso de absorvedores de diversas espessuras e alta pureza, importados, e de arranjos especiais. É um procedimento facilmente incorporável aos programas de controle de qualidade de feixes de radiação $X$.

Para os propósitos deste trabalho não há necessidade imperiosa de "boa inclinação" e "bom formato" das curvas Tandem, mas a reprodutibilidade das medidas para os equipamentos e para as faixas de energia em questão tem uma importância maior. Também não são necessários gráficos, já que os valores a serem comparados são as próprias medidas; os gráficos têm a utilidade de auxiliar a visualização do comportamento dos dados.

\section{6 - Espectrometria de feixes de radiação}

O conhecimento e a medida dos espectros de raios $X$ das qualidades que foram implantadas pode auxiliar no programa de controle de qualidade destes feixes e revelam seu comportamento e sua estabilidade ao longo do tempo (alterações ou mudanças espectrais).

Pode-se definir um espectro de raios $X$ como a distribuição de energia da radiação produzida em um feixe de raios $X^{(56-58)}$. O conhecimento do espectro de raios $\mathrm{X}$ permite, por exemplo, o entendimento das etapas de produção de imagens diagnósticas e, desse modo, viabilizando a redução de dose no paciente com a melhoria da qualidade da imagem produzida. $\mathrm{O}$ espectro de energia e o número de fótons de um feixe de raios $X$ podem ser modificados por alguns parâmetros de ajuste do sistema gerador de raios $\mathrm{X}$, que alteram a intensidade e a qualidade do feixe.

Um espectro de raios $X$ é basicamente formado por duas partes: uma contínua e outra em linhas discretas (estas partes são distintas e superpostas). A 
contínua é causada pelos raios $\mathrm{X}$ de bremsstrahlung e surge de energias muito baixas até uma energia máxima, que é numericamente igual à diferença de potencial aplicada ao tubo (tensão). As linhas discretas decorrem dos raios $\mathrm{X}$ característicos. $\mathrm{A}$ filtração inerente e adicional eliminam as energias baixas (indesejáveis), que poderiam ser absorvidas pelo paciente.

$A$ intensidade de um feixe de raios $X$ representa a quantidade de fótons produzidos e emitidos de um tubo de raios $X$. A quantidade de raios $X$ gerados é proporcional ao número atômico $(\mathrm{Z})$ do material componente do alvo. Além disso, existem ainda outros fatores que interferem na intensidade do feixe de raios- $X$ : a corrente aplicada ao tubo (mA), a forma de onda da tensão que pode alterar o número de elétrons emitidos em direção ao anodo, a espessura de material atenuador que o feixe atravessa e a distância percorrida pelo feixe até o ponto de medição.

Assim, a qualidade de um feixe de raios $X$ é afetado por vários fatores: material do alvo do tubo, forma de onda da tensão, filtração do feixe, tensão de pico. O material do alvo e a forma de onda da tensão são característicos do equipamento de raios $X$, desse modo não podendo ser alterados ou modificados pelo operador do sistema de raios $X$.

Pode-se dizer que a energia máxima dos fótons emitidos de um tubo de raios $X$ é igual à energia cinética máxima dos elétrons que se chocam no alvo, determinada pela escolha da tensão de pico $(k V p)$. Assim, a qualidade do feixe de raios $X$ produzido é proporcional à tensão de pico escolhida: quanto mais energética for a radiação, maior também será o valor da camada semi-redutora necessária para reduzir a intensidade do feixe à metade.

Tem-se que a produção de raios $\mathrm{X}$ é diretamente proporcional ao número de elétrons emitidos pelo filamento que atingem e colidem com o alvo. Quanto maior for a corrente no catodo do tubo de raios $X$, maior será a quantidade de elétrons, $e$ assim maior será a produção de raios $X$. $O$ aumento da corrente não modifica a 
qualidade do feixe, embora possa ocorrer uma ligeira variação do fator de ondulação (ou ripple) ${ }^{1}$ da tensão com o novo valor de corrente selecionada.

Uma vez selecionadas a tensão $(k V p)$ e a corrente $(m A)$ do sistema de raios $\mathrm{X}$, a quantidade de raios $\mathrm{X}$ produzidos é proporcional ao número atômico do material do alvo, muito embora o pico de intensidade do espectro corresponda sempre à mesma energia, que foi determinada pela tensão selecionada. É importante lembrar que quanto maior o número atômico do material do alvo do tubo de raios $\mathrm{X}$, maior também será a energia dos raios $\mathrm{X}$ característicos.

A forma de onda da tensão aplicada, em um tubo de raios $\mathrm{X}$ ligado a um gerador de alta tensão trifásico (transformador e eletrônica de controle associada) produzirá uma quantidade maior de raios $\mathrm{X}$, do que um tubo ligado a um gerador de alta tensão monofásico. Isto se deve ao fato que o gerador trifásico possui um fator de ondulação menor da tensão. Além disso, a energia efetiva de um feixe produzido em um gerador trifásico é maior, porque a tensão permanece com valores maiores durante todo o tempo de exposição. Desse modo, pode-se dizer que a qualidade e a intensidade do feixe de raios $\mathrm{X}$ são proporcionais à forma de onda da tensão.

A distância entre o tubo de raios $X$ e 0 ponto de medição não influencia significativamente a qualidade do feixe de raios $X$, mas afetam somente sua intensidade (a intensidade diminui com o inverso do quadrado da distância). A exceção à regra mencionada anteriormente ocorre para feixes de energias baixas que sofrem uma grande atenuação pelo ar, modificando seu espectro.

\section{7 - Avaliação das incertezas}

Quando se realiza uma avaliação prática ou ensaio surge o conceito de erro e de valor verdadeiro. Desse modo, simplesmente, pode-se dizer que um erro possui um valor numérico e um sinal. Em contraste, a incerteza associada com a medida é um parâmetro, que caracteriza a dispersão do valor medido. Este parâmetro é

\footnotetext{
${ }^{1}$ É definido como uma componente de tensão alternada (variável no tempo) que está sobreposta à tensão (kVp) selecionada do equipamento de raios $\mathrm{X}$. Esta componente indesejável modifica o valor de pico da tensão selecionada.
} 
normalmente uma estimativa do desvio padrão. Uma incerteza, entretanto, não possui um sinal conhecido e é usualmente considerado que ele é simétrico (positivo ou negativo). Se os erros foram exatamente conhecidos, o valor verdadeiro pode ser determinado sem maiores problemas.

Segundo a norma ISO para expressão das incertezas ${ }^{(74)}$, a avaliação das incertezas é classificada em dois tipos: uma avaliação denominada do Tipo A, que é obtida pela análise estatística de séries de observações (medidas); uma outra avaliação é, a do Tipo B, que é obtida por outros meios diferentes da análise estatística de séries de observações. A incerteza dita combinada é obtida a partir das incertezas dos Tipos A e B, sendo a incerteza combinada dada pela raiz quadrada da soma dos quadrados de todas as incertezas, e ainda a incerteza expandida, dada pela multiplicação da incerteza combinada por um fator de abrangência. Para fins da determinação das incertezas expandidas associadas aos coeficientes de calibração, utilizou-se o fator de abrangência $k=2$, relativo a um intervalo de confiança $(P)$ de $95 \%{ }^{(74-77)}$.

Toda a avaliação das incertezas associadas à resposta das câmaras de ionização desenvolvidas e utilizadas neste trabalho, durante os ensaios e calibrações realizadas, atenderam ao recomendado pela norma ISO GUM(74).

Assim, a incerteza expandida foi determinada para cada medidor de radiação por meio da relação:

$$
\mathrm{U}_{95}=\mathrm{k} \times \mathrm{u}_{\mathrm{c}}
$$

onde $\mathrm{k}$ = fator de abrangência que corresponde a um nível de confiança de $95 \%$; $\mathrm{u}_{\mathrm{c}}$ = incerteza padrão combinada.

Os fatores componentes que afetam a incerteza padrão combinada de relevância para este trabalho foram: 
a) Reprodutibilidade da resposta do medidor de radiação, $\mathrm{u}_{1}$, que é uma componente do Tipo A, foi determinada por meio da relação:

$$
\mathrm{u}_{1}=\mathrm{s} /(\mathrm{n})^{1 / 2}
$$

onde $\mathrm{s}=$ desvio padrão das medidas;

$\mathrm{n}=$ número de resultados obtidos com o medidor de radiação. Neste caso, $\mathrm{n}$ foi igual a dez (dez medidas realizadas para cada ensaio).

b) Posicionamento do medidor de radiação, $\mathrm{u}_{2}$, é uma incerteza associada ao posicionamento do medidor do Tipo $\mathrm{B}$; foi determinada levando-se em consideração a resolução do sistema de posicionamento (régua de aço graduada) utilizada para medida da distância fonte-detector; o valor é dado pela relação:

$$
\mathrm{u}_{2}=0,05 /(3)^{1 / 2}
$$

c) Calibração do sistema padrão, $\mathbf{u}_{3}$, é a incerteza do sistema padrão de calibração do Tipo B e o seu valor é obtido diretamente do certificado de calibração da câmara de ionização padrão ou de referência utilizada nos ensaios.

Desse modo, o valor da incerteza padrão combinada foi obtido por meio da relação:

$$
u_{c}=\left[\left(u_{1}\right)^{2}+\left(u_{2}\right)^{2}+\left(u_{3}\right)^{2}\right]^{1 / 2}
$$

Constata-se por meio dos certificados de calibração das câmaras de ionização padrões, que em todos os casos a incerteza associada ao coeficiente de calibração da câmara de ionização padrão foi o maior fator, de modo que ele foi o fator que mais influiu na incerteza expandida. 


\section{MATERIAIS E MÉTODOS}

As câmaras de ionização de placas paralelas, desenvolvidas em sistema Tandem, confeccionadas neste trabalho, apresentam uma diferença em relação ao material utilizado para construção dos eletrodos internos (eletrodos coletores) e dos anéis de guarda, sendo que uma das câmaras possui os eletrodos de alumínio, enquanto que na outra os eletrodos são de grafite. As câmaras de ionização desenvolvidas serão descritas em um próximo capítulo, pois é o objetivo principal desta tese. Este capítulo apresenta as características e os detalhes dos outros materiais e equipamentos utilizados neste trabalho.

\section{1 - Sistemas de medida}

Os sistemas dosimétricos (conjunto câmara de ionização + eletrômetros) foram testados, quando possível, de acordo com os procedimentos e recomendações nacionais $^{(1,7)}$ e internacionais ${ }^{(78-81)}$.

As câmaras de ionização desenvolvidas foram acopladas a eletrômetros da

marca Physikalisch Technische Werkstätten (PTW), assim como as câmaras de ionização de referência e a câmara monitora de feixe de radiação $X$.

Os eletrômetros PTW utilizados com as câmaras de ionização permitem a variação da tensão de polarização das câmaras, assim como a inversão da polaridade de tensão, positiva ou negativa. Permitem ainda a variação de tensão em intervalos de 50 volts. As características principais dos eletrômetros utilizados são mostradas na Tabela 3.1. 
Tabela 3.1: Características dos eletrômetros utilizados neste trabalho.

\begin{tabular}{|c|c|c|c|c|}
\hline & & $\begin{array}{c}\text { Número } \\
\text { de }\end{array}$ & $\begin{array}{c}\text { Tensão } \\
\text { na }\end{array}$ & $\begin{array}{c}\text { Acurácia } \\
\text { das }\end{array}$ \\
\hline Fabricante & Modelo & Série & Câmara & Medições \\
\hline PTW-Freiburg & UNIDOS & 10474 & $0 \ldots \pm 400 \mathrm{~V}$ & $\leq 0,5 \%$ leitura +1 digito \\
\hline PTW-Freiburg ${ }^{*}$ & UNIDOS E & 0190 & $0 \ldots \pm 400 \mathrm{~V}$ & $\leq 0,5 \%$ leitura +1 digito \\
\hline Radcal Corporation & 9015 & 0280 & $+260 \mathrm{~V}$ & $4 \%$ leitura +1 digito \\
\hline
\end{tabular}

Para o estudo da dependência energética, as câmaras de ionização foram inicialmente calibradas em feixes padrões de radiação $X$, por meio da técnica da substituição ${ }^{(13)}$. Nesta técnica de calibração, um instrumento de referência é colocado no campo de radiação desejado tomando-se uma série de leituras e obtendo-se um valor médio; logo após, o instrumento a ser calibrado substitui o de referência, e nas mesmas condições de irradiação e geometria (os dois instrumentos devem ser posicionados à mesma distância, ou na mesma posição) é tomada uma série de leituras deste último instrumento obtendo-se um valor médio. Desse modo, após as medidas realizadas com os dois equipamentos, o coeficiente de calibração ${ }^{(10)}$ é obtido por meio da comparação entre os valores médios das leituras.

As câmaras de ionização pertencentes aos sistemas padrões de referência utilizados para os testes e a calibração das câmaras de ionização desenvolvidas neste trabalho, incluindo suas características são mostradas na Tabela 3.2. 
Tabela 3.2 Características dos sistemas padrões utilizados nos ensaios.

\begin{tabular}{|c|c|c|c|}
\hline $\begin{array}{l}\text { Qualidade } \\
\text { da Radiação }\end{array}$ & $\begin{array}{c}\text { Câmara } \\
\text { de Ionização }\end{array}$ & $\begin{array}{l}\text { Volume Sensível } \\
\qquad\left(\mathrm{cm}^{3}\right)\end{array}$ & $\begin{array}{c}\text { Eletrômetro } \\
\text { (marca/modelo) }\end{array}$ \\
\hline Radioproteção & PTW W32002-A ${ }^{1}$ & 1000 & PTW/UNIDOS \\
\hline Radioproteção & PTW W32002-B ${ }^{2}$ & 1000 & PTW/UNIDOS \\
\hline Diagnóstico & PTW $77334^{3}$ & 1,0 & PTW/UNIDOS \\
\hline Mamografia & $10 \times 5-6 M^{4}$ & 6,0 & Radcal/9015 \\
\hline Terapia & PTW M233445 & 0,2 & PTW/UNIDOS \\
\hline${ }^{60} \mathrm{Co} \mathrm{e}{ }^{137} \mathrm{Cs}$ & PTW W32002-A ${ }^{1}$ & 1000 & PTW/UNIDOS \\
\hline
\end{tabular}

Radioproteção

$\begin{array}{llll}\text { e } & \text { PTW W31002 } & 0,125 & \text { PTW/UNIDOS }\end{array}$

Diagnóstico

Radioproteção

$\begin{array}{llll}\text { e } & \text { PTW W31003 } & 0,3 & \text { PTW/UNIDOS }\end{array}$

Diagnóstico

1 Certificado de calibração № C04/122003 (IRD-LNMRI) - RJ - Brasil
2 Certificado de calibração № 96D035 (DKD) - Alemanha
3 Certificado de calibração № 5222 (PTB) - Alemanha
4 Certificado de calibração № R00-0060 (CDRH-FDA) - EUA
5 Certificado de calibração № 96D032 (DKD) - Alemanha
6 Certificado de calibração № 960867 (PTW) - Alemanha
7 Certificado de calibração № 96D030 (DKD) - Alemanha

Como as câmaras de ionização utilizadas neste trabalho não são seladas, todas as medições foram corrigidas para as condições normais de temperatura e pressão, isto é, $(20,0 \pm 0,1)^{\circ} \mathrm{C}$ e $(101,3 \pm 0,1) \mathrm{kPa}$; as câmaras devem ser operadas em ambiente com umidade relativa do ar em torno de $50 \%$, uma vez que o número 
de pares de íons formados por unidade de caminho percorrido é uma função da densidade do gás em uma câmara de ionização. $A$ correção $F_{T, p}$ para as condições de referência de temperatura e pressão é dada por:

$$
F_{T, p}=[(273,2+T) /(273,2+20)] \times[101,3 / p]
$$

onde: $\mathrm{p}$ é a pressão em $\mathrm{kPa}$ e $\mathrm{T}$ é a temperatura em ${ }^{\circ} \mathrm{C}$, durante o procedimento de calibração.

A Figura 3.1 mostra um sistema dosimétrico, composto por um eletrômetro PTW UNIDOS e uma câmara de ionização esférica de 1,0 litro (PTW 32002-A) e outra câmara de ionização de placas paralelas de $1,0 \mathrm{~cm}^{3}$ (PTW 77334); estas câmaras correspondem aos padrões de radioproteção e radiodiagnóstico, respectivamente.

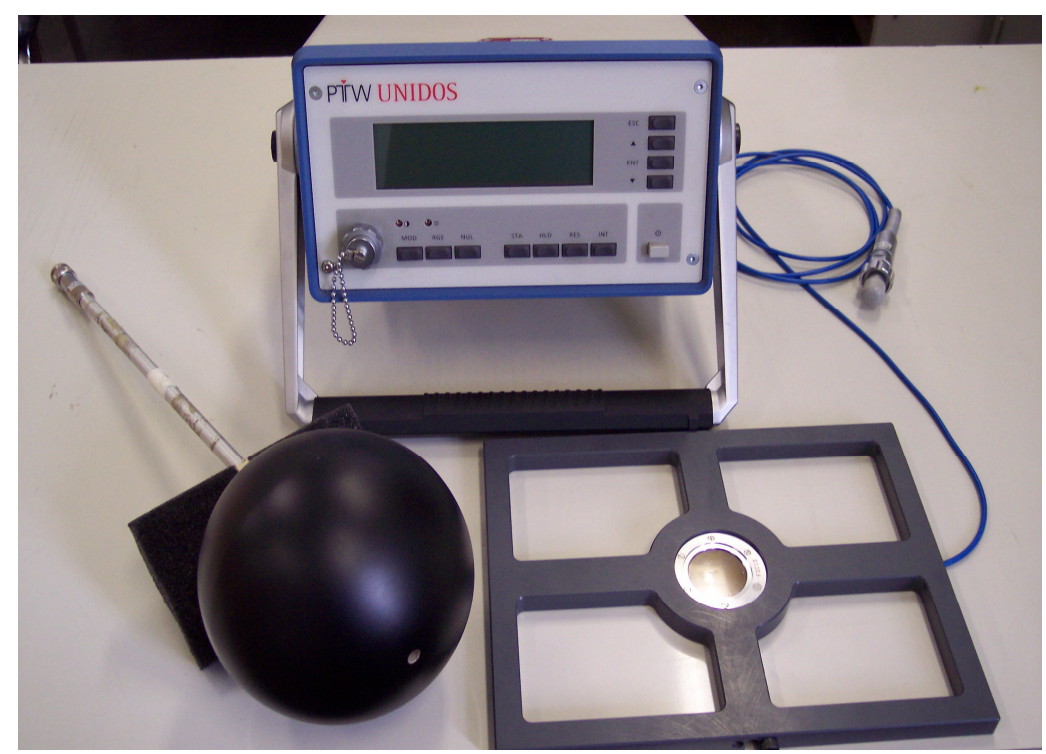

Figura 3.1. Sistema dosimétrico composto por um eletrômetro PTW UNIDOS e uma câmara de ionização esférica de 1,0 litro (PTW 32002-A) e outra câmara de ionização de placas paralelas de $1,0 \mathrm{~cm}^{3}$ (PTW 77334).

\section{2- Sistemas de radiação}

Os ensaios com radiação gama foram realizados com uma fonte radioativa de ${ }^{60} \mathrm{Co}$ de um sistema irradiador gama confeccionado nas oficinas do IPEN; a fonte está inserida em uma blindagem de chumbo com formato cilíndrico e de acionamento 
manual, com atividade nominal de $18 \mathrm{GBq}$ (outubro de 2005); outra fonte utilizada foi de ${ }^{137}$ Cs proveniente de um irradiador da STS Steuerungstechnik \& Strahlenschutz $\mathrm{GmbH}$, Alemanha, modelo OB85, com fontes emissoras de radiação gama de ${ }^{60} \mathrm{Co}(18,0 \mathrm{GBq}),{ }^{137} \mathrm{Cs}(651 \mathrm{GBq}),{ }^{241} \mathrm{Am}(7,3 \mathrm{GBq})$ e ${ }^{226} \mathrm{Ra}(0,4 \mathrm{GBq})$, sendo que a data de referência para todas as fontes mencionadas é dezembro de 2005. As qualidades de radiação gama implantadas nos irradiadores acima mencionados, atendem ao recomendado pela norma ISO $4037-1^{(16)}$, para qualidades de feixes de radiação, nível radioproteção. A Figura 3.2 mostra o sistema irradiador gama STS, modelo OB85.

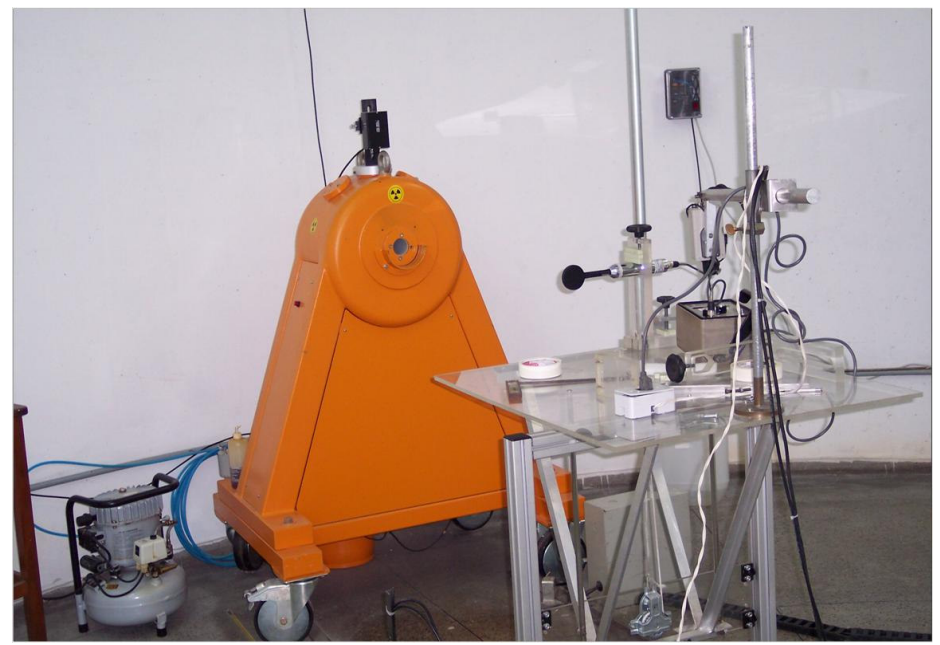

Figura 3.2. Sistema de radiação gama, marca STS, modelo OB85, no detalhe ao fundo, e câmara de ionização posicionada para irradiação.

Foram utilizados os seguintes sistemas de radiação X:

- $\quad$ Sistema de radiação $X$ de energias baixas, constituído por um gerador Rigaku Denki Co. Ltd., Japão, tipo Geigerflex (potencial constante), acoplado a um tubo Philips, modelo PW 2184/00, com janela de $1 \mathrm{~mm}$ de Berílio e alvo de Tungstênio. A tensão de operação do sistema vai de 20 a 60 kV e a corrente do tubo pode variar entre 2 e $80 \mathrm{~mA}$. Sua potência máxima é de 3,0 kW. O sistema possui um obturador do feixe (shutter), marca PTW, modelo 6801. O sistema monitor é composto por uma câmara de transmissão PTW, modelo Tch 7786/k tipo 24390, série 
2882, acoplada ao eletrômetro PTW, modelo DUO/4, série 21142-301086. Neste sistema estão implantadas qualidades de radiação para a calibração de monitores portáteis (nível radioproteção), com energias de 33 e $48 \mathrm{keV}$, e ainda qualidades de radiação nível radioterapia, com energias de 15,5 a 21,2 keV. As Tabelas 3.3, 3.4, 3.5 e 3.6 mostram as qualidades de feixes de raios $X$, níveis radioterapia, mamografia (feixes diretos e atenuados) e radioproteção (energias baixas), utilizadas nos testes. Os feixes de radiação $X$ implantados seguiram as recomendações das normas ISO 4037-1 ${ }^{(16)}$ para qualidades de radiação, nível radioproteção; os feixes de radiação X, nível radioterapia, são os das mesmas qualidades do Laboratório NPL (National Physical Laboratory), da Inglaterra (radioterapia, de energias baixas) e as qualidades de radiação $X$, nível mamografia, são as mesmas qualidades do Laboratório CDRH/FDA (Center for Devices and Radiological Health / U.S. Food and Drug Administration), dos E.U.A.

- $\quad$ Sistema de radiação $X$ de energias intermediárias, constituído por um gerador Agfa NDT Pantak/Seifert GmbH \& Co. KG., Alemanha, modelo ISOVOLT 160 HS, tipo potencial constante, acoplado a um tubo Comet, modelo MRX 160/22, com janela de $1 \mathrm{~mm}$ de Berílio e alvo de Tungstênio. A tensão de operação do sistema vai de 5,0 a $160 \mathrm{kV}$ e a corrente do tubo pode variar entre 0,1 e $45 \mathrm{~mA}$. Sua potência máxima é de 3,0 kW. O sistema possui um obturador do feixe (shutter), marca Pantak Seifert. O sistema monitor é composto por uma câmara de transmissão PTW, modelo 34014, série 0031, acoplada ao eletrômetro PTW, modelo UNIDOS E 10010 , série 190 . Neste sistema estão implantadas qualidades de radiação para a calibração de monitores portáteis e câmaras de ionização, nível radiodiagnóstico, com energias de 27,15 a 82,10 keV. As Tabelas 3.7 e 3.8 mostram as qualidades de feixes de raios $X$, nível radiodiagnóstico (feixes diretos e atenuados), utilizadas nos testes. As qualidades de radiação $X$, nível radiodiagnóstico, foram implantadas conforme recomendado pela norma IEC $61267^{(82)}$.

As Figuras 3.3 e 3.4 mostram os sistemas de raios $X$ utilizados nos ensaios. 


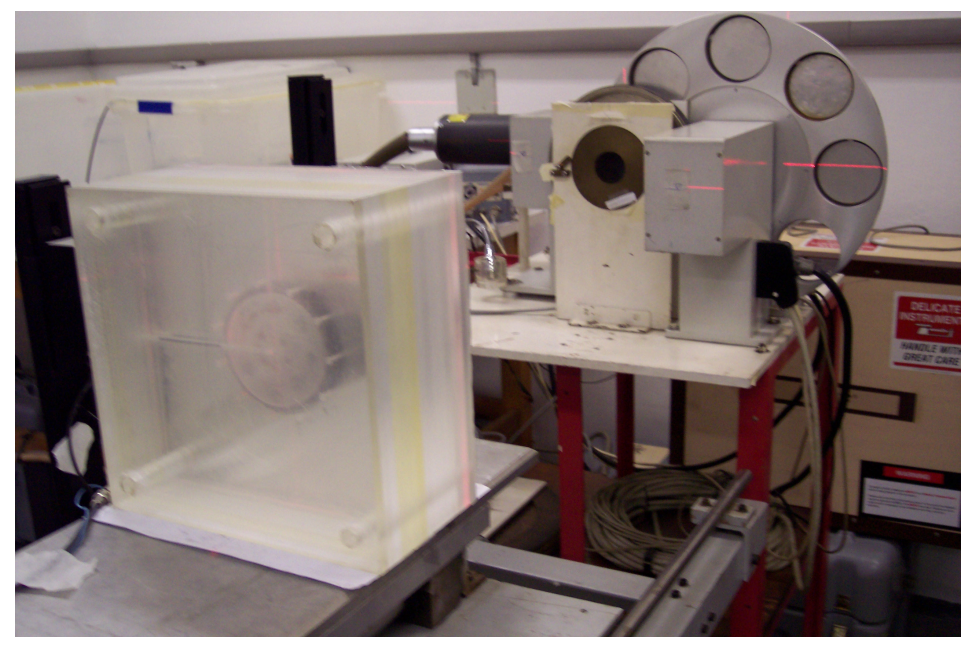

Figura 3.3. Sistema de radiação $X$, marca Rigaku-Denki, modelo Geigerflex, no detalhe ao fundo, e câmara de ionização posicionada para calibração.

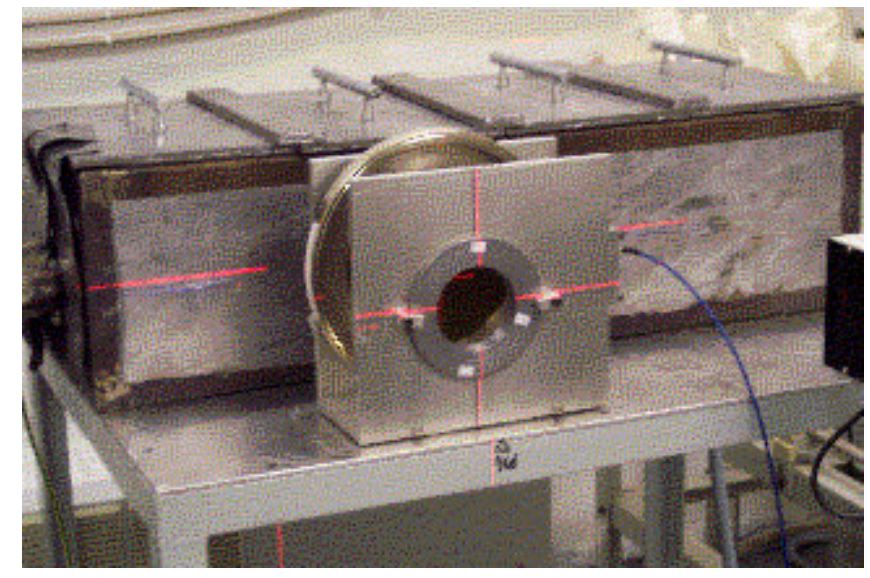

Figura 3.4. Sistema de radiação X, marca Pantak/Seifert, modelo ISOVOLT 160 HS, com caixa moldada em chumbo (10 $\mathrm{mm}$ de espessura) para blindagem do tubo de raios $X$. 
Tabela 3.3: Características do sistema Rigaku-Denki para as qualidades de radioterapia de energias baixas; filtração inerente: $1 \mathrm{mmBe}$.

\begin{tabular}{|c|c|c|c|c|c|}
\hline Qualidade & & & Camada & Filtração & Energia \\
\hline $\mathrm{da}$ & Tensão & Corrente & Semi-Redutora & Adicional & Efetiva \\
\hline Radiação & $(\mathrm{kV})$ & $(\mathrm{mA})$ & $(\mathrm{mm} \mathrm{Al})$ & $(\mathrm{mm} \mathrm{Al})$ & (keV) \\
\hline RT - 30 & 30 & 30 & 0,36 & 0,55 & 15,5 \\
\hline RT - 50 & 50 & 25 & 0,89 & 1,02 & 21,2 \\
\hline
\end{tabular}

Tabela 3.4: Características do sistema Rigaku-Denki para as qualidades de mamografia; feixes de entrada (ou diretos), filtração inerente: $1 \mathrm{mmBe}$.

\begin{tabular}{|c|c|c|c|c|c|}
\hline \multirow{2}{*}{$\begin{array}{c}\text { Qualidade } \\
\text { da }\end{array}$} & \multirow{3}{*}{$\begin{array}{c}\text { Tensão } \\
\text { (kV) }\end{array}$} & \multirow{3}{*}{$\begin{array}{c}\text { Corrente } \\
\text { (mA) }\end{array}$} & \multirow{3}{*}{$\begin{array}{c}\text { Camada } \\
\text { Semi-Redutora } \\
\text { (mm Al) }\end{array}$} & \multirow{3}{*}{$\begin{array}{l}\text { Filtração } \\
\text { Adicional } \\
\text { (mm Mo) }\end{array}$} & \multirow{3}{*}{$\begin{array}{r}\text { Energia } \\
\text { Efetiva } \\
(\mathrm{keV})\end{array}$} \\
\hline & & & & & \\
\hline Radiação & & & & & \\
\hline $\mathrm{RX} M-25$ & 25 & 30 & 0,33 & 0,06 & 15,1 \\
\hline RX M - 28 & 27,5 & 30 & 0,34 & 0,06 & 15,3 \\
\hline RX M - 35 & 35 & 30 & 0,38 & 0,06 & 16,2 \\
\hline
\end{tabular}


Tabela 3.5: Características do sistema Rigaku-Denki para as qualidades de mamografia; feixes de saída (ou atenuados), filtração inerente: $1 \mathrm{mmBe}$.

\begin{tabular}{cccccc}
\hline $\begin{array}{c}\text { Qualidade } \\
\text { da }\end{array}$ & $\begin{array}{c}\text { Tensão } \\
\text { Radiação }\end{array}$ & $\begin{array}{c}\text { Corrente } \\
(\mathrm{kV})\end{array}$ & $\begin{array}{c}\text { Camada } \\
(\mathrm{mA})\end{array}$ & $\begin{array}{c}\text { Filtração } \\
(\mathrm{mm} \mathrm{Al})\end{array}$ & $\begin{array}{c}\text { Energia } \\
\text { Efetiva }\end{array}$ \\
\hline RX M - 25x & 25 & 30 & 0,58 & 0,06 & 18,8 \\
RX M - 28x & 27,5 & 30 & 0,61 & 0,06 & 19,0 \\
RX M - 35x & 35 & 30 & 0,85 & 0,06 & 21,6 \\
\hline * Adicionada ainda uma filtração de 2,0 mm Al & & &
\end{tabular}

Tabela 3.6: Características do sistema Rigaku-Denki para as qualidades de radioproteção de energias baixas; filtração inerente: $1 \mathrm{mmBe}$.

\begin{tabular}{cccccc}
\hline $\begin{array}{c}\text { Qualidade } \\
\text { da }\end{array}$ & Tensão & Corrente & $\begin{array}{c}\text { Camada } \\
\text { Semi-Redutora }\end{array}$ & $\begin{array}{c}\text { Filtração } \\
\text { Adicional }\end{array}$ & $\begin{array}{c}\text { Energia } \\
\text { Efetiva }\end{array}$ \\
Radiação & $(\mathrm{kV})$ & $(\mathrm{mA})$ & $(\mathrm{mm} \mathrm{Cu})$ & $(\mathrm{mm} \mathrm{Al})$ & $(\mathrm{keV})$ \\
\hline ISO 40 N & 40 & 20 & 0,086 & 4,21 & 33,0 \\
ISO 60 N & 60 & 10 & 0,232 & 4,57 & 48,0 \\
\hline
\end{tabular}


Tabela 3.7: Características do sistema Pantak/Seifert para as qualidades de radiodiagnóstico; feixes diretos (ou de entrada), filtração inerente: $1 \mathrm{mmBe}$.

\begin{tabular}{cccccc}
\hline $\begin{array}{c}\text { Qualidade } \\
\text { da }\end{array}$ & $\begin{array}{c}\text { Tensão } \\
\text { Radiação }\end{array}$ & $\begin{array}{c}\text { Corrente } \\
(\mathrm{kV})\end{array}$ & $\begin{array}{c}\text { Camada } \\
(\mathrm{mA})\end{array}$ & $\begin{array}{c}\text { Filtração } \\
(\mathrm{mm} \mathrm{Al})\end{array}$ & $\begin{array}{c}\text { Energia } \\
\text { Efetiva }\end{array}$ \\
\hline RQR 3 & 50 & 10 & 1,79 & 2,5 & 27,15 \\
RQR 5 & 70 & 10 & 2,35 & 2,5 & 30,15 \\
RQR 7 & 90 & 10 & 2,95 & 2,5 & 33,05 \\
RQR 9 & 120 & 10 & 3,84 & 2,5 & 37,05 \\
RQR 10 & 150 & 10 & 4,73 & 2,5 & 40,75 \\
\hline
\end{tabular}

Tabela 3.8: Características do sistema Pantak/Seifert para as qualidades de radiodiagnóstico; feixes atenuados (ou de saída), filtração inerente: $1 \mathrm{mmBe}$.

\begin{tabular}{|c|c|c|c|c|c|}
\hline $\begin{array}{l}\text { Qualidade } \\
\qquad \text { da } \\
\text { Radiação }\end{array}$ & $\begin{array}{c}\text { Tensão } \\
\text { (kV) }\end{array}$ & $\begin{array}{c}\text { Corrente } \\
(\mathrm{mA})\end{array}$ & $\begin{array}{c}\text { Camada } \\
\text { Semi-Redutora } \\
\text { (mm Al) }\end{array}$ & $\begin{array}{l}\text { Filtração } \\
\text { Adicional } \\
\text { (mm Al) }\end{array}$ & $\begin{array}{c}\text { Energia } \\
\text { Efetiva } \\
(\mathrm{keV})\end{array}$ \\
\hline RQA 3 & 50 & 20 & 3,91 & 12,5 & 37,30 \\
\hline RQA 5 & 70 & 20 & 6,86 & 23,5 & 49,40 \\
\hline RQA 7 & 90 & 20 & 9,22 & 32,5 & 59,70 \\
\hline RQA 9 & 120 & 20 & 11,39 & 42,5 & 71,15 \\
\hline RQA 10 & 150 & 20 & 13,02 & 47,5 & 82,10 \\
\hline
\end{tabular}




\section{3 - Sistemas auxiliares}

Foram ainda utilizados os seguintes sistemas auxiliares para a caracterização dos feixes de radiação $\mathrm{X}$, nível radioproteção, como o estabelecimento das camadas semi-redutoras e da filtração adicional: filtros absorvedores de alta pureza (99,99 \%) de alumínio, cobre e estanho, e ainda colimadores de chumbo, com diferentes diâmetros, suportes, morsas, garras e pinças de fixação.

A temperatura e a umidade relativa do ar nos laboratórios de ensaio foram controladas por meio de sistemas de ar condicionado e desumidificadores (climatizados). As medições de temperatura, pressão, umidade relativa do ar e medida de tempo foram obtidas com os seguintes instrumentos auxiliares:

a) Termômetro Incotherm, de mercúrio, com intervalo de medida entre 10 e $+40{ }^{\circ} \mathrm{C}$, e resolução de $0,1^{\circ} \mathrm{C}$;

b) Barômetro Veränderlich, modelo Domatic, Alemanha, com intervalo de medida entre 96 e 104 kPa e resolução de 0,1 kPa;

c) Higrômetro Präzision-Faden, Alemanha, com intervalo de medida entre 0 e 100 \% e com resolução de 1 \% de umidade relativa do ar;

d) Cronômetro digital Nuclear Enterprises, USA, modelo Laboratory Timer no 2546, com intervalo de medida de 0,001 a 9999,99 s, resolução de $0,001 \mathrm{~s}$.

No processo de medida da espessura dos materiais utilizados para a confecção das câmaras de ionização (placas de PMMA, eletrodos coletores e anéis de guarda) desenvolvidas neste trabalho, e ainda para a medida da espessura dos filtros absorvedores de alta pureza (filtração adicional e filtros para determinação das camadas semi-redutoras), empregou-se os seguintes instrumentos de medida: 
a) Paquímetro universal com faces de metal duro, em aço inoxidável, marca Mitutoyo, modelo 530-320, com capacidade de $150 \mathrm{~mm}$ e resolução de 0,05 mm;

b) Micrômetro externo, tipo arco, de ferro fundido modular pintado, pontas de medição de metal duro, marca Mitutoyo, modelo 103-137, com capacidade de 0-25 mm e resolução de 0,01 $\mathrm{mm}$.

Nos procedimentos de secagem das placas e das janelas das câmaras de ionização foi utilizada uma estufa de secagem de materiais da marca ELETROlab, modelo $402(500 \mathrm{~W})$, tensão de operação $110 \mathrm{~V}$, com controle térmico eletrônico por meio de termopar.

No processo de homogeneidade da pintura, foram utilizados um sistema variador de tensão alternada tipo reostato (VARIAC), marca Keldian, modelo FA-1, com potência de $440 \mathrm{~W}$ e tensão máxima de entrada de $220 \mathrm{~V}$ (permite a variação da tensão de entrada de uma furadeira elétrica portátil, para o controle de sua velocidade); e uma furadeira elétrica, tipo portátil, comercial, marca Black\&Decker, com tensão de operação $110 \mathrm{~V}$ e potência de $300 \mathrm{~W}$. 


\section{ESTABELECIMENTO DE CAMPOS PADRÕES DE RADIAÇÃO $X$, DE ENERGIAS INTERMEDIÁRIAS, NÍVEL RADIOPROTEÇÃO}

\section{Estabelecimento de campos padrões}

Os instrumentos medidores de radiação, por meio de suas leituras, permitem o conhecimento dos efeitos diretos e indiretos provocados pela radiação ionizante; desse modo, necessitam que suas medidas sejam obtidas com a maior acurácia possível. A utilização e os propósitos para os quais eles se aplicam exigem muitas vezes limites aceitáveis de exatidão em suas medidas, de forma a garantir a confiabilidade das leituras realizadas por eles.

Esta confiabilidade é assegurada por meio da calibração regular e periódica destes instrumentos. Estes tipos de instrumentos (detectores de radiação), utilizados em campos de radiação $X$, nível radioproteção, são calibrados no Laboratório de Calibração de Instrumentos (LCI) do IPEN, dependendo de sua finalidade e utilização, com radiação $X$ (energias baixas), alfa, beta ou gama.

Muitas vezes recomenda-se a calibração destes detectores de radiação com radiação $X$ de energias médias (ou intermediárias), com o propósito de sua utilização em campos de radiação $X$, nível radioproteção.

No LCI só estavam implantadas duas qualidades de radiação $X$, nível radioproteção, no sistema Rigaku-Denki (que opera apenas até $60 \mathrm{kV}$ ), da norma ISO $4037-1^{(16)}$ ( $\mathrm{N}-40$ e N-60) com rastreabilidade ao Laboratório NPL, da Inglaterra, 
num sistema de raios $X$ de energias baixas, o que tornava inviável a obtenção de curvas de dependência energética da resposta das câmaras de ionização desenvolvidas neste trabalho para serem utilizadas em campos de radiação $X$ (radioproteção).

A implantação destas qualidades de feixes de radiação $X$, nível radioproteção, de energias médias, permitirá ao LCI a realização de trabalhos e pesquisas técnico-científicas, além da calibração de instrumentos medidores de radiação neste intervalo de energias, assim complementando o conjunto de serviços prestados pelo LCI a clínicas, hospitais e indústrias. São calibrados atualmente pelo LCI cerca de 1800 equipamentos medidores de radiação por ano com radiações $\mathrm{X}$, alfa, beta e gama, em uma demanda sempre crescente nos últimos 5 anos, principalmente no caso dos medidores utilizados na área médica (cerca de $10 \%$ ao ano).

Assim, o objetivo desta etapa do trabalho foi a implantação de feixes de radiação $X$, nível radioproteção, num sistema de radiação $X$ de energias intermediárias (Pantak/Seifert).

Foram utilizadas três câmaras de ionização na implantação das qualidades de radiação $X$ de energias intermediárias, nível radioproteção. Uma das câmaras de ionização da marca PTW, modelo 32002-A, foi utilizada como câmara de referência (formato esférico, volume sensível de 1 litro). A Figura 4.1 mostra a câmara de ionização de referência posicionada para medida das taxas de kerma no ar das qualidades de radiação $X$, no sistema Pantak/Seifert. 


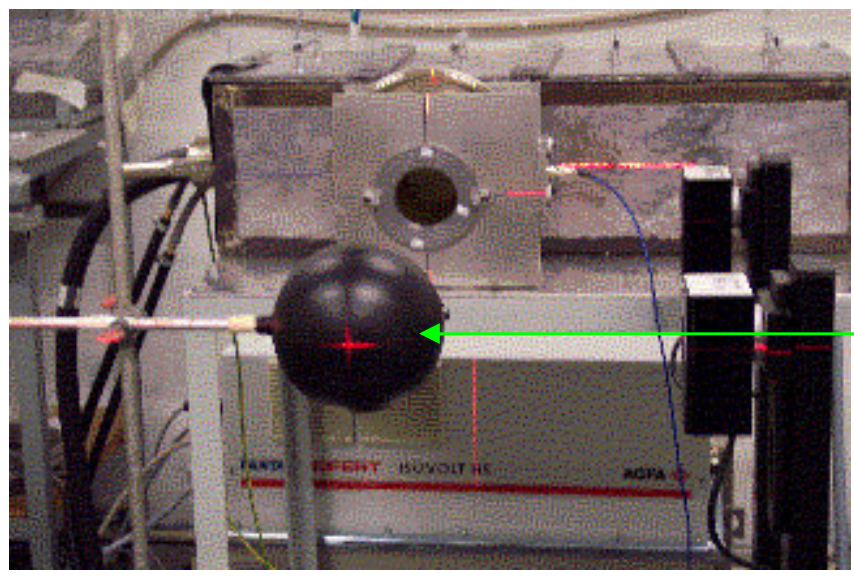

Câmara de ionização posicionada, com auxílio de sistemas laser

Figura 4.1. Câmara de ionização de referência (1 litro) posicionada para medida das taxas de kerma no ar das qualidades de radiação $X$, nível radioproteção, de energias intemediárias, no sistema Pantak/Seifert.

Uma segunda câmara de ionização que foi utilizada neste trabalho é exatamente do mesmo modelo que a câmara de ionização de referência (PTW 32002A), foi utilizada como padrão de trabalho (PTW 32002-B); a terceira câmara de ionização empregada nas medidas é da marca PTW, modelo 31002 (do tipo dedal), com $0,125 \mathrm{~cm}^{3}$, que foi utilizada para o mapeamento do campo de radiação e a medida da linearidade de resposta com a corrente do tubo de raios $X$. Vide Figura 4.2.

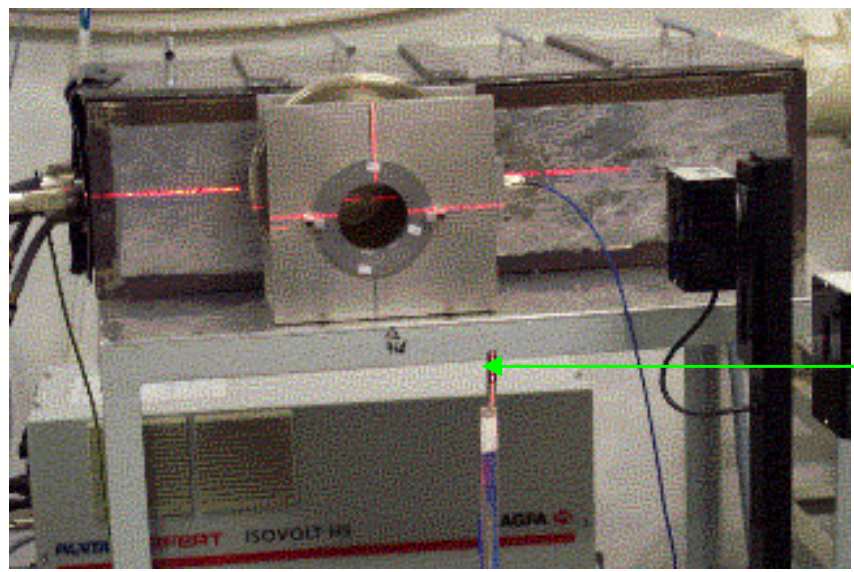

Câmara de ionização, tipo dedal, posicionada com auxílio de sistemas laser

Figura 4.2. Câmara de ionização PTW $31002\left(0,125 \mathrm{~cm}^{3}\right)$ posicionada para medida da linearidade de sua resposta com a corrente do tubo de raios- $X$ e para o mapeamento do campo das qualidades de radiação $X$, nível radioproteção, de energias intemediárias, no sistema Pantak/Seifert. 
Inicialmente, antes do mapeamento do campo de radiação $X$, realizou-se uma verificação da dependência da resposta da câmara de ionização PTW 31002, com a corrente elétrica ajustada no tubo de raios $X$ do equipamento Pantak/Seifert. $O$ posicionamento da câmara de ionização no feixe é o mesmo mostrado na Figura 4.2.

As medidas de corrente de ionização foram realizadas com a câmara de ionização posicionada a uma distância de $2,5 \mathrm{~m}$ do foco do tubo de raios $\mathrm{X}$ e foi aplicada uma tensão de $60 \mathrm{kV}$ no sistema de raios X. Para estas medidas de corrente não se utilizou filtração adicional, sendo a corrente variada de 5 a $35 \mathrm{~mA}$, em intervalos de $5 \mathrm{~mA}$. Foi efetuada, para cada valor de corrente selecionado, uma série de seis leituras, obtendo-se ao final o valor médio destas leituras. A Figura 4.3 mostra a variação da resposta da câmara de ionização PTW 31002 em relação ao valor da corrente no tubo de raios $\mathrm{X}$, para a distância de $2,5 \mathrm{~m}$.

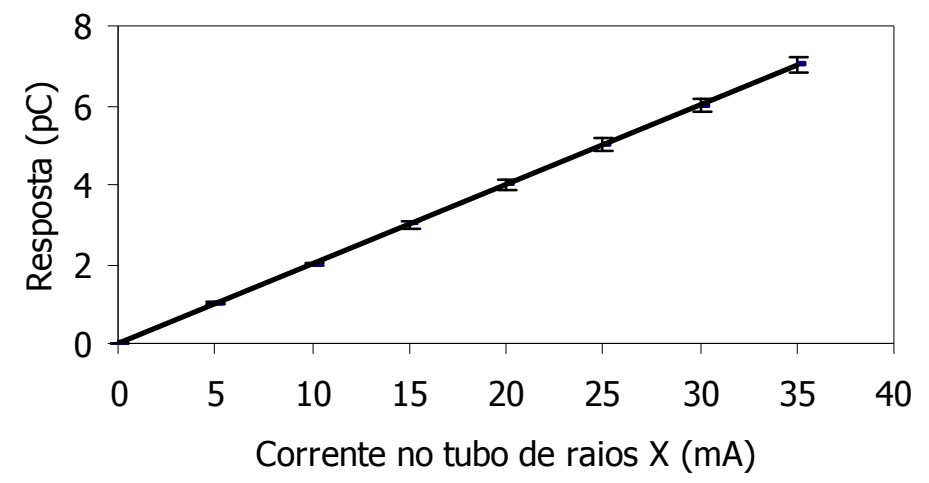

Figura 4.3. Dependência da resposta da câmara de ionização PTW $31002\left(0,125 \mathrm{~cm}^{3}\right)$ em relação à corrente no tubo de raios $X$, para a distância foco-detector de 2,5 m, no sistema Pantak/Seifert.

Na Figura 4.3 tem-se que a variação da resposta da câmara de ionização PTW 31002, em relação à corrente no tubo de raios $X$, é linear.

Em fase posterior, com o mesmo arranjo experimental, procedeu-se 0 mapeamento do campo de radiação $\mathrm{X}$ produzido pelo equipamento Pantak/Seifert, 
com a utilização da câmara de ionização tipo dedal PTW 31002. Neste procedimento é desejável que a câmara de ionização tenha dimensões pequenas, pois uma câmara de ionização com dimensões grandes dificulta o seu posicionamento, que é feito geralmente em unidades de centímetros ou milímetros. A câmara de ionização deve ter todo seu volume sensível dentro do campo de radiação, onde o uso de colimadores com diâmetro pequeno (feixe bem colimado, ou campo menor), auxiliam na redução de eventual radiação espalhada durante a realização das medidas; desse modo, empregou-se uma câmara de ionização do tipo dedal, que foi mais adequada. Este procedimento representa um dos passos no estabelecimento de campos padrões de radiação $X$ de energias médias, nível radioproteção.

O ensaio foi realizado utilizando-se um colimador de $70,5 \mathrm{~mm}$ de diâmetro, distância entre a câmara de ionização e o foco do tubo de raios $X$ de $2,5 \mathrm{~m}$, tensão aplicada aos eletrodos do tubo de raios X de $60 \mathrm{kV}$ e corrente de $30 \mathrm{~mA}$. A câmara de ionização foi posicionada no centro do feixe de radiação, e desse modo, a posição da câmara de ionização em relação ao centro do feixe de radiação foi variada de 2 em $2 \mathrm{~cm}$, tanto na direção vertical como na direção horizontal, tomando-se em cada posição cinco leituras e calculando-se os seus valores médios.

Para visualização dos resultados obtidos, foram elaborados os gráficos de mapeamento de campo nas posições horizontal e vertical. Próximo às extremidades do campo, o intervalo de varredura da câmara de ionização foi reduzido para valores entre 1 e $5 \mathrm{~mm}$ da borda, para se obter uma medida mais precisa das regiões limítrofes do campo de radiação. Este último procedimento foi adotado para o posicionamento tanto horizontal como vertical da câmara de ionização.

As Figuras 4.4 e 4.5 mostram os resultados obtidos dos procedimentos de mapeamento do campo de radiação $X$, na direção horizontal e vertical, em relação à resposta obtida no centro do feixe. 


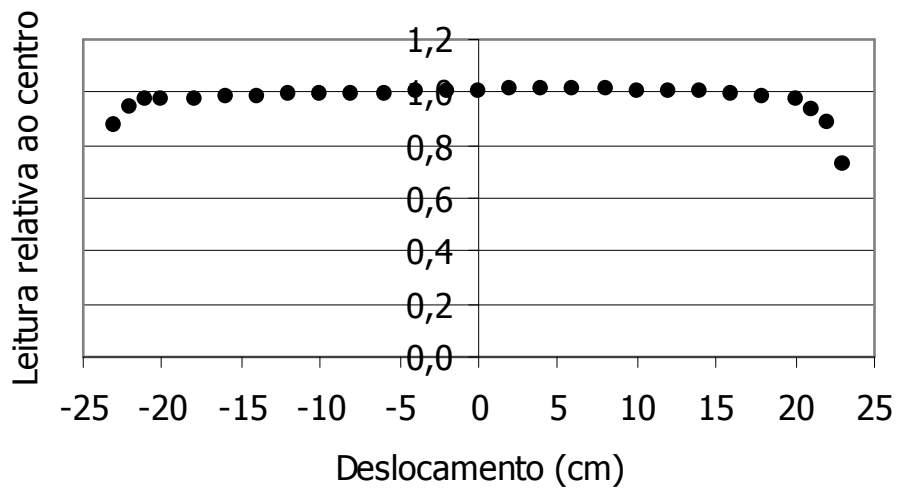

Figura 4.4. Mapeamento do campo de radiação X, na direção horizontal, utilizando a câmara de ionização PTW 31002, no sistema de radiação X Pantak/Seifert (tensão de $60 \mathrm{kV}$, corrente de $30 \mathrm{~mA}$ e sem filtração adicional, a 2,5 m de distância do foco do tubo de raios $\mathrm{X}$ ao detector).

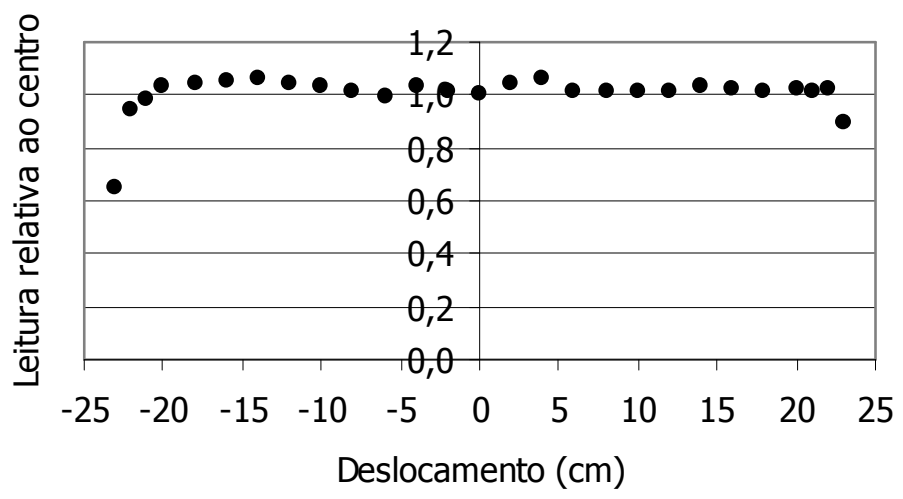

Figura 4.5. Mapeamento do campo de radiação $X$, na direção vertical, utilizando a câmara de ionização PTW 31002, no sistema de radiação X Pantak/Seifert (tensão de 60 kV, corrente de $30 \mathrm{~mA}$ e sem filtração adicional, a 2,5 m de distância do foco do tubo de raios $\mathrm{X}$ ao detector).

O limite do campo de radiação é definido pela posição em que a resposta obtida pelo detector de radiação vale cerca de $95 \%$ do valor medido no centro do campo $^{(16,62)}$. Desse modo, o tamanho do campo foi obtido com $42,2 \mathrm{~cm}$ na direção horizontal e de $42,5 \mathrm{~cm}$ na direção vertical. 
As qualidades de feixes de radiação $\mathrm{X}$, nível radioproteção, foram obtidas com filtração adicional de alumínio, cobre e estanho de alta pureza, ou seja , com pureza de $99,99 \%$, conforme recomendado pela norma ISO 4037-1 ${ }^{(16)}$.

As camadas semi-redutoras (CSR) foram determinadas com a câmara de ionização PTW 31003, com volume sensível de $0,3 \mathrm{~cm}^{3}$ posicionada a $1 \mathrm{~m}$ do foco do tubo de raios $X$, conforme recomendação da norma ${ }^{(16)}$. Foram utilizados filtros de cobre, com pureza de 99,99\%.

Para reduzir a influência da radiação espalhada, utilizou-se um colimador com abertura relativamente pequena, com cerca de $17 \mathrm{~mm}$ de diâmetro. A escolha da câmara de ionização PTW 31003, que possui dimensões pequenas, recaiu no fato de que todo o volume sensível dela deve ser completamente irradiado pelo campo de radiação durante as medidas a serem realizadas.

Para a calibração de instrumentos e das câmaras de ionização desenvolvidas neste trabalho, os campos de radiação foram estabelecidos a uma distância de 2,5 m do foco do tubo de raios X. Assim, o tamanho do campo de radiação a essa distância, delimitado por um colimador com 70,5 mm de diâmetro, é suficientemente grande para permitir a irradiação de toda a face frontal das câmaras de ionização desenvolvidas ( $300 \mathrm{~mm}$ x $300 \mathrm{~mm}$ ) e dos equipamentos a serem calibrados pelo LCI do IPEN. O diâmetro útil total do campo é de cerca de 42,2 cm, valor verificado por meio do mapeamento horizontal e vertical, sendo o valor limitante aquele obtido no mapeamento horizontal $(42,2 \mathrm{~cm})$ em relação ao vertical que é maior $(42,5 \mathrm{~cm})$.

Considerando que a medida diagonal máxima das câmaras de ionização desenvolvidas neste trabalho não ultrapassam $42,0 \mathrm{~cm}$, o campo de radiação estabelecido é suficiente para a utilização neste trabalho e ainda para a calibração de instrumentos com volumes sensíveis com dimensões da mesma ordem de grandeza, ou seja $42,0 \mathrm{~cm}$ de diâmetro. 
As CSRs dos feixes de radiação $\mathrm{X}$ implantados também foram determinadas à distância de 2,5 m do foco do tubo de raios $\mathrm{X}$, ou seja, onde as câmaras de ionização desenvolvidas e os equipamentos medidores de radiação serão posicionados para calibração (posição de calibração). Para estas medidas, utilizou-se um colimador de chumbo com $70,5 \mathrm{~mm}$ de diâmetro e a câmara de ionização de referência (PTW 32002-A), com volume sensível de 1 litro, tendo em vista que a câmara de ionização PTW 31003, devido ao seu pequeno volume sensível, não é recomendada para medidas de taxas de kerma no ar, nível radioproteção, pois não consegue acumular carga suficiente, num tempo de medida relativamente curto, inviabilizando sua utilização para este fim. Os tempos de irradiação longos causam superaquecimento do gerador de raios $\mathrm{X}$ e instabilidade no sistema.

As taxas de kerma no ar foram também medidas a 2,5 $\mathrm{m}$ de distância do foco do tubo de raios $X$, na posição de calibração, com a utilização da câmara de ionização padrão, PTW 32002-A (1 litro) e empregando-se o colimador de chumbo de $70,5 \mathrm{~mm}$ de diâmetro, que delimita o campo de radiação com diâmetro total de cerca de $42,2 \mathrm{~cm}$.

Para obtenção dos valores de CSRs e das taxas de kerma no ar, das qualidades implantadas, foi realizada (para cada valor medido) uma série de 10 medidas consecutivas de carga acumulada durante 1 minuto. Ao final do ensaio foi calculado o valor médio para cada uma destas medidas.

Para o ensaio da determinação das camadas semi-redutoras procedeu-se ao recomendado pela norma ISO 4037-1 ${ }^{(16)}$, ou seja, a câmara de ionização de referência (PTW 31002, tipo dedal) foi posicionada a $1 \mathrm{~m}$ de distância do foco do tubo de raios $X$, com uma tensão de $60 \mathrm{kV}$ e corrente de $1 \mathrm{~mA}$; desse modo, foram colocados materiais atenuadores (filtros de cobre de alta pureza, cerca de 99,99\%), com diversas espessuras, entre o feixe de raios $X$ e a câmara de ionização; $a$ intensidade do feixe de radiação foi atenuado por um fator de 2 (reduzido à metade para $1^{\mathrm{a}}$ CSR, e a um quarto para $\left.2^{\mathrm{a}} \mathrm{CSR}\right)$. 
De modo análogo, o processo foi repetido à distância de $2,5 \mathrm{~m}$, que corresponde à posição onde as câmaras de ionização desenvolvidas neste trabalho foram calibradas e os equipamentos do LCI serão calibrados posteriormente.

As qualidades de feixes de radiação $X$, nível radioproteção, conforme recomendado pela norma ISO $4037-1^{(16)}$, para espectros estreitos são mostradas na Tabela 4.1.

Tabela 4.1: Características dos feixes de radiação X, nível radioproteção, segundo a norma ISO 4037-1 ${ }^{(16)}$, para feixes estreitos. Em todos os casos foram adicionados ainda $4,0 \mathrm{~mm}$ Al à filtração de $\mathrm{Cu}$ e $\mathrm{Sn}$, perfazendo a filtração total para cada qualidade de radiação.

\begin{tabular}{|c|c|c|c|c|c|}
\hline \multirow{3}{*}{$\begin{array}{l}\text { Qualidade } \\
\text { da }\end{array}$} & & \multirow{3}{*}{$\begin{array}{l}\text { Filtração } \\
\text { Adicional }\end{array}$} & \multirow{3}{*}{$\begin{array}{l}\text { Camada } \\
\text { Semi- }\end{array}$} & \multirow{3}{*}{$\begin{array}{l}\text { Energia } \\
\text { Média }\end{array}$} & Taxas \\
\hline & \multirow[b]{2}{*}{ Tensão } & & & & Típicas de \\
\hline & & & & & Kerma no \\
\hline Radiação & & & Redutora & & $\operatorname{Ar}^{*}$ \\
\hline & (kV) & $(\mathrm{mm})$ & $(\mathrm{mm} \mathrm{Cu})$ & $(\mathrm{keV})$ & $\left(G y \cdot h^{-1}\right)$ \\
\hline $\mathrm{N}-60$ & 60 & $0,6(\mathrm{Cu})$ & 0,240 & 48 & \\
\hline $\mathrm{N}-80$ & 80 & $2,0(\mathrm{Cu})$ & 0,580 & 65 & \\
\hline $\mathrm{N}-100$ & 100 & $5,0(\mathrm{Cu})$ & 1,11 & 83 & $10^{-3}$ a $10^{-2}$ \\
\hline$N-150$ & 150 & $2,5(\mathrm{Sn})$ & 2,36 & 118 & \\
\hline
\end{tabular}

As características dos feixes de radioproteção implantados no LCI, com as respectivas camadas semi-redutoras determinadas às distâncias de $1 \mathrm{~m}$ e 2,5 m, estão apresentadas na Tabela 4.2. Estas qualidades de feixes estão baseadas na norma ISO 4037-1 ${ }^{(16)}$, conforme recomendado pela IAEA em sua publicação Safety Report Series $16^{(62)}$. 
Tabela 4.2: Características dos feixes de radiação X, nível radioproteção, implantados no LCI / IPEN. Em todos os casos foram adicionados ainda 4,0 mm Al à filtração de $\mathrm{Cu}$, perfazendo a filtração total para cada qualidade de radiação.

\begin{tabular}{|c|c|c|c|c|c|c|}
\hline \multirow{3}{*}{$\begin{array}{c}\text { Qualidade } \\
\text { da }\end{array}$} & & \multirow{3}{*}{$\begin{array}{l}\text { Filtração } \\
\text { Adicional }\end{array}$} & Camada & \multirow{2}{*}{$\begin{array}{l}\text { Camada } \\
\text { Semi - }\end{array}$} & \multirow{2}{*}{$\begin{array}{c}\text { Taxa de } \\
\text { Kerma }\end{array}$} & \multirow{3}{*}{$\begin{array}{c}\text { Taxa de } \\
\text { Kerma } \\
\text { no } \text { Ar* }^{* *}\end{array}$} \\
\hline & \multirow[b]{2}{*}{ Tensão } & & Semi - & & & \\
\hline & & & Redutora & Redutora & no $\operatorname{Ar}^{*}$ & \\
\hline Radiação & & & $\mathrm{d}=1,0 \mathrm{~m}$ & $\mathrm{~d}=2,5 \mathrm{~m}$ & $\mathrm{~d}=1,0 \mathrm{~m}$ & $\mathrm{~d}=2,5 \mathrm{~m}$ \\
\hline & $(\mathrm{kV})$ & $(\mathrm{mm} \mathrm{Cu})$ & $(\mathrm{mm} \mathrm{Cu})$ & $(\mathrm{mm} \mathrm{Cu})$ & $\left(G y \cdot h^{-1}\right)$ & $\left(G y \cdot h^{-1}\right)$ \\
\hline $\mathrm{N}-60$ & 60 & $0,60(\mathrm{Cu})$ & 0,247 & 0,250 & $6,20 \mathrm{E}-03$ & $1,99 \mathrm{E}-02$ \\
\hline $\mathrm{N}-80$ & 80 & $2,0(\mathrm{Cu})$ & 0,597 & 0,612 & $3,29 \mathrm{E}-03$ & $1,05 \mathrm{E}-02$ \\
\hline $\mathrm{N}-100$ & 100 & $5,0(\mathrm{Cu})$ & 1,10 & 1,14 & 1,57E-03 & $5,01 E-03$ \\
\hline $\mathrm{N}-150$ & 150 & $2,5(\mathrm{Sn})$ & 2,32 & 2,40 & $1,30 \mathrm{E}-02$ & $4,15 \mathrm{E}-02$ \\
\hline
\end{tabular}

*Taxa de kerma no ar medida à distância de $1,0 \mathrm{~m}$ do ponto focal, com uma corrente no tubo de raios $\mathrm{X}$ de $1,0 \mathrm{~mA}$.

** Taxa de kerma no ar medida à distância de 2,5 $\mathrm{m}$ do ponto focal, com uma corrente no tubo de raios $X$ de $20 \mathrm{~mA}$.

Os valores de camadas semi-redutoras dos feixes de radiação $\mathrm{X}$ implantados e apresentados na Tabela 4.2, para distâncias de $1 \mathrm{~m}$ mostram uma pequena variação em relação aos valores recomendados pela norma ISO 4037-1 ${ }^{(16)}$, conforme observado na Tabela 4.1. Desse modo, pode-se verificar que nas camadas semiredutoras determinadas a $1 \mathrm{~m}$ do ponto focal, a maior variação obtida foi no caso da qualidade $\mathrm{N}-60$, que apresentou uma diferença de $0,0074 \mathrm{~mm} \mathrm{Cu}(3,1 \%)$, e nas CSRs determinadas a 2,5 m de distância, a maior variação foi na qualidade $\mathrm{N}-80$, que apresentou uma diferença de 0,032 $\mathrm{mm} \mathrm{Cu}(4,9 \%)$. As diferenças obtidas nas medidas das CSRs das qualidades implantadas estão dentro dos valores recomendados pela norma ISO $4037-1^{(16)}$, ou seja, uma variação nas medidas dos valores das CSRs de até $5 \%$ são admissíveis, podendo os feixes implantados ser utilizados para fins de calibração de instrumentos. 
Os coeficientes de homogeneidade das qualidades de radiação $\mathrm{X}$ implantadas no LCI foram obtidos por meio da razão entre as medidas da $1^{\underline{a}}$ CSR e da $2^{\underline{a}}$ CSR, para as distâncias de $1,0 \mathrm{~m}$ e 2,5 m. Os valores dos coeficientes de homogeneidade obtidos são mostrados na Tabela 4.3.

Tabela 4.3: Parâmetros dos feixes de radiação X, nível radioproteção, implantados no LCI / IPEN, para distâncias foco-detector de 1,0 e 2,5 m.

\begin{tabular}{|c|c|c|c|c|c|c|}
\hline \multirow{3}{*}{$\begin{array}{l}\text { Qualidade } \\
\qquad \text { da }\end{array}$} & \multicolumn{3}{|c|}{$\begin{array}{l}\text { Distância foco-detector } \\
\qquad \mathrm{d}=1,0 \mathrm{~m}\end{array}$} & \multicolumn{3}{|c|}{$\begin{array}{l}\text { Distância foco-detector } \\
\qquad \mathrm{d}=2,5 \mathrm{~m}\end{array}$} \\
\hline & $1^{\mathrm{a}}$ & $2^{\underline{a}}$ & & $1^{\mathrm{a}}$ & $2^{\mathrm{a}}$ & \\
\hline & Camada & Camada & Coeficiente & Camada & Camada & Coeficiente \\
\hline \multirow[t]{3}{*}{ Radiação } & Semi- & Semi- & de & Semi- & Semi- & de \\
\hline & Redutora & Redutora & Homogeneidade & Redutora & Redutora & Homogeneidade \\
\hline & $(\mathrm{mm} \mathrm{Cu})$ & $(\mathrm{mm} \mathrm{Cu})$ & & $(\mathrm{mm} \mathrm{Cu})$ & $(\mathrm{mm} \mathrm{Cu})$ & \\
\hline $\mathrm{N}-60$ & 0,25 & 0,27 & 0,92 & 0,25 & 0,28 & 0,88 \\
\hline $\mathrm{N}-80$ & 0,60 & 0,62 & 0,96 & 0,61 & 0,65 & 0,94 \\
\hline $\mathrm{N}-100$ & 1,1 & 1,2 & 0,94 & 1,1 & 1,2 & 0,95 \\
\hline$N-150$ & 2,3 & 2,4 & 0,97 & 2,4 & 2,5 & 0,95 \\
\hline
\end{tabular}

Antes dos procedimentos de medida das CSRs e das taxas de kerma no ar, as câmaras de ionização utilizadas foram testadas. Testes de estabilidade a curto prazo foram realizados com as câmaras de ionização PTW 32002-B e 23361. Neste ensaio obtém-se 10 medidas consecutivas de carga acumulada durante 1 minuto, gerada pela irradiação de uma fonte de controle $\left({ }^{90} \mathrm{Sr}+{ }^{90} \mathrm{Y}\right)$, com atividade nominal de $33 \mathrm{MBq}$ (data referência 1988), colocada em um suporte apropriado (permite geometria fixa entre fonte e detector), para que as condições de medida possam ser as mais reprodutíveis possíveis. Uma pré-irradiação de cerca de 15 minutos antecede a série de medidas, o que permite uma estabilização mais rápida da câmara de ionização ensaiada.

Para os ensaios de estabilidade a curto prazo, as câmaras de ionização atenderam ao recomendado pela norma IEC $60731^{(80)}$, ou seja, segundo esta norma, uma variação nas medidas realizadas por uma câmara de ionização de até $\pm 0,5 \%$ é 
admissível. A câmara de ionização PTW 32002-B apresentou uma variação máxima de 0,068 \% e a câmara PTW 23361 de 0,028 \%.

Após a implantação dos feixes de radiação $X$ de energias intermediárias, nível radioproteção da ISO 4037-1 ${ }^{(16)}$, foram obtidos os coeficientes de calibração das câmaras de ionização utilizadas, conforme mostrado na Tabela 4.4, para a distância foco-detector de $2,5 \mathrm{~m}$.

Tabela 4.4: Coeficientes de calibração das câmaras de ionização utilizadas na caracterização dos feixes de radiação $X$, nível radioproteção, segundo a norma ISO 4037-1 ${ }^{(16)}$, para feixes estreitos, implantados no LCI, para distância foco-detector de 2,5 m.

\begin{tabular}{|c|c|c|c|c|}
\hline \multirow{2}{*}{$\begin{array}{l}\text { Qualidade } \\
\text { da }\end{array}$} & \multicolumn{2}{|c|}{$\begin{array}{l}\text { Coeficiente de Calibração } \\
\qquad\left(\times 10^{4} \mathrm{~Gy} / \mathrm{C}\right)\end{array}$} & \multicolumn{2}{|c|}{$\begin{array}{c}\text { Resposta Normalizada para a } \\
\text { Qualidade N-60 }\end{array}$} \\
\hline & Câmara & Câmara & Câmara & Câmara \\
\hline Radiação & PTW 32002-B & PTW 23361 & PTW 32002-B & PTW 23361 \\
\hline $\mathrm{N}-60$ & 2,40 & 86,10 & 1,00 & 1,00 \\
\hline $\mathrm{N}-80$ & 2,43 & 88,80 & 1,01 & 1,03 \\
\hline $\mathrm{N}-100$ & 2,46 & 90,01 & 1,03 & 1,05 \\
\hline $\mathrm{N}-150$ & 2,44 & 87,80 & 1,02 & 1,02 \\
\hline
\end{tabular}

As incertezas expandidas na determinação das medidas dos coeficientes de calibração são da ordem de 3,4\%. A maior contribuição para esta incerteza foi a incerteza do certificado de calibração da câmara de ionização padrão (PTW 32002-A), que foi de $\pm 3 \%$. 


\section{PROJETO E CONSTRUÇÃO DAS CÂMARAS DE IONIZAÇÃO}

Neste capítulo serão apresentados os detalhes do projeto de construção das câmaras de ionização de placas paralelas especificamente desenvolvidas para este trabalho, com o objetivo de medir o Equivalente de Dose Pessoal Hp (10) e para verificação da constância dos feixes de radiação $X$, para níveis de radioproteção.

\section{1 - Considerações preliminares}

Inicialmente foram confeccionados os desenhos técnicos, tanto das câmaras de ionização como do objeto simulador (phantom) do tronco humano; em seguida foi feita uma verificação junto aos mercados nacional e internacional para a determinação dos materiais a serem utilizados (tipo de material, pureza, dimensões, facilidade de manuseio, entre outros).

No caso das câmaras de ionização, a maior dificuldade encontrada foi na escolha dos materiais que seriam empregados nos eletrodos coletores, como grafite e alumínio de pequena espessura. Outro ponto crítico foi a obtenção do material da janela das câmaras de ionização que, devido a sua pequena espessura, necessitou de métodos alternativos para a sua confecção, por não serem encontrados no mercado nacional materiais com as dimensões necessárias (espessura de cerca de $40 \mu \mathrm{m}$ ); no exterior, materiais como grafite (com pequena espessura) somente são encontrados sob encomenda, porém com um custo ${ }^{2}$ muito alto.

\footnotetext{
${ }^{2}$ Uma folha com grafite depositado em uma folha de acetato com dimensões de $10 \mathrm{~cm} \times 10 \mathrm{~cm}$ custa cerca de $€ 1.400$, conforme orçamento fornecido pela Firma GoodFellow, Inglaterra.
} 
Devido a este custo alto do material importado, foram procuradas junto ao mercado nacional outras formas de confecção das janelas das câmaras de ionização, empregando materiais como tintas líquidas eletrocondutivas com grafite, para aplicação em superfícies de diferentes materiais; e tinta do tipo spray (com grafite), que foi aplicada no processo. Foram encontradas algumas tintas líquidas da marca Acheson, denominadas Aquadag e Eletrodag, que utilizam diferentes tipos de solventes, como água no caso da primeira e um solvente especial (cuja fórmula é de propriedade da empresa) para a tinta Eletrodag; para uma outra tinta em aerossol chamada Aerodag G da mesma empresa, o solvente é o álcool isopropílico.

Após este levantamento foi realizada uma análise do comportamento de cada uma das tintas, como tempo de secagem, homogeneidade do grafite, resistência elétrica e aderência ao PMMA (polimetil-metacrilato), empregado na confecção do corpo das câmaras de ionização. Ao final dos testes, verificou-se que a tinta Aerodag G foi a tinta que apresentou maior aderência às placas de PMMA e melhor homogeneidade; assim, foi tomada a decisão de se utilizar esta tinta no processo de confecção das janelas das câmaras de ionização desenvolvidas neste trabalho.

Os desenhos técnicos do projeto das câmaras de ionização foram revisados para sua adequação aos novos materiais a serem utilizados, levando-se em conta a fixação das câmaras no simulador.

Alguns processos foram desenvolvidos e/ou aplicados para a confecção das janelas das câmaras de ionização. Para uma maior aderência da tinta aerossol de grafite (Aerodag $\mathrm{G}$ ), as placas de PMMA sofreram um processo de limpeza com detergentes e lavagens com água; logo após, foi realizada a secagem em estufa por 15 minutos a $35{ }^{\circ} \mathrm{C}$ (para secagem das placas de PMMA). Antes da aplicação da tinta, a placa ainda foi lixada, para que a superfície ficasse menos lisa, permitindo maior aderência da tinta. 
Para permitir uma maior homogeneidade da tinta de grafite na superfície da placa de PMMA, foi aplicado o "método do tornete"13, que consiste em uma plataforma giratória onde a placa a ser pintada (PMMA) é fixada e girada com velocidade constante durante a aplicação da tinta. Este procedimento permitiu uma maior cobertura de área com a tinta, com uma homogeneidade maior do que aquela que seria obtida pelo espalhamento natural (escoamento) da tinta na superfície da placa, mantendo uma espessura de tinta homogênea. Este procedimento evita ainda a formação de gotículas de tinta, que são dispersas pelo sistema em rotação. A Figura 5.1 mostra o sistema utilizado e as etapas de pintura anterior (a) e posterior (b).

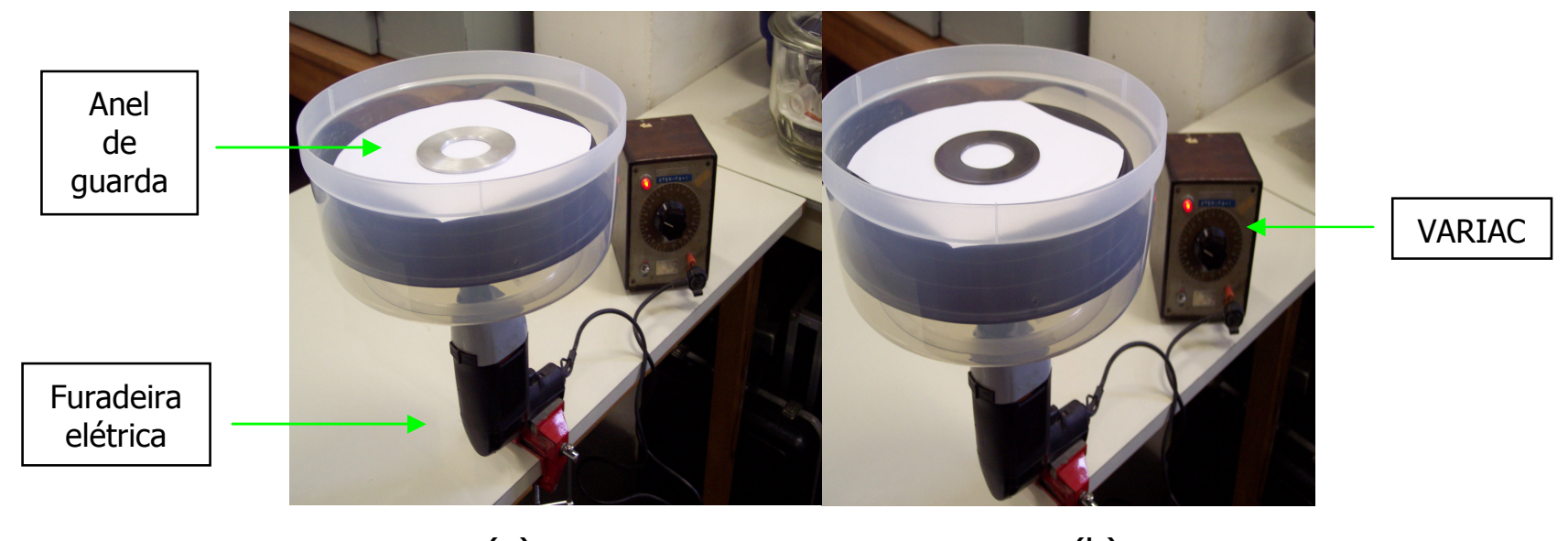

(a)

(b)

Figura 5.1. Anel de guarda da câmara de ionização fixado no centro do sistema de homogenização de pintura ("método do tornete"), momentos antes de receber a camada de tinta spray com grafite (a), e após receber uma camada de pintura (b). O controle de velocidade é realizado por meio de um reostato, adequado para uso em tensão alternada (VARIAC), acoplado a uma furadeira elétrica comercial.

Após receber a camada de pintura, o anel de guarda fica com o aspecto mostrado na Figura 5.1. (b), em seguida o anel de guarda foi levado para a secagem dentro da estufa, por cerca de 15 minutos em temperatura em torno de $30^{\circ} \mathrm{C}$. $\mathrm{O}$ processo de secagem é importante para a fixação da pintura no material.

\footnotetext{
${ }^{3}$ Método utilizado para homogenização de pintura em superfícies lisas e com aderência baixa, como
} 
Em seguida serão apresentados os detalhes construtivos do desenvolvimento do projeto e montagem das câmaras de ionização e do objeto simulador, abordando itens como: materiais empregados, dimensões, entre outros.

\section{2 - Detalhes do projeto de construção das câmaras de ionização e sua montagem dentro do simulador de tronco humano.}

As câmaras de ionização de placas paralelas desenvolvidas neste trabalho utilizam dois eletrodos planos e paralelos, separados apenas por alguns milímetros de ar. Este tipo de câmara foi projetada para ser utilizada com a janela de entrada de frente para a fonte de radiação e de modo perpendicular ao eixo do feixe incidente. As câmaras de placas paralelas são normalmente caracterizadas pelos seguintes detalhes construtivos ${ }^{(22-24,79)}$ :

- $\quad$ O volume de ar é uma região pequena em forma circular (ou de moeda) logo acima do eletrodo interno. A superfície da janela de entrada é condutora elétrica e constitui o eletrodo externo. O eletrodo interno é um disco circular condutor elétrico montado no corpo isolante da câmara (PMMA). O volume sensível é aquela fração do volume de ar total através da qual passam as linhas de força elétrica entre os eletrodos interno e externo.

- $\quad$ Os eletrodos interno e externo são montados em um bloco de material (denominado corpo da câmara) ao qual os cabos de ligação elétrica da câmara são fixados. Os cabos de ligação elétrica normalmente saem do corpo da câmara em uma direção paralela à janela de entrada.

- $\quad$ O volume sensível é tipicamente uma fração de um centímetro cúbico, para feixes de raios $X$ terapêuticos. Para feixes de raios- $X$, diagnóstico convencional, são adequados volumes de alguns centímetros cúbicos, e para feixes de raios-X, nível radioproteção, são adequados volumes de vários centímetros cúbicos.

metais, vidros e plásticos. O método é empregado na confeç̧ão de mostradores de relógios. 
- $\quad$ O potencial de polarização é aplicado ao eletrodo externo e o sinal elétrico ou de carga é coletado pelo eletrodo interno.

- Um terceiro eletrodo, denominado anel de guarda, que circunda o eletrodo interno, é mantido no mesmo potencial que o eletrodo interno e conserva as linhas de campo uniformes, eliminando qualquer sinal de espalhamento indesejável, isto é, ele define melhor o volume sensível de ar.

A Figura 5.2 mostra um esquema da câmara de ionização de placas paralelas para medida do equivalente de dose pessoal, $\mathrm{Hp} \mathrm{(10).}$

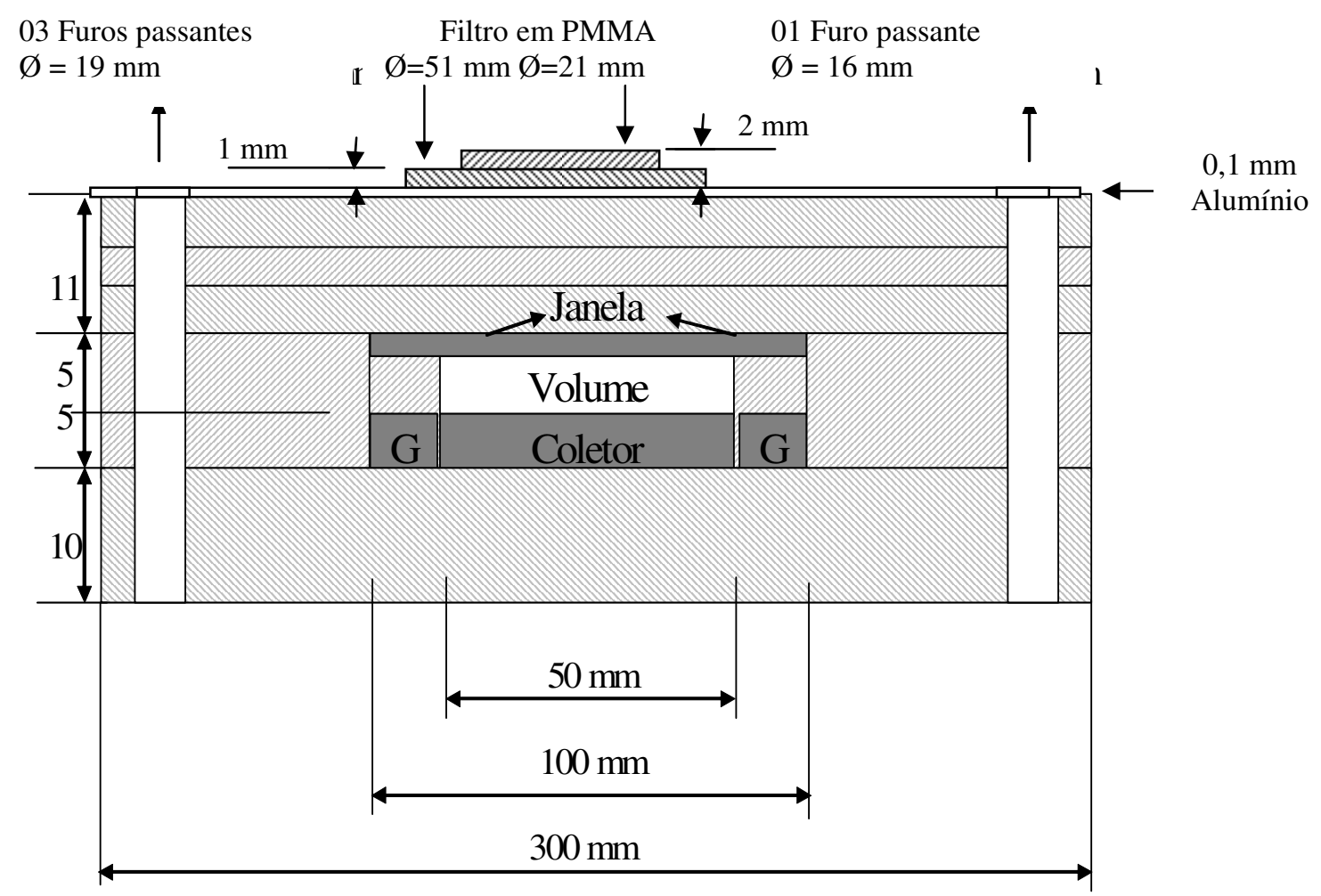

Figura 5.2. Câmara de ionização de placas paralelas, volume sensível de $10 \mathrm{~cm}^{3}$, eletrodo coletor e anel de guarda com espessura de $5 \mathrm{~mm}$ e janela com 0,04 mm de espessura, no meio de placas de PMMA. As áreas achuradas representam as placas de PMMA; a letra G representa o anel de guarda. 
Foram utilizados grafite e alumínio para a construção dos eletrodos internos e anéis de guarda das câmaras de ionização desenvolvidas neste trabalho. Para a confecção do corpo da câmara e para o isolamento entre os eletrodos internos e os anéis de guarda foram utilizadas placas de PMMA, assim como para a confecção do objeto simulador de tronco humano.

Na parte frontal das câmaras de ionização desenvolvidas, à frente do volume ativo das câmaras, foi adicionado um filtro consistindo de duas camadas de PMMA em formato cilíndrico, com diâmetros de $51 \mathrm{~mm}$ e $21 \mathrm{~mm}$ e respectivas espessuras, cada uma de $2 \mathrm{~mm}$. Completando ainda este sistema de filtros, foi colocada uma placa de alumínio (espessura de 0,1 mm) cobrindo toda a face frontal de cada uma das câmaras de ionização, com um furo centralizado com $51 \mathrm{~mm}$ de diâmetro, onde foram posicionados os dois discos de PMMA de 21 e $51 \mathrm{~mm}$ de diâmetro. A geometria e as características dos materiais empregados neste conjunto de filtros foram otimizadas para a obtenção de uma resposta da câmara de ionização quase constante com relação ao $\mathrm{H}_{\mathrm{P}}(10)$ para ângulos de incidência da radiação em relação à face frontal da câmara de ionização, para ângulos de até $75^{\circ}$ e para energias de radiação no intervalo de $10 \mathrm{keV}$ a $1400 \mathrm{keV}$. Em princípio, a resposta constante da câmara de ionização para medidas de $\mathrm{H}_{\mathrm{P}}(10)$ deve ser a mesma para as diferentes qualidades de radiação. Porém, na prática, devido a diferenças no espectro de fótons, isto não ocorre, ou seja, para qualidades de radiação diferentes, ou ainda, para qualidades de radiação geradas por sistemas de raios $X$ diferentes podem ocorrer diferenças nas medidas realizadas pelas câmaras de ionização. Pode também ocorrer uma dependência pequena da resposta das câmaras de ionização, com o ângulo da radiação incidente ${ }^{(41-44)}$.

A primeira câmara de ionização foi projetada para utilização em feixes de raios $X$ de qualidades de radioproteção, onde os seus eletrodos internos possuem $2 \mathrm{~mm}$ de espessura e $50 \mathrm{~mm}$ de diâmetro e foram confeccionados em discos de grafite sólidos. $O$ anel de guarda tem espessura de $2 \mathrm{~mm}$ e diâmetro externo de $100 \mathrm{~mm}$. As janelas de entrada têm espessura de cerca de 0,04 mm e diâmetros a de 
$100 \mathrm{~mm}$, confeccionadas por meio do processo de pintura e deposição de grafite, com material cedido gentilmente pela empresa Acheson Produtos Químicos Ltda., Cotia, São Paulo, como já descrito no item 5.1. A distância entre os eletrodos internos e externos é de $5 \mathrm{~mm}$. $O$ volume sensível é de $10 \mathrm{~cm}^{3}$. Este volume é adequado para a medida de feixes de raios $\mathrm{X}$ nas qualidades de radioproteção ${ }^{(16)}$.

Uma segunda câmara de ionização foi construída, também para utilização em feixes de raios $X$, nível radioproteção; esta câmara foi desenvolvida de modo análogo à anterior, com as mesmas dimensões dos eletrodos (internos e externos) e volume, porém com eletrodos internos em alumínio, para formação, de um sistema Tandem de câmaras de ionização, quando utilizada com a câmara de ionização com eletrodos internos de grafite.

As câmaras de ionização desenvolvidas neste trabalho, devido às suas características operacionais e físicas (peso de $\pm 18 \mathrm{~kg}$, dimensões de $300 \mathrm{~mm} x$ $300 \mathrm{~mm} \times 150 \mathrm{~mm}$ ), são adequadas para utilização como sistemas de trabalho ou de referência para medida em equipamentos de radiação $X$ e gama, em laboratórios de calibração de instrumentos, podendo ser empregadas em intercomparações interlaboratoriais. Na Figura 5.2 vê-se um esquema somente das câmaras de ionização de placas paralelas para medida do equivalente de dose pessoal, $\mathrm{H}_{\mathrm{P}}(10)$; elas devem ser posicionadas à frente de um objeto simulador para a realização das medidas para determinação do $H_{P}(10)$. As Figuras 5.3 e 5.4 mostram o objeto simulador ao qual as câmaras de ionização são acopladas.

As duas câmaras de ionização foram montadas cada uma adjacente a um simulador de tronco humano.

Na confecção do simulador não houve grandes dificuldades, pois o material utilizado foi somente o PMMA. Devido a sua densidade ser próxima à do tecido humano, alguns simuladores são confeccionados com material sólido, ou maciço (PMMA, água sólida, entre outros), outros são preenchidos com água. Neste trabalho o simulador foi confeccionado em fatias (placas) de PMMA sobrepostas. 
Para a confeç̧ão do simulador, no projeto inicial havia se optado pela colagem das placas para constituir um bloco maciço (compacto), porém pelo fato das propriedades químicas e físicas das colas não serem bem conhecidas, principalmente quando submetidas a campos de radiação, realizou-se uma nova avaliação do projeto inicial e algumas alterações foram realizadas.

Assim, quatro furos nos extremos das placas de cada objeto simulador permitem a colocação de barras cilíndricas (tarugos) de PMMA, de modo a deixá-las encaixadas e superpostas e permanecendo bem juntas umas às outras. Este formato permite ainda que o simulador, quando necessário, seja desmontado, conforme mostrado na Figura 5.3.

A Figura 5.4 mostra uma vista em perspectiva o objeto simulador de tronco humano.

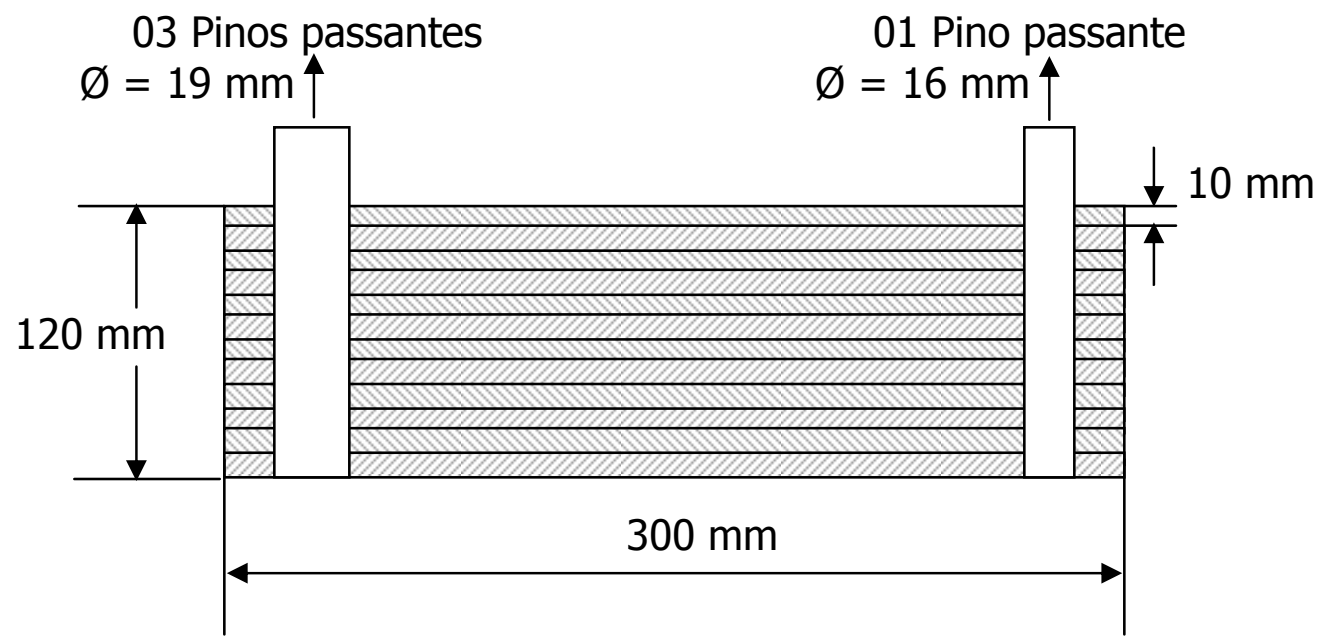

Figura 5.3. Conjunto simulador de tronco humano confeccionado com 12 placas de PMMA justapostas, com $10 \mathrm{~mm}$ de espessura cada uma e pinos de PMMA que dão sustentação ao conjunto, além de servirem como guia para a colocação das placas. A parte achurada representa as placas de PMMA e a parte branca os pinos de PMMA. 


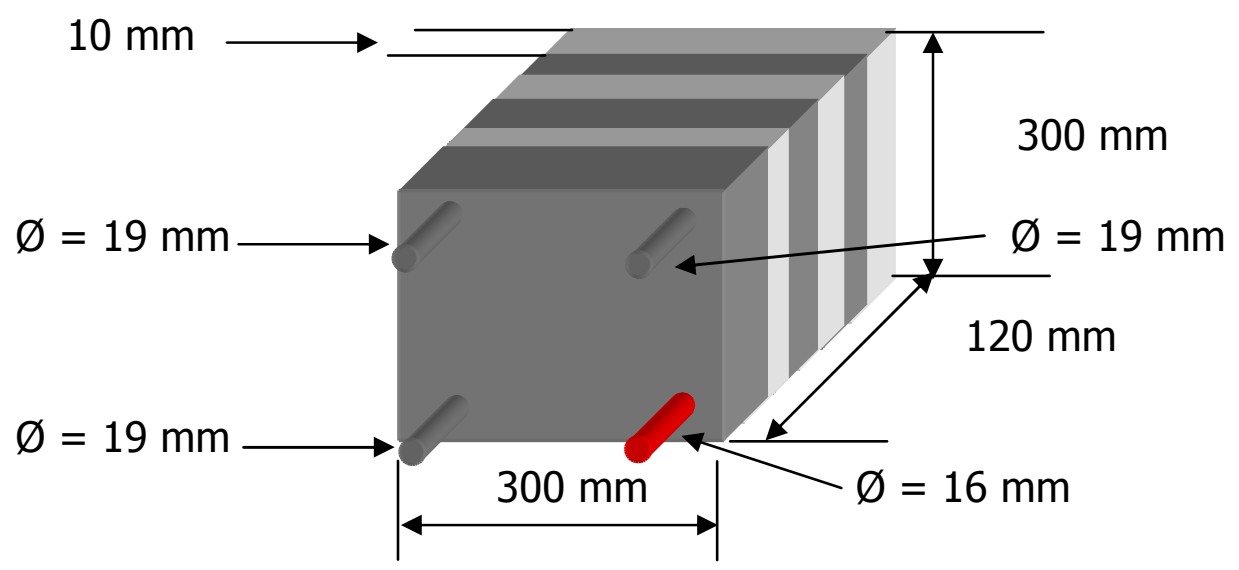

Figura 5.4. Conjunto objeto simulador de tronco humano multicamadas, em perspectiva, confeccionado com placas de PMMA.

A barra de cor vermelha representa um tubo de PMMA de dimensões diferentes das demais barras, de modo a possibilitar que a montagem do simulador seja realizada com as placas sempre na mesma posição, garantindo a reprodutibilidade de geometria do sistema. A Figura 5.5 mostra a câmara de ionização de placas paralelas com eletrodo coletor de grafite.

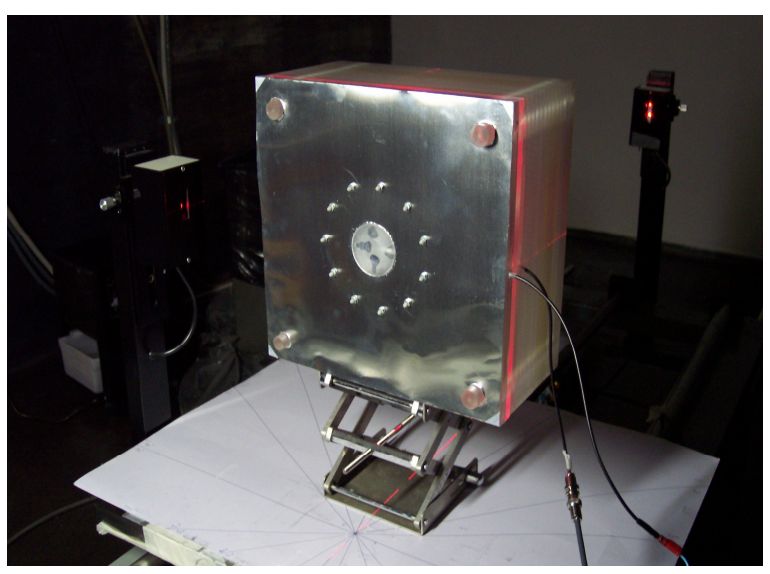

Figura 5.5. Câmara de ionização de placas paralelas, acoplado no objeto simulador de tronco humano (confeccionado com PMMA, com dimensões de $300 \mathrm{~mm} \times 300 \mathrm{~mm} \times 120 \mathrm{~mm}$ ) para a medida do equivalente de dose pessoal $\mathrm{Hp}(10)$, com eletrodo coletor de grafite; em destaque estão os 04 pinos de referência (salientes no painel frontal), que permitem manter o alinhamento das placas do simulador com as placas da câmara de ionização. 
A Figura 5.6 mostra a câmara de ionização de placas paralelas com eletrodo coletor de alumínio.

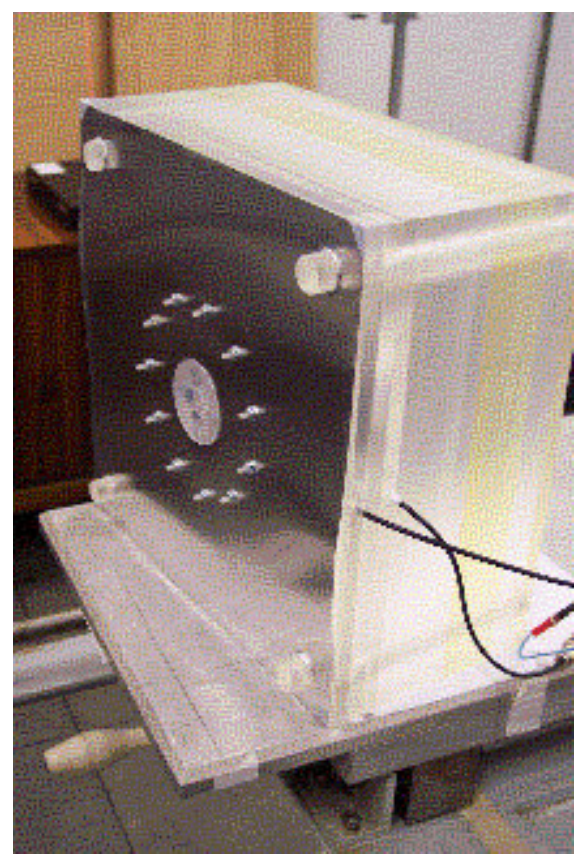

Figura 5.6. Câmara de ionização de placas paralelas, com eletrodo coletor de alumínio, inserida em um simulador de tronco humano (confeccionado com PMMA, com dimensões de 300 mm x 300 mm x 120 mm).

Para a realização de ensaios com as câmaras de ionização em campos de radiação provenientes de fontes radioativas de ${ }^{137} \mathrm{Cs}$ e ${ }^{60} \mathrm{Co}$ não foi necessária a utilização de uma capa de equilíbrio eletrônico, pois a janela de entrada da radiação e os outros eletrodos da câmara estão internos (dentro do bloco simulador de tronco), inclusive a janela. Assim, existe uma espessura de $13 \mathrm{~mm}$ de PMMA, entre o feixe de radiação gama incidente e a janela de entrada da câmara, conforme mostrado na Figura 5.2; a partir de uma espessura de $3 \mathrm{~mm}$ de espessura de PMMA na frente do medidor de radiação, é possível obter-se equilíbrio eletrônico, para fontes radioativas de ${ }^{137} \mathrm{Cs}^{(16,62)}$ e cerca de $4 \mathrm{~mm}$ de espessura para fontes de ${ }^{60} \mathrm{Co}$. Desta forma, os 13 mm de PMMA das câmaras de ionização desenvolvidas são suficientes para a ocorrência de equilíbrio eletrônico. 


\section{3 - Estimativa de custo na confecção das câmaras de ionização dentro dos simuladores de tronco humano.}

Para um levantamento do custo da confecção das câmaras de ionização de eletrodos coletores de grafite e alumínio desenvolvidas neste trabalho foram enumerados os materiais empregados, assim como as etapas realizadas, inclusive a etapa referente à mão-de-obra necessária para o manuseio e adequação dos materiais (montagem, ajustes, solda elétrica dos conectores, entre outros).

Os materiais utilizados na elaboração das câmaras de ionização foram basicamente 02 (duas) placas de PMMA, tendo sido adquiridas uma placa com dimensões de $2 \mathrm{~m} \times 1 \mathrm{~m}$ e outra placa com dimensões de 1,5 m x $1 \mathrm{~m}$, ambas com $10 \mathrm{~mm}$ de espessura, de material incolor. $\mathrm{O}$ custo total das placas foi $\mathrm{R} \$ 845,00$. Este tipo de material é facilmente encontrado no mercado nacional (Macedo Plásticos Ind. Com. Ltda). O material foi utilizado para a confecção do corpo das câmaras de ionização, e ainda dos objetos simuladores de troco humano.

A escolha dos materiais utilizados na confecção dos eletrodos coletores das câmaras de ionização exigiu uma pesquisa no mercado nacional e internacional. Os eletrodos coletores e os anéis de guarda de grafite foram adquiridos de uma empresa nacional especializada na comercialização e manufatura de peças em grafite, que exigem máquinas especiais no manuseio destes materiais, ou seja, são utilizadas máquinas com blindagem contra o pó de grafite liberado (altamente impregnante e lubrificante); desse modo, foram confeccionados um anel de guarda e um eletrodo coletor com $100 \mathrm{~mm}$ de diâmetro e $50 \mathrm{~mm}$, respectivamente, ambos com espessura de $2 \mathrm{~mm}$. A espessura de $2 \mathrm{~mm}$ foi escolhida pois era a menor espessura encontrada no mercado para a confecção do anel de guarda e eletrodo coletor. O custo total destas peças foi de $R \$ 200,00$. O eletrodo coletor e o anel de guarda de alumínio foram adquiridos por cerca de $R \$ 8,00$; este custo baixo deve-se ao fato deste tipo de material ser facilmente encontrado no mercado nacional, não exigindo nenhum tratamento ou manuseio especial como no caso do grafite. As janelas das câmaras de 
ionização foram confeccionadas em grafite, que por causa de sua pequena espessura $(0,04 \mathrm{~mm})$ foram obtidas por meio de camadas sobrepostas de tinta com grafite. Para a confecção das janelas das câmaras de ionização foi empregada uma tinta com grafite em spray (Aerodag G, da marca Acheson Ind.Com. Ltda.), cujo custo do tubo de tinta foi de $\mathrm{R} \$ 60,00$.

Os cabos e conectores foram escolhidos levando-se em conta a qualidade, a funcionabilidade e o baixo custo. Desse modo, os conectores são do tipo coaxial (tipo $B N C$, fêmea para cabo) pelo preço de $R \$ 15,00$ cada (foram utilizadas 02 unidades), e ainda dois conectores do tipo pino banana miniatura, com banho dourado, que permite menor oxidação e resistência de contato (02 unidades empregadas). 0 custo dos pinos bananas foi de $R \$ 4,00$. O cabo coaxial utilizado foi o do tipo RG 174, empregado em sistemas que operam com sinais elétricos pequenos (baixas correntes: $\mathrm{nA}, \mathrm{pA}$, entre outras). Foram utilizados cerca de $2 \mathrm{~m}$ deste cabo a um custo de $R \$ 2,00$.

Foram ainda empregados outros materiais, como para a limpeza das placas (retirada de poeira, gordura, entre outras), e ainda para a fixação das partes e peças das câmaras de ionização (eletrodos coletores, anéis de guarda, placas do simulador de tronco humano, cabos, entre outros). Nesta etapa utilizou-se detergente de cozinha (01 frasco), cola para acrílico (100 g), cola adesiva incolor (tipo Super Bonder, $10 \mathrm{~g})$, sabão saponáceo em pó $(50 \mathrm{~g})$, álcool isopropílico $(100 \mathrm{ml})$, estanho para ferro elétrico (solda, $2 \mathrm{~g}$ ), parafusos confeccionados em nylon, porcas e arruelas (foram empregados 22 unidades de cada). 0 custo total destes materiais utilizados foi de $R \$ 36,00$.

A mão de obra para a confecção das placas (desenhos técnicos do projeto das câmaras de ionização, corte, furos, serviços de fresa) consumiu um total de $83 \mathrm{~h}$. $\mathrm{Na}$ fase posterior foi realizada a limpeza das placas, secagem e pintura das janelas de grafite das câmaras de ionização (09 h). 
$\mathrm{Na}$ fase final do processo foram realizados pequenos ajustes mecânicos nas placas de PMMA, solda dos fios elétricos nos conectores, colagem dos eletrodos coletores e anéis de guarda, montagem final de todo conjunto (câmaras de ionização acoplados aos objetos simuladores de tronco humano) e ajustes finais. Nesta fase final foi empregada uma quantidade total de $99 \mathrm{~h}$. Considerando que o custo médio de mão de obra especializada no mercado é cerca de $R \$ 50,00$ por hora, o custo desta etapa foi de $(99 \mathrm{~h} \times \mathrm{R} \$ 50,00 /$ hora $) \mathrm{R} \$ 4.950,00$. O custo total para a confecção das câmaras de ionização com eletrodos coletores de grafite e alumínio, considerando o custo do material utilizado e mão de obra, foi de $R \$ 6.149,00$. Assim, o custo de confecção de cada câmara de ionização foi de cerca de $R \$ 3.075,00$. A Tabela 5.1 mostra de forma detalhada o custo de confecção das câmaras de ionização com eletrodos coletores de grafite e alumínio e ainda do simulador de tronco humano, confeccionado em PMMA.

Tabela 5.1. Detalhamento da estimativa de custo de confecção das câmaras de ionização com eletrodos coletores de grafite e alumínio, e do simulador de tronco humano, confeccionado em PMMA.

\begin{tabular}{lc}
\hline \multicolumn{1}{c}{ Item } & Custo \\
& $(\mathrm{R} \$)$ \\
\hline Placas de PMMA (02 placas com $2 \mathrm{~m} \times 1 \mathrm{~m}$ ) & 845,00 \\
Cabo coaxial RG 174 (2 m) & 2,00 \\
Conector pino banana miniatura (02 peças) & 4,00 \\
Conector BNC fêmea para cabo (02 peças) & 30,00 \\
Anel de guarda e eletrodo coletor de grafite (01 peça de cada) & 200,00 \\
Anel de guarda e eletrodo coletor de alumínio(01 peça de cada) & 8,00 \\
Placa de alumínio (02 placas, com 300 mm x 300 mm x 0,1 mm) & 6,00 \\
Parafuso de nylon (22 peças, com 1/8"de diâmetro) & 6,00 \\
Porcas e arruelas de ferro (22 peças, com 1/8"de diâmetro) & 2,00 \\
Tinta aerossol de grafite & 60,00 \\
Detergente (500 ml), saponáceo em pó (50 g), álcool isopropílico (100 ml) & 10,00 \\
Cola para acrílico (100 g) & 10,00 \\
Adesivo transparente rápido (10 g) & 15,00 \\
Fio de estanho para ferro elétrico de soldar (2 g) & 1,00 \\
Mão de obra total (do projeto à montagem final) & $4.950,00$ \\
\hline Custo total da confecção das 02 câmaras de ionização & $6.149,00$ \\
\hline Custo total por câmara de ionização & $3.075,00$ \\
\hline
\end{tabular}


Lenvando-se em conta que somente o custo de confecção das janelas de grafite das câmaras de ionização, conforme visto no item 5.1 (£1.400 cada janela de grafite com espessura de $0,04 \mathrm{~mm}$ ) é alto, e ainda é realizado somente no exterior (Inglaterra), em comparação com o custo da tinta de grafite empregada neste trabalho que é encontrada no mercado nacional por cerca de $R \$ 60,00$, torna viável a confecção destas câmaras de ionização, com um custo otimizado e com materiais encontrados no mercado nacional. Outro ponto importante foi a escolha de conectores do tipo BNC no lugar dos tradicionais conectores triaxiais utilizados, e ainda o uso de cabos triaxiais que são encontrados no exterior com um custo alto (os conectores triaxiais mais simples custam cerca de US\$50,00, cada um). Desse modo, pode-se afirmar que a relação custo-beneficio na confeç̧ão das câmaras de ionização é adequado. 


\section{CARACTERIZAÇÃO DAS CÂMARAS DE IONIZAÇÃO EM FEIXES DE RADIAÇÃO, NÍVEL RADIOPROTEÇÃO}

Os sistemas compostos pelas câmaras de ionização desenvolvidas acopladas a seus eletrômetros, para utilização em procedimentos de dosimetria de feixes de radioproteção, foram testados de acordo com as especificações da International Electrotechnical Commission ${ }^{(80,81)}$. Os resultados dos ensaios são apresentados a seguir.

\section{1 - Saturação, eficiência de coleção de íons e efeitos de polaridade}

As câmaras de ionização de placas paralelas foram inicialmente estudadas com relação as suas características de saturação, eficiência de coleção de íons e efeitos de polaridade seguindo-se os procedimentos recomendados por normas internacionais $^{(80,81)}$ e propostos por alguns autores ${ }^{(79,83)}$.

Quando uma câmara de ionização está sujeita a um campo de radiação, a corrente de ionização medida inicialmente aumenta com a tensão aplicada e então ela se estabiliza. O aumento inicial da corrente de ionização com a tensão é causado pela coleção de íons incompleta em tensões baixas. Os íons positivos e negativos tendem a se recombinar, a menos que eles sejam rapidamente separados pelo campo elétrico. Esta recombinação pode ser minimizada pelo aumento do campo elétrico.

Se a tensão é aumentada para um valor muito acima da tensão em que ocorre a saturação, os íons, acelerados pelo campo elétrico, podem ganhar energia 
suficiente para produzir ionização por colisão com as moléculas do gás. Isto resultará numa rápida multiplicação de íons, e a corrente, novamente, torna-se fortemente dependente da tensão aplicada. A câmara deve ser utilizada na região de saturação, de modo que pequenas mudanças na tensão não resultem em alterações e mudanças na corrente ${ }^{(80,81,83)}$.

Seguindo estas recomendações, as duas câmaras foram irradiadas tomandose como referência os centros de seus volumes sensíveis, com a janela de entrada perpendicular ao feixe de radiação incidente, com uma qualidade de radiação $X$, nível radioproteção, ISO N-60, tensão de $60 \mathrm{kV}$, corrente $45 \mathrm{~mA}$ e uma taxa de kerma no ar de $746,2 \mu \mathrm{Gy} / \mathrm{min}$, variando-se a tensão de polarização aplicada entre $-400 \mathrm{~V}$ e $+400 \mathrm{~V}$, em intervalos de 50V. Com os valores obtidos deste ensaio foram obtidas as curvas de saturação para cada uma das câmaras de ionização, as quais são apresentadas nas Figuras 6.1 e 6.2. As correntes de ionização medidas representam valores médios de dez leituras para cada caso. As incertezas nas medidas das correntes de ionização foram sempre menores que $0,6 \%$. 


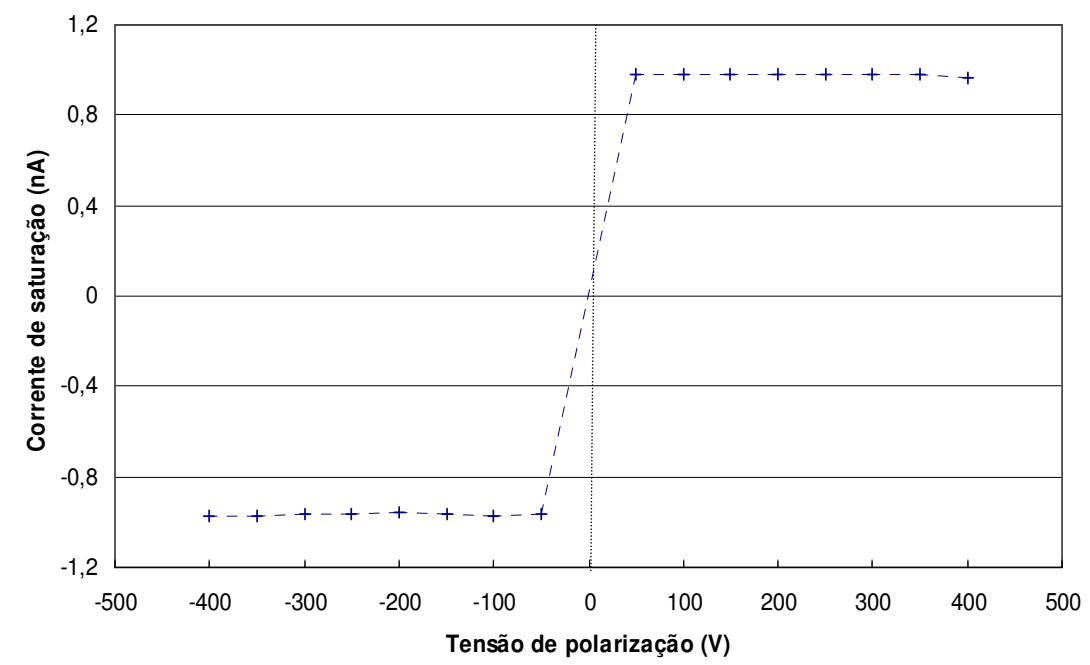

Figura 6.1. Curva de saturação da câmara de ionização com eletrodo coletor de alumínio. Qualidade de radiação X, ISO N-60, tensão 60 kV e corrente de 45 mA, distância foco-câmara de 2,5 m.

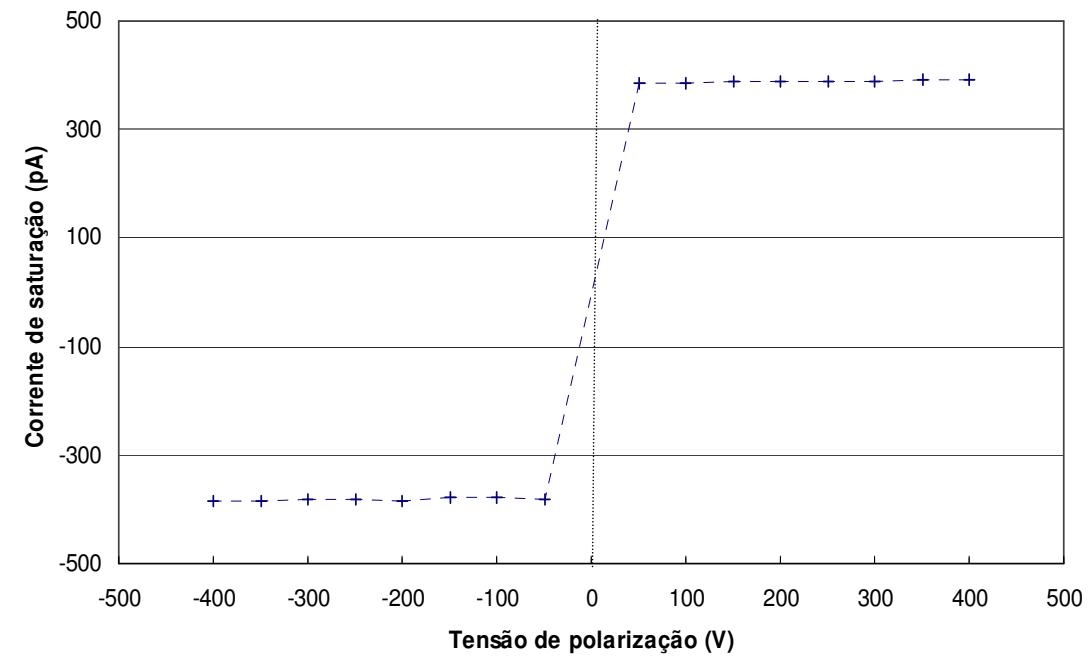

Figura 6.2. Curva de saturação da câmara de ionização com eletrodo coletor de grafite. Qualidade de radiação X, ISO N-60, tensão 60 kV e corrente de 45 mA, distância foco-câmara de 2,5 m.

Pode-se verificar que as câmaras apresentaram o comportamento esperado, com a saturação atingida logo acima de $50 \mathrm{~V}$. Desse modo, os resultados mostram que a utilização destas câmaras pode ser feita conectando-as aos tipos mais comuns 
de eletrômetros, que geralmente possuem tensões para polarização das câmaras superiores a 50 V. No eletrômetro utilizado com estas câmaras de ionização, a tensão de operação máxima é de $400 \mathrm{~V}$.

Algumas vezes, para uma dada exposição, a carga coletada por uma câmara de ionização muda em intensidade quando a polaridade da tensão é invertida. 0 efeito de polaridade para uma qualidade de raios-X (neste caso foi utilizada a qualidade ISO N-60, nível radioproteção, vide Tabela 4.2), com os valores máximos permitidos de tensão de polarização positiva e negativa, deve ser menor que 1\%; caso contrário, devem ser determinados fatores de correção com uma incerteza associada menor que $1 \%{ }^{(80,81)}$. Isto significa que a razão entre as cargas coletadas positiva e negativa, com os valores máximos de tensão de polarização positiva e negativa, em função da qualidade da radiação incidente deve estar entre 0,99 e 1,01. As Tabelas 6.1 e 6.2 mostram os valores obtidos para este ensaio para as duas câmaras, aplicando-se uma tensão de polarização de $+400 \mathrm{~V}$ até $-400 \mathrm{~V}$, com intervalos de incremento de tensão de $50 \mathrm{~V}$.

Todos os resultados obtidos mantiveram-se dentro do intervalo recomendado, exceto para as tensões de $+150 \mathrm{~V}$ e $-150 \mathrm{~V}$, e de $+200 \mathrm{~V}$ e $200 \mathrm{~V}$ no caso da câmara de eletrodo coletor de alumínio, e nas tensões de $+150 \mathrm{~V}$ e $-150 \mathrm{~V}$, e de $+250 \mathrm{~V}$ e $-250 \mathrm{~V}$, no caso da câmara com eletrodo coletor de grafite, porém sendo que estes valores de tensão de polarização não serão utilizados. As medidas realizadas estão dentro dos padrões recomendados.

Na região de saturação, o efeito de polaridade é menor que $1 \%$ para ambas as câmaras de ionização. Tomando-se os valores médios obtidos pelas câmaras, verifica-se que a câmara com eletrodo de alumínio é cerca de 2,5 vezes mais sensível que a câmara com eletrodos de grafite. A tensão de $+400 \mathrm{~V}$ (tensão positiva) foi utilizada como tensão de polarização para a câmara de ionização com eletrodo coletor de grafite, assim como para a câmara de ionização com eletrodo coletor de 
alumínio, uma vez que é praticamente inexistente, para este valor de tensão de polarização, a probabilidade de ocorrência do efeito de recombinação de íons.

O efeito de recombinação de íons tem sua maior probabilidade de ocorrência com tensões de polarização baixas, ou seja, com tensões próximas à tensão de início da curva de saturação (onde, para valores de tensões de polarização baixas, o campo elétrico formado entre os eletrodos das câmaras é mais fraco, permitindo que o efeito de recombinação iônica seja maior).

Tabela 6.1. Efeito de polaridade da câmara de ionização com eletrodo coletor de alumínio.

\begin{tabular}{ccc}
\hline $\begin{array}{c}\text { Tensão de Polarização } \\
(\mathrm{V})\end{array}$ & $\begin{array}{c}\text { Carga } \\
(\mathrm{pC})\end{array}$ & $\begin{array}{c}\text { Razão } \\
(\mathrm{Q}+/ \mathrm{Q}-)\end{array}$ \\
\hline$+50 /-50$ & $982,20 / 973,00$ & 1,01 \\
$+100 /-100$ & $983,90 / 970,90$ & 1,01 \\
$+150 /-150$ & $983,90 / 964,40$ & 1,02 \\
$+200 /-200$ & $982,20 / 959,55$ & 1,02 \\
$+250 /-250$ & $982,20 / 968,73$ & 1,01 \\
$+300 /-300$ & $982,20 / 972,57$ & 1,01 \\
$+350 /-350$ & $981,70 / 977,10$ & 1,00 \\
$+400 /-400$ & $965,30 / 976,50$ & 0,99
\end{tabular}

Q+ = carga coletada com aplicação de tensão de polarização positiva na câmara de ionização Q- = carga coletada com aplicação de tensão de polarização negativa na câmara de ionização 
Tabela 6.2. Efeito de polaridade da câmara de ionização com eletrodo coletor de grafite.

\begin{tabular}{ccc}
\hline $\begin{array}{c}\text { Tensão de Polarização } \\
(\mathrm{V})\end{array}$ & $\begin{array}{c}\text { Carga } \\
(\mathrm{pC})\end{array}$ & $\begin{array}{c}\text { Razão } \\
(\mathrm{Q}+\text { / Q- })\end{array}$ \\
\hline$+50 /-50$ & $386,01 / 380,93$ & 1,01 \\
$+100 /-100$ & $386,33 / 381,50$ & 1,01 \\
$+150 /-150$ & $387,63 / 379,36$ & 1,02 \\
$+200 /-200$ & $387,64 / 383,81$ & 1,01 \\
$+250 /-250$ & $389,37 / 380,08$ & 1,02 \\
$+300 /-300$ & $388,94 / 383,27$ & 1,01 \\
$+350 /-350$ & $389,00 / 383,85$ & 1,01 \\
$+400 /-400$ & $389,50 / 384,50$ & 1,01
\end{tabular}

Q+ = carga coletada com aplicação de tensão de polarização positiva na câmara de ionização Q- = carga coletada com aplicação de tensão de polarização negativa na câmara de ionização

Como visto anteriormente, o campo máximo que pode ser aplicado à câmara de ionização é limitado pelo início do processo de ionização por colisão. Dependendo do projeto da câmara e da intensidade da ionização, certa quantidade de perda de íons por recombinação pode ser esperada. Para uma intensidade de ionização muito alta, como pode acontecer no caso de feixes pulsados, perdas significativas de carga podem ocorrer por recombinação, até mesmo nas tensões máximas possíveis de serem aplicadas à câmara. Sob estas condições, devem ser aplicadas correções para perdas por recombinação.

A eficiência de coleção de íons definida como a razão entre o número de íons coletados e o número de íons produzidos, pode ser determinada por meio de cálculo ${ }^{(78,84,85)}$ ou experimentalmente, por meio de um gráfico do inverso da corrente de ionização medida (1/I) em função do quadrado da tensão de polarização $\left(1 / \mathrm{V}^{2}\right)$. A corrente de saturação desejável é então determinada extrapolando-se a curva para a tensão de polarização infinita $\left(1 / \mathrm{V}^{2}=0\right)$. No entanto, não é recomendável que a eficiência de coleção de íons de uma câmara de ionização de placas paralelas 
utilizada para raios $\mathrm{X}$ de energias baixas seja medida variando-se a tensão de polarização.

A recombinação normalmente é desprezível e as mudanças na tensão de polarização geralmente distorcem a janela, resultando em variações na resposta da câmara que excedem qualquer efeito de recombinação ${ }^{(78)}$. A tensão na câmara, sempre que possível, deve ser ajustada para se obter menos de $1 \%$ de perdas, ou seja, eficiência de coleção de íons melhor que $99 \%{ }^{(80)}$.

A partir dos valores obtidos nos ensaios de saturação, foram feitos os cálculos da eficiência de coleta de íons para cada uma das câmaras. Foram utilizados os valores de $200 \mathrm{~V}$ e $400 \mathrm{~V}$, positivos e negativos, para este cálculo, para cada câmara de ionização. A eficiência de coleção de íons $K_{s}$ foi determinada pelo método das duas tensões usando-se a relação ${ }^{(78)}$ :

$$
K_{s}=\left[\left(\frac{V_{1}}{V_{2}}\right)-1\right] /\left[\left(\frac{V_{1}}{V_{2}}\right)^{2}-\left(\frac{M_{1}}{M_{2}}\right)\right]
$$

onde :

$\mathrm{K}_{\mathrm{s}}=$ eficiência de coleta de íons

$M_{1}$ e $M_{2}=$ leituras às tensões $V_{1}$ e $V_{2}$

$\bigvee_{1}$ e $\bigvee_{2}=$ tensões de polarização

$\mathrm{V}_{1} / \mathrm{V}_{2}=2$

Os valores obtidos estão apresentados na Tabela 6.3. Como a eficiência de coleta de íons deve ser melhor que $99 \%(78,80,81)$, as duas câmaras de ionização atenderam ao recomendado. As eficiências para a câmara com eletrodo de grafite ficaram em torno de $100 \%$, lembrando que existe uma incerteza nas leituras devida ao próprio instrumento de medida, no caso o eletrômetro, em torno de $0,3 \%$. 
Tabela 6.3. Eficiência de coleta de íons das duas câmaras de ionização para a qualidade de radiação ISO N-60 (raios X, nível radioproteção).

Câmara de Ionização com

Eletrodo Coletor

de

Alumínio

Grafite
Eficiência de Coleta de Íons

Tensão de Polarização

Negativa

\begin{tabular}{ccc}
\hline Alumínio & 0,9942 & 1,0066 \\
Grafite & 1,0045 & 1,0001 \\
\hline
\end{tabular}

As variações nas leituras obtidas dos ensaios realizados para as curvas de saturação não superaram $1 \%$ para aplicação de tensões de polarização positivas e negativas nas câmaras de ionização no intervalo de $+400 \mathrm{~V}$ até $-400 \mathrm{~V}$, com variações de 50 V. Com relação ao efeito de polaridade, as câmaras ensaiadas atenderam ao recomendado pela norma, ou seja, os valores obtidos ficaram entre 0,99 e 1,01. O mesmo ocorreu com o ensaio de recombinação iônica. Os ensaios atenderam ao recomendado pela norma IEC $60731^{(80)}$. A eficiência de coleção é melhor que $99 \%$ em + 400V para as câmaras de ionização, isto é, as perdas por recombinação iônica são menores que 1 \%.

\section{2 - Variação da resposta com o tamanho do campo}

Para o estudo da variação da resposta das câmaras desenvolvidas em função do tamanho do campo foram utilizados campos de radiação com três diâmetros diferentes. As câmaras foram irradiadas na qualidade de radiação $X$, nível radioproteção, ISO N-60, espectro estreito, norma ISO 4037-1 ${ }^{(16)}$, variando-se 0 diâmetro do colimador de chumbo que delimita o tamanho do campo.

Para este processo de medidas, utilizou-se a qualidade de radiação de $60 \mathrm{kV}$ e 45 mA (ISO N-60) como radiação de referência para a qualidade de radioproteção. Este ensaio permitiu verificar o comportamento, ou a variação da resposta das câmaras desenvolvidas neste trabalho, em campos de radiação de tamanhos diferentes, sendo que a condição necessária para a medida do equivalente de dose 
pessoal é que todo o conjunto câmara + objeto simulador seja irradiado. Esta condição somente ocorre quando o colimador de diâmetro de $70,5 \mathrm{~mm}$ é utilizado. Para os demais colimadores somente a área da câmara é totalmente irradiada e o simulador não tem toda sua superfície frontal irradiada.

Na Tabela 6.4 são apresentadas as dimensões dos campos de radiação em função do tamanho do colimador. A Tabela 6.5 mostra os resultados obtidos dos ensaios. Verifica-se que para uma redução de cerca de $27,9 \%$, no diâmetro do colimador de 70,5 a 50,8 mm, e conseqüente redução de cerca de 32,4\% no tamanho do campo de radiação (a 2,5 m), houve uma redução no valor de carga medida de apenas $1,6 \%$ para a câmara de ionização com eletrodo coletor de alumínio e de 1,2 \% para a câmara de ionização com eletrodo coletor de grafite. Para o colimador com diâmetro de $32 \mathrm{~mm}$, obteve-se uma variação nos valores das medidas de carga de 6,4 \% e 7,3 \% para as câmaras de ionização com eletrodos coletores de alumínio e grafite, respectivamente (para um diâmetro de campo de cerca de $57,3 \%$ menor).

Para o colimador de $17 \mathrm{~mm}$ de diâmetro, portanto para uma redução no tamanho do campo de radiação de $77,3 \%$, as variações na leitura de carga foram de 21,3 \% e 23,1 \% menores, para as câmaras de ionização com eletrodos coletores de alumínio e grafite, respectivamente. Desse modo, pode-se observar que o tamanho do campo de radiação afeta as medidas de carga realizadas pelas câmaras de ionização. Assim, todo o volume sensível das câmaras de ionização deve estar dentro do campo de radiação, para que as câmaras de ionização meçam corretamente a corrente elétrica (ou carga) gerada dentro dos seus volumes sensíveis. 
Tabela 6.4. Tamanho de campo útil para o ensaio de resposta relativa em função do tamanho do campo para posicionamento das câmaras de ionização desenvolvidas.
Diâmetro do Colimador
de Chumbo
do Tubo de Raios $X$
$(\mathrm{mm})$
(cm)
17,0
$9,5 \pm 1,0$
32,0
$17,9 \pm 1,5$
50,8
$28,4 \pm 2,0$
70,5
$42,0 \pm 2,0$

Diâmetro do Campo a 2,5 m do Foco

Tabela 6.5. Resposta relativa das câmaras de ionização desenvolvidas, em função do tamanho do campo para radiação $X$, nível radioproteção (ISO N-60). Distância foco-detector $=2,5 \mathrm{~m}$.

\begin{tabular}{ccccc}
\hline $\begin{array}{c}\text { Câmara } \\
\text { de } \\
\text { Ionização } \\
\text { com Eletrodo } \\
\text { de }\end{array}$ & 70,5 & 50,8 & 32,0 & $\begin{array}{c}\text { Diâmetro do Colimador } \\
(\mathrm{mm})\end{array}$ \\
\hline Alumínio & 1 & $0,984 \pm 0,030$ & $0,936 \pm 0,030$ & $0,787 \pm 0,030$ \\
Grafite & 1 & $0,988 \pm 0,030$ & $0,927 \pm 0,030$ & $0,769 \pm 0,030$ \\
\hline
\end{tabular}

\section{3 - Tempo de estabilização}

Neste ensaio, durante um período entre 15 min e $2 \mathrm{~h}$ após a aplicação da tensão de polarização às câmaras de ionização, as variações de resposta não devem ser maiores do que $\pm 0,5 \%$ da resposta medida $1 \mathrm{~h}$ após a aplicação da tensão de polarização, para o caso em que a câmara de ionização é irradiada continuamente desde o momento em que a tensão de polarização é aplicada ${ }^{(80)}$. 
As câmaras de ionização com eletrodos coletores de grafite e alumínio foram posicionadas em um campo de radiação $X$, da qualidade ISO N-60 (60 kV e 45 mA) com taxa de kerma no ar de $746,2 \mu \mathrm{Gy} / \mathrm{min}$. A resposta das câmaras neste campo de radiação foi determinada como sendo o valor médio de dez medidas consecutivas. Os resultados são mostrados nas Tabelas 6.6 e 6.7. As câmaras com eletrodos coletores de alumínio e de grafite atenderam às exigências ${ }^{(80)}$ para 0 teste de tempo de estabilização (respostas relativas entre 0,995 e 1,005)

Tabela 6.6. Tempo de estabilização: resposta relativa da câmara de ionização com eletrodo coletor de alumínio em função do tempo.

\begin{tabular}{cc}
\hline Tempo & Resposta \\
\hline 15 min & $0,995 \pm 0,029$ \\
$1 \mathrm{~h}$ & 1 \\
$2 \mathrm{~h}$ & $1,001 \pm 0,029$ \\
\hline
\end{tabular}

Tabela 6.7. Tempo de estabilização: resposta relativa da câmara de ionização com eletrodo coletor de grafite em função do tempo.

\begin{tabular}{cc}
\hline Tempo & Resposta \\
\hline 15 min & $1,004 \pm 0,031$ \\
$1 \mathrm{~h}$ & 1 \\
$2 \mathrm{~h}$ & $1,005 \pm 0,031$ \\
\hline
\end{tabular}

\section{4 - Estabilidade a curto prazo ou teste de repetitividade}

O teste de estabilidade a curto prazo, ou teste de repetitividade, representa o estudo do grau de concordância entre os resultados de medições sucessivas de um mesmo mensurando, efetuadas sob as mesmas condições de medição. A repetitividade pode ser expressa quantitativamente, em função das características de dispersão dos resultados, como por exemplo o desvio padrão percentual. Dez 
medições sucessivas foram feitas várias vezes, utilizando-se o sistema de radiação $X$, na qualidade ISO N-60 (60 kV e $45 \mathrm{~mA}$ ) e taxa de kerma no ar de 746,2 $\mu \mathrm{Gy} / \mathrm{min}$. Para todos os casos, o desvio padrão percentual mostrou-se igual ou inferior a 0,5\%, que é o valor máximo aceitável, estabelecido por norma para os instrumentos de campo $^{(80,81)}$. Desse modo, obteve-se um desvio percentual máximo nas medidas de 0,28 \% de variação para a câmara com eletrodo coletor de alumínio e igual a 0,30 \% para a câmara com eletrodo coletor de grafite.

\section{5 - Estabilidade a longo prazo}

Ainda como forma de verificar as condições de funcionamento dos sistemas de medida desenvolvidos neste trabalho, além de verificar os limites máximos de variação nas suas respostas obtidas, foram realizados os testes de rotina conhecidos como testes de estabilidade a longo prazo.

Nestes ensaios, as câmaras de ionização foram expostas a um feixe de radiação padronizado, que neste caso foi o sistema de radiação $X$, Pantak/Seifert na qualidade ISO N-60 (60 kV e $45 \mathrm{~mA}$ ) com taxa de kerma no ar de 746,2 $\mu \mathrm{Gy} / \mathrm{min}$. Recomenda-se que, antes de realizar qualquer ensaio, o sistema de medida (eletrômetro e câmara de ionização) deve ser ligado ao menos 15 minutos antes do início das medidas, para que o sistema de medida se estabilize. Em todos os testes e medidas realizadas, os sistemas foram ligados por 30 minutos antes do início das medidas, para fins de estabilização. Este procedimento somente não foi adotado quando o ensaio específico a ser realizado com as câmaras de ionização assim determinava.

Para o teste de repetitividade foi tomado o valor médio de 10 leituras consecutivas. Desse modo, cada uma destas medidas corresponde ao teste de estabilidade a curto prazo (ou teste de repetitividade). Os desvios padrões percentuais estabelecidos, pelas recomendações internacionais para instrumentos de referência e de campo utilizados em radioproteção, podem variar até $\pm 0,5$ e $\pm 1,0 \%$, respectivamente ${ }^{(61-62,80)}$. 
A realização dos testes de repetitividade periodicamente, ao longo do tempo, sempre sob as mesmas condições geométricas, constitui o teste de estabilidade a longo prazo. Esta estabilidade pode ser verificada por meio de um gráfico cronológico, onde se registra a variação das medidas obtidas periodicamente (semanalmente, mensalmente, entre outras), sendo estas medidas comparadas com um valor de referência, que é a média das 10 primeiras séries de medidas realizadas com o sistema. Do exposto, pode-se desse modo verificar a tendência das medidas obtidas com o sistema de medidas, ou seja, se estas medidas estão dentro do intervalo máximo admissível de variação, estabelecido por recomendações internacionais, conforme já mencionado ${ }^{(61-62,80)}$. Neste trabalho, o eixo X (número de medidas) corresponde a uma escala de tempo de semanas.

As Figuras 6.3 e 6.4 mostram o comportamento apresentado pelas câmaras de ionização (com eletrodos de grafite e alumínio) nos ensaios de estabilidade a longo prazo.

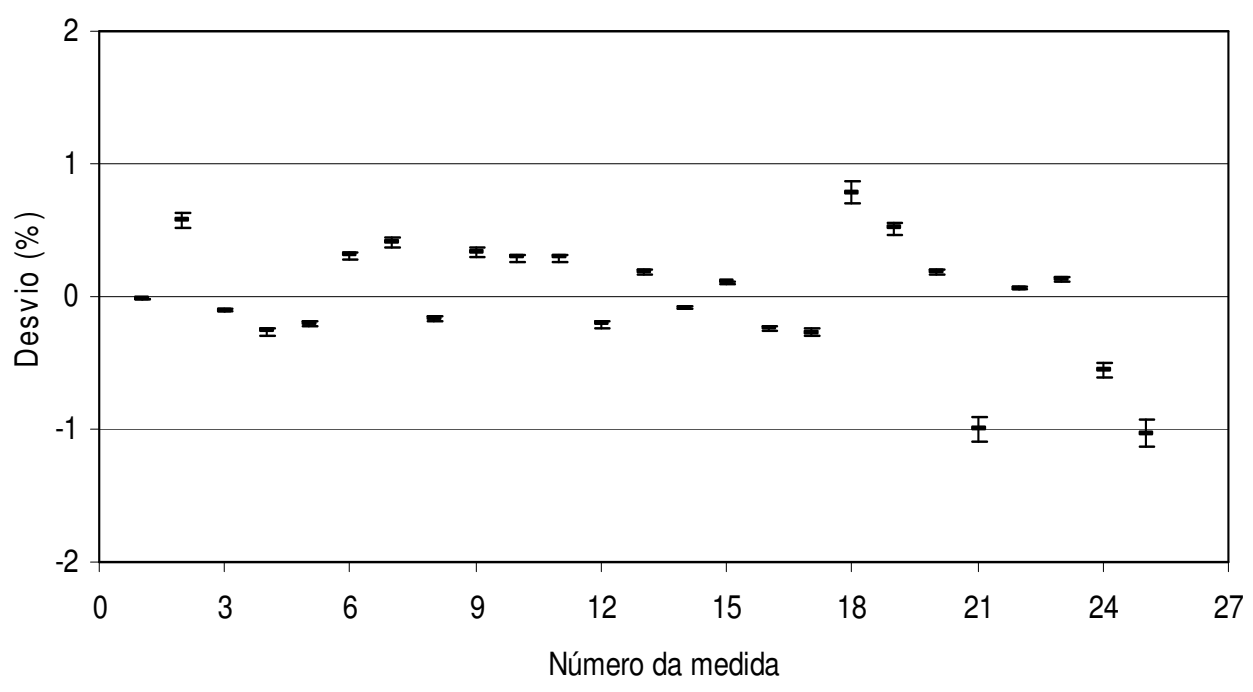

Figura 6.3. Variação da resposta da câmara de ionização com eletrodo coletor de grafite, comparada com a média ao longo de 25 medidas, do ensaio de estabilidade a longo prazo. 


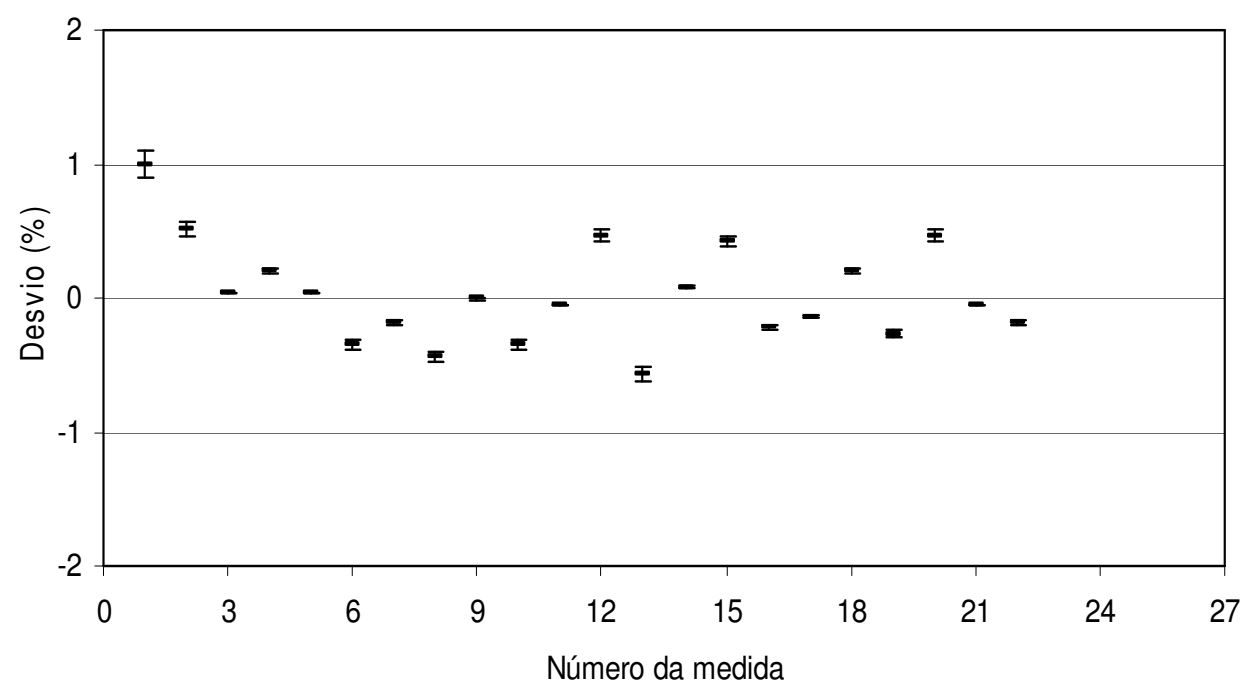

Figura 6.4. Variação da resposta da câmara de ionização com eletrodo coletor de alumínio, comparada com a média ao longo de 25 medidas, do ensaio de estabilidade a longo prazo.

Pode-se observar que as câmaras de ionização testadas apresentaram uma variação máxima nas medidas de 1,0 \%; assim, as duas câmaras de ionização atenderam ao recomendado pelos TRS $133^{(61)}$ e SRS $16^{(62)}$.

\section{6 - Corrente de fuga sem irradiação}

A corrente de fuga é definida como qualquer sinal coletado que não seja produzido pela ionização decorrente da irradiação do volume sensível da câmara. Pode ter origem no eletrômetro, no cabo, nos conectores e na própria câmara, continuando após o término da irradiação e geralmente decrescendo exponencialmente com o tempo.

A corrente de fuga de uma câmara de ionização, não exposta à radiação, mas com a tensão de polarização máxima aplicada à câmara, não deve exceder a $\pm 0,5 \%$ da corrente de ionização produzida pela taxa de kerma no ar mínima a que a câmara deva ser exposta ${ }^{(80)}$. 
Foi aplicada a tensão de polarização máxima $(+400 \mathrm{~V})$ às câmaras de ionização com eletrodos coletores de alumínio e grafite e foram medidas as correntes de fuga (sem irradiação) após $15 \mathrm{~min}, 1 \mathrm{~h}$ e $6 \mathrm{~h}$, como mostrado na Tabela 6.8. As correntes de fuga sem irradiação medidas nas câmaras de ionização não excederam a $0,4 \%$ da corrente de ionização produzida durante os ensaios. Desse modo, as duas câmaras de ionização atenderam ao recomendado pela norma IEC $60731^{(80)}$.

Tabela 6.8. Corrente de fuga ( $\mathrm{fA}$ ) sem irradiação, medida nos intervalos de tempo especificados após a aplicação de tensão de polarização de $+400 \mathrm{~V}$ às câmaras de ionização desenvolvidas.

\begin{tabular}{ccc}
\hline & \multicolumn{2}{c}{ Câmara de Ionização com Eletrodo Coletor de } \\
\cline { 2 - 3 } Tempo & $\begin{array}{c}\text { Alumínio } \\
(\mathrm{fA})\end{array}$ & $\begin{array}{c}\text { Grafite } \\
(\mathrm{fA})\end{array}$ \\
\hline 15 min & 2,0 & 2,0 \\
$1 \mathrm{~h}$ & 1,0 & 1,0 \\
$6 \mathrm{~h}$ & 1,0 & 1,0 \\
\hline
\end{tabular}

\section{7 - Corrente de fuga após irradiação}

Para este ensaio, a recomendação é que dentro de $5 \mathrm{~s}$ após o término de uma irradiação de $10 \mathrm{~min}$, a corrente de fuga transiente deve decrescer a $\pm 1,0 \%$ da corrente de ionização produzida na câmara durante a irradiação ${ }^{(80)}$.

As câmaras de ionização com eletrodos coletores de alumínio e grafite foram posicionadas em um campo de radiação $\mathrm{X}$, nível radioproteção, com tensão de $60 \mathrm{kV}$ e corrente de $45 \mathrm{~mA}$ (ISO N-60), com taxa de kerma no ar de 746,2 $\mu \mathrm{Gy} / \mathrm{min}$ por 10 minutos e medido o tempo de decréscimo da leitura, que foi de cerca de 4,8 s para a câmara com eletrodo coletor de alumínio e de 4,7 s para a câmara com eletrodo coletor de grafite. Desse modo, ambas as câmaras atenderam ao solicitado pela norma ${ }^{(80)}$. 


\section{8 - Linearidade da resposta}

Determinou-se a relação linear entre a corrente de ionização e a taxa de kerma no ar irradiando-se as câmaras, com eletrodos de grafite e de alumínio, sob as condições de referência: qualidade de raios $X$, nível radioproteção, com tensão de $60 \mathrm{kV}$ e a corrente variando de 0,5 mA até $45 \mathrm{~mA}$. Foram realizadas dez medidas sucessivas e foi tomado o valor médio para cada corrente selecionada. Nas qualidades de radiação $X$, nível radioproteção, a incerteza na linearidade de resposta foi de $\pm 2,5 \%$ para a câmara com eletrodo coletor de grafite e de $\pm 1,3 \%$ para a câmara com eletrodo coletor de alumínio.

As Figuras 6.5 e 6.6 mostram os resultados obtidos. Pode-se observar que ambas câmaras de ionização apresentaram um comportamento linear na qualidade ensaiada. Do mesmo modo, pode-se concluir que o sistema gerador de raios $\mathrm{X}$ também teve um comportamento estável e linear (corrente no tubo de raios $\mathrm{X}$ ), podendo este conjunto (gerador de raios $X$ e câmaras de ionização) ser utilizado para fins de calibração, e como sistema de referência de trabalho, no LCI e para fins deste trabalho.

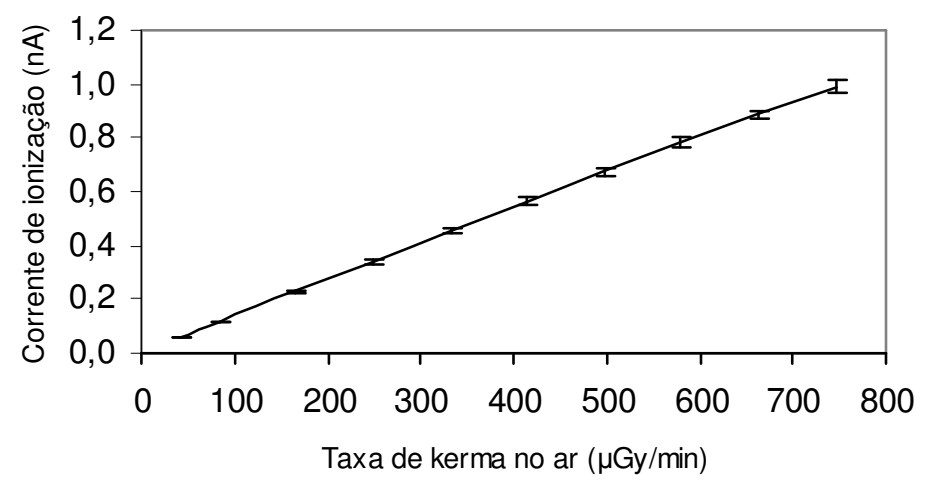

Figura 6.5. Linearidade de resposta da câmara de ionização (com eletrodo coletor de alumínio) com a corrente, para raios $X$, nível radioproteção, ISO N-60, $60 \mathrm{kV}(0,247 \mathrm{mmCu})$. 


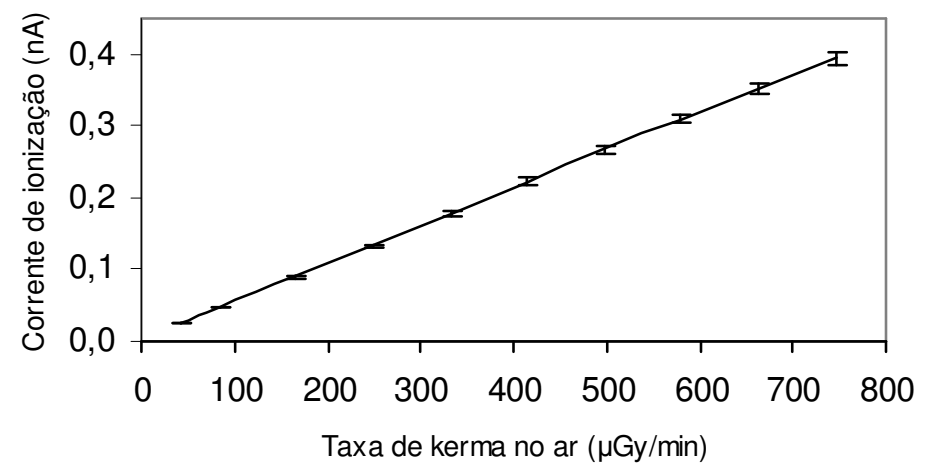

Figura 6.6. Linearidade de resposta da câmara de ionização (com eletrodo coletor de grafite) com a corente, para raios $\mathrm{X}$, nível radioproteção, ISO N-60, 60 kV $(0,247 \mathrm{mmCu})$.

\section{9 - Dependência angular}

Outros tipos de câmaras de ionização de placas paralelas foram estudadas em relação à dependência angular por Souza e col ${ }^{(32)}$ e Caldas e Albuquerque ${ }^{(27)}$. As câmaras de placas paralelas desenvolvidas neste trabalho foram projetadas para serem utilizadas com a sua janela de entrada de frente para a fonte de radiação perpendicularmente ao eixo do feixe de radiação incidente. Como na prática, no posicionamento da câmara, pode ocorrer uma pequena variação no ângulo de incidência da radiação, foi testada a dependência angular das câmaras desenvolvidas neste trabalho.

Para este ensaio foi utilizada a qualidade de radiação ISO N-60, proveniente do sistema de radiação X Pantak/Seifert, e ainda foram utilizadas as fontes radioativas de ${ }^{60} \mathrm{Co} \mathrm{e}{ }^{137} \mathrm{Cs}$ do irradiador do IPEN e STS. As distâncias foco-câmara utilizadas foram de 2,5 m, no caso do sistema de raios $X$; de 2,27 m para a fonte de ${ }^{137} \mathrm{Cs}$ e de $2,90 \mathrm{~m}$ para a fonte de ${ }^{60} \mathrm{Co}$, sendo que todos os campos tinham diâmetro de $42 \mathrm{~cm}$. A câmara foi irradiada no ar, tomando-se como referência o centro do volume sensível da câmara. A medida foi obtida variando-se o ângulo de incidência da radiação entre $0^{\circ}$ e $90^{\circ}$, girando-se a câmara no sentido horário (ângulos positivos) e anti-horário (ângulos negativos), onde $0^{\circ}$ significa irradiação frontal. 
As respostas foram normalizadas para o ângulo de $0^{\circ}$ para cada uma das qualidades e correspondem aos valores médios de dez medidas sucessivas. Pode-se observar que as câmaras com eletrodos de alumínio e grafite atendem à exigência da Norma IEC $61674^{(81)}$, ou seja, o limite de variação da resposta não deve superar $\pm 3,0 \%$ do valor obtido para posição de irradiação de $0^{\circ}$ para variações de até $\pm 5^{\circ}$. As Tabelas 6.9 a 6.12 e as Figuras 6.7 a 6.12 mostram os valores obtidos dos ensaios de dependência angular.

Tabela 6.9. Resposta relativa da câmara de ionização com eletrodo coletor de alumínio em função da inclinação e da qualidade da radiação (nível radioproteção) com o sistema Pantak/Seifert.

\begin{tabular}{ccccc}
\hline & \multicolumn{4}{c}{ Qualidade de Radiação X } \\
\cline { 2 - 5 } Ângulo de \\
\cline { 2 - 5 } Inclinação ( $\left.{ }^{\circ}\right)$ & ISO N-60 & ISO N-80 & ISO N-100 & ISO N-150 \\
\hline 0 & 1 & 1 & 1 & 1 \\
+15 & $0,990 \pm 0,008$ & $0,978 \pm 0,008$ & $0,940 \pm 0,007$ & $0,965 \pm 0,007$ \\
+45 & $0,923 \pm 0,006$ & $0,909 \pm 0,006$ & $0,909 \pm 0,006$ & $0,901 \pm 0,006$ \\
+60 & $0,840 \pm 0,005$ & $0,839 \pm 0,005$ & $0,846 \pm 0,005$ & $0,836 \pm 0,005$ \\
+90 & $0,126 \pm 0,004$ & $0,194 \pm 0,006$ & $0,280 \pm 0,006$ & $0,246 \pm 0,006$ \\
-15 & $0,972 \pm 0,008$ & $0,971 \pm 0,007$ & $0,972 \pm 0,008$ & $0,959 \pm 0,007$ \\
-45 & $0,942 \pm 0,006$ & $0,927 \pm 0,006$ & $0,924 \pm 0,006$ & $0,906 \pm 0,006$ \\
-60 & $0,845 \pm 0,005$ & $0,834 \pm 0,005$ & $0,835 \pm 0,005$ & $0,834 \pm 0,005$ \\
-90 & $0,152 \pm 0,006$ & $0,203 \pm 0,006$ & $0,255 \pm 0,006$ & $0,261 \pm 0,006$ \\
\hline
\end{tabular}


Tabela 6.10. Resposta relativa da câmara de ionização com eletrodo coletor de alumínio em função da inclinação e da qualidade da radiação, com sistema sistema irradiador STS $\left({ }^{137} \mathrm{Cs}\right)$ e sistema irradiador IPEN $\left({ }^{60} \mathrm{Co}\right)$.

\begin{tabular}{|c|c|c|}
\hline \multirow{2}{*}{$\begin{array}{c}\text { Ângulo de } \\
\text { Inclinação }\left({ }^{\circ}\right)\end{array}$} & \multicolumn{2}{|c|}{ Radiação Gama } \\
\hline & ${ }^{137} \mathrm{Cs}$ & ${ }^{60} \mathrm{Co}$ \\
\hline 0 & 1 & 1 \\
\hline+15 & $0,980 \pm 0,007$ & $0,951 \pm 0,007$ \\
\hline+45 & $0,950 \pm 0,006$ & $0,891 \pm 0,005$ \\
\hline+60 & $0,880 \pm 0,005$ & $0,830 \pm 0,005$ \\
\hline+90 & $0,402 \pm 0,007$ & $0,789 \pm 0,007$ \\
\hline-15 & $0,989 \pm 0,007$ & $0,942 \pm 0,008$ \\
\hline-45 & $0,979 \pm 0,006$ & $0,878 \pm 0,007$ \\
\hline-60 & $0,950 \pm 0,008$ & $0,835 \pm 0,008$ \\
\hline-90 & $0,413 \pm 0,007$ & $0,782 \pm 0,007$ \\
\hline
\end{tabular}

Tabela 6.11. Resposta relativa da câmara de ionização com eletrodo coletor de grafite em função da inclinação e da qualidade da radiação (nível radioproteção), com o sistema Pantak/Seifert.

\begin{tabular}{ccccc}
\hline & \multicolumn{4}{c}{ Qualidade de Radiação X } \\
\cline { 2 - 5 } Ângulo de \\
Inclinação $\left(^{\circ}\right)$ & ISO N-60 & ISO N-80 & ISO N-100 & ISO N-150 \\
\hline 0 & 1 & 1 & 1 & 1 \\
+15 & $0,920 \pm 0,007$ & $0,929 \pm 0,007$ & $0,960 \pm 0,008$ & $0,989 \pm 0,007$ \\
+45 & $0,822 \pm 0,006$ & $0,845 \pm 0,005$ & $0,880 \pm 0,006$ & $0,878 \pm 0,007$ \\
+60 & $0,740 \pm 0,007$ & $0,768 \pm 0,007$ & $0,855 \pm 0,007$ & $0,854 \pm 0,006$ \\
+90 & $0,181 \pm 0,006$ & $0,191 \pm 0,006$ & $0,250 \pm 0,006$ & $0,268 \pm 0,006$ \\
-15 & $0,939 \pm 0,007$ & $0,982 \pm 0,008$ & $0,930 \pm 0,007$ & $0,970 \pm 0,007$ \\
-45 & $0,883 \pm 0,006$ & $0,921 \pm 0,008$ & $0,909 \pm 0,007$ & $0,927 \pm 0,007$ \\
-60 & $0,782 \pm 0,007$ & $0,829 \pm 0,006$ & $0,859 \pm 0,007$ & $0,917 \pm 0,006$ \\
-90 & $0,184 \pm 0,006$ & $0,213 \pm 0,007$ & $0,271 \pm 0,006$ & $0,270 \pm 0,007$ \\
\hline
\end{tabular}


Tabela 6.12. Resposta relativa da câmara de ionização com eletrodo coletor de grafite em função da inclinação e da qualidade da radiação, com sistema irradiador STS $\left({ }^{137} \mathrm{CS}\right)$ e sistema irradiador IPEN $\left({ }^{60} \mathrm{Co}\right)$.

\begin{tabular}{ccc}
\hline $\begin{array}{c}\text { Ângulo de } \\
\text { Inclinação }\left({ }^{\circ}\right)\end{array}$ & \multicolumn{2}{c}{ Radiação Gama } \\
\cline { 2 - 3 }+15 & 1 & ${ }^{137} \mathrm{Cs}$ \\
+45 & $0,930 \pm 0,007$ & $0,915 \pm 0,006$ \\
+60 & $0,925 \pm 0,007$ & $0,809 \pm 0,006$ \\
+90 & $0,898 \pm 0,006$ & $0,775 \pm 0,007$ \\
-15 & $0,428 \pm 0,007$ & $0,750 \pm 0,007$ \\
-45 & $0,912 \pm 0,006$ & $0,920 \pm 0,006$ \\
-60 & $0,889 \pm 0,008$ & $0,791 \pm 0,007$ \\
-90 & $0,882 \pm 0,007$ & $0,765 \pm 0,008$ \\
& $0,470 \pm 0,008$ & $0,745 \pm 0,006$ \\
\hline
\end{tabular}

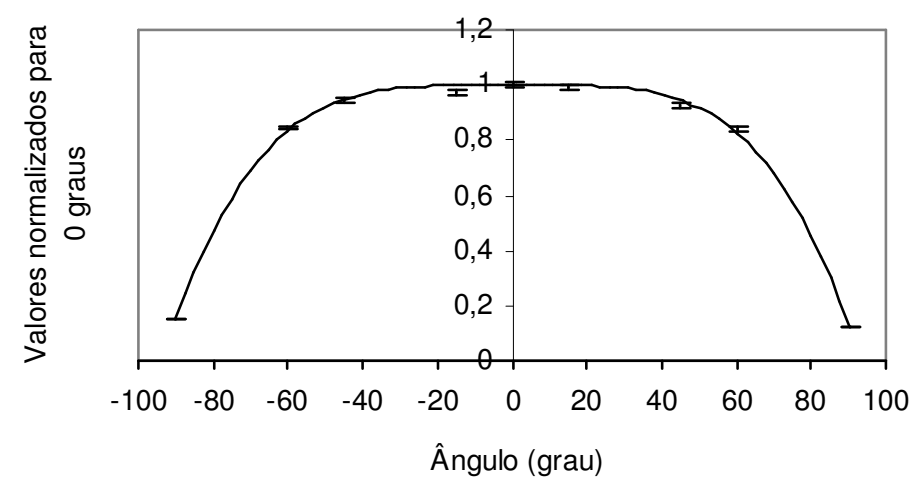

Figura 6.7. Resposta relativa em função da inclinação da câmara de ionização com eletrodo coletor de alumínio para raios $\mathrm{X}$, nível radioproteção, ISO N60. 


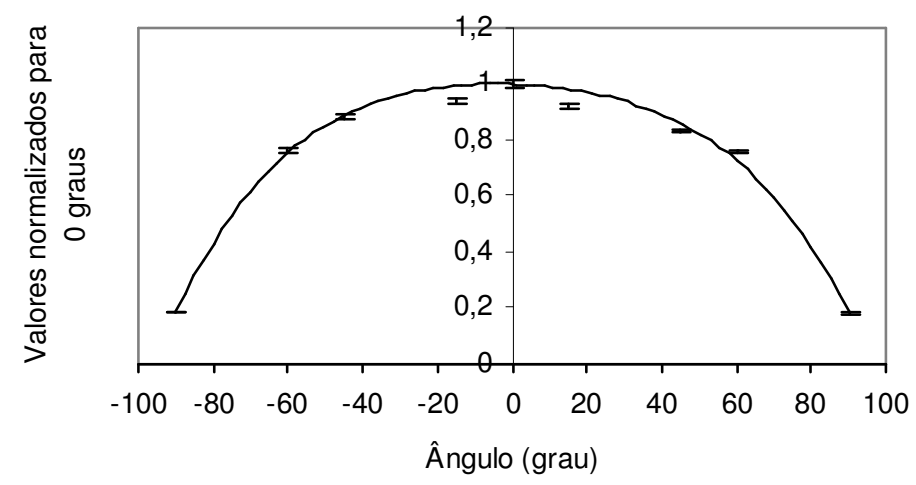

Figura 6.8. Resposta relativa em função da inclinação da câmara de ionização com eletrodo coletor de grafite para raios X, nível radioproteção, ISO N-60.

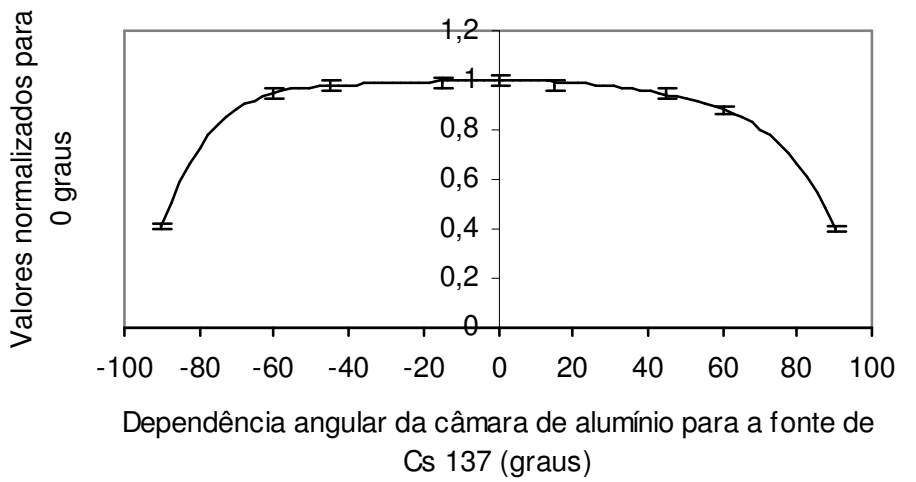

Figura 6.9. Resposta relativa em função da inclinação da câmara de ionização com eletrodo coletor de alumínio, para a fonte de ${ }^{137} \mathrm{Cs}$.

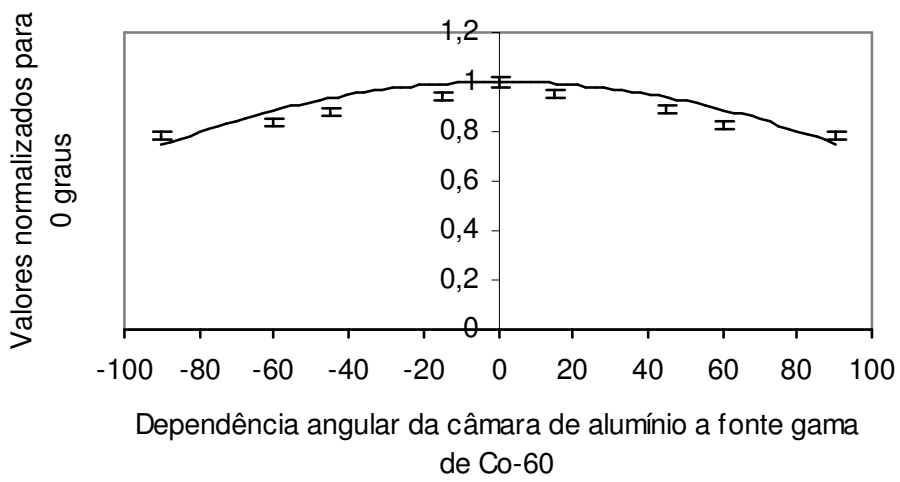

Figura 6.10. Resposta relativa em função da inclinação da câmara de ionização com eletrodo coletor de alumínio, para a fonte de ${ }^{60} \mathrm{Co}$. 


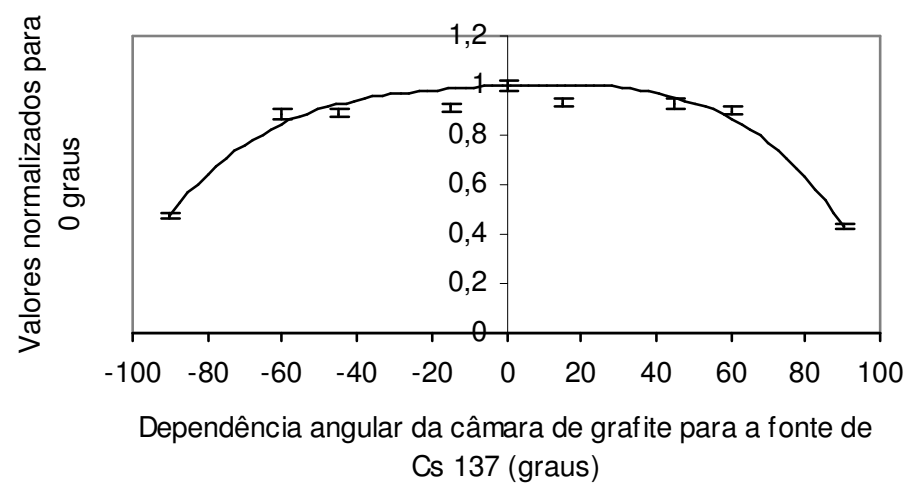

Figura 6.11. Resposta relativa em função da inclinação da câmara de ionização com eletrodo coletor de grafite, para a fonte de ${ }^{137} \mathrm{Cs}$.

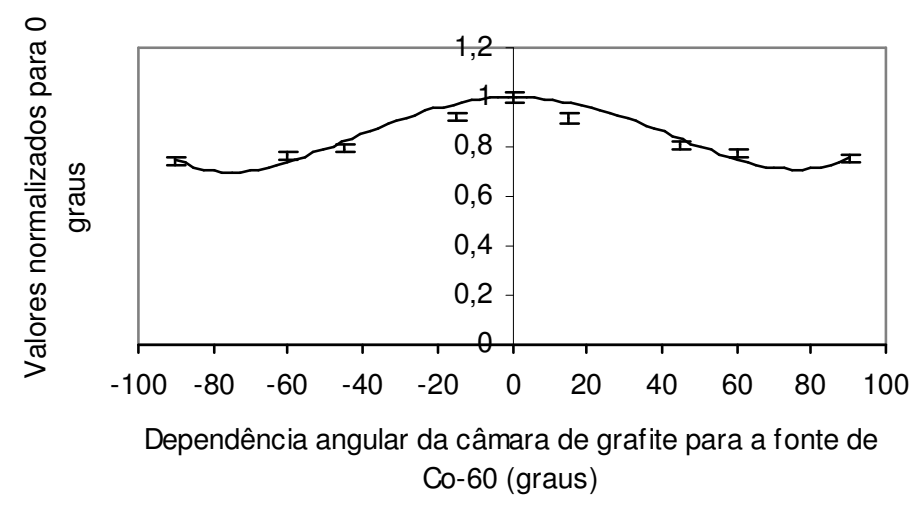

Figura 6.12. Resposta relativa em função da inclinação da câmara de ionização com eletrodo coletor de grafite, para a fonte de ${ }^{60} \mathrm{Co}$.

Dos resultados obtidos dos ensaios de dependência angular das câmaras de ionização pode-se verificar que para algumas qualidades de radiação, para ângulos entre $+15^{\circ} \mathrm{e}-15^{\circ}$, as câmaras atenderam à norma IEC $61674^{(81)}$. A câmara com eletrodo coletor de alumínio atendeu ao recomendado pela norma IEC $61674^{(81)}$, com exceção das qualidades ISO N-100 (somente para ângulo de $-15^{\circ}$ ) e ISO N-150, e para a fonte de ${ }^{60} \mathrm{Co}$. No caso da câmara de ionização com eletrodo coletor de grafite, ela não atendeu ao recomendado pela norma nas qualidades ISO N-60, ISO N-80 (somente para ângulo de $-15^{\circ}$ ), ISO $\mathrm{N}-100$ e nos ensaios com as fontes de ${ }^{60} \mathrm{Co}$ e ${ }^{137}$ Cs. No entanto, apesar dos resultados obtidos aparentemente 
desfavoráveis, é importante salientar que as incertezas nas medidas, somadas à incerteza no posicionamento (cerca de \pm 5 graus) das câmaras de ionização deste trabalho, as tornam viáveis para utilização em intervalos de até $\pm 15^{\circ}$ em seu posicionamento. Segundo a norma IEC $61674^{(81)}$, uma variação na leitura de $\pm 3 \%$ é admissível para posicionamentos das câmaras de ionização de até $\pm 5^{\circ}$, e considerando que as leituras das câmaras durante os ensaios, para intervalos de variação no posicionamento até $\pm 15^{\circ}$, mesmo que as leituras obtidas não atingiram (em alguns casos) o limite de variação de leitura recomendado pela norma, elas podem ser consideradas aprovadas neste ensaio. Uma vez que o posicionamento das câmaras de ionização, para intervalos de até $\pm 5^{\circ}$, como sugere a norma, não é facilmente obtido (a incerteza no posicionamento foi estimada em cerca de \pm 5 graus), para um posicionamento mais preciso seria necessário um sistema mecânico, ou uma mesa giratória de alta precisão, e tendo em vista que o posicionamento foi manual, uma incerteza menor do que a estimada neste trabalho seria impraticável.

Além disso, nos laboratórios de calibração raramente erra-se no posicionamento das câmaras de ionização mais do que alguns graus, devido aos sistemas de raios laser geralmente utilizados, porém, quando a câmara de ionização é girada para a direita ou para a esquerda, a incerteza no posicionamento aumenta, considerando que as câmaras de ionização desenvolvidas são de grandes dimensões e peso elevado, o que dificulta ainda mais seu posicionamento.

\subsection{0 - Calibração das câmaras de ionização}

As qualidades de raios-X utilizadas na calibração das câmaras de ionização com eletrodos coletores de alumínio e grafite são dadas na Tabela 4.2. Neste caso foram também utilizadas as fontes de ${ }^{60} \mathrm{Co}$ e ${ }^{137} \mathrm{Cs}$, à distância fonte-câmara de 2,90 m e diâmetro de campo de $42 \mathrm{~cm}$ para a primeira fonte e distância fontecâmara de 2,27 m e o mesmo diâmetro de campo para a segunda fonte. Para as medidas nas qualidades de raios $X$, nível radioproteção, utilizou-se uma distância foco-câmara de 2,5 m e campo de 42 cm de diâmetro. 
Os coeficientes de calibração ${ }^{(10)}$ foram obtidos utilizando-se os sistemas padrões para cada faixa de energia apresentados na Tabela 3.2. A Tabela 6.13 mostra os valores obtidos dos coeficientes de calibração. O coeficiente de calibração, ou fator de calibração, é obtido por meio da razão entre a taxa de kerma no ar medido com a câmara de ionização padrão e a leitura da câmara sob calibração.

Desse modo, a carga coletada (corrigida para as condições de pressão e temperatura de referência) é transformada em taxa de kerma no ar, por meio de um fator de correção. Pode-se verificar dos resultados da Tabela 6.13, que os valores dos coeficientes de calibração da câmara de ionização com eletrodo coletor de grafite são sempre mais altos que os da câmara de eletrodo coletor de alumínio, evidenciando, desse modo, que a câmara de ionização com eletrodo coletor de alumínio é mais sensível que a câmara com eletrodo coletor de grafite nas medidas dos feixes de radiação utilizados.

Tabela 6.13. Coeficientes de calibração das câmaras de ionização (com eletrodos coletores de alumínio e grafite) para radiação X (nível radioproteção) e radiação gama de ${ }^{137} \mathrm{Cs} \mathrm{e}{ }^{60} \mathrm{Co}$.

\begin{tabular}{|c|c|c|c|c|c|}
\hline \multirow{2}{*}{\multicolumn{2}{|c|}{$\begin{array}{c}\text { Qualidade } \\
\text { da } \\
\text { Radiação }\end{array}$}} & \multirow{2}{*}{$\begin{array}{l}\text { Camada } \\
\text { Semi- } \\
\text { Redutora } \\
(\mathrm{mm})\end{array}$} & \multirow{2}{*}{$\begin{array}{l}\text { Energia } \\
\text { Efetiva } \\
\text { (keV) }\end{array}$} & \multicolumn{2}{|c|}{$\begin{array}{l}\text { Coeficiente de Calibração } \\
\text { x } 10^{5} \mathrm{~Gy} / \mathrm{C}\end{array}$} \\
\hline & & & & Alumínio & Grafite \\
\hline \multirow{4}{*}{ Radioproteção } & ISO N-60 & $0,247 \mathrm{Cu}$ & 48,0 & $7,5 \pm 0,2$ & $18,9 \pm 0,6$ \\
\hline & ISO N-80 & $0,597 \mathrm{Cu}$ & 65,0 & $7,0 \pm 0,2$ & $16,4 \pm 0,5$ \\
\hline & ISO N-100 & $1,10 \mathrm{Cu}$ & 83,0 & $8,0 \pm 0,3$ & $16,0 \pm 0,5$ \\
\hline & ISO N-150 & $2,32 \mathrm{Cu}$ & 118,0 & $10,3 \pm 0,3$ & $16,7 \pm 0,5$ \\
\hline${ }^{137} \mathrm{Cs}$ & -- & -- & 662 & $14,1 \pm 0,5$ & $16,2 \pm 0,5$ \\
\hline${ }^{60} \mathrm{Co}$ & -- & -- & 1250 & $10,9 \pm 0,4$ & $14,3 \pm 0,5$ \\
\hline
\end{tabular}




\subsection{1 - Dependência energética}

A dependência energética de câmaras de ionização de placas paralelas foi estudada em vários trabalhos ${ }^{(22,24,28,29,32)}$. As Figuras 6.13 e 6.14 mostram os fatores de correção, obtidos pela normalização dos coeficientes de calibração para a camada semi-redutora de $1,10 \mathrm{mmCu}$, nas qualidades de radiação $\mathrm{X}$, nível radioproteção.

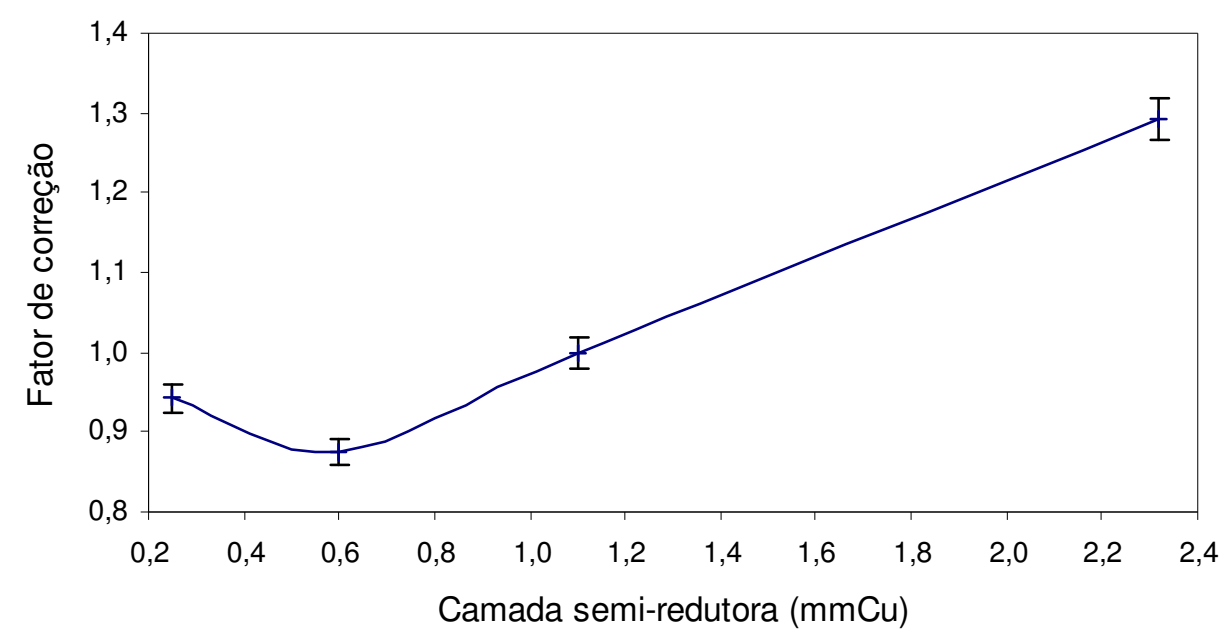

Figura 6.13: Fatores de correção da resposta da câmara de ionização com eletrodo coletor de alumínio, para as qualidades de raios $\mathrm{X}$, nível radioproteção, normalizados para a camada semi-redutora de $1,10 \mathrm{mmCu}$. 


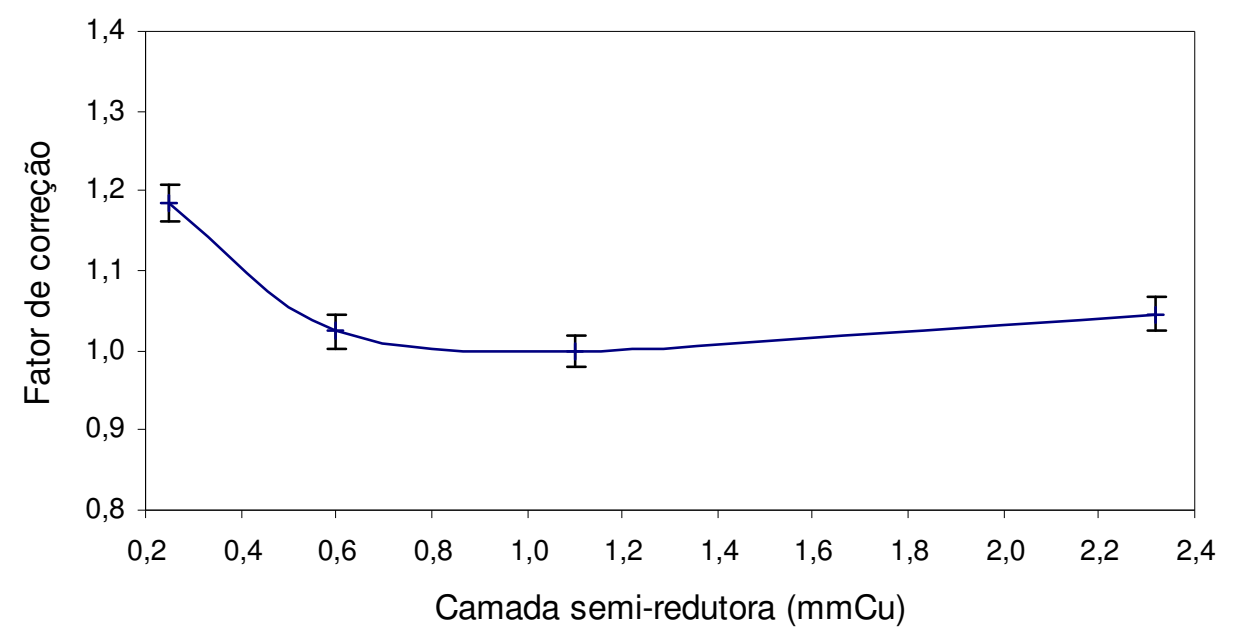

Figura 6.14: Fatores de correção da resposta da câmara de ionização com eletrodo coletor de grafite, para as qualidades de raios $X$, nível radioproteção, normalizados para a camada semi-redutora de $1,10 \mathrm{mmCu}$.

Verifica-se que a câmara de ionização com eletrodo coletor de alumínio apresenta uma dependência energética máxima de $41 \%$ para as qualidades de raios X, nível radioproteção (ISO N-60 a ISO N-150), e a câmara de ionização com eletrodo coletor de grafite apresentou uma dependência energética de $18 \%$ para as mesmas qualidades de radiação ensaiadas.

\subsection{2 - Formação dos sistemas Tandem}

As câmaras de ionização de placas paralelas desenvolvidas neste trabalho apresentam curvas de dependência energética diferentes. A diferença na dependência energética entre as duas câmaras de ionização de eletrodos de alumínio e grafite constitui a maior vantagem na formação de um sistema Tandem. A Figura 6.15 mostra a curva Tandem obtida para as câmaras de ionização com eletrodos coletores de alumínio e grafite. Tanto a razão entre os valores dos coeficientes de calibração obtidos, como simplesmente a razão dos valores de leituras das câmaras, resultam na mesma curva Tandem, demonstrando a simplicidade e a eficácia deste 
método e viabilizando a utilização das câmaras desenvolvidas neste trabalho, para medida e verificação da constância de feixes de radiação $X$ em programas de controle de qualidade. É conveniente salientar que o método convencional de obtenção das camadas semi-redutoras na implantação de qualidades de feixes de radiação, com o uso de absorvedores, é indispensável para o estabelecimento inicial dos feixes padronizados. O uso do sistema Tandem será primordial para a verificação periódica da constância dos feixes, no programa de controle de qualidade do laboratório. Estas medidas devem ser realizadas periodicamente de modo a assegurar sua eficácia, numa freqüência muito maior do que a aplicada pelo método convencional de absorvedores, que demanda muito mais tempo.

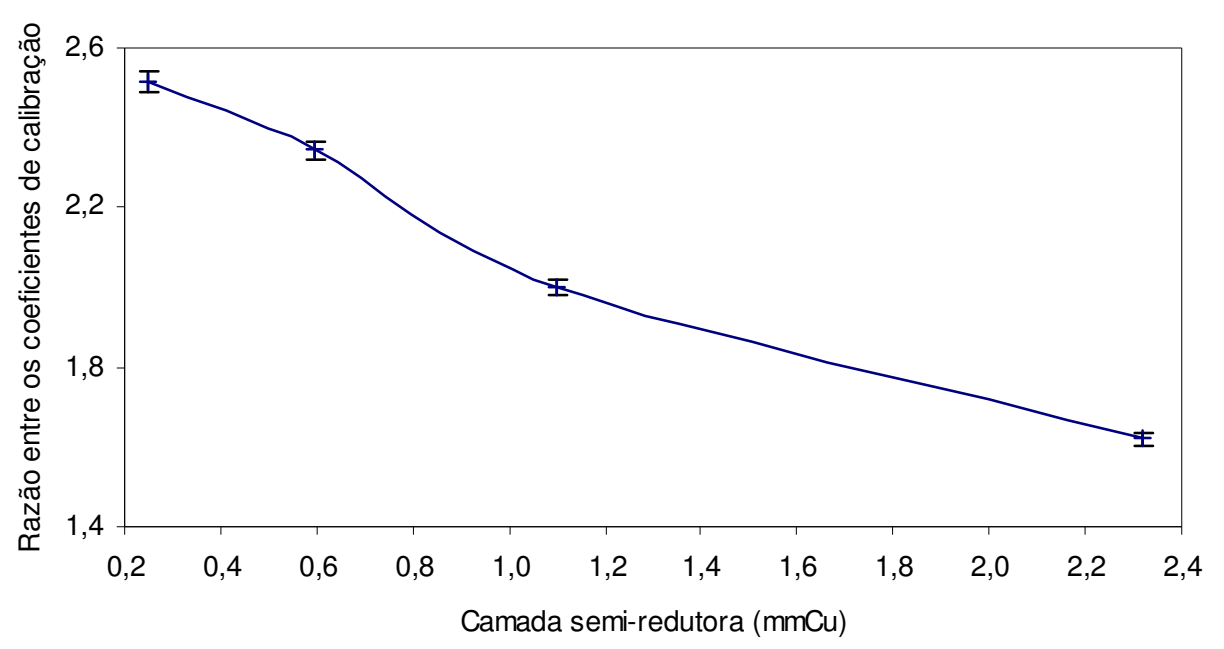

Figura 6.15. Curva Tandem para qualidades de raios $X$, nível radioproteção, das câmaras de ionização com eletrodos coletores de alumínio e de grafite.

Da Figura 6.15 pode-se verificar que as câmaras de ionização com eletrodos coletores de alumínio e grafite podem ser utilizadas em sistema Tandem para a verificação periódica da constância dos valores já pré-determinados de camada semiredutora. Na verdade, basta verificar-se o valor da razão entre as leituras das duas câmaras, não havendo a necessidade de se utilizar gráficos. 


\section{DETERMINAÇÃO DE Hp (10) EM CAMPOS PADRÕES DE RADIAÇÃO $X$, NÍVEL RADIOPROTEÇÃO}

Para a calibração das câmaras de ionização desenvolvidas e a posterior determinação do valor verdadeiro convencional do equivalente de dose pessoal, $H_{p}(10)$, é conveniente estabelecer-se um roteiro que permita a perfeita reprodutibilidade do processo como um todo.

Anteriormente à etapa de medidas, propriamente dita, com as câmaras de ionização, é recomendável que elas permaneçam acondicionadas em caixas adequadas, por cerca de uma semana, com sílica gel para a eliminação de umidade e preservação de suas características elétricas e mecânicas, para garantir a qualidade das medidas realizadas, as câmaras de ionização devem ser sempre acondicionadas de modo adequado, não somente antes da realização dos ensaios e calibrações.

As câmaras de ionização devem ser posicionadas no banco de calibração, à distância adequada para a medida, tanto a câmara padrão (ou de referência), quanto as câmaras de ionização a serem calibradas. Isto implica que elas deverão estar alinhadas com o feixe de radiação, e o centro de seus volumes sensíveis devem estar à distância de calibração de $2,5 \mathrm{~m}$ do foco do tubo de raios- $X$. O laboratório de calibração deve ter as suas condições ambientais devidamente controladas, isto é, baixa umidade relativa do ar (referência de 50 \%), temperaturas não superiores a 
$24{ }^{\circ} \mathrm{C}$, e deve possuir um medidor de pressão barométrica (barômetro), para que os valores obtidos destas variáveis sejam utilizados nas correções das leituras efetuadas com as câmaras de ionização.

Aplica-se a tensão de polarização, conforme definida anteriormente pelos ensaios de saturação e recombinação iônica, que no caso das câmaras de ionização desenvolvidas foi de $+400 \mathrm{~V}$. Para fins de estabilização, deve ser aguardado um intervalo de tempo de cerca de $1 \mathrm{~h}$, com a tensão de polarização aplicada às câmaras de ionização antes do início das medidas. Após isto, é conveniente realizar-se uma pré-irradiação, com feixes de radiação $X$, nas qualidades que serão utilizadas na calibração das câmaras de ionização. Uma pré-irradiação por cerca de 15 min permite uma maior estabilidade na resposta das câmaras de ionização durante os procedimentos de calibração. O procedimento de pré-irradiação permite a retirada de cargas elétricas residuais, que poderiam alterar as medidas realizadas com as câmaras de ionização, ou tornar estas medidas instáveis. Deve-se ainda verificar a estabilidade a curto prazo das câmaras de ionização e as suas correntes de fuga, que podem afetar as medidas realizadas. O acompanhamento da estabilidade das câmaras de ionização a longo prazo auxilia na verificação do comportamento do instrumento ao longo do tempo, principalmente no intervalo entre as calibrações periódicas.

Após estes procedimentos iniciais, as câmaras de ionização padrão (PTW 32002-A) e as câmaras de ionização com eletrodos coletores de grafite e alumínio foram irradiadas com feixes de radiação- $X$, qualidades da norma ISO $4037-1^{(16)}$, série $N$, espectro estreito, para realização das medidas.

Após a realização das medidas com as câmaras de ionização, realiza-se o cálculo do valor verdadeiro convencional $\left(\mathrm{V}_{\mathrm{vc}}\right)$ do equivalente de dose pessoal, $H_{P}(10)$. 
Para uma qualidade de radiação $X$ ou campos de radiação gama, representada por $\mathrm{R}$, o valor verdadeiro convencional do equivalente de dose pessoal, $H_{\mathrm{P}}(10)$, em um objeto simulador de tronco humano (definido no item 5.2), para um ângulo de incidência $\alpha$, formado entre o feixe de radiação proveniente do sistema de radiação e a superfície de entrada (janela, ou face frontal) da câmara de ionização, o $V_{V c}$ do $H_{p}(10)$ é dado por:

$$
H_{P}(10 ; R, \alpha)=N_{H} \cdot k(R, \alpha) \cdot Q
$$

onde: $\quad N_{H}=$ coeficiente de calibração para a qualidade da radiação de referência ISO N-60 e para o ângulo de incidência da radiação, ou seja, $\quad \alpha=$ $0^{\circ} ;$

$k(R, \alpha)=$ coeficiente de conversão para qualidade da radiação $R$ e ângulo de incidência $\alpha$;

$\mathrm{Q}=$ carga medida pela câmara de ionização sob teste.

Desse modo, para se efetuar o cálculo do $V_{\mathrm{vc}}$ do equivalente de dose pessoal é necessário desmembrar-se os termos da relação 7.1.

O coeficiente de calibração, $N_{H}$, com respeito ao equivalente de dose pessoal, $H_{p}(10)$, é determinado para a qualidade da radiação de referência (ISO N60) e ângulo de incidência da radiação $\alpha=0^{\circ}$. Assim, o coeficiente de calibração é dado por:

$$
\mathrm{N}_{\mathrm{H}}=\mathrm{h}_{\mathrm{PK}}\left(10 ; \mathrm{ISO} \mathrm{N}-60,0^{\circ}\right) \mathrm{K}_{\mathrm{ar}} / \mathrm{Q}
$$

onde: $\mathrm{K}_{\mathrm{ar}}=$ valor verdadeiro convencional do kerma no ar livre, medido com a câmara de ionização padrão, ou de referência (PTW 32002-A);

$h_{P K}\left(10 ;\right.$ ISO N-60, $\left.0^{\circ}\right)=$ coeficiente de conversão de $k_{a r}$ para o $H_{P}(10)$ para um simulador de tronco humano na qualidade de radiação ISO N-60 e ângulo da radiação de incidência $=0^{\circ}$. 
O coeficiente de correção $k(R, \alpha)$, para a qualidade da radiação $R$ e ângulo de incidência, a, é dado por:

$$
k(R, \alpha)=\left[h_{P K}(10 ; R, \alpha) \times\left(k_{a r} / Q\right)\right] \times\left(N_{H}\right)^{-1}
$$

Da relação (7.3), e com os valores de $h_{P K}(10 ; R, \alpha), k_{a r}$, $Q$ e $N_{H}$ determina-se o valor de $k(R, \alpha)$. Desse modo, pode-se ainda dizer que a resposta da câmara de ionização com respeito a $H_{P}(10)$ é o valor recíproco do produto entre $N_{H}$ e $k(R, \alpha)$.

Os valores dos coeficientes de conversão $h_{P K}(10 ; R, \alpha)$, ou seja, os coeficientes de conversão de $k_{a r}$ para $H_{P}(10)$ para um objeto simulador de tronco humano, para qualidades de radiação $X$, nível radioproteção, espectro estreito, são dados pela norma ISO $4037-3^{(53)}$.

No entanto, para a determinação do coeficiente de calibração, $N_{H}$, e o coeficiente de conversão de correção para qualidade da radiação, $k(R, \alpha)$, foram realizadas medidas com a câmara de ionização com eletrodo coletor de grafite, em feixes de radiação $X$, nível radioproteção, série $N$ da norma ISO 4037-1 ${ }^{(16)}$. Foram realizadas medidas com a câmara de ionização com eletrodo coletor de grafite acoplada ao objeto simulador de tronco humano, nas qualidades ISO N-60, ISO N-80, ISO N-100, ISO N-150 e ainda com radiação gama das fontes de ${ }^{137} \mathrm{Cs}$ e ${ }^{60} \mathrm{Co}$.

Para a determinação do equivalente de dose pessoal, $\mathrm{H}_{\mathrm{P}}(10)$, é necessário o conhecimento do $\mathrm{V}_{\mathrm{vc}}$ da taxa de kerma no ar e ainda dos valores das leituras de carga realizadas com as câmaras de ionização utilizadas e desenvolvidas neste trabalho. Para a obtenção do $\mathrm{V}_{\mathrm{vc}}$ da taxa de kerma no ar, empregou-se a câmara de ionização de referência (PTW 32002-A), posicionada nas mesmas distâncias de calibração das câmaras de ionização, ou melhor, distância foco-detector de 2,5 m para as qualidades de radiação X da ISO 4037-1(16), espectro estreito, nível 
radioproteção, e 2,27 m de distância foco-detector para a fonte de ${ }^{137} \mathrm{Cs}$ e distância de $2,90 \mathrm{~m}$ para a fonte de ${ }^{60} \mathrm{Co}$.

Por meio da câmara de ionização padrão (PTW 32002-A), foram obtidos os valores $\mathrm{V}_{\mathrm{Vc}}$ da taxa de kerma no ar, nas qualidades de radiação $\mathrm{X}$, nível radioproteção, espectro estreito, da norma ISO 4037-1 ${ }^{(16)}$, e ainda para radiação gama das fontes de ${ }^{137} \mathrm{Cs}$ e de ${ }^{60} \mathrm{Co}$, os valores são mostrados na Tabela 7.1.

Tabela 7.1. Valores da taxa de kerma no ar obtidos com a câmara de ionização padrão, nas qualidades de radiação $X$, nível radioproteção, espectro estreito, da norma ISO $4037-1^{(16)}$, e para radiação gama das fontes de ${ }^{137} \mathrm{Cs} \mathrm{e}{ }^{60} \mathrm{Co}$.

\begin{tabular}{cc}
\hline Qualidade & $\begin{array}{c}\text { Valor Verdadeiro Convencional } \\
\text { da Taxa de Kerma } \\
\text { no Ar }\end{array}$ \\
Radiação & $(\mu \mathrm{Gy} / \mathrm{min})$ \\
\hline ISO N-60 & $331,0 \pm 19,9$ \\
ISO N-80 & $175,0 \pm 10,6$ \\
ISO N-100 & $83,0 \pm 5,0$ \\
ISO N-150 & $691,0 \pm 41,7$ \\
${ }^{137} \mathrm{Cs}$ & $6,2 \pm 0,4$ \\
${ }^{60} \mathrm{Co}$ & $24,0 \pm 1,5$ \\
\hline
\end{tabular}

Na Tabela 7.2 são mostrados os valores obtidos das leituras com a câmara de ionização com eletrodo coletor de grafite, nas qualidades de radiação $X$, nível radioproteção, da norma ISO 4037-1 ${ }^{(16)}$, espectro estreito, e para radiação gama das fontes de ${ }^{137} \mathrm{Cs}$ e de ${ }^{60} \mathrm{Co}$. 
Tabela 7.2. Valores obtidos da câmara de ionização com eletrodo coletor de grafite, nas qualidades de radiação $X$, nível radioproteção, da norma ISO 4037$1^{(16)}$, espectro estreito, e para radiação gama das fontes de ${ }^{137} \mathrm{Cs}$ e ${ }^{60} \mathrm{Co}$.

\begin{tabular}{cc}
$\begin{array}{c}\text { Qualidade } \\
\text { da }\end{array}$ & Carga $^{*}$ \\
Radiação & $(\mathrm{pC})$ \\
\hline ISO N-60 & $175,2 \pm 1,1$ \\
ISO N-80 & $106,9 \pm 0,7$ \\
ISO N-100 & $51,9 \pm 0,3$ \\
ISO N-150 & $413,7 \pm 2,6$ \\
${ }^{137} \mathrm{Cs}$ & $4,00 \pm 0,03$ \\
${ }^{60} \mathrm{Co}$ & $15,48 \pm 0,11$ \\
\hline
\end{tabular}

* Tempo de irradiação = 1 min.

Com os valores das leituras obtidas pela câmara de ionização com eletrodos coletores de grafite e com os valores verdadeiros convencionais do kerma no ar, o próximo passo é a determinação do coeficiente de calibração, $\mathrm{N}_{\mathrm{H}}$, em relação ao equivalente de dose pessoal, $H_{p}(10)$, que é determinado para a qualidade da radiação de referência (ISO $\mathrm{N}-60$ ) e ângulo de incidência da radiação $a=0^{\circ}$. Assim, 0 coeficiente de calibração é dado pela relação 7.2 e substituindo os valores de $K_{a r}$, Q e $\mathrm{h}_{\mathrm{PK}}\left(10\right.$; ISO $\left.\mathrm{N}-60,0^{\circ}\right)$, onde este valor é fornecido pela norma ISO $4037-3^{(53)}$, para esta qualidade de radiação $X$ e ângulos diferentes de incidência da radiação $\left(0\right.$ a $\left.80^{\circ}\right)$ :

$$
\mathrm{N}_{H(60)}=\mathrm{h}_{\mathrm{PK}}\left(10 ; \text { ISO N-60, } 0^{\circ}\right)_{(60)} \mathrm{K}_{\mathrm{ar}(60)} / \mathrm{Q}_{(60)}
$$

Assim, a relação fica:

$$
\mathrm{N}_{\mathrm{H}(60)}=1,65(\mathrm{~Sv} / \mathrm{Gy}) \cdot 331,0 \times 10^{-6}(\mathrm{~Gy} / \mathrm{min}) / 175,2 \times 10^{-12}(\mathrm{pC})
$$


Logo, tem-se que:

$$
\mathrm{N}_{\mathrm{H}(60)}=3,1 \pm 0,2\left(\mathrm{~Sv} / \mu \mathrm{C} \times \mathrm{min}^{-1}\right)
$$

Assim o valor acima determinado de $\mathrm{N}_{\mathrm{H}(60)}$ será utilizado como valor de referência para a determinação do equivalente de dose pessoal, $H_{p}(10)$, das demais qualidades de radiação estudadas neste trabalho.

Para a determinação do valor do equivalente de dose pessoal, $H_{P}(10)$, para a qualidade de radiação $X$, ISO N-60, utilizou-se o valor de $\mathrm{N}_{\mathrm{H}(60)}$, o valor da carga $\mathrm{Q}_{(60)}$ e o valor de $k(R, \alpha)$ obtido da norma DIN 6818-1 ${ }^{(86)}$. Substituindo os valores na relação 7.1 obtêm-se o valor do equivalente de dose pessoal, $H_{P}(10)$, para a qualidade de radiação $X$, ISO N-60.

$$
\mathrm{N}_{\mathrm{H}\left(60,0^{0}\right)}=3,1\left(\mathrm{~Sv} / \mu \mathrm{C} \times \mathrm{min}^{-1}\right) \cdot 1,00 \cdot 175,2(\mathrm{pC})
$$

Logo:

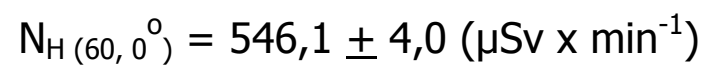

O valor determinado do equivalente de dose pessoal, $H_{p}(10)$, é válido somente para inclinação de $0^{\circ}$ do feixe de radiação $X$ incidente com relação à janela de entrada da câmara de ionização com eletrodo coletor de grafite. Desse modo, para diferentes ângulos de incidência devem ser aplicados os fatores de correção adequados que constam nas normas ISO $4037-3^{(53)}$ e DIN 6818-1 ${ }^{(86)}$. Para cada qualidade de radiação $X$, devem ser aplicados os fatores correspondentes $[k(R, \alpha)]$. A Tabela 7.3 mostra os valores de equivalente de dose pessoal, $H_{P}(10)$, determinados para as qualidades de radiação $\mathrm{X}$, ISO N-60, ISO N-80, ISO N-100, ISO N-150.

As Figuras 7.1 a 7.6 mostram as curvas de dependência angular da câmara de ionização com eletrodo de grafite para as qualidades de radiação $X$, ISO N-60, ISO N-80, ISO N-100, ISO N-150, e ainda para radiação gama das fontes de ${ }^{137} \mathrm{Cs}$ e ${ }^{60} \mathrm{Co}$. 
Tabela 7.3. Valores de taxa de equivalente de dose pessoal, $H_{P}(10)$, para as qualidades de radiação $X$ (nível radioproteção) ISO N-60, ISO N-80, ISO N-100, ISO N-150, com a câmara de ionização com eletrodo coletor de grafite, no sistema Pantak/Seifert.

\begin{tabular}{ccccc}
\hline \multirow{2}{*}{$\begin{array}{c}\text { Ângulo de } \\
\text { Inclinação }\left(^{\circ}\right)\end{array}$} & \multicolumn{4}{c}{$\begin{array}{c}\text { Taxa de Equivalente de Dose Pessoal } \mathrm{H}_{\mathrm{P}}(10) \\
(\mu \mathrm{Sv} / \mathrm{min})\end{array}$} \\
\cline { 2 - 5 } & ISO N-60 & ISO N-80 & ISO N-100 & ISO N-150 \\
\hline 0 & $546,1 \pm 33,0$ & $318,3 \pm 19,3$ & $155,4 \pm 9,4$ & $1173,9 \pm 71,0$ \\
+15 & $508,5 \pm 31,0$ & $311,2 \pm 18,9$ & $155,0 \pm 9,4$ & $1167,0 \pm 70,7$ \\
+45 & $457,9 \pm 27,7$ & $270,4 \pm 16,4$ & $138,2 \pm 8,4$ & $1042,0 \pm 63,0$ \\
+60 & $424,4 \pm 25,7$ & $253,4 \pm 15,3$ & $137,0 \pm 8,3$ & $1046,6 \pm 63,3$ \\
+90 & $114,7 \pm 6,9$ & $72,6 \pm 4,4$ & $42,5 \pm 2,6$ & $328,4 \pm 19,9$ \\
-15 & $519,0 \pm 31,4$ & $329,0 \pm 19,9$ & $152,2 \pm 9,2$ & $1144,9 \pm 69,4$ \\
-45 & $492,0 \pm 29,8$ & $294,7 \pm 17,9$ & $142,7 \pm 8,6$ & $1100,2 \pm 66,6$ \\
-60 & $448,4 \pm 27,1$ & $273,6 \pm 16,6$ & $137,6 \pm 8,3$ & $1123,8 \pm 68,0$ \\
-90 & $116,6 \pm 7,1$ & $81,0 \pm 4,9$ & $46,1 \pm 2,8$ & $330,9 \pm 20,0$ \\
\hline
\end{tabular}

Tabela 7.4. Valores de taxa de equivalente de dose pessoal, $H_{p}(10)$, para radiação gama, com a câmara de ionização com eletrodo coletor de grafite, no sistema irradiador STS $\left({ }^{137} \mathrm{Cs}\right)$ e sistema irradiador IPEN $\left({ }^{60} \mathrm{Co}\right)$.

\begin{tabular}{ccc}
\hline & \multicolumn{2}{c}{ Taxa de Equivalente de Dose Pessoal $\mathrm{H}_{\mathrm{p}}(10)$} \\
Ângulo de & \multicolumn{2}{c}{$(\mu \mathrm{Sv} / \mathrm{min})$} \\
\cline { 2 - 3 } Inclinação $\left(^{\circ}\right)$ & ${ }^{137} \mathrm{Cs}$ & ${ }^{60} \mathrm{Co}$ \\
\hline 0 & $10,90 \pm 0,32$ & $42,2 \pm 1,1$ \\
+15 & $10,30 \pm 0,30$ & $39,9 \pm 1,1$ \\
+45 & $10,30 \pm 0,30$ & $39,8 \pm 1,1$ \\
+60 & $10,10 \pm 0,29$ & $39,1 \pm 1,1$ \\
+90 & $4,90 \pm 0,14$ & $19,0 \pm 0,5$ \\
-15 & $10,10 \pm 0,30$ & $39,1 \pm 1,1$ \\
-45 & $9,90 \pm 0,29$ & $38,3 \pm 1,0$ \\
-60 & $9,90 \pm 0,29$ & $38,2 \pm 1,0$ \\
-90 & $5,40 \pm 0,16$ & $21,00 \pm 0,57$ \\
\hline
\end{tabular}




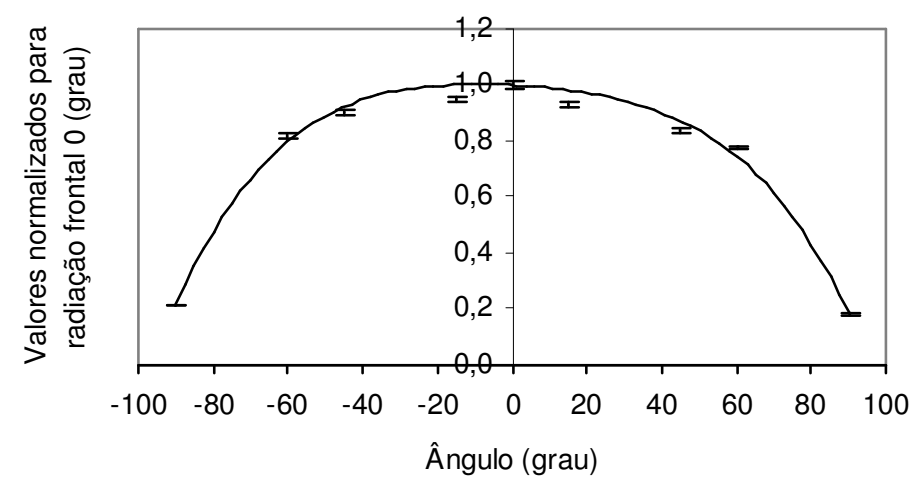

Figura 7.1. Dependência angular da câmara de ionização com eletrodo coletor de grafite para a qualidade de radiação X, ISO N-60.

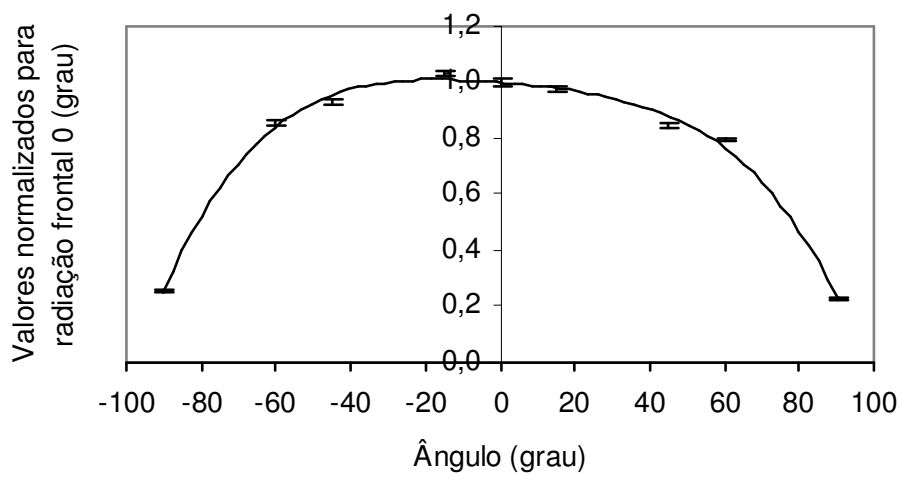

Figura 7.2. Dependência angular da câmara de ionização com eletrodo coletor de grafite para a qualidade de radiação X, ISO N-80.

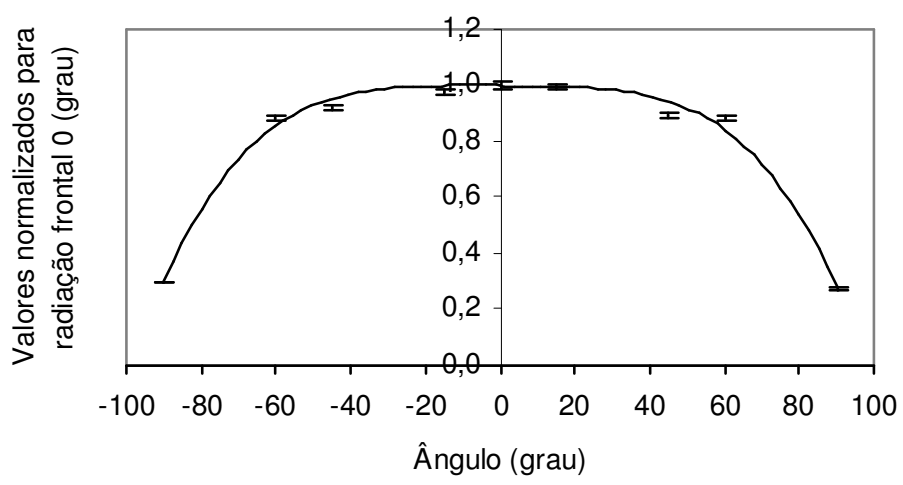

Figura 7.3. Dependência angular da câmara de ionização com eletrodo coletor de grafite para a qualidade de radiação X, ISO N-100. 


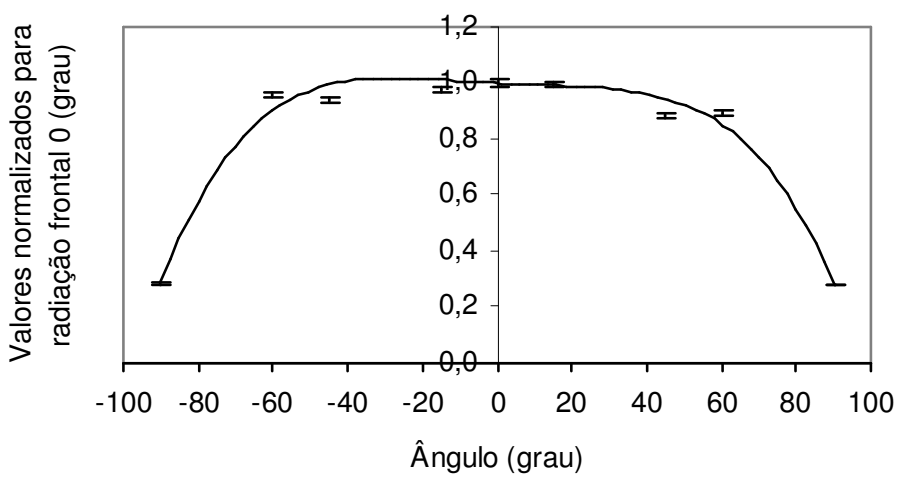

Figura 7.4. Dependência angular da câmara de ionização com eletrodo coletor de grafite para a qualidade de radiação X, ISO N-150.

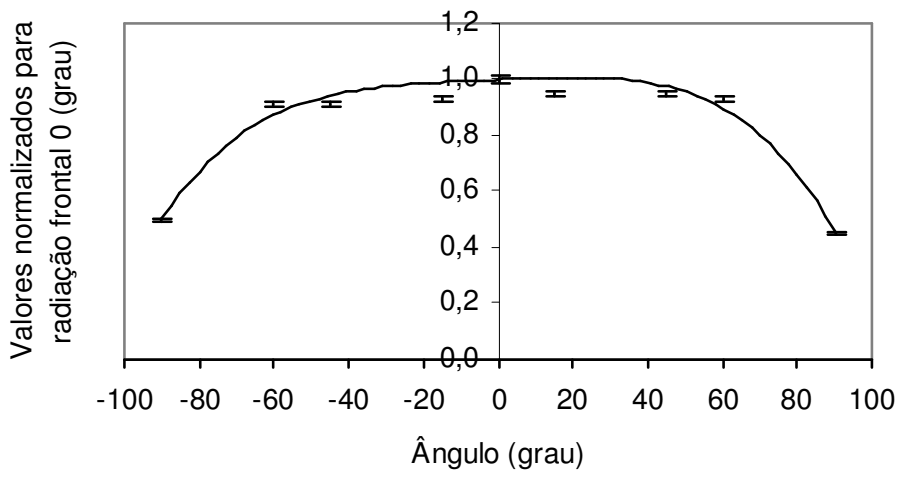

Figura 7.5. Dependência angular da câmara de ionização com eletrodo coletor de grafite para radiação gama de ${ }^{137} \mathrm{Cs}$.

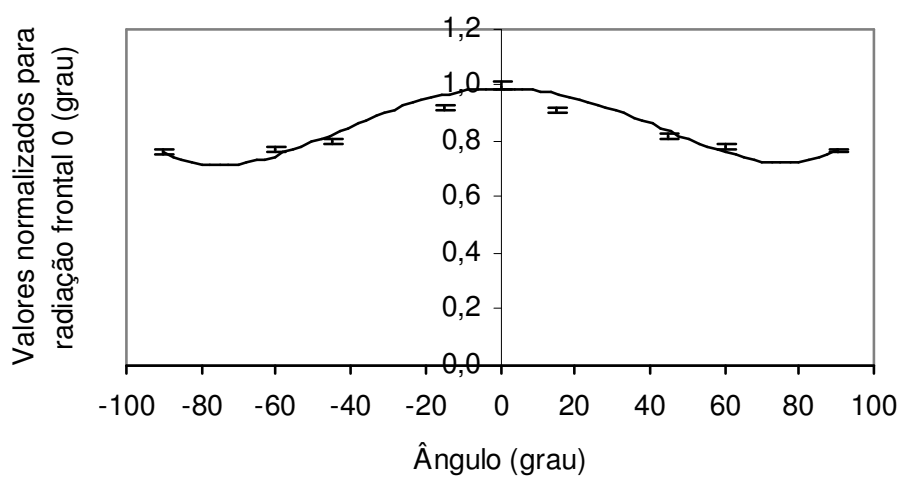

Figura 7.6. Dependência angular da câmara de ionização com eletrodo coletor de grafite para radiação gama de ${ }^{60} \mathrm{Co}$. 
A Tabela 7.5 mostra a variação entre os valores dos coeficientes de calibração $\left(\mathrm{N}_{\mathrm{H}}\right)$, obtidos com a câmara de ionização com eletrodo coletor de grafite, desenvolvida neste trabalho com relação aos valores de coeficientes de calibração obtidos por Ankerhold ${ }^{(41-43)}$. A Tabela 7.5 foi obtida para auxiliar na comparação dos resultados obtidos, nesta etapa do trabalho, com os resultados obtidos por Ankerhold ${ }^{(41-43)}$.

Dos resultados obtidos na determinação da taxa do equivalente de dose pessoal, $H_{P}(10)$, o fator que mais influenciou na determinação das incertezas nos valores de $H_{P}(10)$ foi a incerteza do Tipo $B$, proveniente dos certificados de calibração das câmaras de ionização de referência (padrão).

Tabela 7.5. Coeficientes de calibração $\left(\mathrm{N}_{\mathrm{H}}\right)$, obtidos com a câmara de ionização com eletrodo coletor de grafite desenvolvida neste trabalho, em relação aos valores obtidos por Ankerhold ${ }^{(41-43)}$, nas qualidades de radiação $X$, da norma ISO 4037-1 ${ }^{(16)}$, nível radioproteção, e radiação gama de fontes de ${ }^{137} \mathrm{Cs} \mathrm{e}{ }^{60} \mathrm{Co}$.

\begin{tabular}{|c|c|c|c|}
\hline & $\begin{array}{c}\text { Coeficiente } \\
\text { de }\end{array}$ & $\begin{array}{c}\text { Coeficiente } \\
\text { de }\end{array}$ & $\begin{array}{c}\text { Coeficiente } \\
\text { de }\end{array}$ \\
\hline Qualidade & Calibração & Calibração & Calibração* \\
\hline da & obtido & obtido & normalizado \\
\hline \multirow[t]{2}{*}{ Radiação } & neste & por & para \\
\hline & Trabalho & Ankerhold & ISO N-60 \\
\hline ISO N-60 & $3,12 \pm 0,20$ & $3,60 \pm 0,09$ & 1 \\
\hline ISO N-80 & $3,08 \pm 0,20$ & $3,42 \pm 0,09$ & $0,987 \pm 0,06$ \\
\hline ISO N-100 & $3,01 \pm 0,20$ & $3,46 \pm 0,09$ & $0,965 \pm 0,06$ \\
\hline ISO N-150 & $2,89 \pm 0,19$ & $3,28 \pm 0,09$ & $0,926 \pm 0,06$ \\
\hline${ }^{137} \mathrm{Cs}$ & $2,85 \pm 0,20$ & $3,16 \pm 0,09$ & $0,913 \pm 0,06$ \\
\hline${ }^{60} \mathrm{Co}$ & $2,80 \pm 0,20$ & $3,13 \pm 0,09$ & $0,897 \pm 0,06$ \\
\hline
\end{tabular}

\footnotetext{
* Resultados obtidos com as câmaras de ionização desenvolvidas neste trabalho.
} 
Para uma melhor visualização dos resultados obtidos com a câmara de ionização com eletrodo coletor de grafite nas qualidades de radiação $X$, da norma ISO $4037-1^{(16)}$, da série $N$, nível radioproteção, e radiação gama das fontes de ${ }^{137}$ Cs e ${ }^{60} \mathrm{Co}$, foi obtida a Figura 7.7 , que mostra a variação do coeficiente de calibração $\mathrm{N}_{\mathrm{H}}$ em função da energia da radiação.

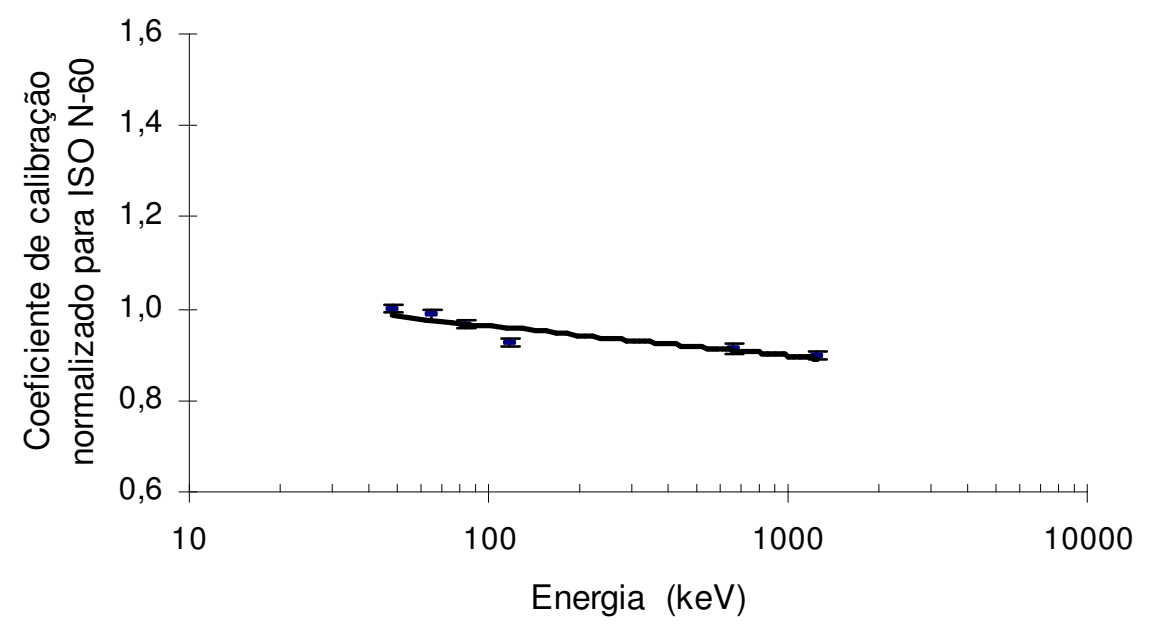

Figura 7.7. Dependência energética do coeficiente de calibração $N_{H}$, obtido com a câmara de ionização com eletrodo coletor de grafite nas qualidades de radiação $X$, da norma ISO $4037-1^{(16)}$, da série $N$, nível radioproteção, e radiação gama das fontes de ${ }^{137} \mathrm{Cs}$ e ${ }^{60} \mathrm{Co}$, em função da energia da radiação.

Dos valores mostrados na Tabela 7.5 e da Figura 7.7, pode-se verificar que o comportamento da câmara de ionização com eletrodo coletor de grafite para as qualidades de radiação $X$, nível radioproteção, da série ISO N-60, ISO N-80, ISO N100, ISO N-150, espectros estreitos, apresenta uma variação máxima no coeficiente de calibração $N_{H}$ de 8,0 \%, para os feixes de radiação $X$, e uma variação de 9,5 \% e $11,4 \%$ para radiação gama das fontes de ${ }^{137} \mathrm{Cs} \mathrm{e}{ }^{60} \mathrm{Co}$, respectivamente, em relação à qualidade de radiação ISO N-60. Quando os valores obtidos pelas câmaras de ionização desenvolvidas são comparados com os valores obtidos por Ankerhold ${ }^{(41-43)}$, a máxima variação entre os valores de $\mathrm{N}_{\mathrm{H}}$ foi de $15,4 \%$ (ISO N-60). Entretanto, a dependência energética máxima dos coeficientes de calibração $\left(\mathrm{N}_{H}\right)$ obtidos por 
Ankerhold ${ }^{(41-43)}$ para radiação $X$ foi de $9,8 \%$ e para as fontes de ${ }^{137} \mathrm{Cs}$ e ${ }^{60} \mathrm{Co}$, de $13,9 \%$ e $15 \%$, respectivamente, em relação a qualidade de radiação ISO N-60. Assim, mesmo considerando as incertezas envolvidas na determinação dos coeficientes de calibração $\left(\mathrm{N}_{\mathrm{H}}\right)$, os resultados obtidos com as câmaras de ionização desenvolvidas foram melhores que os resultados obtidos por Ankerhold. Para um intervalo de energia relativamente grande (de $48 \mathrm{keV}$ a $1250 \mathrm{keV}$ ), pode-se concluir que a câmara de ionização apresenta uma resposta satisfatória, ou seja, uma variação pequena na resposta em função da energia dos feixes de radiação, para as qualidades de radiação $X$ e gama, em que foi ensaiada.

Deve-se levar em conta que a câmara de ionização desenvolvida neste trabalho possui características construtivas diferentes em relação à câmara de ionização tipo protótipo construída por Ankerhold ${ }^{(41-43)}$. Entre as diferenças principais pode-se citar a espessura do eletrodo coletor de grafite e do anel de guarda ( $2 \mathrm{~mm}$ contra $0,04 \mathrm{~mm}$ ), o procedimento para obtenção da janela, por meio de pintura com tinta com grafite (o procedimento utilizado por Ankerhold não foi declarado), o objeto simulador de tronco humano foi obtido em multicamadas (o de Ankerhold ${ }^{(41-43)}$ era um bloco maciço ou sólido), o que resultou numa dependência energética da resposta melhor que a de Ankerhold.

Tendo em vista as diferenças construtivas citadas e considerando que mesmo câmaras de ionização de características semelhantes podem possuir respostas relativamente diferentes, uma variação máxima de cerca de $15,4 \%$ entre os valores dos coeficientes de calibração $\mathrm{N}_{\mathrm{H}}$ (obtidos por Ankerhold e neste trabalho) podem ser considerados aceitáveis. Desse modo, fica evidenciado que a câmara de ionização com eletrodo coletor de grafite está em concordância com os valores obtidos por Ankerhold, mostrando a viabilidade de uso da câmara de ionização desenvolvida neste trabalho para a medida do equivalente de dose pessoal, $\mathrm{H}_{\mathrm{P}}(10)$.

A Tabela 7.6 mostra a planilha utilizada na determinação das incertezas do equivalente de dose pessoal, $H_{P}(10)$, para radiação gama, com a câmara de 
ionização com eletrodo coletor de grafite, no sistema irradiador STS $\left({ }^{137} \mathrm{Cs}\right)$ e sistema irradiador IPEN ( $\left.{ }^{60} \mathrm{Co}\right)$ e para o sistema de radiação X, Pantak/Seifert.

Tabela 7.6. Planilha das incertezas na determinação do equivalente de dose pessoal, $H_{P}(10)$, para radiação gama, com a câmara de ionização com eletrodo coletor de grafite, no sistema irradiador STS $\left({ }^{137} \mathrm{Cs}\right)$ e sistema irradiador IPEN $\left({ }^{60} \mathrm{Co}\right)$ e para o sistema de radiação $X$, Pantak/Seifert.

\begin{tabular}{|c|c|c|c|c|c|c|}
\hline Símbolo & Componente & Valor & $\begin{array}{c}\text { Tipo } \\
\text { de } \\
\text { Distribuição }\end{array}$ & Divisor & $\begin{array}{c}\text { Incerteza } \\
\text { Padrão } \\
\text { u }\end{array}$ & $\begin{array}{c}\text { Graus } \\
\text { de } \\
\text { Liberdade }\end{array}$ \\
\hline $\mathrm{u}_{1}$ & $\begin{array}{c}\text { Reprodutibilidade } \\
\text { Coeficiente }\end{array}$ & $*$ & $\begin{array}{c}\text { Normal } \\
\text { (Tipo A) } \\
\text { Normal }\end{array}$ & 1 & - & 9 \\
\hline $\mathrm{u}_{2}$ & $\begin{array}{l}\text { k }(\mathrm{R}, \alpha) \\
\text { Padrão }\end{array}$ & $\begin{array}{c}* * \\
1,4\left({ }^{137} \mathrm{Cs}\right)\end{array}$ & (Tipo B) & 1 & $\begin{array}{l}- \\
1,4\end{array}$ & Infinito \\
\hline $\mathrm{u}_{3}$ & $\begin{array}{c}\text { De } \\
\text { Calibração }\end{array}$ & $\begin{array}{c}1,3\left({ }^{60} \mathrm{Co}\right) \\
3,0(\mathrm{X})\end{array}$ & $\begin{array}{l}\text { Normal } \\
\text { (Tipo B) }\end{array}$ & 1 & $\begin{array}{l}1,3 \\
3,0\end{array}$ & Infinito \\
\hline $\mathrm{u}_{4}$ & Posicionamento & $0,05^{* * *}$ & $\begin{array}{c}\text { Retangular } \\
\text { (Tipo B) } \\
\text { Normal } \\
\text { (Tipo B) }\end{array}$ & $(3)^{1 / 2}$ & 0,029 & Infinito \\
\hline
\end{tabular}

*Estes valores dependem dos valores obtidos de desvio padrão percentual das medidas realizadas, com a câmara de ionização com eletrodos coletores de grafite.

**Estes valores dependem da posição da câmara de ionização durante as medidas, e da qualidade da radiação.

***Valor válido somente para posicionamento de $0^{\circ}$ (irradiação frontal), utilizado como valor de referência.

$\mathrm{u}_{\mathrm{C}}=\left[\left(\mathrm{u}_{1}\right)^{2}+\left(\mathrm{u}_{2}\right)^{2}+\left(\mathrm{u}_{3}\right)^{2}+\left(\mathrm{u}_{4}\right)^{2}+\left(\mathrm{u}_{5}\right)^{2}\right]^{1 / 2}$

$\mathrm{U}=\mathrm{u}_{\mathrm{C}} \times \mathrm{k}\left(\mathrm{U}_{95}\right.$, nível de confiança de $\left.95 \%\right)$

A planilha da Tabela 7.6 foi utilizada para a etapa da determinação das incertezas do equivalente de dose pessoal, $\mathrm{H}_{\mathrm{p}}(10)$. $\mathrm{O}$ valor das incertezas variou entre $2,8 \%$ e $6,2 \%$. Os cálculos a seguir mostram como os valores mínimos e máximos das incertezas nesta etapa foram determinados. 
Para a avaliação da incerteza máxima nas medidas para a qualidade da radiação ISO $\mathrm{N}-60$, posição de irradiação $0^{\circ}$, para determinação do equivalente de dose pessoal, $H_{P}(10)$, foram utilizados os seguintes parâmetros:
$\mathrm{U}_{1}$ (reprodutibilidade $)=0,090$
$\mathrm{U}_{2}$ (coeficiente $\left.\mathrm{K}(\mathrm{R}, \alpha)\right)=0,030$
$\mathrm{u}_{3}$ (padrão de calibração) $=3,0$
$\mathrm{u}_{4}$ (posicionamento) $=0,029$
$\mathrm{u}_{5}$ (coeficiente de calibração) $\mathrm{N}_{\mathrm{H}}=0,61$.

Assim, tem-se:

$$
u_{c}=\left[\left(u_{1}\right)^{2}+\left(u_{2}\right)^{2}+\left(u_{3}\right)^{2}+\left(u_{4}\right)^{2}+\left(u_{5}\right)^{2}\right]^{1 / 2}
$$

Substituindo-se os valores na relação:

$$
\begin{gathered}
u_{C}=\left[(0,090)^{2}+(0,030)^{2}+(3,0)^{2}+(0,029)^{2}+(0,61)^{2}\right]^{1 / 2} \\
u_{C}=3,1 \%
\end{gathered}
$$

Como se optou por um nível de confiança de $95 \%\left(U_{95}\right)$, o valor final da incerteza na determinação do valor do equivalente de dose pessoal, $H_{P}(10)$, será dado por $\mathrm{U}=\mathrm{u}_{\mathrm{C}} \times \mathrm{k}$, onde $\mathrm{k}=2$ (para $\left.\mathrm{U}_{95}\right)$; assim, a incerteza final é:

$$
U=3,1 \times 2=6,2 \%
$$

Pode-se notar que o parâmetro que mais influenciou a determinação da incerteza nesta qualidade de radiação foi a incerteza do sistema padrão de calibração $(3,0 \%)$. 
Do mesmo modo, para a avaliação da incerteza mínima, no caso das medidas para a fonte gama de ${ }^{60} \mathrm{Co}$, posição de irradiação $0^{\circ}$, para determinação do equivalente de dose pessoal, $\mathrm{H}_{\mathrm{P}}(10)$, foram utilizados os seguintes parâmetros:

$$
\begin{aligned}
& \mathrm{u}_{1}(\text { reprodutibilidade })=0,092 \\
& \mathrm{u}_{2}(\text { coeficiente } \mathrm{K}(\mathrm{R}, \alpha))=0,030 \\
& \mathrm{u}_{3} \text { (padrão de calibração) }=1,3 \\
& \mathrm{u}_{4} \text { (posicionamento) }=0,029 \\
& \mathrm{u}_{5} \text { (coeficiente de calibração) } \mathrm{N}_{\mathrm{H}}=0,61 .
\end{aligned}
$$

Assim, tem-se:

$$
\mathrm{u}_{\mathrm{C}}=\left[\left(\mathrm{u}_{1}\right)^{2}+\left(\mathrm{u}_{2}\right)^{2}+\left(\mathrm{u}_{3}\right)^{2}+\left(\mathrm{u}_{4}\right)^{2}+\left(\mathrm{u}_{5}\right)^{2}\right]^{1 / 2}
$$

Substituindo-se os valores na relação:

$$
\begin{gathered}
u_{C}=\left[(0,092)^{2}+(0,030)^{2}+(1,3)^{2}+(0,029)^{2}+(0,61)^{2}\right]^{1 / 2} \\
u_{C}=1,4 \%
\end{gathered}
$$

Como se optou por um nível de confiança de $95 \%\left(U_{95}\right)$, o valor final da incerteza na determinação do valor do equivalente de dose pessoal, $H_{P}(10)$, será dado por $\mathrm{U}=\mathrm{u}_{\mathrm{c}} \times \mathrm{k}$, onde $\mathrm{k}=2$ (para $\left.\mathrm{U}_{95}\right)$; assim, a incerteza final é:

$$
U=1,4 \times 2=2,8 \%
$$

A incerteza do sistema padrão de calibração (câmara de ionização padrão) foi também o fator que mais influenciou na incerteza final, para a radiação gama da fonte de ${ }^{60} \mathrm{Co}$.

Assim, pode-se concluir que a incerteza combinada variou entre $2,8 \%$ e $6,2 \%$. 


\section{APLICAÇÃO DAS CÂMARAS DE IONIZAÇÃO EM OUTROS CAMPOS PADRÕES DE RADIAÇÃO $X$, NÍVEIS RADIODIAGNÓSTICO E RADIOTERAPIA}

As câmaras de ionização sempre foram um dos principais objetos de pesquisa no grupo (LCI), em campos de radiação diferentes, como sistemas de referência em qualidades de radiodiagnóstico e radioterapia ${ }^{(87-88)}$. As câmaras de ionização desenvolvidas no presente trabalho para feixes de radioproteção foram ainda testadas em campos de radiação $X$, para se verificar o seu comportamento, nos feixes de energia de radiodiagnóstico (convencional e de mamografia), como também para terapia. Como as câmaras de ionização desenvolvidas apresentaram um comportamento satisfatório para feixes de radioproteção, resolveu-se avaliar o seu comportamento também para utilização em outros campos padrões.

As câmaras de ionização desenvolvidas foram testadas de acordo com as especificações da International Electrotechnical Commission ${ }^{(80,81)}$. Os ensaios de caracterização das câmaras de ionização foram realizados em feixes de radiodiagnóstico convencional ${ }^{(82)}$. As câmaras de ionização foram ainda calibradas em feixes padronizados para radioterapia e de mamografia. Os resultados dos ensaios são apresentados a seguir.

\section{1 - Saturação, eficiência de coleção de íons e efeitos de polaridade}

As câmaras de ionização foram estudadas com relação as suas características de saturação, eficiência de coleção de íons e efeitos de polaridade seguindo-se os 
mesmos procedimentos utilizados nos ensaios para qualidades de radiação $X$, nível radioproteção e seguindo recomendações dadas por algumas normas específicas $^{(78,80,81)}$.

Para avaliação da tensão de saturação, as duas câmaras de ionização foram irradiadas nas seguintes condições: tomando-se como referência o centro do volume sensível, com a janela de entrada perpendicular ao feixe de radiação incidente; utilizou-se a qualidade de radiação $X$, nível radiodiagnóstico, RQR 3, tensão de 50 kV, corrente $10 \mathrm{~mA}$; taxa de kerma no ar de $2,8 \mathrm{mGy} / \mathrm{min}$; tensão de polarização aplicada entre $-400 \mathrm{~V}$ e $+400 \mathrm{~V}$, em intervalos de 50V. As curvas de saturação obtidas são apresentadas nas Figuras 8.1 e 8.2. As correntes de ionização medidas representam valores médios de dez leituras em cada caso. As incertezas nas medidas das correntes de ionização foram sempre menores que $0,3 \%$.

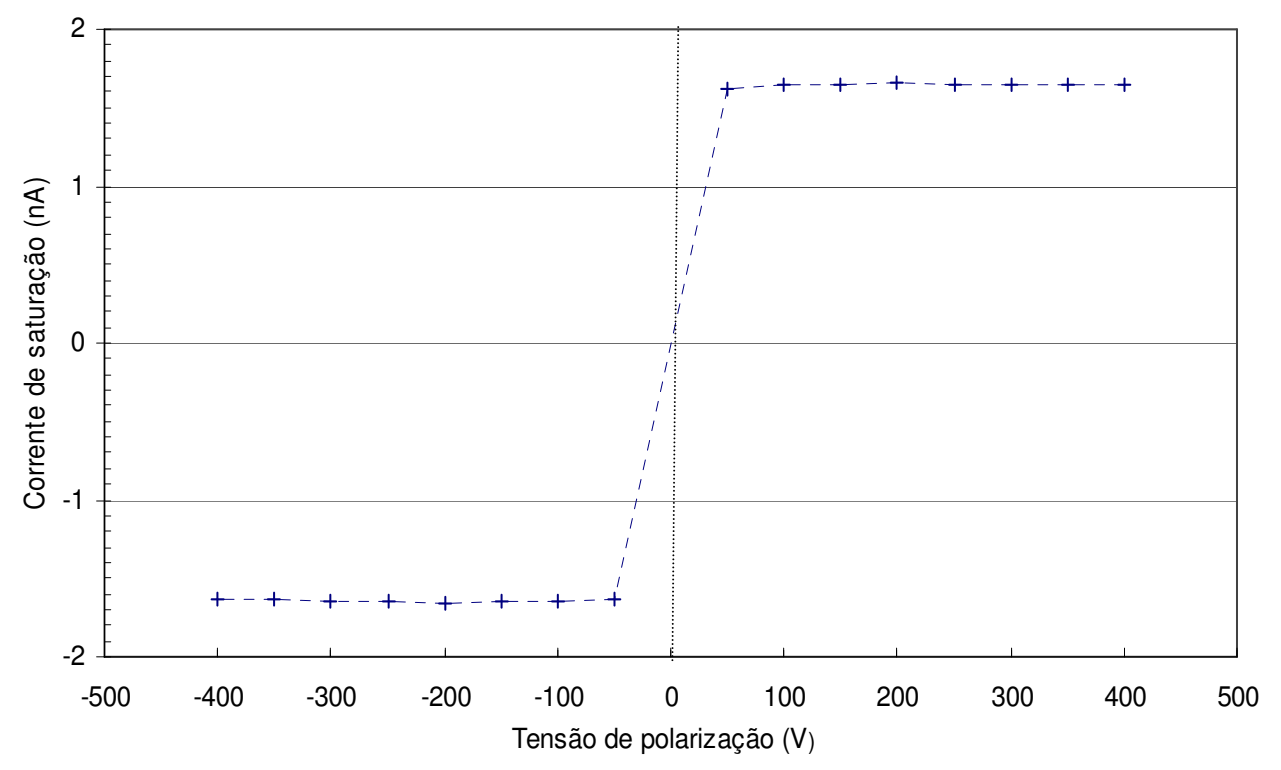

Figura 8.1. Curva de saturação da câmara de ionização com eletrodo coletor de alumínio. Qualidade de radiação X, RQR 3, tensão 50 kV e corrente de 10 mA, distância foco-câmara de $1 \mathrm{~m}$. 


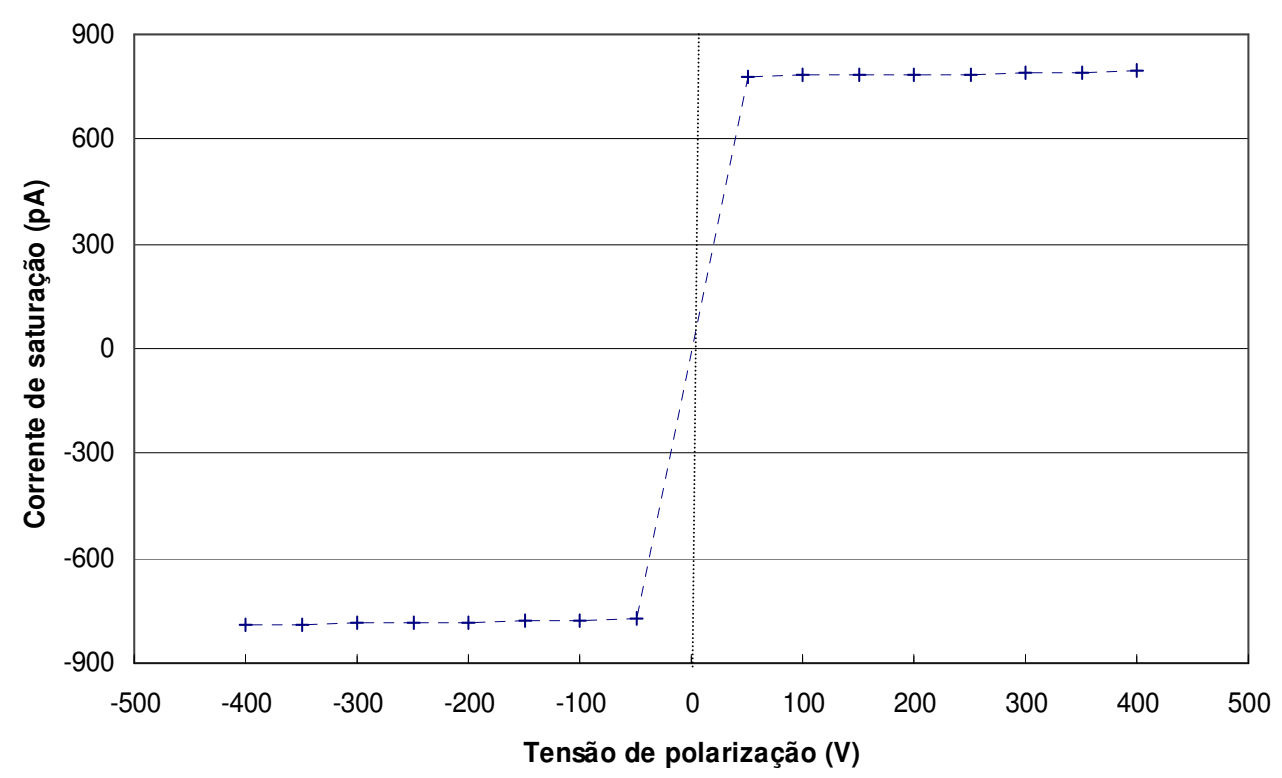

Figura 8.2. Curva de saturação da câmara de ionização com eletrodo coletor de grafite. Qualidade de radiação X, RQR 3, tensão $50 \mathrm{kV}$ e corrente de 10 mA, distância foco-câmara $1 \mathrm{~m}$.

Nas curvas de saturação das Figuras 8.1 e 8.2, pode-se observar que as câmaras apresentaram o comportamento esperado, com a saturação atingida acima de $50 \mathrm{~V}$, de modo análogo ao ocorrido com as qualidades de radiação $\mathrm{X}$, nível radioproteção.

Para a etapa de verificação do efeito de polaridade nas câmaras de ionização desenvolvidas neste trabalho, utilizou-se a qualidade de raios $X$ RQR 3, nível radiodiagnóstico, lembrando que o efeito de polaridade para uma qualidade de raios $\mathrm{X}$, com os valores máximos permitidos de tensão de polarização positiva e negativa, deve ser menor que $1 \%{ }^{(80)}$.

Desse modo, a razão entre as cargas coletadas positiva e negativa, com os valores máximos de tensão de polarização positiva e negativa, em função da qualidade da radiação incidente deve estar entre 0,99 e 1,01. As Tabelas 8.1 e 8.2 mostram os valores obtidos para este ensaio para as duas câmaras. Foram aplicadas 
tensões de polarização de $+400 \mathrm{~V}$ até $-400 \mathrm{~V}$, com intervalos de incremento de tensão de $50 \mathrm{~V}$.

Para ambas as câmaras de ionização, os resultados obtidos mantiveram-se dentro do intervalo recomendado (entre 0,99 e 1,01). Assim, na região de saturação, o efeito de polaridade foi menor que $1 \%$ para as duas câmaras de ionização. Dos valores médios obtidos pelas câmaras, verifica-se que a câmara de ionização com eletrodo coletor de alumínio é cerca de 2,3 vezes mais sensível que a câmara com eletrodo de grafite.

Para as duas câmaras de ionização utilizou-se a tensão de +400 V. Para este valor de tensão de polarização a probabilidade de ocorrência do efeito de recombinação de íons, nestas câmaras de ionização, é praticamente inexistente.

Tabela 8.1. Efeito de polaridade da câmara de ionização com eletrodo coletor de alumínio.

\begin{tabular}{ccc}
\hline $\begin{array}{c}\text { Tensão de Polarização } \\
(\mathrm{V})\end{array}$ & $\begin{array}{c}\text { Carga } \\
(\mathrm{nC})\end{array}$ & $\begin{array}{c}\text { Razão } \\
(\mathrm{Q}+/ \mathrm{Q}-)\end{array}$ \\
\hline$+50 /-50$ & $1,61 / 1,63$ & 0,99 \\
$+100 /-100$ & $1,65 / 1,64$ & 1,01 \\
$+150 /-150$ & $1,64 / 1,64$ & 1,00 \\
$+200 /-200$ & $1,66 / 1,65$ & 1,01 \\
$+250 /-250$ & $1,64 / 1,65$ & 0,99 \\
$+300 /-300$ & $1,65 / 1,64$ & 1,01 \\
$+350 /-350$ & $1,64 / 1,63$ & 1,01 \\
$+400 /-400$ & $1,65 / 1,63$ & 1,01 \\
\hline
\end{tabular}

Q+ = carga coletada com aplicação de tensão de polarização positiva na câmara de ionização Q- = carga coletada com aplicação de tensão de polarização negativa na câmara de ionização 
Tabela 8.2. Efeito de polaridade da câmara de ionização com eletrodo coletor de grafite.

\begin{tabular}{ccc}
\hline $\begin{array}{c}\text { Tensão de Polarização } \\
(\mathrm{V})\end{array}$ & $\begin{array}{c}\text { Carga } \\
(\mathrm{pC})\end{array}$ & $\begin{array}{c}\text { Razão } \\
(\mathrm{Q}+/ \mathrm{Q}-)\end{array}$ \\
\hline$+50 /-50$ & $781,34 / 771,81$ & 1,01 \\
$+100 /-100$ & $781,91 / 776,20$ & 1,01 \\
$+150 /-150$ & $783,26 / 779,10$ & 1,01 \\
$+200 /-200$ & $784,72 / 782,11$ & 1,00 \\
$+250 /-250$ & $786,04 / 784,16$ & 1,00 \\
$+300 /-300$ & $788,26 / 786,00$ & 1,00 \\
$+350 /-350$ & $793,40 / 787,63$ & 1,01 \\
$+400 /-400$ & $799,21 / 789,66$ & 1,01 \\
\hline
\end{tabular}

Q+ = carga coletada com aplicação de tensão de polarização positiva na câmara de ionização Q- = carga coletada com aplicação de tensão de polarização negativa na câmara de ionização

Foram utilizados os valores de $200 \mathrm{~V}$ e $400 \mathrm{~V}$, positivos e negativos, obtidos nos ensaios de saturação, e assim foram feitos os cálculos da eficiência de coleta de íons para cada uma das câmaras de ionização. Desse modo, a eficiência de coleção de íons $\mathrm{K}_{\mathrm{s}}$ foi determinada pelo método das duas tensões usando-se a relação $(6.1)^{(78)}$.

As duas câmaras de ionização atenderam ao recomendado, ou melhor, a eficiência para as duas câmaras de ionização ficaram em torno de 100 \%, lembrando que a eficiência de coleta de íons deve ser melhor que $99 \%{ }^{(78,80,81)}$. Os valores obtidos estão apresentados na Tabela 8.3

Tabela 8.3. Eficiência de coleta de íons das duas câmaras de ionização para a qualidade de radiação RQR 3 (raios X, nível radiodiagnóstico).

Câmara de Ionização com Eficiência de Coleta de Íons

\begin{tabular}{ccc} 
Eletrodo Coletor & $\begin{array}{c}\text { Tensão de Polarização } \\
\text { de }\end{array}$ & $\begin{array}{c}\text { Tensão de Polarização } \\
\text { Positiva }\end{array}$ \\
\hline Alumínio & 0,9969 & 0,9957 \\
Grafite & 1,0062 & 1,0032
\end{tabular}


Dos resultados obtidos, pode-se concluir que as variações nas leituras obtidas dos ensaios realizados para as curvas de saturação não superaram $1 \%$ para aplicação de tensões de polarização positivas e negativas nas câmaras de ionização no intervalo de $+400 \mathrm{~V}$ até $-400 \mathrm{~V}$, com variações de $50 \mathrm{~V}$. Com relação ao efeito de polaridade, as câmaras ensaiadas atenderam ao recomendado pela norma, ou seja, os valores obtidos ficaram entre 0,99 e 1,01. O mesmo ocorreu com o ensaio de recombinação iônica. Os ensaios atenderam ao recomendado pela norma IEC $60731^{(80)}$. A eficiência de coleção é melhor que $99 \%$ em $+400 \mathrm{~V}$ para as câmaras de ionização, isto é, as perdas por recombinação iônica são menores que $1 \%$.

\section{2 - Variação da resposta com o tamanho do campo}

As câmaras foram irradiadas nas qualidades de radiação $X$, nível radiodiagnóstico, RQR 3 (feixes diretos) e RQA 3 (feixes atenuados), de acordo com a norma IEC $61627^{(82)}$, variando-se o diâmetro do colimador de chumbo que delimita o tamanho do campo (com três diâmetros diferentes).

Foram utilizadas as qualidades de radiação de $50 \mathrm{kV}$ e $10 \mathrm{~mA}$ (RQR 3) e 50 kV e 20 mA (RQA 3) como radiações de referência, ou seja, para a condição que utiliza o colimador de chumbo, com diâmetro de $70,5 \mathrm{~mm}$. Todas as medidas foram realizadas em uma distância foco-detector de $1 \mathrm{~m}$.

As dimensões dos campos de radiação em função do tamanho do colimador são apresentadas na Tabela 8.4. Nas Tabelas 8.5 e 8.6 são apresentados os resultados obtidos dos ensaios. Após realizadas as medidas, nota-se que para um diâmetro de campo de 12,2 cm (utilizando-se o colimador de 50,8 mm), ocorreu uma redução no valor de carga medida de apenas 0,3 \% para a câmara de ionização com eletrodo coletor de alumínio e 1,2 \% para a câmara de ionização com eletrodo coletor de grafite, para os feixes diretos (RQR 3) e 2,3\% e 1,5\% para os feixes atenuados (RQA 3). 
No entanto, para um diâmetro de campo de $7,5 \mathrm{~cm}$ (com o uso do colimador de $32 \mathrm{~mm}$ ), obteve-se uma variação nos valores das medidas de carga de 1,5\% para a câmara de ionização com eletrodo coletor de alumínio e 2,3 \% para a câmara de ionização com eletrodo coletor de grafite, para a qualidade de radiação RQR 3. Para a qualidade RQA 3 obteve-se uma variação nas medidas de carga de 4,3 \% para a câmara de ionização com eletrodo coletor de alumínio e de 5,1 \% para a câmara de ionização com eletrodo coletor de grafite.

Para um diâmetro de campo de radiação de $3,6 \mathrm{~cm}$ (empregando-se o colimador de 17 mm de diâmetro), obteve-se variações na leitura de carga de 10,2 \% para a câmara de ionização com eletrodo coletor de alumínio e de 11,9 \% para a câmara de ionização com eletrodo coletor de grafite utilizando-se a qualidade RQR 3. De modo análogo, empregou-se qualidade RQA 3 e foram obtidos os seguintes resultados: variação de 15,2 \% nas medidas realizadas com a câmara de ionização com eletrodo coletor de alumínio e 15,5 \% para a câmara com eletrodo coletor de grafite.

Tabela 8.4. Tamanho de campo útil para o ensaio de resposta relativa em função do tamanho do campo para posicionamento das câmaras de ionização desenvolvidas.

\begin{tabular}{cc}
\hline $\begin{array}{c}\text { Diâmetro do Colimador } \\
\text { de Chumbo } \\
(\mathrm{mm})\end{array}$ & $\begin{array}{c}\text { Diâmetro do Campo a 1,0 m do Foco } \\
\text { do Sistema de Raios X } \\
(\mathrm{cm})\end{array}$ \\
\hline 17,0 & $3,6 \pm 0,3$ \\
32,0 & $7,5 \pm 0,5$ \\
50,8 & $12,2 \pm 0,6$ \\
70,5 & $17,2 \pm 0,7$ \\
\hline
\end{tabular}


Tabela 8.5. Resposta relativa das câmaras de ionização desenvolvidas, em função do tamanho do campo para radiação $X$, nível radiodiagnóstico, feixes diretos (RQR 3).

\begin{tabular}{ccccc}
\hline \begin{tabular}{c} 
Câmara \\
de \\
$\begin{array}{c}\text { Ionização com } \\
\text { Eletrodo } \\
\text { de }\end{array}$ \\
\cline { 2 - 5 }
\end{tabular} & \multicolumn{4}{c}{$\begin{array}{c}\text { Diâmetro do Colimador } \\
(\mathrm{mm})\end{array}$} \\
\hline Alumínio & 1 & $0,997 \pm 0,030$ & $0,985 \pm 0,030$ & $0,898 \pm 0,030$ \\
Grafite & 1 & $0,988 \pm 0,030$ & $0,977 \pm 0,030$ & $0,881 \pm 0,030$ \\
\hline
\end{tabular}

Tabela 8.6. Resposta relativa das câmaras de ionização desenvolvidas, em função do tamanho do campo para radiação $X$, nível radiodiagnóstico, feixes atenuados (RQA 3).

\begin{tabular}{ccccc}
\hline \begin{tabular}{c} 
Câmara \\
de \\
Ionização com \\
Eletrodo \\
\cline { 2 - 4 }
\end{tabular} & 70,5 & 50,8 & \multicolumn{4}{c}{$\begin{array}{c}\text { Diâmetro do Colimador } \\
(\mathrm{mm})\end{array}$} \\
\hline Alumínio & 1 & $0,977 \pm 0,030$ & $0,957 \pm 0,030$ & $0,848 \pm 0,030$ \\
Grafite & 1 & $0,985 \pm 0,030$ & $0,949 \pm 0,030$ & $0,845 \pm 0,030$ \\
\hline
\end{tabular}

\section{3 - Tempo de estabilização}

Nesta etapa, as câmaras de ionização com eletrodos coletores de grafite e alumínio foram irradiadas em feixes de radiação $X$, da qualidade RQR 3 (50 kV e $10 \mathrm{~mA}$ ) com uma taxa de kerma no ar de $24,2 \mathrm{mGy} / \mathrm{min}$. As câmaras de ionização foram irradiadas continuamente por $2 \mathrm{~h}$, após a aplicação da tensão de polarização. Foram obtidas as respostas das câmaras de ionização, nos intervalos de tempo de 15 min, $1 \mathrm{~h}$ e $2 \mathrm{~h}$, sendo que a resposta das câmaras de ionização neste campo de radiação foi determinada como sendo o valor médio de dez medidas consecutivas. Os resultados são mostrados nas Tabelas 8.7 e 8.8. As duas câmaras de ionização (com 
eletrodos de alumínio e de grafite) atenderam às recomendações da norma IEC $60731^{(80)}$ para o teste de tempo de estabilização, ou seja, suas respostas relativas ficaram entre 0,995 e 1,005.

Tabela 8.7. Tempo de estabilização: resposta relativa da câmara de ionização com eletrodo coletor de alumínio em função do tempo.

\begin{tabular}{cc}
\hline Tempo & Resposta \\
\hline 15 min & $1,002 \pm 0,030$ \\
$1 \mathrm{~h}$ & 1 \\
$2 \mathrm{~h}$ & $0,997 \pm 0,030$ \\
\hline
\end{tabular}

Tabela 8.8. Tempo de estabilização: resposta relativa da câmara de ionização com eletrodo coletor de grafite em função do tempo.

\begin{tabular}{cc}
\hline Tempo & Resposta \\
\hline 15 min & $0,998 \pm 0,027$ \\
$1 \mathrm{~h}$ & 1 \\
$2 \mathrm{~h}$ & $1,002 \pm 0,027$ \\
\hline
\end{tabular}

\section{4 - Estabilidade a curto prazo ou teste de repetitividade}

As câmaras de ionização com eletrodos coletores de alumínio e grafite tiveram seus comportamentos verificados quanto à estabilidade a curto prazo (teste de repetitividade). Para tal foram realizadas dez medições sucessivas, por diversas vezes, utilizando-se o sistema de radiação X, na qualidade RQR 3 (50 kV e $10 \mathrm{~mA}$ ) e com taxa de kerma no ar de 24,2 mGy/min. Em todos os resultados obtidos, o desvio padrão percentual mostrou-se inferior a 0,5\%, sendo este o valor máximo aceitável, segundo a norma IEC $60731^{(80)}$. Assim, o desvio percentual máximo nas medidas de 0,06 \% de variação foi obtido para a câmara com eletrodo coletor de alumínio e de 0,12 \% para a câmara com eletrodo coletor de grafite. 


\section{5 - Corrente de fuga após irradiação}

As câmaras de ionização com eletrodos coletores de alumínio e grafite foram irradiadas em um campo de radiação $X$, nível radiodiagnóstico, com tensão de $50 \mathrm{kV}$ e corrente de $1 \mathrm{~mA}$ (qualidade de radiação RQR 3), com taxa de kerma no ar de 2,4 mGy/min. As câmaras de ionização foram irradiadas continuamente por 10 minutos e logo após a irradiação foi medido o tempo de decréscimo da leitura. Para a câmara com eletrodo coletor de alumínio este tempo de decréscimo da leitura foi de cerca de 3,0 s e para a câmara com eletrodo coletor de grafite este tempo foi de cerca de 2,5 s. Assim, as duas câmaras de ionização atenderam ao solicitado pela norma IEC $60731^{(80)}$. Neste ensaio, a recomendação é que dentro de $5 \mathrm{~s}$ após o término de uma irradiação de 10 min, a corrente de fuga transiente deve decrescer a $\pm 1,0 \%$ da corrente de ionização produzida na câmara durante a irradiação ${ }^{(80)}$.

\section{6 - Linearidade da resposta}

As câmaras de ionização com eletrodos coletores de grafite e de alumínio foram irradiadas com a qualidade de raios $X$, nível radiodiagnóstico, com tensão de $50 \mathrm{kV}$ e a corrente variando de 0,5 mA até $25 \mathrm{~mA}$. Foram realizadas dez medidas sucessivas e foi tomado o valor médio para cada corrente selecionada. Após realizadas as medidas, determinou-se a relação linear entre a corrente de ionização e a taxa de kerma no ar. Nas qualidades de radiação $X$, nível radiodiagnóstico, a incerteza na linearidade de resposta foi de $\pm 2,4 \%$ para a câmara com eletrodo coletor de grafite e de $\pm 1,4 \%$ para a câmara com eletrodo coletor de alumínio. As Figuras 8.3 e 8.4 mostram os resultados obtidos.

Pode-se observar que as duas câmaras de ionização apresentaram um comportamento linear nesta qualidade ensaiada (RQR 3), assim como o sistema gerador de raios $X$, que também se manteve estável, apresentando comportamento linear (corrente no tubo de raios X). Assim, de modo análogo aos ensaios já realizados para as qualidades de radiação $X$, nível radioproteção (item 6.8), as 
câmaras de ionização com eletrodos coletores de grafite e alumínio mostraram um bom desempenho em qualidades de radiação $X$, nível radiodiagnóstico.

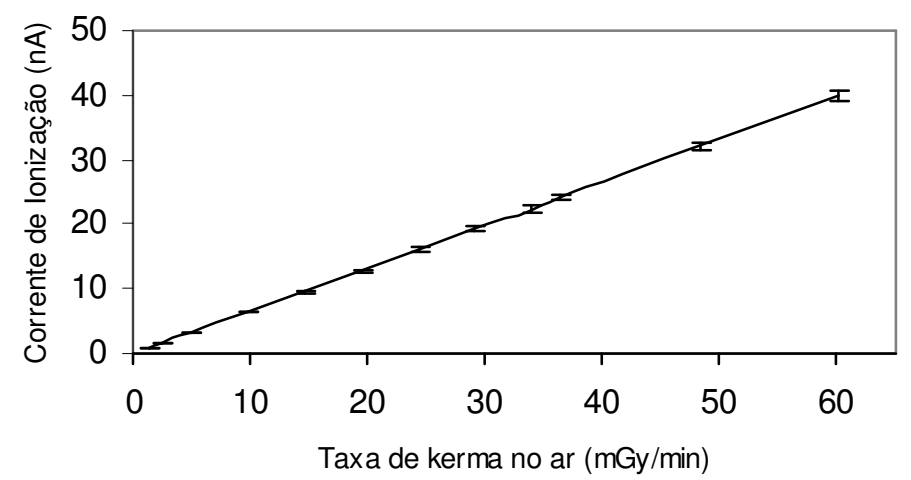

Figura 8.3. Linearidade de resposta da câmara de ionização com eletrodo coletor de alumínio, para raios $\mathrm{X}$, nível radiodiagnóstico, RQR 3, de $50 \mathrm{kV}$ $(1,5 \mathrm{mmAl})$.

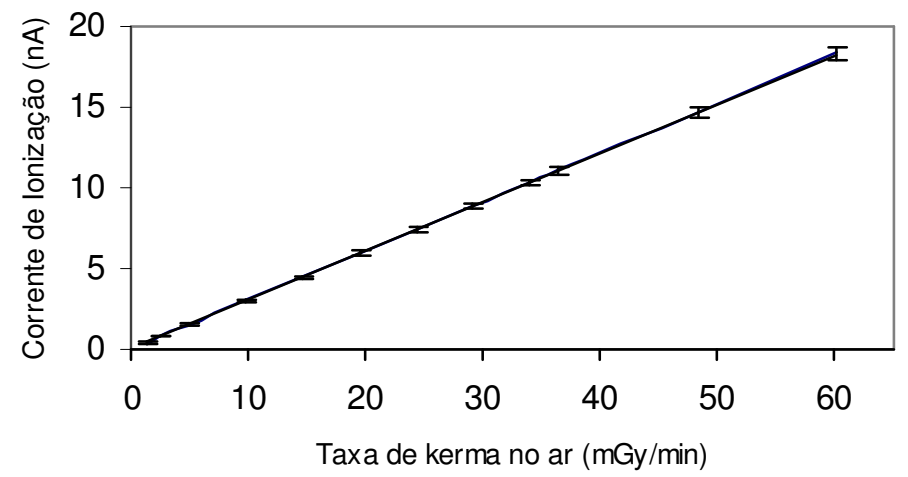

Figura 8.4. Linearidade de resposta da câmara de ionização com eletrodo coletor de grafite, para raios $\mathrm{X}$, nível radiodiagnóstico, RQR 3, de $50 \mathrm{kV}$ (1,5 mmAl).

\section{7 - Dependência angular}

Pode ocorrer na prática, durante o posicionamento das câmaras de ionização, uma ligeira variação no ângulo de incidência da radiação; por isso foi testada a dependência angular das câmaras desenvolvidas neste trabalho, em feixes de radiodiagnóstico. 
Assim, foi testada a dependência angular das câmaras de ionização desenvolvidas neste trabalho. Utilizou-se neste ensaio a qualidade de radiação RQR 3, implantada no sistema de radiação X Pantak/Seifert. A distância foco-detector utilizada foi de $1 \mathrm{~m}$.

As câmaras de ionização foram irradiadas no ar, tomando-se como referência o centro do volume sensível das câmaras. As medidas foram obtidas variando-se o ângulo de incidência da radiação entre $0^{\circ}$ e $90^{\circ}$, girando-se a câmara no sentido horário (ângulos positivos) e anti-horário (ângulos negativos), onde $0^{\circ}$ significa irradiação frontal.

As respostas obtidas correspondem aos valores médios de dez medidas sucessivas e foram normalizadas para o ângulo de $0^{\circ}$ para cada uma das qualidades. Dos resultados obtidos pode-se observar que a câmara de ionização com eletrodo coletor de alumínio atende ao recomendado pela norma para inclinação de $+15^{\circ}$. A câmara de ionização com eletrodo coletor de grafite atendeu à exigência da norma IEC $60731^{(80)}$, tanto para inclinação de $+15^{\circ}$, como para $-15^{\circ}$. O limite de variação da resposta não deve superar $\pm 3,0 \%$ do valor obtido para posição de irradiação de $0^{\circ}$ para variações de até $\pm 5^{\circ}$. As Tabelas 8.9 e 8.10 e as Figuras 8.5 e 8.6 mostram os valores obtidos dos ensaios de dependência angular, normalizados para irradiação frontal.

Com relação aos dados obtidos com as qualidades de radiação $\mathrm{X}$ e radiação gama, nível radioproterção, pode-se verficar que apesar das câmaras de ionização desenvolvidas neste trabalho serem adequadas para utilização nestas qualidades de radiação, elas apresentaram um desempenho também muito bom em qualidades de radiação $X$, nível radiodiagnóstico; assim, elas podem ser utilizadas para a verificação da constância de feixes de radiação $X$, tanto nível radioproteção, como radiodiagnóstico. 
Tabela 8.9. Resposta relativa da câmara de ionização com eletrodo coletor de alumínio em função da inclinação, para a qualidade da radiação $X$ RQR 3, nível radiodiagnóstico, com o sistema Pantak/Seifert.

\begin{tabular}{cc}
\hline $\begin{array}{c}\text { Ângulo de } \\
\text { Inclinação } \\
\left({ }^{\circ}\right)\end{array}$ & Radiação X \\
\hline 0 & 1 \\
+15 & $0,974 \pm 0,007$ \\
+45 & $0,921 \pm 0,006$ \\
+60 & $0,769 \pm 0,005$ \\
+90 & $0,036 \pm 0,008$ \\
-15 & $0,946 \pm 0,007$ \\
-45 & $0,912 \pm 0,006$ \\
-60 & $0,850 \pm 0,005$ \\
-90 & $0,049 \pm 0,008$ \\
\hline
\end{tabular}

Tabela 8.10. Resposta relativa da câmara de ionização com eletrodo coletor de grafite em função da inclinação para a qualidade da radiação X RQR 3, nível radiodiagnóstico, com o sistema Pantak/Seifert.

\begin{tabular}{cc}
\hline $\begin{array}{c}\text { Angulo de } \\
\text { Inclinação } \\
\left({ }^{\circ}\right)\end{array}$ & Radiação X \\
\hline 0 & 1 \\
+15 & $0,989 \pm 0,007$ \\
+45 & $0,887 \pm 0,006$ \\
+60 & $0,748 \pm 0,006$ \\
+90 & $0,091 \pm 0,008$ \\
-15 & $0,985 \pm 0,007$ \\
-45 & $0,833 \pm 0,007$ \\
-60 & $0,605 \pm 0,008$ \\
-90 & $0,061 \pm 0,008$ \\
\hline
\end{tabular}




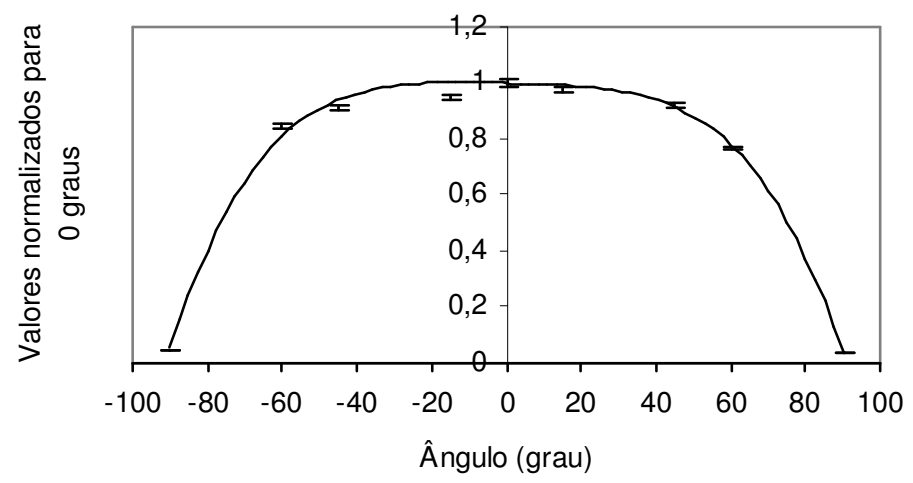

Figura 8.5. Resposta relativa em função da inclinação da câmara com eletrodo coletor de alumínio, para raios $X$, nível radiodiagnóstico, RQR 3 .

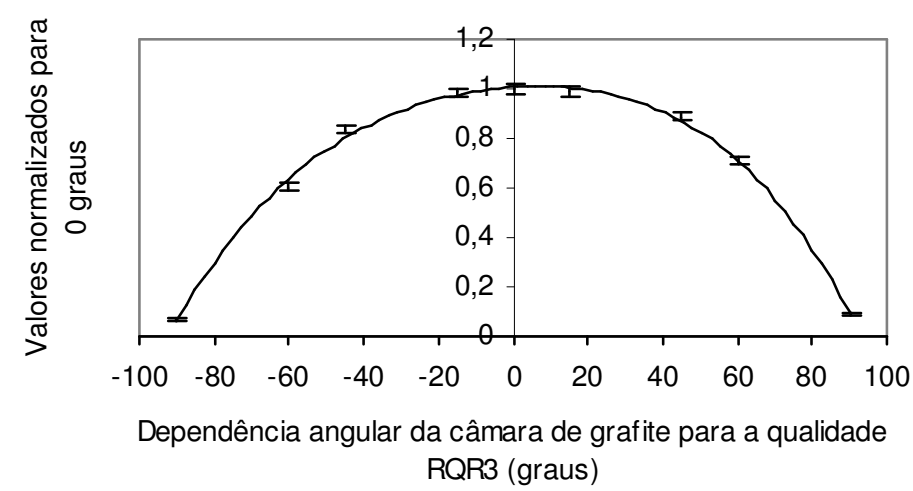

Figura 8.6. Resposta relativa em função da inclinação da câmara com eletrodo coletor de grafite, para raios $\mathrm{X}$, nível radiodiagnóstico, RQR 3 .

\section{8 - Calibração das câmaras de ionização}

As câmaras de ionização com eletrodos coletores de alumínio e grafite desenvolvidas, foram ainda calibradas em qualidades de radiação $X$, níveis radioadiagnóstico, radioterapia e mamografia. Nas Tabelas 3.3 a 3.5, 3.7 e 3.8 estão apresentadas as qualidades de radiação $X$ utilizadas para a calibração das câmaras de ionização. As distâncias foco-detector utilizadas foram de $1 \mathrm{~m}$ para as qualidades de radiação $X$, nível radioadiagnóstico e mamografia, e de $50 \mathrm{~cm}$ para as qualidades de radioterapia. 
De modo análogo aos coeficientes de calibração ${ }^{(10)}$ obtidos com qualidades de radiação $X$, nível radioproteção (item 6.10 ), os coeficientes de calibração para as qualidades de raios $X$, níveis radiodiagnóstico, radioterapia e mamografia foram obtidos empregando-se os sistemas padrões para cada faixa de energia e qualidade apresentados na Tabela 3.2. As cargas coletadas (corrigidas para as condições de pressão e temperatura de referência) foram transformadas em taxa de kerma no ar, por meio de um fator de correção. Os coeficientes de calibração, ou fatores de calibração, são obtidos por meio da razão entre a taxa de kerma no ar medido com a câmara de ionização padrão ou de referência e a leitura da câmara de ionização sob calibração. As Tabelas 8.11 e 8.12 mostram os valores obtidos dos coeficientes de calibração para as qualidades de radiação $X$, níveis radiodiagnóstico (feixes diretos $\mathrm{e}$ atenuados), radioterapia e mamografia.

Tabela 8.11. Coeficientes de calibração das câmaras de ionização (com eletrodos coletores de alumínio e grafite) para radiação $X$, nível radiodiagnóstico (feixes diretos e atenuados).

\begin{tabular}{|c|c|c|c|c|c|}
\hline \multirow{3}{*}{\multicolumn{2}{|c|}{$\begin{array}{l}\text { Qualidade } \\
\text { da } \\
\text { Radiação }\end{array}$}} & \multirow{3}{*}{$\begin{array}{l}\text { Camada } \\
\text { Semi- } \\
\text { Redutora } \\
(\mathrm{mm})\end{array}$} & \multirow{3}{*}{$\begin{array}{c}\text { Energia } \\
\text { Efetiva } \\
\text { (keV) }\end{array}$} & \multicolumn{2}{|c|}{$\begin{array}{c}\text { Coeficiente de Calibração } \\
\times 10^{5} \mathrm{~Gy} / \mathrm{C}\end{array}$} \\
\hline & & & & \multicolumn{2}{|c|}{ Câmara com Eletrodo de } \\
\hline & & & & Alumínio & Grafite \\
\hline & RQR3 & $1,79 \mathrm{Al}$ & 27,15 & $13,6 \pm 0,4$ & $30,0 \pm 1,0$ \\
\hline Diagnóstico & RQR5 & $2,35 \mathrm{Al}$ & 30,15 & $11,5 \pm 0,4$ & $26,4 \pm 0,8$ \\
\hline FEIXES & RQR7 & 2,95 Al & 33,05 & $10,4 \pm 0,3$ & $23,9 \pm 0,8$ \\
\hline \multirow[t]{3}{*}{ DIRETOS } & RQR9 & $3,84 \mathrm{Al}$ & 37,05 & $9,7 \pm 0,3$ & $21,8 \pm 0,7$ \\
\hline & RQR10 & $4,73 \mathrm{Al}$ & 40,75 & $9,4 \pm 0,3$ & $20,5 \pm 0,7$ \\
\hline & RQA3 & $3,91 \mathrm{Al}$ & 37,30 & $9,8 \pm 0,3$ & $23,9 \pm 0,8$ \\
\hline Diagnóstico & RQA5 & $6,86 \mathrm{Al}$ & 49,40 & $8,6 \pm 0,3$ & $21,2 \pm 0,7$ \\
\hline FEIXES & RQA7 & $9,22 \mathrm{Al}$ & 59,70 & $8,1 \pm 0,3$ & $18,1 \pm 0,6$ \\
\hline \multirow[t]{2}{*}{ ATENUADOS } & RQA9 & $11,39 \mathrm{Al}$ & 71,15 & $8,8 \pm 0,3$ & $17,8 \pm 0,6$ \\
\hline & RQA10 & $13,02 \mathrm{Al}$ & 82,10 & $9,4 \pm 0,3$ & $17,6 \pm 0,6$ \\
\hline
\end{tabular}


Tabela 8.12. Coeficientes de calibração das câmaras de ionização (alumínio e grafite) para radiação $X$ (níveis radioterapia e mamografia).

\begin{tabular}{|c|c|c|c|c|c|}
\hline Qual & & $\begin{array}{l}\text { Camada } \\
\text { Semi- }\end{array}$ & $\begin{array}{l}\text { Energia } \\
\text { Efetiva }\end{array}$ & $\begin{array}{r}\text { Coeficiente } \\
\times 10\end{array}$ & $\begin{array}{l}\text { e Calibração } \\
\text { Gy/C }\end{array}$ \\
\hline & & Redutora & & Câmara con & Eletrodo de \\
\hline Rad & & $(\mathrm{mm})$ & (keV) & Alumínio & Grafite \\
\hline & RT-30 & $0,36 \mathrm{Al}$ & 15,50 & $49,1 \pm 2,0$ & $82,9 \pm 3,0$ \\
\hline Terapia & RT-50 & $0,89 \mathrm{Al}$ & 21,20 & $29,9 \pm 1,2$ & $50,0 \pm 2,0$ \\
\hline Mamografia & M 25 & $0,33 \mathrm{Al}$ & 15,10 & $57,8 \pm 4,0$ & $87,4 \pm 5,3$ \\
\hline FEIXES DE & M 28 & $0,34 \mathrm{Al}$ & 15,30 & $56,3 \pm 3,4$ & $84,6 \pm 5,1$ \\
\hline ENTRADA & M 35 & $0,38 \mathrm{Al}$ & 16,20 & $49,2 \pm 3,0$ & $75,8 \pm 4,6$ \\
\hline Mamografia & M 25x & $0,58 \mathrm{Al}$ & 18,80 & $35,4 \pm 2,1$ & $58,0 \pm 3,5$ \\
\hline FEIXES DE & M $28 x$ & $0,61 \mathrm{Al}$ & 19,00 & $32,1 \pm 1,9$ & $52,4 \pm 3,2$ \\
\hline SAÍDA & M $35 x$ & $0,85 \mathrm{Al}$ & 21,60 & $21,9 \pm 1,3$ & $42,5 \pm 2,6$ \\
\hline
\end{tabular}

Dos resultados obtidos nas Tabelas 8.11 e 8.12 para as qualidades de radiação $\mathrm{X}$, níveis radiodiagnóstico (convencional e mamografia) e radioterapia, podese verificar que os coeficientes de calibração das câmaras de ionização desenvolvidas com eletrodos coletores de alumínio e grafite, decrescem com o aumento da energia destes feixes de radiação $X$.

\section{9 - Dependência energética}

Neste trabalho, foi ainda estudada a dependência energética das câmaras de ionização de placas paralelas em qualidades de radiação $X$, níveis radiodiagnóstico (feixes diretos e atenuados) e mamografia. As Figuras 8.7 a 8.14 , mostram os fatores de correção, obtidos pela normalização dos coeficientes de calibração para a camada semi-redutora de 2,35 mmAl, nas qualidades de radiação $X$, nível radiodiagnóstico, feixes diretos, e normalização dos coeficientes de calibração para a camada semiredutora de $6,86 \mathrm{mmAl}$ no caso dos feixes atenuados, nível radiodiagnóstico. Os 
fatores de correção para as qualidades de radiação $X$, nível mamografia, foram obtidos pela normalização para a camada semi-redutora de $0,34 \mathrm{mmAl}$ para feixes de entrada e de 0,61 mmAl para os feixes de saída.

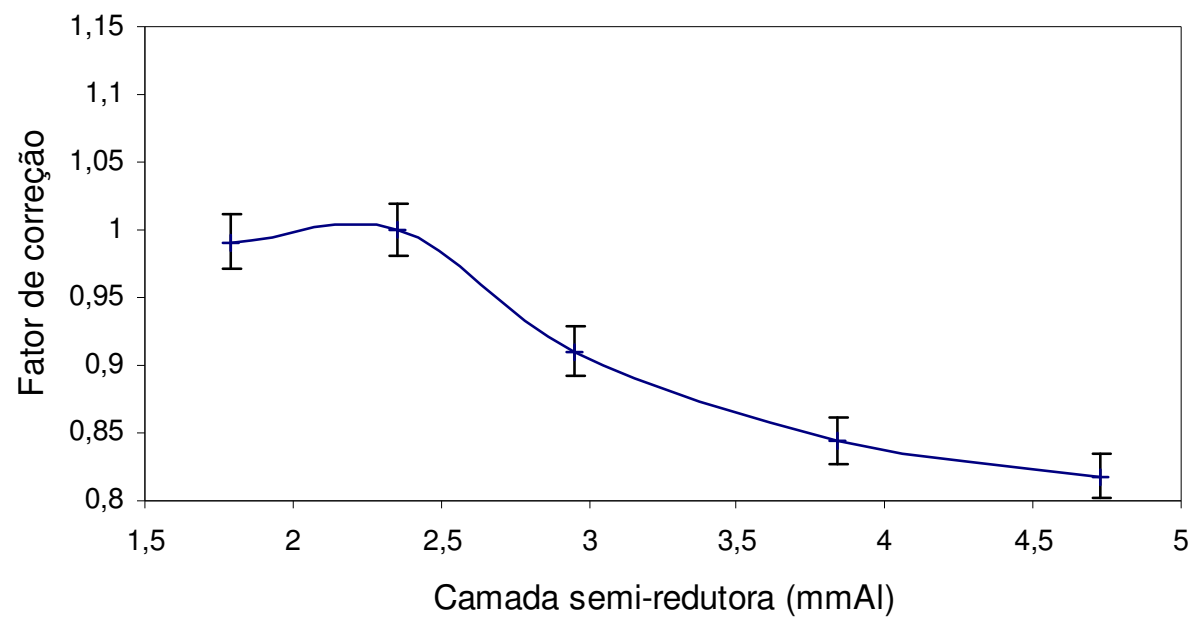

Figura 8.7. Fatores de correção da resposta da câmara de ionização com eletrodo coletor de alumínio, para as qualidades de raios $\mathrm{X}$, nível diagnóstico, feixes diretos, normalizados para a camada semi-redutora de 2,35 mmAl.

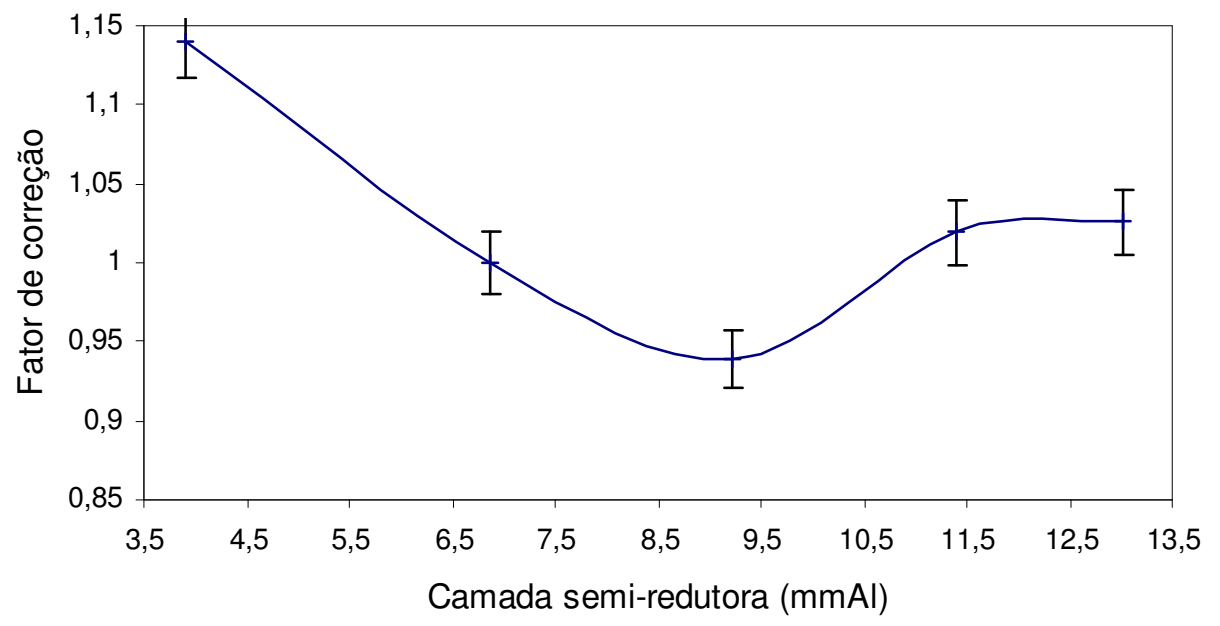

Figura 8.8. Fatores de correção da resposta da câmara de ionização com eletrodo coletor de alumínio, para as qualidades de raios $\mathrm{X}$, nível diagnóstico, feixes atenuados, normalizados para a camada semi-redutora de $6,86 \mathrm{mmAl}$. 


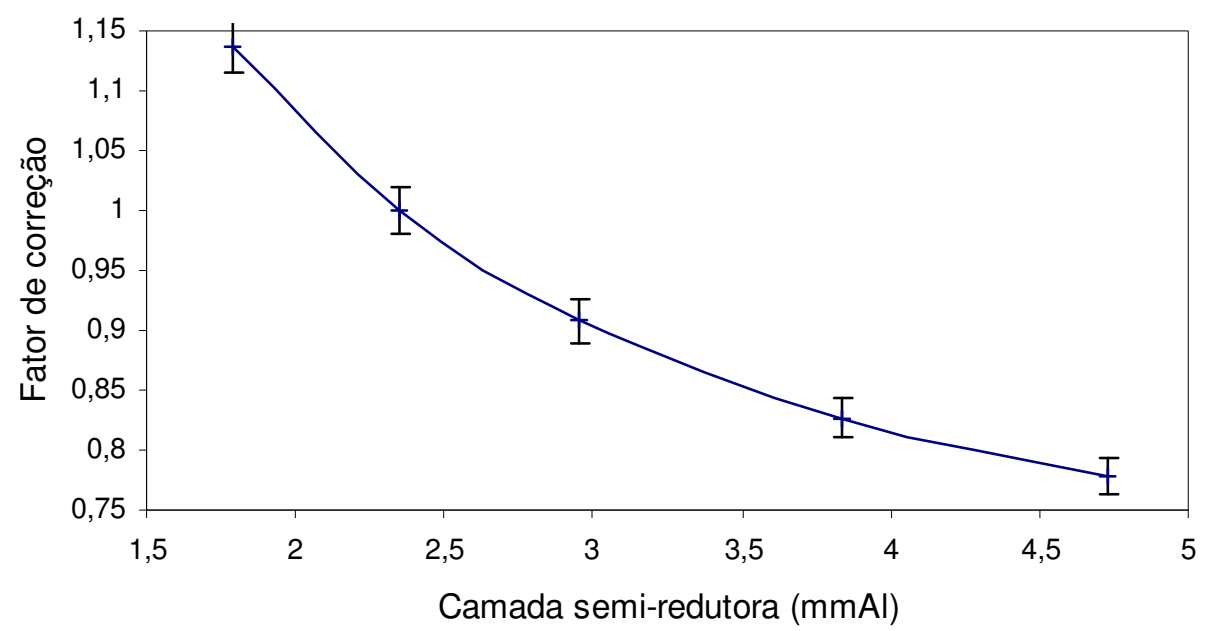

Figura 8.9. Fatores de correção da resposta da câmara de ionização com eletrodo coletor de grafite, para as qualidades de raios $X$, nível diagnóstico, feixes diretos, normalizados para a camada semi-redutora de 2,35 mmAl.

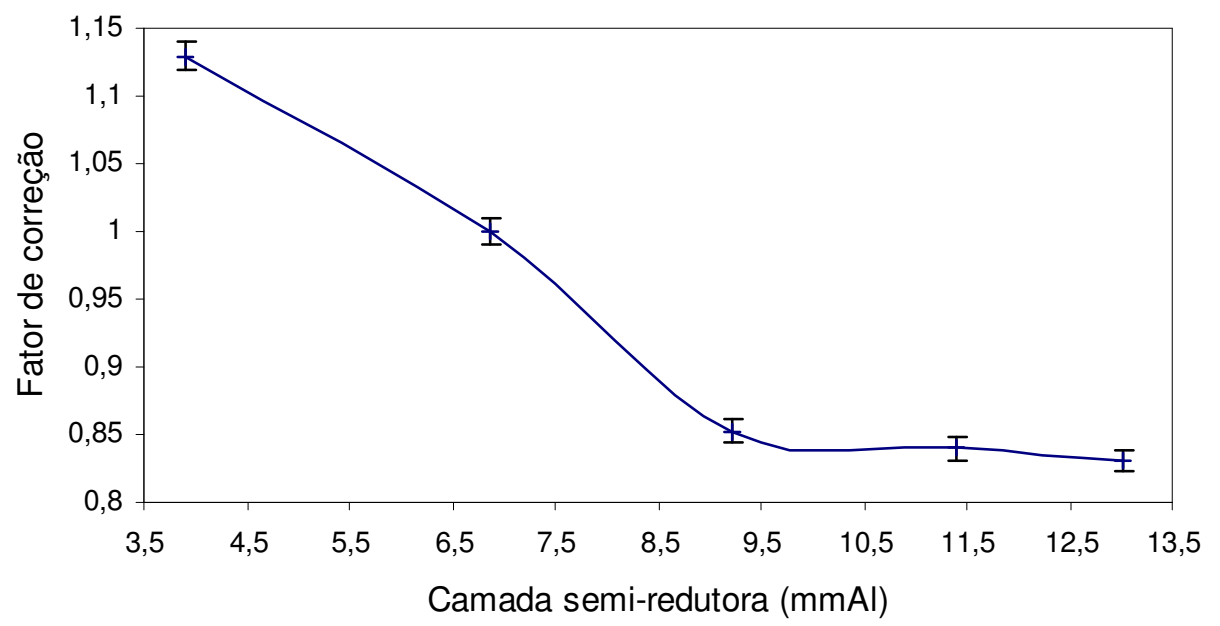

Figura 8.10. Fatores de correção da resposta da câmara de ionização com eletrodo coletor de grafite, para as qualidades de raios $\mathrm{X}$, nível diagnóstico, feixes atenuados, normalizados para a camada semi-redutora de $6,86 \mathrm{mmAl}$. 


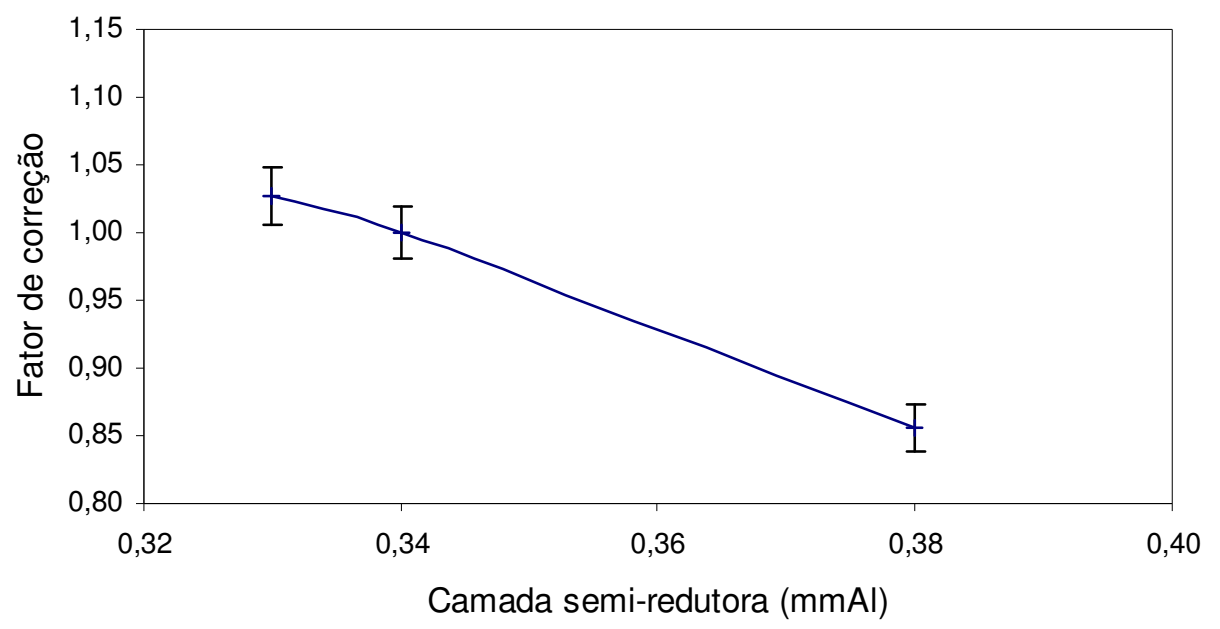

Figura 8.11. Fatores de correção da resposta da câmara de ionização com eletrodo coletor de alumínio, para as qualidades de raios $\mathrm{X}$, nível mamografia, feixes de entrada, normalizados para a camada semi-redutora de $0,34 \mathrm{mmAl}$.

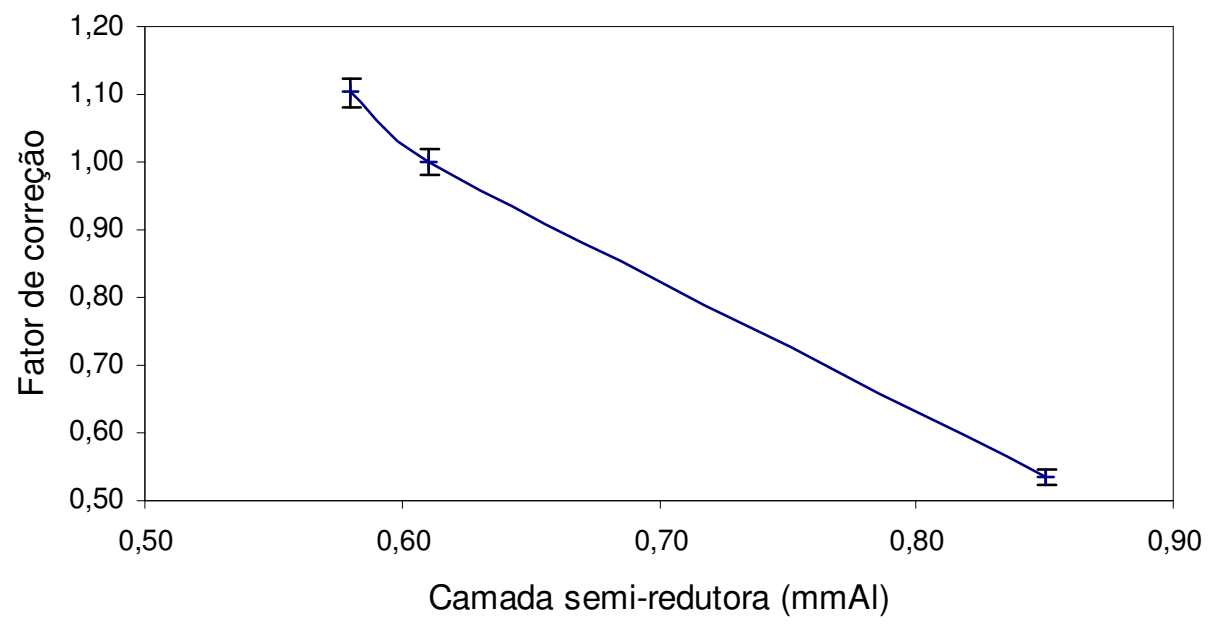

Figura 8.12. Fatores de correção da resposta da câmara de ionização com eletrodo coletor de alumínio, para as qualidades de raios $\mathrm{X}$, nível mamografia, feixes de saída, normalizados para a camada semi-redutora de $0,61 \mathrm{mmAl}$. 


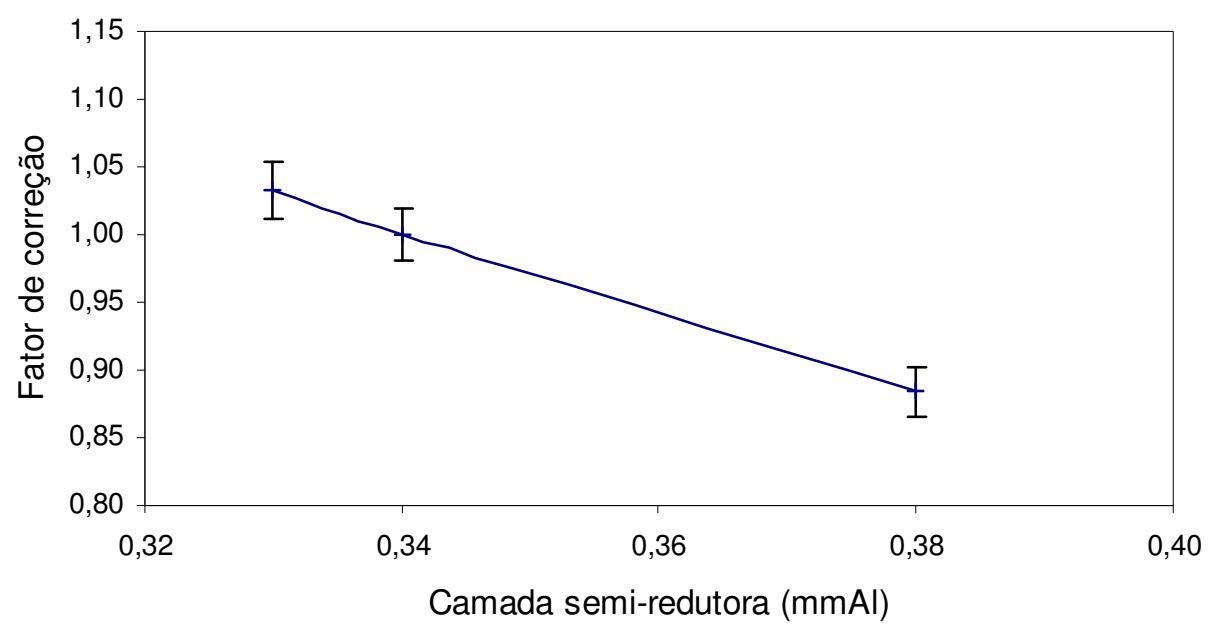

Figura 8.13. Fatores de correção da resposta da câmara de ionização com eletrodo coletor de grafite, para as qualidades de raios $X$, nível mamografia, feixes de entrada, normalizados para a camada semi-redutora de 0,34 mmAl.

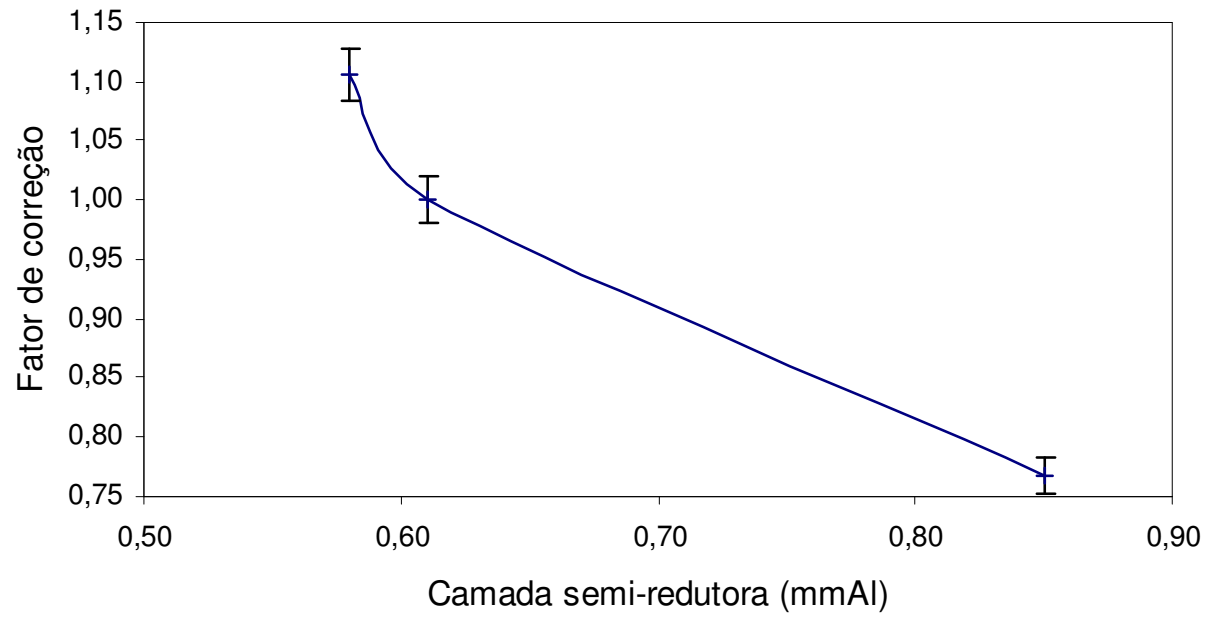

Figura 8.14. Fatores de correção da resposta da câmara de ionização com eletrodo coletor de grafite, para as qualidades de raios $X$, nível diagnóstico, feixes de saída, normalizados para a camada semi-redutora de 0,61 mmAl.

Das Figuras 8.7 a 8.14 pode-se verificar que a câmara de ionização com eletrodo coletor de alumínio apresenta dependência energética máxima de $22 \%$ para as qualidades de raios $X$, nível radiodiagnóstico, feixes diretos (RQR 3 a RQR 10) e de $17 \%$ para feixes atenuados (RQA 3 a RQA 10). Ela apresenta uma dependência 
energética de $20 \%$ para qualidades de raios $X$, nível mamografia, feixes de entrada (M 25 a M 35), e de cerca de $100 \%$, em feixes de radiação $X$, nível mamografia, feixes de saída ( $M 25 x$ a M 35x). No caso da câmara de ionização com eletrodo coletor de grafite, obteve-se os seguintes valores: $42 \%, 34 \%, 14 \%$ e $42 \%$ de dependência energética, respectivamente para as mesmas qualidades de radiação ensaiadas.

\subsection{0 - Formação dos sistemas Tandem}

Foram obtidas as curvas de dependência energética das câmaras de ionização de placas paralelas desenvolvidas neste trabalho, nas qualidades de radiação $X$, níveis radiodiagnóstico feixes diretos e atenuados (RQR 3 a RQR 10 e RQA 3 a RQA 10), e ainda para qualidades de radiação $X$, nível mamografia, para feixes de entrada e saída. As Figuras 8.15 a 8.18 mostram as curvas Tandem obtidas para as câmaras de ionização com eletrodos coletores de alumínio e grafite. As curvas Tandem podem ser obtidas tanto pela razão entre os valores dos coeficientes de calibração, como pela razão dos valores de leitura das câmaras de ionização.

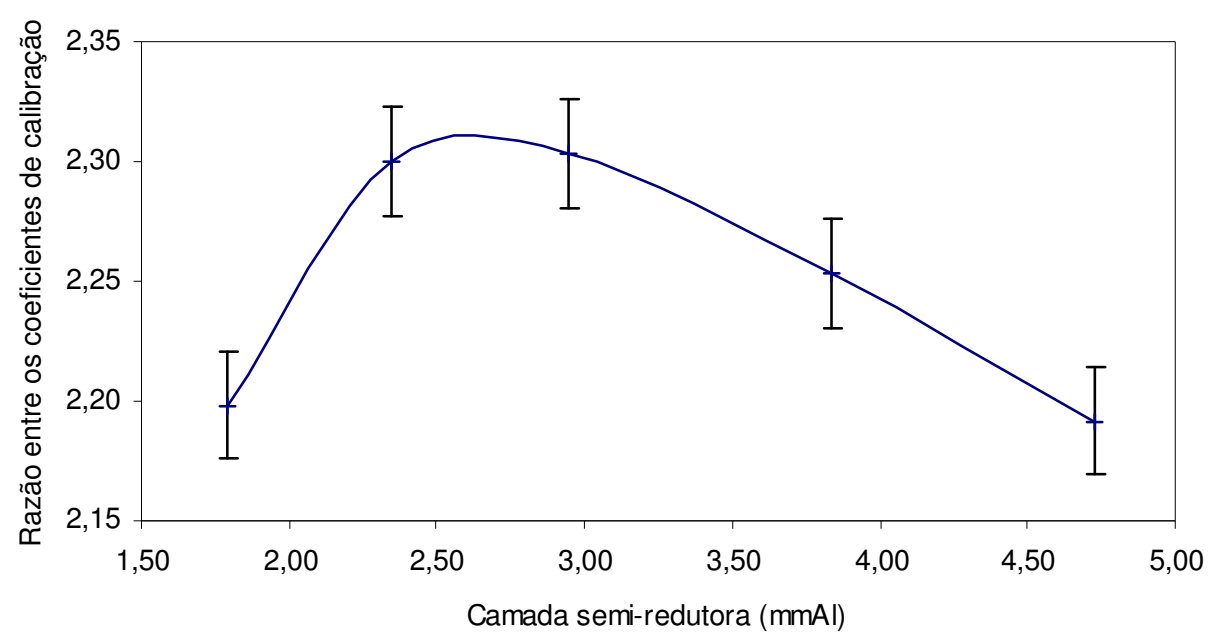

Figura 8.15. Curva Tandem para qualidades de raios $X$, nível diagnóstico, feixes diretos, das câmaras de ionização com eletrodo coletor de alumínio e de grafite. 


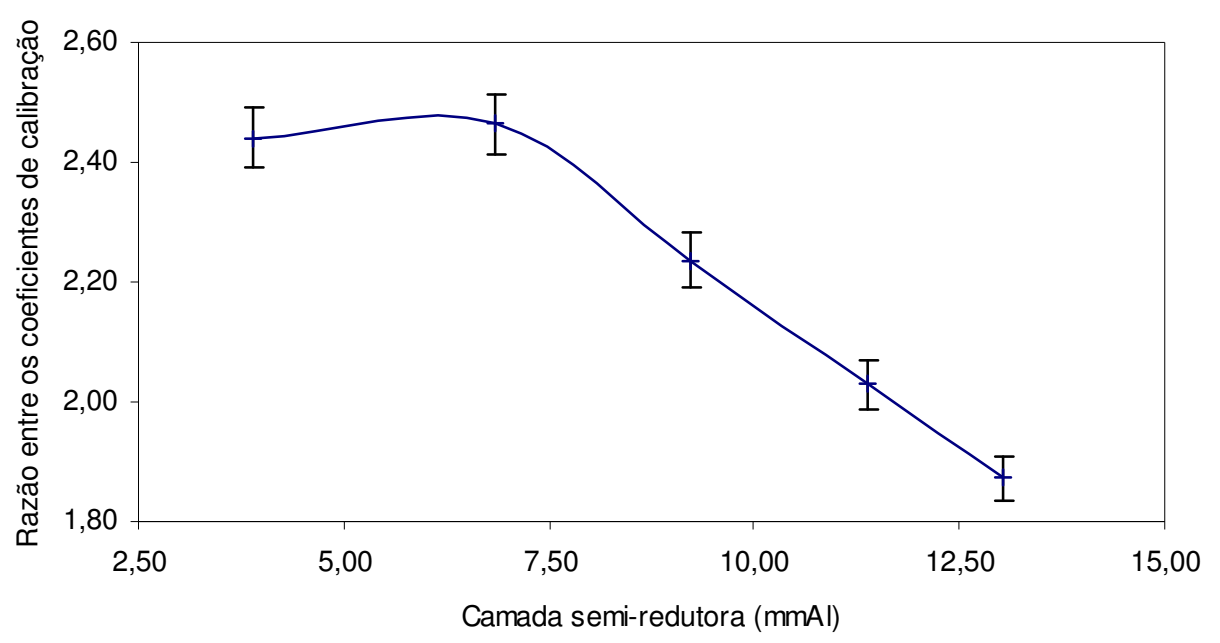

Figura 8.16. Curva Tandem para qualidades de raios $X$, nível diagnóstico, feixes atenuados, das câmaras de ionização com eletrodos coletores de alumínio e de grafite.

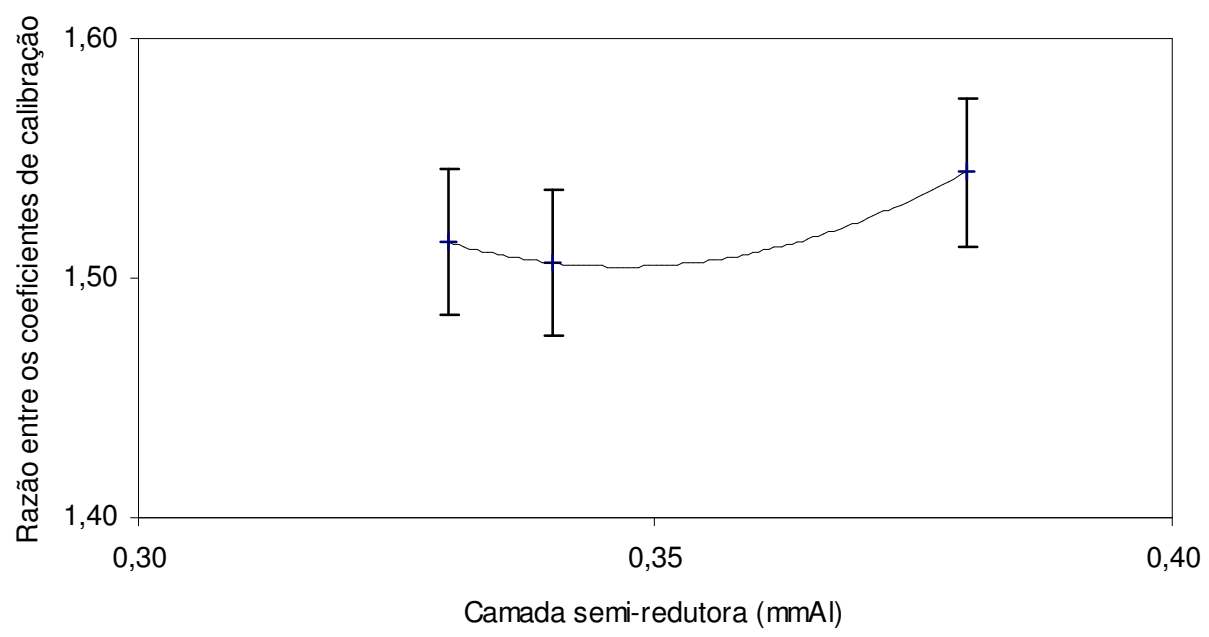

Figura 8.17. Curva Tandem para qualidades de raios $X$, nível mamografia, feixes de entrada, das câmaras de ionização com eletrodos coletores de alumínio e de grafite. 


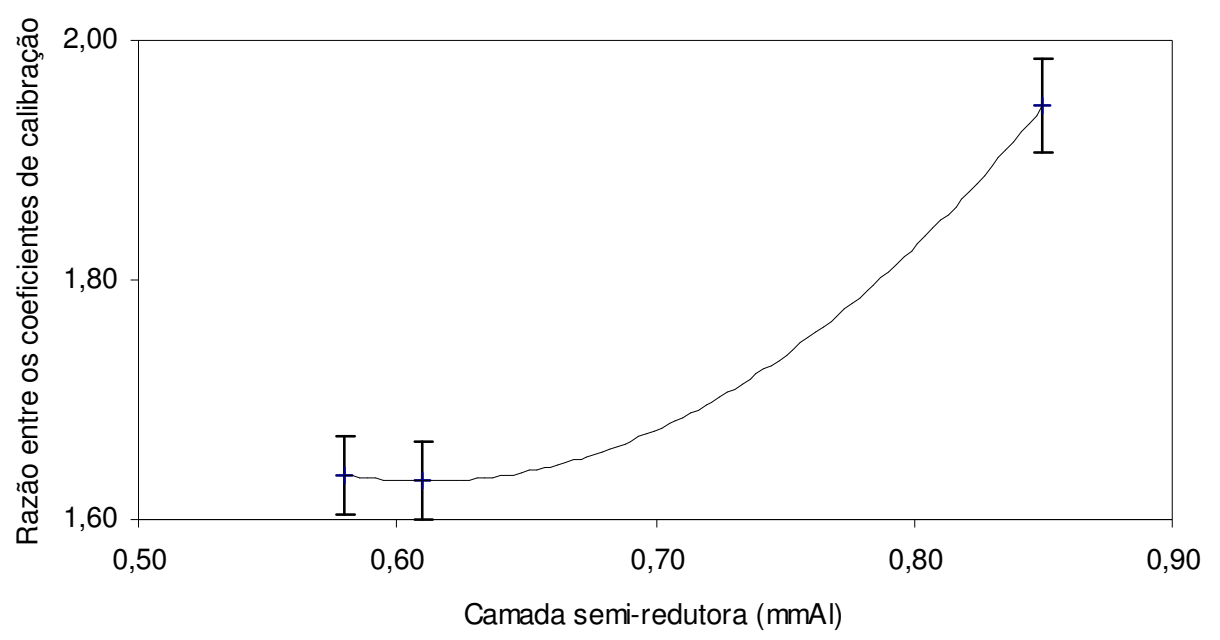

Figura 8.18. Curva Tandem para qualidades de raios $X$, nível mamografia, feixes de saída, das câmaras de ionização com eletrodos coletores de alumínio e de grafite.

Das Figuras 8.15 a 8.18 pode-se verificar que as câmaras de ionização com eletrodos coletores de alumínio e grafite podem ser utilizadas em sistema Tandem, à exceção das curvas das Figuras 8.15 e 8.17, que devem ser utilizadas com cuidado, pois para alguns valores de razão de leituras (ou coeficientes de calibração), pode-se encontrar dois ou mais valores diferentes de camada semi-redutora. A situação ideal é quando se tem apenas um único valor de camada semi-redutora para cada valor da razão das leituras das câmaras, mas as curvas Tandem são utilizadas somente como uma ferramenta para visualização dos resultados obtidos, bastando na verdade a verificação dos valores das razões entre as leituras. 


\section{CONCLUSÕES}

Neste trabalho foram desenvolvidas e construídas duas câmaras de ionização de placas paralelas inseridas em objetos simuladores de tronco humano (300 mm x $300 \mathrm{~mm} \times 150 \mathrm{~mm}$ ); uma foi confeccionada com eletrodo coletor de grafite, especialmente desenvolvida para permitir a determinação do equivalente de dose pessoal, $H_{P}(10)$; a segunda câmara de ionização possui as mesmas dimensões e características da primeira, porém foi construída com o eletrodo coletor de alumínio.

As câmaras de ionização de placas paralelas com eletrodos coletores de grafite e alumínio foram desenvolvidas e construídas no Laboratório de Calibração de Instrumentos, com tecnologia e materiais nacionais, não necessitando de cabos, conectores ou quaisquer outros materiais importados. Estas câmaras de ionização são adequadas para utilização em qualidades de radiação $X$, em especial as qualidades da série $\mathrm{N}$ da norma ISO 4037-1 (espectro estreito), de energias intermediárias.

Como as duas câmaras de ionização desenvolvidas possuem eletrodos coletores de materiais diferentes, elas apresentam respostas com dependências

energéticas diferentes. É grande o benefício desta prática, pois a diferença de dependência energética entre as câmaras de ionização desenvolvidas permite que elas sejam utilizadas em conjunto para a verificação da constância de feixes de radiação $\mathrm{X}$, formando um sistema Tandem de medida. A utilização das câmaras de ionização desenvolvidas em sistema Tandem permite a confirmação periódica da constância dos feixes de radiação $X$, com maior freqüência e com boa acurácia. Este procedimento dispensa o uso de absorvedores de alta pureza (materiais de alto custo) ou de arranjos especiais. Somente a razão entre as respostas (duas medições sucessivas de pelo menos dez leituras para cada qualidade de radiação $X$ ) das duas 
câmaras de ionização devem ser comparadas com os seus valores de referência, que foram estabelecidos durante a calibração inicial do sistema de raios $X$ (ou após cada manutenção corretiva, que pode afetar as qualidades dos feixes), e as suas variações percentuais devem ser menores que as tolerâncias especificadas pelo programa de controle de qualidade do sistema de raios $X$ utilizado nas rotinas e procedimentos de calibração de equipamentos medidores de radiação X, do LCI do IPEN.

Foram implantados feixes padronizados de radiação $X$ de energias intermediárias, nível radioproteção, por meio do desenvolvimento de uma metodologia dosimétrica e da análise dos parâmetros físicos destes feixes. Os feixes implantados complementaram os arranjos experimentais do LCI na área de metrologia das radiações, permitindo ao LCI a oferta de prestação de novos serviços de calibração de instrumentos medidores de radiação para clínicas, hospitais, universidades, centros de pesquisa e industriais.

As câmaras de ionização desenvolvidas foram testadas em relação às suas características operacionais: saturação, eficiência de coleção de íons, efeito de polaridade, tempo de estabilização, estabilidade a curto prazo (repetitividade), corrente de fuga sem irradiação e após irradiação, e estabilidade a longo prazo. Dos resultados pode-se concluir que as câmaras de ionização desenvolvidas obtiveram desempenhos muito bons, típicos de câmaras de ionização de referência. As câmaras de ionização foram calibradas em feixes de radiação $X$, níveis radioproteção $e$ radiodiagnóstico (convencional e mamografia), radioterapia, e ainda em campos de radiação gama, seguindo as recomendações internacionais, e apresentaram um nível de desempenho também muito bom.

As câmaras de ionização desenvolvidas permitem a determinação do valor verdadeiro convencional do equivalente de dose pessoal, $H_{P}(10)$, e da verificação da constância de feixes de radiação $X$, em laboratórios de calibração de instrumentos. As câmaras poderão ser utilizadas como sistemas de referência e ainda em programas de intercomparação laboratoriais. 
Foi estabelecido o procedimento da determinação do equivalente de dose pessoal, $\mathrm{Hp}(10)$, que será utilizado nas rotinas de calibração de instrumentos medidores de radiação do LCI, nesta grandeza operacional de proteção radiológica.

O desenvolvimento da câmara de ionização com eletrodo coletor de grafite permitiu a obtenção de um procedimento para a determinação do equivalente de dose pessoal, $H_{P}(10)$, que será utilizado nas rotinas de calibração do LCI, e ainda as duas câmaras de ionização de placas paralelas utilizadas em conjunto permitiram o estabelecimento de um procedimento para verificação periódica da constância (programa de controle da qualidade) dos feixes de radiação $\mathrm{X}$, nível radioproteção, utilizados na calibração de instrumentos medidores de radiação do LCI; assim, as câmaras de ionização e os procedimentos desenvolvidos estão de acordo com o objetivo principal deste trabalho. 


\section{REFERÊNCIAS BIBLIOGRÁFICAS}

1. BRASIL. MINISTÉRIO DA CIÊNCIA E TECNOLOGIA. COMISS ÃO NACIONAL DE ENERGIA NUCLEAR. Norma CNEN-NN-3.01 - Diretrizes básicas de proteção radiológica - Resolução No 27. Diário Oficial da União, Brasília, 6 jan. 2005.

2. MOZUMDER, A.; HATANO, Y. Charged particle and photon interactions with matter; chemical, physicochemical and biological consequences with applications. 1.ed. New York, NY: Marcel Dekker, 2004.

3. BRADLEY, F. J. The international atom: evolution of radiation control programs. Health. Phys., v. 83, n. 1, p. 121-134, 2002.

4. INTERNATIONAL COMMISSION ON RADIATION UNITS AND MEASUREMENTS. Determination of absorbed dose in a patient irradiated by beams of $X$ or gamma rays in radiotherapy procedures. ICRU Report 24, ICRU Publication, Bethesda, MD, 1976.

5. BRAHME, A. Dosimetric precision requirements in radiation therapy. Acta Radiol. Oncol. v. 23, p. 379-391, 1984.

6. POTIENS, M. P. A.; CALDAS, L. V. E. Calibration of $k V p$ meters used in quality control tests in diagnostic radiology by spectrometry. Radiat. Prot. Dosim., v. 98, n. 3, p. 343-346, 2002.

7. BRASIL. MINISTÉRIO DA SAÚDE. AGÊNCIA NACIONAL DE VIGILÂNCIA SANITÁRIA. Portaria 453/98 - Diretrizes de proteção radiológica em radiodiagnóstico médico e odontológico. Diário Oficial da União, Brasília, 2 jun. 1998.

8. BRASIL. MINISTÉRIO DA SAÚDE. INSTITUTO NACIONAL DO CÂNCER. TECDOC -1151: Aspectos físicos da garantia da qualidade em radioterapia. v.1, 162 p. Ed. INC., Rio de Janeiro: INCA, 2000.

9. INTERNATIONAL SYMPOSIUM ON STANDARDS AND CODES OF PRACTICE IN MEDICAL RADIATION DOSIMETRY, November 25-28, 2002, Vienna.

Procedings... Vienna: IAEA, 2002.

10. MEGHZIFENE, A.; SHORTT, K. R. Calibration factor or calibration coefficient?, SSDL Newsletter, v. 46, p. 33-33, 2002. 
11. POSTON, J. W. External dosimetry and personnel monitoring. Health. Phys., v. 88, n. 4, p. 289-296, 2005.

12. INTERNATIONAL ATOMIC ENERGY AGENCY. Calibration of dose meters used in radiotherapy. IAEA, Vienna, 1979 (Technical Reports Series No. 185).

13. INTERNATIONAL ATOMIC ENERGY AGENCY. Calibration of dosimeters used in radiotherapy. IAEA, Vienna, 1994 (Technical Reports Series No. 374).

14. INTERNATIONAL ATOMIC ENERGY AGENCY. The use of plane parallel ionization chambers in high energy electron and photon beams - An international code of practice for dosimetry. IAEA, Vienna, 1997 (Technical Reports Series No. 381).

15. INTERNATIONAL ATOMIC ENERGY AGENCY. Absorbed dose determination in photon and electron beams. An international code of practice. IAEA, Vienna, 2000 (Technical Reports Series No. 277).

16. INTERNATIONAL ORGANIZATION FOR STANDARDIZATION. $\boldsymbol{X}$ and gamma reference radiations for calibrating dosemeters and dose ratemeters and for determining their response as a function of photon energy. PART 1: Characteristics of the radiation and their methods of production. ISO, Geneva, 1996. (ISO 4037 - 1).

17. ATTIX, F. H. Application of a commercial solid-water plane-parallel ionization chamber to the AAPM TG-21 protocol. Med. Phys. v. 20, n. 3, p. 735-737, 1993.

18. GUOSHAN, Y.; YONGKU, X., FANGONG, C. Large volume ionization chamber used as reference for low energy X-ray measurement. Nucl. Sci. Techn., v. 5, n. 3, p. 166-169, 1994.

19. KUBO, H. Evaluations of two solid state water parallel plate chambers in highenergy photon and electron beams. Med. Phys., v. 20, p. 341-345, 1993.

20. GERBI, B. J. The response characteristics of a newly designed plane parallel ionization chamber in high-energy photon and electron beams. Med. Phys., v. 20, n. 5, p. 1411-1415, 1993.

21. FRANCESCON, P.; CORA, S.; CAVEDON, C.; SCALCHI, P.; RECCANELLO, S.; COLOMBO, F. Use of a new type of radiochromic film, a new parallel-plate microchamber, MOSFETs, and TLD 800 microcubes in dosimetry of small beams. Med. Phys., v. 25, n.4, p. 503-511, 1998. 
22. CAMPOS, C. A. A. L. Construção, calibração e testes de uma câmara de ionização para medidas de exposição na região de 40 a $1250 \mathrm{keV}$. Rio de Janeiro: 1982. Dissertação (Mestrado). Universidade Estadual do Rio de Janeiro.

23. SILVA, I. Projeto e construção de uma câmara de extrapolação para dosimetria beta. Belo Horizonte: 1985. Dissertação (Mestrado). Universidade Federal de Minas Gerais.

24. ALBUQUERQUE, M. P. P. Projeto, construção e calibração de câmaras de ionização de placas paralelas para radiação X. São Paulo: 1989. Dissertação (Mestrado). Instituto de Pesquisas Energéticas e Nucleares/USP.

25. ALBUQUERQUE, M. P. P.; CALDAS, L. V. E. New ionization chambers for beta and X radiation. Nucl. Instr. Meth. Phys. Res., v. A280, p. 310-313, 1989.

26. CALDAS, L. V. E. A sequential Tandem system of ionization chambers for effective energy determination of X radiation fields. Radiat. Prot. Dosim., v. 36, n. 1, p. 47-50, 1991.

27. CALDAS, L. V. E.; ALBUQUERQUE, M. P. P. Angular dependence of parallel plate ionization chambers. Radiat. Prot. Dosim., v. 37, n. 1, p. 55-57, 1991.

28. CALDAS, L. V. E.; ALBUQUERQUE, M. P. P. Calibration of parallel plate ionization chambers in different kinds of radiation. Proceed. $\boldsymbol{8}^{\text {th }}$ International Congress of IRPA, Montreal, Canada, 17-22 May 1992, p. 144-147, 1992.

29. SOUZA, C. N.; CALDAS, L. V. E. A parallel plate ionization chamber for electron dosimetry. Proceed. $\boldsymbol{8}^{\text {th }}$ International Congress of IRPA, Montreal, Canada, 17-22 May 1992, p. 644-647, 1992.

30. SOUZA, C. N. Desenvolvimento de um sistema dosimétrico para feixes de elétrons de energias altas. São Paulo: 1994. Tese (Doutorado) - Instituto de Pesquisas Energéticas e Nucleares, Universidade de São Paulo.

31. DIAS, S. K.; CALDAS, L. V. E. Extrapolation chamber response in low energy $X$ radiation standard beams. J. Appl. Phys., v. 89, n. 1, p. 669-671, 2001.

32. SOUZA, C. N.; CALDAS, L. V. E.; SIBATA, C. H.; HO, A. K.; SHIN, K. H. Two new parallel-plate ionization chambers for electron beam dosimetry. Radiat. Measurem., v. 26, n. 1, p. 65-74, 1996.

33. DIAS, S. K. Desenvolvimento de uma câmara de extrapolação como instrumento de referência para dosimetria de radiação beta. São Paulo: 1996. Tese (Doutorado) - Instituto de Pesquisas Energéticas e Nucleares, Universidade de São Paulo. 
34. DIAS, S. K.; CALDAS, L. V. E. Development of an extrapolation chamber for the calibration for beta-ray applicators. IEEE Trans. Nucl. Sci., v. 45, n. 3, p. 16661669, 1998.

35. DIAS, S. K.; CALDAS, L. V. E. Characteristics of an extrapolation chamber for beta ray protection level measurements. J. Appl. Phys., v. 86, n. 1, p. 671-673, 1999.

36. COSTA, A. M. da. Desenvolvimento de câmaras de ionização Tandem para utilização em programas de controle de qualidade em radioterapia e radiodiodiagnóstico. São Paulo: 2003. Tese (Doutorado) - Instituto de Pesquisas Energéticas e Nucleares, Universidade de São Paulo.

37. COSTA, A. M. da.; CALDAS, L. V. E. Response characteristics of a Tandem ionization chamber in standard X-ray beams. Appl. Radiat. Isot., v.58, n.4, p.495-500, 2003.

38. COSTA, A. M. da.; CALDAS, L. V. E. A special ionization chamber for quality control of diagnostic and mammography $X$-ray equipment. Radiat. Prot. Dosim., v.104, n.1, p.41-45, 2003.

39. OLIVEIRA, M. L.; CALDAS, L. V. E. A special mini-extrapolation chamber for calibration of ${ }^{90} \mathrm{Sr}+{ }^{90} \mathrm{Y}$ sources. Phys. Med. Biol., v. 50, p. 2929-2936, 2005.

40. MAIA, A. F.; CALDAS, L. V. E. A new extended-length parallel-plate ionization chamber. Phys. Med. Biol., v. 50, In press, 2005.

41. ANKERHOLD, U.; BEHRENS, R.; AMBROSI, P. A prototype ionisation chamber as a secondary standard for the measurement of personal dose equivalent, $H_{p}(10)$, on a slab phantom. Radiat. Prot. Dosim., v. 86, n. 3, p. 167-173, 1999.

42. ANKERHOLD, U.; AMBROSI, P.; EBERLE, T. A chamber for determining the conventionally true value of $\mathrm{Hp}(10)$ and $\mathrm{H}^{*}(10)$ needed by calibration laboratories. Radiat. Prot. Dosim., v. 96, n. (1-3), p. 133-137, 2001.

43. ANKERHOLD, U. "Comunicação Pessoal"; Pesquisadora e Assessora Técnica do PTB, Physikalisch-Technische Bundesanstalt. Braunschweig, Germany, 2005.

44. ANKERHOLD, U.; BEHRENS, R.; AMBROSI, P. X ray spectrometry of low energy photons for determining conversion coefficients from air kerma, $\mathrm{k}_{\mathrm{a}}$, to personal dose equivalent, $\mathrm{Hp}(10)$, for radiation qualities of the ISO narrow spectrum series. Radiat. Prot. Dosim., v. 81, n. 4, p. 247-258, 1999. 
45. TAUHATA, L.; RAMOS, M. M. O.; PRINZIO, M. A. R. R. Di. Grandezas e unidades para radiação ionizante. Primeira edição em língua portuguesa. Rio de Janeiro: IRD-CNEN-MCT, INMETRO, 2003.

46. STROM, D. J.; WATSON, C. R. On being understood: clarity and jargon in radiation protection. Health. Phys., v. 82, n. 3, p. 373-386, 2002.

47. COUNCIL DIRECTIVE EURATOM. Safety standards for the protection of the health of workers and the general public against the dangers arising from ionizing radiation. Official Journal no. L 159, l-114, 1996.

48. INTERNATIONAL ORGANIZATION FOR STANDARDIZATION. $\boldsymbol{X}$ and gamma reference radiations for calibrating dosemeters and doserate meters and for determining their response as function of photon energy. PART 3: Calibration of area and personal dosemeters and the measurement of their response as a function of energy and angle of incidence. ISO, Geneva, Aug. 1999. (ISO 4037 - 3).

49. CLARK, R.; VALENTIN, J. A history of the international commission on radiological protection. Health. Phys., v. 88, n. 5, p. 407-422, 2005.

50. INTERNATIONAL COMMISSION ON RADIOLOGICAL PROTECTION. Conversion coefficientes for use in radiological protection against external radiation. ICRP Publication 74, Ann. ICRP 26 (3-4), Oxford, Elsevier, 1997.

51. INTERNATIONAL COMMISSION ON RADIATION UNITS AND MEASUREMENTS. Conversion coefficientes for use in radiological protection against external radiation. ICRU Report 57, ICRU Publication, Bethesda, MD, 1998.

52. BORRÁS, C. Control de Calidad em América Latina y em el Contexto Mundial. In: II Workshop em Normalização e Certificação de Equipamentos Eletromédicos, Novembro 4, Anais..., São Paulo: 1997, p. 15-20.

53. INTERNATIONAL ORGANIZATION FOR STANDARDIZATION. $\boldsymbol{X}$ and gamma reference radiations for calibrating dosemeters and doserate meters and for determining their response as function of photon energy. PART 2: Dosimetry for radiation protection over the energy ranges $8 \mathrm{keV}$ to 1,4 MeV and 4 MeV to 9 MeV. ISO, Geneva, 1996. (ISO 4037 - 3).

54. KENNEY, G. N.; CAMERON, J. R. X-ray beam quality measurements utilizing TL dosimeters. Progress Report, AEC Contract No AT 11-1-1105-TID-19112, 1963.

55. GORBICS, S. G.; ATTIX, F. H. LiF and $\mathrm{CaF}_{2}$ : Mn thermoluminescent dosimeters in Tandem system. Int.J. Appl. Radiat. Isot., v.19, n.1, p.81-89, 1968. 
56. SEELENTAG, W. W.; PANZER,W.; DREXLER, G.; PLATZ, L.; SANTNER, F. A. Catalogue of spectra for the calibration of dosemeters, GSF Bericht 560, Strahlen-und Umweltforschung mbH, München, 1979.

57. DA ROSA, L. A. R. Utilização de dosímetros termoluminescentes para determinação da exposição ou dose absorvida em campos de radiação gama ou X com distribuição espectral desconhecida. Dissertação de Mestrado, Universidade Federal do Rio de Janeiro, Rio de Janeiro, 1981.

58. READ, L. R. \& HAGREEN, M. The ISO spectrum series of filtered $X$ radiations at NPL. Middlesex, Aug. 1987. (NPL Report RS(EXT)92).

59. KNOLL, G. F. Radiation detection and measurements. 2. ed. New York, NY: Willey, 1989.

60. АTTIX, F. H. Introduction to radiological physics and radiation dosimetry. 2. ed. New York, NY: Wiley, 1986.

61. INTERNATIONAL ATOMIC ENERGY AGENCY. Handbook on calibration of radiation protection monitoring instruments. IAEA, Vienna, 1971 (Technical Reports Series No. 133).

62. INTERNATIONAL ATOMIC ENERGY AGENCY. Calibration of radiation protection monitoring instruments. IAEA, Vienna, 2000, (Safety Reports Series No. 16).

63. POTIENS, M. P. A.; FIGUEIREDO, A. M.; VIVOLO, V.; CALDAS, L. V. E. Caracterização de um sistema de radiação $X$ por espectrometria. In: III CONGRESSO LATINO AMERICANO DE FÍSICA MÉDICA. 26-29 setembro, 2004, Rio de Janeiro. Anais... Rio de Janeiro: III Iberian Latin American Congress of Medical Physics, 2004. 1 CD-ROM.

64. POTIENS, M. P. A.; VIVOLO, V.; MIRANDA, J. A.; CALDAS, L. V. E. Flat ionization chambers as monitors in $x$ ray beams. In: FIRST INTERNATIONAL MEETING ON APPLIED PHYSICS-APHYS 2003. Out. 13-18, 2003, Badajoz. Anais... Badajoz: First International Meeting on Applied Physics, 2003.

65. POTIENS, M. P. A.; VIVOLO, V.; CALDAS, L. V. E. Calibração de câmaras de ionização (nível radiodiagnóstico) em feixes de raios- $x$ nas qualidades de radioproteção e de radiodiagnóstico. In: VII CONGRESSO BRASILEIRO DE FÍSICA MÉDICA. 13-17 novembro, 2002, Campos do Jordão. Anais... Campos do Jordão: VII Congresso da Associação Brasileira de Física Médica, 2002. 1 CD-ROM. 
66. VIVOLO, V.; COSTA, A. M.; MANZOLI, J. E.; CALDAS, L. V. E. Determinação de parâmetros dos campos de radiação gama do Laboratório de Calibração do IPEN. In: INTERNATIONAL CONGRESS, INDUSTRIAL BUSINESS FORUM AND MEASUREMENT INSTRUMENTS EXHIBITION IN ADVANCED METROLOGY. 4-7 dezembro, 2000, São Paulo. Anais... São Paulo: International Congress, Industrial Business Forum and Measurement Instruments Exhibition in Advanced Metrology, 2000. 1 CD-ROM.

67. KLEVENHAGEN, S. C.; THWAITES, D. I.; AUKETT, R. J. Kilovoltage X-rays. In: WILLIANS, J. R.; THWAITES, D. I. (Ed.). Radiotherapy physics; in practice. 2. ed. New York, NY: Oxford, 2000. p. 99-117.

68. JOHNS, H. E.; CUNNINGHAM, J. R. The physics of radiology. 4. ed. Springfield, IL: Charles C. Thomas, 1983.

69. KHAN, F. M. The physics of radiation therapy. 2. ed. Baltimore, MD. Willians, 1994.

70. RAJAN, K. N. G. Advanced medical radiation dosimetry. New Delhi: PrenticeHall of India, 1992.

71. HUBELL, J. H. Photon mass attenuation and energy absorption coefficients from 1 keV to 20 MeV. Int. J. Appl. Radiation. Isot., v. 133, p. 1269-1290, 1982.

72. INTERNATIONAL COMMISSION ON RADIATION UNITS AND MEASUREMENTS. Fundamental quantities and units for ionizing radiation. ICRU, Bethesda, MD, 1998. (ICRU Report 60).

73. SARTORIS, C. E.; CALDAS, L. V. E. Aplicação de metodologia dosimétrica de feixes terapêuticos de raios X com sistema Tandem. Radiol. Bras., v. 34, n. 6, p. 337-342, 2001.

74. INTERNATIONAL ORGANIZATION FOR STANDARDIZATION. Guide to the expression of uncertainty in measurement. Geneva, 1995.

75. VUOLO, J. H. Fundamentos da teoria de erros. 2ª Ed., São Paulo. Brasil: Editora Edgard Blücher Ltda., 1996.

76. ASSOCIAÇÃO BRASILEIRA DE NORMAS TÉCNICAS: INSTITUTO NACIONAL DE METROLOGIA NORMATIZAÇÃO E QUALIDADE INDUSTRIAL. Guia para a Expressão da Incerteza de Medição. 3ª Edição Brasileira. Rio de Janeiro, 2003.

77. FIGUEIREDO, A. M.; CALDAS, L. V. E. Estudo das incertezas associadas à calibração de um câmara de ionização tipo lápis. In: METROLOGIA 2003 METROLOGIA PARA A VIDA. 01-05 setembro, 2003, Recife. Anais... Recife: Congresso da Sociedade Brasileira de Metrologia, 2003. 1 CD-ROM. 
78. INTERNATIONAL ATOMIC ENERGY AGENCY. Absorbed dose determination in external beam radiotherapy: implementation of the international code of practice on dosimetry in radiotherapy (TRS 398): review of testing results. Jun. 2005 (Final Report) IAEA, Vienna, 2000, (IAEA-TECDOC-1455).

79. DEWERD, L. A.; WAGNER, L. K. Characteristics of radiation detectors for diagnostic radiology. Appl. Radiat. Isot., v. 50, p. 125-136, 1999.

80. INTERNATIONAL ELECTROTECHNICAL COMMISSION. Medical electrical equipment. Dosemeters with ionization chambers as used in radiotherapy. IEC, Geneva, Jul. 1997. (IEC 60731).

81. INTERNATIONAL ELECTROTECHNICAL COMMISSION. Medical electrical equipment. Dosemeters with ionization chambers and/or semiconductor detectors as used in X-ray diagnostic imaging. IEC, Geneva, Oct. 1997. (IEC 61674).

82. INTERNATIONAL ELECTROTECHNICAL COMMISSION. Medical diagnostic $\boldsymbol{X}$ ray equipment - Radiation conditions for use in the determination of characteristics. IEC, Geneva, Jun. 1994. (IEC 61267).

83. TAKATA, N.; TAKEDA, N.; YIN, Z. Decreases in output currents due to back diffusion of ions in ionization chambers. Radiat. Prot. Dosim., v. 71, n. 4, p. 309-312, 1997.

84. DIAS, I. J.; AKBER, S. F. Ion recombination and polarity effect of ionization chambers in kilovoltage x-ray exposure measurememts. Med. Phys., v. 25, n. 9, p. 1751-1757, 1998.

85. BOAG, J. W. Ionization chambers. In: KASE, K. R.; BJARNGARD, B. E.; ATTIX, F. $\mathrm{H}$. (Ed.). The dosimetry of ionizing radiation., v. II. Orlando, Fla.: Academic, 1987. p. $169-243$.

86. DEUTSCHES INSTITUT FüR NORMUNG. Strahlenschutzdosimiter. German Standard DIN, Berlin, Apr. 1992. (DIN 6818-1).

87. POTIENS, M. P. A. Metodologia dosimétrica e sistema de referência para radiação X nível diagnóstico. São Paulo: 1999. Tese (Doutorado) - Instituto de Pesquisas Energéticas e Nucleares, Universidade de São Paulo .

88. GALHARDO, E. P. Caracterização de sistemas Tandem de câmaras de ionização comerciais para dosimetria de feixes de raios $X$ (nível radioterapia). São Paulo: 1998. Dissertação (Mestrado) - Instituto de Pesquisas Energéticas e Nucleares, Universidade de São Paulo.

89. INTERNATIONAL ATOMIC ENERGY AGENCY. Dosimetry in diagnostic radiology - An international code of practice. Jan. 2005 (Draft TRS) IAEA, Vienna, 2005 (Technical Reports Series ). 